Luiz Ricardo Kabbach de Castro

\title{
VALOR PERCEBIDO COMO FERRAMENTA PARA TOMADA DE DECISÃO: UMA APLICAÇÃO NA INDÚSTRIA HOTELEIRA UTILIZANDO A ANÁLISE CONJUNTA
}

Dissertação apresentada à Escola de Engenharia de São Carlos da Universidade de São Paulo, como parte dos requisitos para a obtenção do Título de Mestre em Engenharia de Produção.

Orientador: Prof. Dr. Aquiles Elie Guimarães Kalatzis

São Carlos

2006 
Dedico este trabalho a Deus, meu criador, e a meu pai (in memorian), meu maior incentivador. 


\section{AGRADECIMENTOS}

Agradeço à Escola de Engenharia de São Carlos, e à Universidade de São Paulo, por acreditar no ensino e apoiá-lo neste país, que só será o país do "futuro" por meio de uma educação de qualidade e para todos.

Ao meu orientador, Professor Aquiles, pela paciência e compreensão.

À Professora Daisy, pelo estímulo e apoio.

À Professora Maria Aparecida, pelo despertar da análise quantitativa e, pelos conselhos.

Ao José Luiz, grande colaborador em todos os momentos do curso, e nos mais decisivos.

Aos meus irmãos, Fabiane, Fernando e Régis, e cunhados, Fabiana e Cláudio, pelo apoio incondicional, sem os quais não sei se estaria aqui.

Ao Felipinho, graça de vida.

A minha mãe, Laila, pelo amor e pela vida; à segunda mãe Alberta, pelo amor.

A minha amada, Mariana, pela compreensão nos momentos decisivos.

Ao amigo, Rafael, pela colaboração inestimável no trabalho de campo.

A todos os empregados do Habitat Hotel, pela dedicação e esforço, pois puderam tornar este trabalho um caso prático da indústria hoteleira; e que este seja o despertar da importância da educação em suas vidas.

E a todos que, direta ou indiretamente, contribuíram para a realização deste trabalho. 
O temor do SENHOR é o princípio do conhecimento; os loucos desprezam a sabedoria e a instrução. (Provérbios $1: 7$ ) 


\section{RESUMO}

CASTRO, L.R.K. (2006). Valor percebido como ferramenta para tomada de decisão: Uma aplicação na indústria hoteleira utilizando a análise conjunta. Dissertação (Mestrado) - Escola de Engenharia de São Carlos, Universidade de São Paulo, São Carlos, 2006.

Este trabalho de pesquisa apresentará uma aplicação metodológica para a medida do valor percebido na prestação de serviços de hospedagem. Conhecido o valor percebido, será possível compará-lo com os custos do serviço, bem como com os preços ofertados e, a partir daí, fornecer ao administrador uma base para o planejamento das ações de melhoria e para a priorização das atividades que oferecem maior valor, segundo a visão de cliente. O modelo pretende estimar o valor percebido que os consumidores formam no ambiente de serviços; focado no desempenho dos serviços e considerando valor um constructo relacionado com os atributos característicos do serviço que influenciam a preferência, e, como conseqüência, a escolha do consumidor. A modelagem proposta será ilustrada por meio de um estudo de caso contemplando um Hotel de categoria econômica no interior de São Paulo, devendo ser tratado segundo o método de análise conjunta, técnica de estatística multivariada de análise de dados. Esta técnica busca atribuir a importância relativa que os consumidores (hóspedes) associam a um conjunto de características particulares na prestação de serviços, e o grau de utilidade percebida de diferentes níveis destes atributos.

Palavras-chave: Valor Percebido, Serviços, Hotelaria, Comportamento do Consumidor, Utilidade, Análise Conjunta. 


\section{ABSTRACT}

CASTRO, L.R.K. (2006). Perceived value as a decision support tool: An application in hospitality industry through conjoint analysis. M.Sc. Dissertation Escola de Engenharia de São Carlos, Universidade de São Paulo, São Carlos, 2006.

This study presents a methodology application for perceived value in hospitality industry. The knowledge of perceived value will help managers to compare these consumer preferences with operational costs, and also with price strategies, and then will give the managers a tool to their improvement actions planning, and also to choice the most important attributes to improve value for customers. This model intends to get the perceived values from a qualitative and quantitative research in service industry, focused on the services performance, considering value as a construct of attributes that explain service and influence the customer stated preference, and customer's choice as a consequence. The empirical research will take place in a budget-Hotel, located in the countryside of São Paulo State, and based on a multivariate conjoint analysis, This technique aims to give the relative importance which consumers (guests) associate to a group of particular characteristics in hospitality industry, and the degree of perceived utility of different levels of those attributes.

Key words: Perceived value, Services, Hospitality, Consumer Behavior, Utility, Conjoint Analysis. 


\section{LISTA DE FIGURAS}

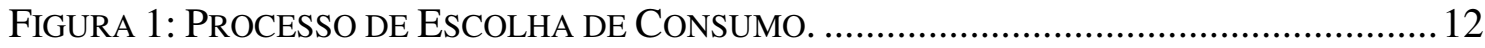

FIgURA 2: O PROCESSO DE ESCOLHA. AdAPTADO DE BEN-AKIVA (1999)........................ 15

FIGURA 3: MODELO DE COMPORTAMENTO DO CONSUMIDOR. .......................................... 19

FIGURA 4: MODELO DE RELACIONAMENTO DE PREÇO, QUALIDADE E VALOR. ...................42

Figura 5: Modelo de Hierarquia de VALOR. AdAPTAdo de WoOdrufF (1997). ..... 43

FIGURA 6: RECENTES DESENVOLVIMENTOS EM MÉTODOS DE UTILIDADES-PARCIAIS. ...... 75

FIGURA 7: ESTÁGIOS 1-7 DO DIAGRAMA DE DECISÃO DA ANÁLISE CONJUNTA...................82

FIGURA 8: OS TRÊS TIPOS BÁSICOS DE RELAÇÕES ENTRE NÍVEIS FATORIAIS EM ANÁLISE

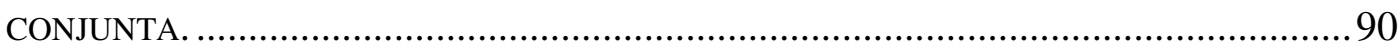

FIGURA 9: EXEMPLO DO FORMATO DE APRESENTAÇÃO DOS CARTÕES............................. 115

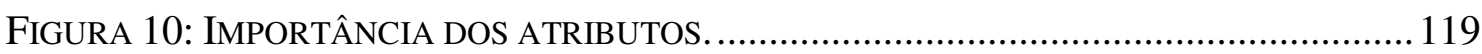

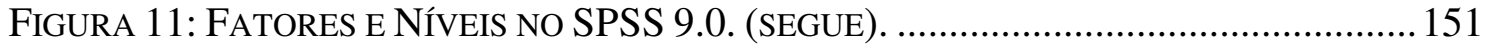

FIGURA 12: DELINEAMENTO FATORIAL FRACIONÁRIO NO SPSS 9.0, COM ESTÍMULOS DE

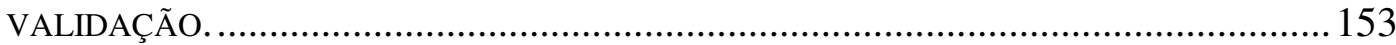

FIGURA 13: RESULTADO DE DELINEAMENTO FATORIAL FRACIONÁRIO............................ 154

FIGURA 14: INSTRUÇÕES DAS ENTREVISTAS PESSOAIS DE COLETA DE DADOS E QUESTIONÁRIOS. (SEGUE)

FIGURA 15: PREFERÊNCIA DOS ATRIBUTOS PELOS RESPONDENTES NO QUESTIONÁRIO PRELIMINAR. 168

FIGURA 16: SINTAXE DO PLANEJAMENTO DO EXPERIMENTO. 169

FIGURA 17: ARQUIVO DE SAÍDA DO SPSS, VERSÃO 9.0.............................................. 170

FIGURA 18: UTILIDADE INDIVIDUAL DO ATRIBUTO EQUIPAMENTOS.............................. 171

FIGURA 19: UTILIDADE INDIVIDUAL DO ATRIBUTO CONFORTO DO APARTAMENTO. ........ 171

FIGURA 20: UTILIDADE INDIVIDUAL DO ATRIBUTO SERVIÇOS DISPONÍVEIS...................... 172

FIGURA 21: UTILIDADE INDIVIDUAL DO ATRIBUTO CAFÉ DA MANHÃ. .............................. 172

FIGURA 22: UTILIDADE INDIVIDUAL DO ATRIBUTO CONFORTO DO BANHEIRO................ 173

FIGURA 23: UTILIDADE INDIVIDUAL CONSOLIDADA DOS ATRIBUTOS DO EXPERIMENTO. 173

FIGURA 24: UTILIDADE AGREGADA DO ATRIBUTO EQUIPAMENTOS. ................................ 174

FIGURA 25: UTILIDADE AGREGADA DO ATRIBUTO CONFORTO DO APARTAMENTO. ......... 174

FIGURA 26: UTILIDADE AGREGADA DO ATRIBUTO SERVIÇOS DISPONÍVEIS....................... 175 
FIGURA 27: UTILIDADE AGREGADA DO ATRIBUTO CAFÉ DA MANHÃ. ............................ 175

FIGURA 28: UTILIDADE AGREGADA DO ATRIBUTO CONFORTO DO BANHEIRO.................. 176

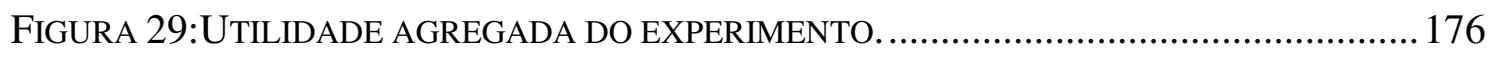

FIGURA 30: MATRIZ DE CLASSIFICAÇÃO HOTELEIRA (SEGUE). ...................................... 179 


\section{LISTA DE QUADROS}

QUADRO 1: ESTUDOS ANTERIORES SOBRE VALOR PERCEBIDO. ........................................ 33

QUADRO 2: A MUDANÇA DO FOCO NA ABORDAGEM DAS COMPETÊNCIAS FUNDAMENTAIS.

Quadro 3: Etapas do Método Científico de uma Pesquisa de Marketing E DE uM

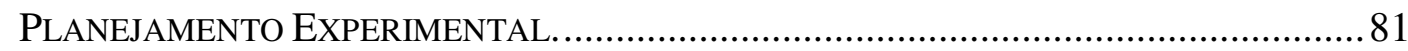

QUADRO 4: UMA COMPARAÇÃO DE METODOLOGIAS CONJUNTAS ALTERNATIVAS............. 85

QUADRO 5: UMA COMPARAÇÃO DE METODOLOGIAS CONJUNTAS ALTERNATIVAS........... 110

QUADRO 6: ATRIBUTOS E NÍVEIS DO EXPERIMENTO................................................... 111

QUADRO 7: RELAÇÃO DOS ATRIBUTOS E NÚMERO DE NÍVEIS. ........................................ 117

QUADRO 8: QUADRO DE ITENS DE SATISFAÇÃO E SEUS RESPECTIVOS INCIDENTES CRÍTICOS 


\section{LISTA DE TABELAS}

TABELA 1: CRESCIMENTO DA OFERTA HOTELEIRA NO BRASIL. ......................................... 64

TABELA 2: CRESCIMENTO DA OFERTA DE HOTÉIS DE REDE..............................................64

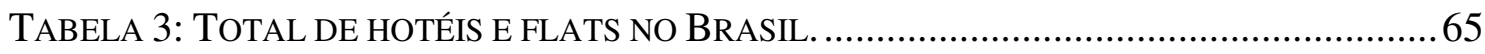

TABEla 4: SEGMENTAÇÃO DA DEMANDA DE HOTÉIS SEGUNDO O MOTIVO DA VIAGEM E A

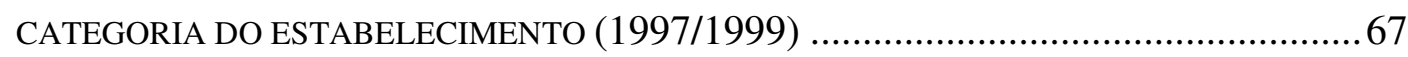

TABELA 5: COMPARAÇÃO DOS MÉTODOS DE APRESENTAÇÃO NA ANÁLISE CONJUNTO, PELA

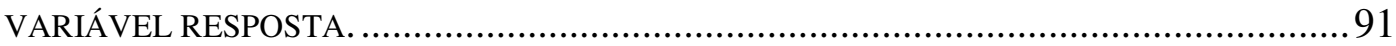

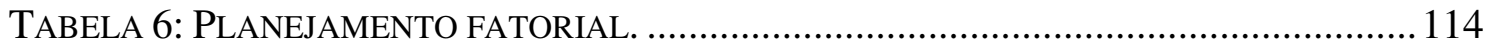

TABELA 7: TABELA DE SUMÁRIO DOS RESULTADOS DA ESTIMAÇÃO DO MODELO............ 118

TABELA 8: EXEMPLO DE CÁLCULO DE IMPORTÂNCIA RELATIVA PARA O RESPONDENTE 1 121

TABELA 9: EXEMPLO DE CÁLCULO DE IMPORTÂNCIA RELATIVA PARA O RESPONDENTE 29. 122

TABELA 10: FAIXA ETÁRIA DA AMOSTRA QUALITATIVA. .............................................. 147

TABELA 11: DISTRIBUIÇÃO POR SEXO DA AMOSTRA QUALITATIVA................................. 147

TABELA 12: DiSTRIBUIÇÃO POR ESTADO CIVIL DA AMOSTRA QUALITATIVA..................... 147

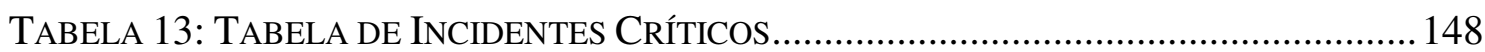

TABELA 14: DADOS DEMOGRÁFICOS DA AMOSTRA DO EXPERIMENTO CONJUNTO. .......... 160

TABELA 15: RESULTADO DAS UTILIDADES PARCIAIS E ESCORES POR RESPONDENTE. ..... 177 


\section{SUMÁRIO}

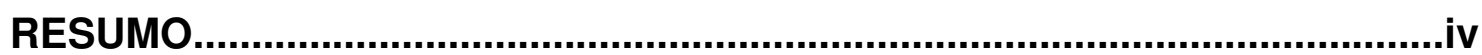

ABSTRACT

LISTA DE FIGURAS....................................................................................

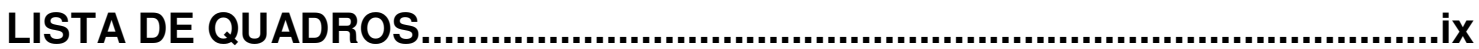

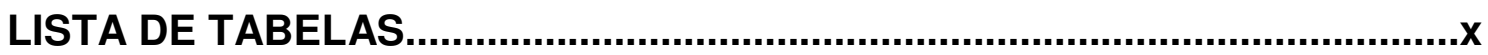

1 INTRODUÇÃO 1

1.1 CARACTERIZAÇÃO DO TEMA 2

1.2 FORMULAÇ̃̃O DO PROBLEMA

1.3 OBJETIVOS 5

1.4 JUSTIFICATIVA DO TEMA

$\begin{array}{lll}1.5 & \text { ESTRUTURA DO TRABALHO }\end{array}$

2 FUNDAMENTAÇÃO TEÓRICA 9

2.1 COMPORTAMENTO DO CONSUMIDOR 10

2.1.1 Teoria econômica de escolha (Economic Choice Theory) 11

2.1.2 Teorias racionais 20

2.1.3 Teorias da motivação 21

2.1.4 Teoria do comportamento 25

2.2 VALOR PERCEBIDO 30

2.2.1 Medida de valor percebido 34

2.2.2 $O$ valor percebido como medida de comportamento 41

2.2.3 Atributos de valor 43

2.3 SETOR DE SERVIÇOS 44

2.3.1 As características dos serviços 46

2.3.2 As competências em serviços 48

2.3.3 Turismo e hotelaria 52

3 METODOLOGIA DE PESQUISA: DESENHO E DESCRIÇÃO DA ANÁLISE CONJUNTA 
$3.1 \quad$ TÉCNICA DO INCIDENTE CRÍTICO 68

3.1.1 Estabelecimento do objetivo geral do estudo 70

3.1.2 Desenvolvimento de um plano de coleta de dados 70

3.1.3 Coleta de dados 71

3.1.4 Análise dos dados 71

$\begin{array}{lll}\text { 3.1.5 Interpretação dos dados } & 71\end{array}$

$\begin{array}{lll}3.2 & \text { ANÁlise CONJUNTA }\end{array}$

3.2.1 A função utilidade na análise conjunta 76

3.2.2 Planejamento de um experimento em análise conjunta 80

4 UMA APLICAÇÃO NA INDÚSTRIA HOTELEIRA

4.1 Descrição do OBJETO DE ESTUdo: O HABitAT Hotel 102

$\begin{array}{lll}4.2 & \text { TÉCNICA DO INCIDENTE CRÍTICO } & 105\end{array}$

4.2.1 Obtenção e coleta de dados 105

$\begin{array}{lll}4.3 & \text { AnÁlise CONJUNTA } & 108\end{array}$

4.3.1 Estágio 1: os objetivos da análise conjunta 109

4.3.2 Estágio 2: o projeto de uma análise conjunta 110

4.3.3 Estágio 3: pressupostos da análise conjunta 115

4.3.4 Estágio 4: estimação do modelo da análise conjunta 116

$\begin{array}{ll}\text { 4.3.5 Estágio 5: interpretação dos resultados } & 117\end{array}$

4.3.6 Estágio 6: validação dos resultados 124

5 CONCLUSÕES 127

$\begin{array}{ll}\text { 5.1 RECOMENDAÇÃO DE ESTUdOS FUTUROS } & 128\end{array}$

REFERÊNCIAS BIBLIOGRÁFICAS

$\begin{array}{lr}\text { GLOSSÁRIO } & 143\end{array}$

ANEXO 1 - RESULTADOS DA TÉCNICA DO INCIDENTE CRÍTICO 146

ANEXO 2 - RESULTADOS DA ANÁLISE CONJUNTA 150

ANEXO 3 - MATRIZ DE CLASSIFICAÇÃO HOTELEIRA 178 


\section{INTRODUÇÃO}

Existimos para fornecer valor a nossos clientes [...] Nada acontece até que um cliente entre em uma loja com um propósito, adquira algo e depois saia (Samuel Moore Walton, fundador da Wal-Mart Stores, Inc). ${ }^{1}$

As empresas não têm uma visão abrangente daquilo que cria ou destrói valor. Seus dirigentes normalmente têm dificuldade para identificar todas as fontes de valor, internas e externas, para a empresa. O resultado: a liderança possui uma visão incompleta de como lucrar no mercado. (BOULTON, LIBERT e SAMEK, 2001).

A atividade de marketing, há tempos, reconhece a importância de se procurar medir qualidade e valor percebido pelos consumidores e sua interdependência com a satisfação (ZEITHAML, 1988). Daí resultam benefícios mercadológicos à atividade empresarial, traduzido em termos de lealdade do consumidor, particularmente relevante em um período como o atual, de intensa competição, justificando a preocupação com a percepção de valor do consumidor, por parte dos empresários, assim como sua inserção nas estratégias de marketing dos seus estabelecimentos (CRONIN, BRADY e HULT, 2000; HOLBROOK, 1999; WOODRUFF, 1997).

O atendimento da expectativa do cliente é uma das chaves para obter sucesso frente à concorrência. A tecnologia de informação (TI), propiciando grandes avanços em comunicações (por exemplo, a Internet), e disponibilizando sistemas de apoio ao relacionamento com os clientes (como: CRM - customer relationship management, DBM - database marketing),

\footnotetext{
${ }^{1}$ Samuel Moore Walton, fundador da Wal-Mart Stores, Inc., em discurso a seus funcionários.
} 
propicia às empresas ferramentas para identificar o que satisfaz o cliente e, com base nos resultados destas informações, estabelecer em que dimensões a gerência deve aportar recursos para a obtenção de desempenho superior.

Cronin, Brady e Hult (2000), ao examinarem as relações entre qualidade, valor, satisfação e intenções comportamentais, comprovam que é necessário medir todas estas variáveis, dado seu efeito complexo e compreensivo sobre as intenções de comportamento dos consumidores. Isso demonstra a significância prática de cada uma delas e a necessidade de se ter uma abordagem holística da literatura, já que qualidade e valor estão fortemente integrados em seus efeitos sobre as intenções dos consumidores.

O conhecimento das percepções e reações dos clientes pode aumentar muito as possibilidades de se tomar melhores decisões empresariais (HAYES, 2001).

\subsection{Caracterização do tema}

O conceito de valor percebido vem ganhando importância e popularidade no ambiente de negócios. Isto ocorre devido ao impacto que o valor percebido representa no comportamento do consumidor e, também, pelas implicações estratégicas dos resultados dos estudos de análise de valor percebido nos resultados das empresas. É reconhecido que a relação custobenefício não somente influencia o processo de compra, mas é também determinante na satisfação e na intenção de recomendação e recompra. (DODDS, MONROE e GREWAL, 1991; PARASURAMAN e GREWAL, 2000; PETRICK, 2001). Assim, o estudo do valor percebido é aclamado por ser uma ferramenta que ajuda os prestadores de serviços a construírem uma posição competitiva no mercado (WOODRUFF, 1997; PARASURAMAN, 1997; HUBER, HERRMANN E MORGAN, 2001; NAUMANN, 1995; STAHL, BARNES, GARDIAL, PARR e WOODRUFF, 1999).

Entretanto, apesar da importância estratégica para o composto mercadológico, o valor percebido não foi suficientemente estudado na literatura da indústria de hospitalidade (DODDS et al., 1991). Muitos esforços foram 
feitos para mensurar este constructo nesta indústria (BOJANIC, 1996; JAYANTI e GHOSH, 1996; KASHYAP e BOJANIC, 2000; OH, 1999) ${ }^{2}$. Apesar de a teoria do valor percebido datar de meados da década de 70 , pesquisadores mais recentes vêm operacionalizando o seu uso por meio de pesquisas empíricas (SWEENEY, SOUTAR e JOHNSON, 1997). Estes estudos apresentam várias dificuldades, principalmente devido a uma inadequada conceituação e a uma vasta quantidade de constructos envolvendo a medida do valor no julgamento do consumidor. Benefícios percebidos, preços percebidos, preços reais, preço psicológico e preço comportamental são conceitos geralmente associados ao valor percebido. Mais que isso, a percepção de valor é afetada por estímulos externos e respostas individuais dos consumidores a determinadas características dos produtos, suas necessidades, motivações, expectativas, personalidade, influenciadores, status social, etc (ATELJEVIC, 2000; SOLOMON, 1999).

Em função disso, a definição deste constructo depende da avaliação da percepção de cada indivíduo, tornando a medida do valor percebido uma tarefa complicada e desafiadora (SEMON, 1998). Apesar destas dificuldades, segundo Anderson, Jain e Chintagunta (1993), existem algumas técnicas para avaliar o valor percebido. Por exemplo, caso o objetivo da pesquisa seja explorar o conceito de valor, entrevistas do tipo focadas (focus groups) são utilizadas. Caso o estudo exija uma decomposição do valor total do produto e/ou serviço em julgamentos dos seus diversos benefícios, é recomendado o uso da análise conjunta. Alguns pesquisadores confiam na análise de dados secundários originária de relatórios de consumo (BOJANIC, 1996; BOLTON e DREW, 1991).

Na literatura mais recente, o valor percebido é mensurado por uma escala única que busca capturar o julgamento do cliente por meio de uma declaração afirmativa (p.ex.: o hotel possui uma boa relação custo-benefício) (JAYANTI e GHOSH, 1996; KASHYAP e BOJANIC, 2000; OH, 1999). Entretanto, esta prática apresenta duas falhas claras.

\footnotetext{
${ }^{2}$ Constructo.1.Aquilo que é elaborado ou sintetizado com base em dados simples, especialmente um conceito.
} 
Na primeira falha, a abordagem não reflete a definição teórica mais aceita de que o valor percebido representa a avaliação geral de utilidade de um produto e/ou serviço baseada nas percepções do que é recebido (benefício) pelo que é entregue (preço) (ZEITHAML, 1988). Isto implica dizer que o valor percebido é uma escolha entre dois componentes, benefícios e sacrifícios. Os benefícios são reconhecidos pelo componente recebido, ou o que o cliente recebe ou usufrui de um produto; os sacrifícios são conhecidos como o componente entregue, ou o que o cliente entrega com o fim de receber; normalmente associado a valor monetário, preço pago (DODDS et al. 1991; KOTLER, BOWEN e MAKENS, 1999; NAUMANN, 1995).

Na segunda falha, o conceito de valor percebido é propositadamente multi-dimensional e, consequentemente, o uso de uma escala de um único item (atributo) não captura adequadamente as dimensões necessárias do constructo (KOTLER, 2000).

Alguns estudos foram desenvolvidos com o intuito de medir o valor percebido (DODDS et al. 1991; GREWAL et al. 1998; SWEENEY et al. 1997). Em suas pesquisas, Grewal et al. (1998) concentraram-se em experimentos de medida do valor percebido de produtos e no comportamento de escolha do consumidor na fase de pré-venda. Neste estudo, o valor percebido foi mensurado por uma escala de doze itens distribuídos em duas dimensões. Como resultado, estas dimensões apresentaram-se válidas e confiáveis.

Entretanto, apesar do pioneirismo, a experiência pautou-se pela avaliação de produtos em detrimento dos serviços. Zeithaml (1997) argumenta que os produtos possuem atributos de melhor qualidade para o estudo de valor percebido pelo seu valor tangível intrínseco que pode ser melhor reconhecido durante e depois do seu consumo. Na mesma linha deste argumento, a percepção de benefício e sacrifício (os dois componentes do valor percebido), associada ao consumo de produtos e serviços durante ou depois deste consumo, pode ser diferente da fase de pré-venda (WOODRUFF, 1997; WOODRUFF e GARDIAL, 1996). 
Caracterizado o tema da pesquisa, passa-se à formulação do problema, identificando-se o objeto de estudo e sua importância no contexto da indústria de hospitalidade.

\subsection{Formulação do Problema}

Um problema comum no setor de serviços e, especificamente, na indústria de hospitalidade, é identificar quais atributos, ou conjunto de características particulares que definem o produto/ serviço, os clientes valorizam. Por sua natureza intrínseca de subjetividade e intangibilidade, a medição das reações dos clientes, apesar de muito importante para a tomada de decisão, é uma tarefa árdua.

Dessa forma, o problema principal deste estudo é dimensionar, por meio de uma função de utilidade, a influência dos diversos atributos da prestação de serviços na tomada de decisão do cliente na escolha de um produto hoteleiro. Ou seja, qual o valor percebido pelo cliente que determina suas intenções comportamentais no momento do consumo do serviço, neste caso, da hospedagem.

\subsection{Objetivos}

Estudos anteriores sobre o valor percebido do cliente apontam ser essencial este conhecimento na análise da satisfação dos clientes em qualquer episódio no qual o cliente entra em contato com qualquer aspecto da organização e obtém uma impressão da qualidade de seu serviço a que eles se expõem (ALBRECHT,1992).

Isso se verifica, com clareza, na indústria hoteleira em que o cliente (hóspede) vivencia estes episódios em todos os processos pelos quais passa dentro da prestação de serviços de hospedagem, desde a reserva até sua saída do Hotel (check out).

O presente trabalho tem por objetivo apresentar uma aplicação da técnica de estatística de análise conjunta como ferramenta de avaliação 
quantitativa do valor percebido na indústria hoteleira, que sirva de apoio ao processo de tomada de decisões de investimento do gestor hoteleiro.

Como objetivos secundários, o trabalho apresenta uma análise qualitativa dos atributos de valor na hotelaria.

\subsection{Justificativa do tema}

Esta modelagem do valor percebido é uma ferramenta útil para identificar eventuais melhorias nos processos de negócios e, mais assertivamente, naqueles atributos identificados pelos clientes como sendo de maior relevância e importância naquele tipo de serviço.

A gestão do valor percebido, inserida num contexto de orientação para o mercado e de efetivo marketing de relacionamento, pode ser uma abordagem estratégica adequada ao atual cenário de acirrada competitividade e de constantes mudanças do ambiente, do consumidor e das próprias empresas.

Este projeto de pesquisa busca contribuir com o estudo teórico e prático da prestação de serviços em hospitalidade. Primeiramente, por utilizar a teoria de valor percebido num ambiente onde ainda não foi explorada à exaustão (indústria de serviços de hospitalidade) e, desta forma, agregar um conceito importante para esta Indústria. Dado que o ambiente da indústria de hospitalidade apresenta numerosas características e atributos próprios, sua aplicação é esperada como uma forte contribuição ao estudo da teoria de valor percebido. Mais do que isso, seus resultados poderão servir para o melhor entendimento do comportamento de consumo deste setor.

Segundo, a análise prática do comportamento de consumo, baseada numa abordagem metodológica qualitativa e quantitativa, será de grande utilidade para os gestores replicarem este estudo em seu próprio negócio como uma ferramenta de apoio à decisão.

Para atingir estes objetivos, estruturou-se o presente trabalho da seguinte forma. 


\subsection{Estrutura do trabalho}

Este capítulo apresenta a introdução do tema de pesquisa, bem como a formulação do problema, os objetivos do trabalho, sua justificativa e estrutura.

No capítulo seguinte, é apresentada a fundamentação teórica referente ao comportamento do consumidor, apresentando a teoria do comportamento do consumidor sob diferentes óticas, passando pela teoria econômica do consumidor até o comportamento psicossocial do indivíduo, e suas motivações.

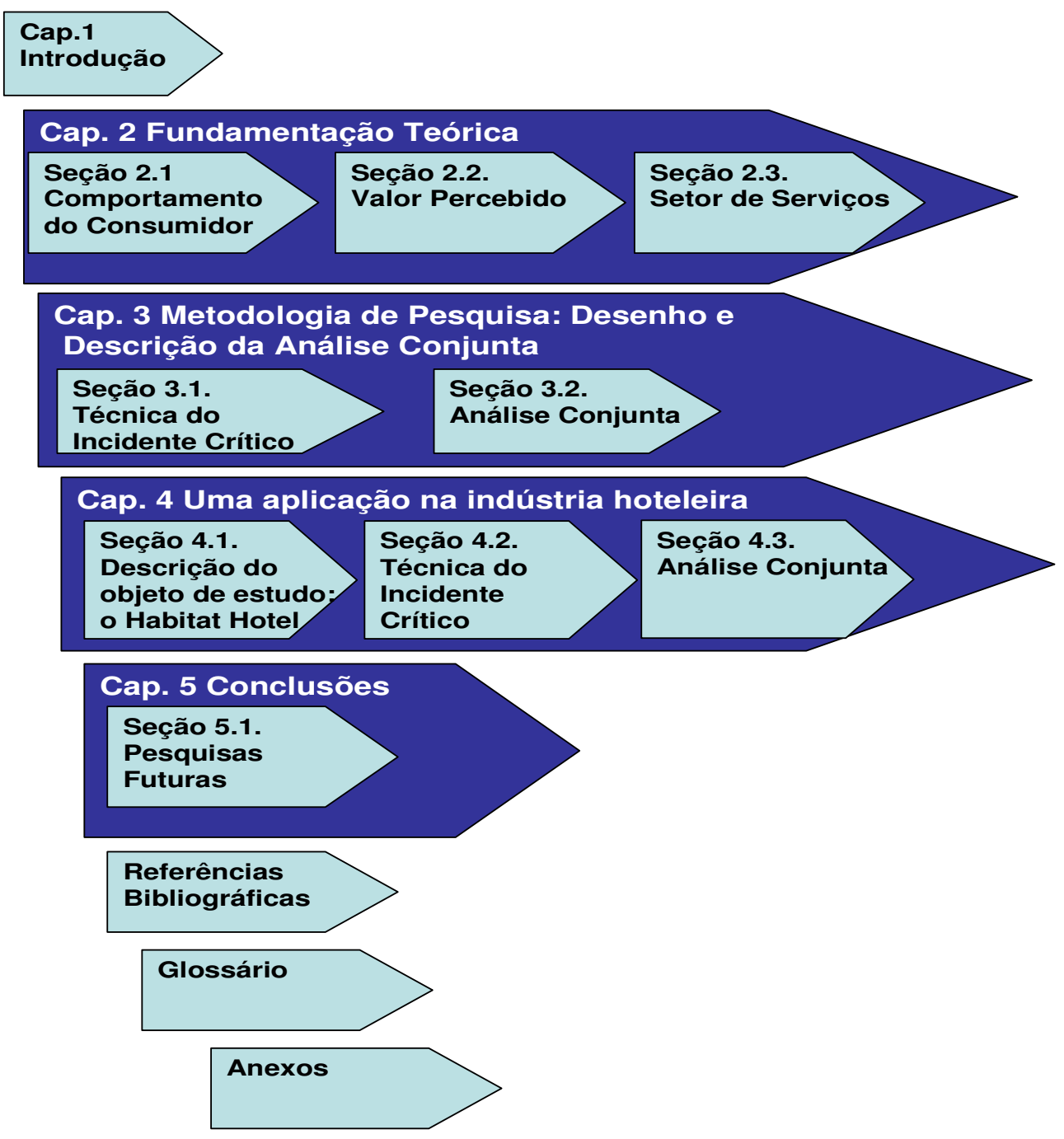

Figura 1: Estrutura do texto 
A figura acima representa a estrutura do trabalho, apresentando sequencialmente os capítulos tratados no texto e suas principais seções. Neste sentido, ainda na fundamentação teórica, e a partir do entendimento do comportamento do consumidor, a seção que segue traz o conceito de valor percebido. Ou seja, quais as características e atributos de um produto ou serviço geram valor e, portanto, são percebidos pelo indivíduo a ponto de este escolher e decidir pela compra. Além disso, o capítulo mostra o setor de serviços e descreve a indústria do turismo e hospitalidade.

O capítulo 3 apresenta a metodologia utilizada para o estudo de valor percebido. Em sua primeira parte, apresenta o método de análise qualitativa e sua aplicação, aqui representada pela Técnica do Incidente Crítico (TIC). A segunda contém a Análise Conjunta (AC), descrevendo o método de análise conjunta proposto para o planejamento da pesquisa.

O capítulo 4 apresenta uma aplicação da metodologia proposta para ilustrar sua aplicabilidade na indústria de hospitalidade. Mais do que isso, apresenta o estudo realizado na identificação dos atributos de valor em hotelaria, segundo a análise qualitativa da técnica do incidente crítico, ampliando seu escopo original para adequar ao caso em questão.

Ainda no capítulo 4, o leitor encontrará uma aplicação da análise conjunta, visando atribuir aos fatores representativos dos serviços hoteleiros uma função de utilidade que represente efetivamente o valor percebido pelo hóspede.

Por fim, o capítulo 5 encerra o trabalho com as conclusões sobre o método proposto e aplicado, bem como as generalizações admissíveis para o mesmo. E completa-se com as proposições de estudos futuros. 


\section{FUNDAMENTAÇÃO TEÓRICA}

O objetivo deste capítulo é apresentar as contribuições teóricas que norteiam os estudos nas áreas de interesse deste trabalho e que serão utilizadas como suporte conceitual para abordar o problema enunciado.

A referência utilizada procura abordar o tema proposto com citação de autores nacionais e internacionais, haja vista que o material explorado na revisão da literatura apresenta uma grande quantidade de estudos e pesquisas fora do Brasil, tanto no tema do valor percebido quanto na indústria de hospitalidade, escolhida para aplicação do método proposto.

O capítulo inicia tratando do comportamento do consumidor, tomando por base a teoria econômica de consumo, passando pelas influências psicológicas e sociais na escolha do consumidor moderno. Na seqüência, aborda o tema central do estudo, o valor percebido, cuja teoria está fortemente associada ao comportamento do consumidor, indicando tal sinergia entre ambos que a relação causal entre as duas teorias se confunde.

Por fim, uma breve revisão da literatura do setor de serviços, nela incluídos o turismo e a hotelaria, prepara o arcabouço teórico para a introdução do método de pesquisa.

Neste propósito, são abordados os conceitos fundamentais de:

- Comportamento do Consumidor

- Valor Percebido

- Setor de Serviços 


\subsection{Comportamento do Consumidor}

Os únicos capazes de demitir a todos nós são os clientes (Samuel Moore Walton, fundador da Wal-Mart Stores, Inc). ${ }^{3}$

Durante os últimos 30 anos, muitas empresas se criaram como resultado de uma franca expansão do mercado mundial de hospitalidade. $O$ resultado disto é o crescente aumento da concorrência entre as diversas companhias que lutam para manter e aumentar seus mercados. Com este objetivo, elas têm aumentado seus investimentos em pesquisas que revelem o que seus clientes querem comprar, para que localidades querem viajar, quais serviços são importantes, como e porque eles compram. A questão central, portanto, é como os indivíduos, consumidores, respondem aos estímulos de marketing?

Segundo Kotler (2000), as empresas que entenderem como os consumidores respondem aos diferentes atributos e características dos produtos, a preços e estímulos de marketing, terão uma vantagem competitiva sobre seus concorrentes. Desta forma, trabalhos teóricos e empíricos buscam entender a relação entre estes estímulos e as respostas dos consumidores como fator para tomada de decisão gerencial.

A teoria do comportamento do consumidor, portanto, estuda a influência dos fatores culturais, sociais, demográficos, psicológicos, econômicos, entre outros, que são abordados neste capítulo. Existem variações no conceito de comportamento do consumidor, segundo os vários autores da área de marketing. Para Kotler (2000), o campo do comportamento do consumidor estuda como as pessoas, grupos e organizações selecionam, compram, usam e descartam artigos, serviços, idéias ou experiências para satisfazer as necessidades de seus desejos.

Engel, Blackwell, Miniard (2000) definem o comportamento do consumidor como as atividades diretamente envolvidas em obter, consumir e

\footnotetext{
${ }^{3}$ Samuel Moore Walton, fundador da Wal-Mart Stores, Inc., em discurso a seus funcionários.
} 
dispor de produtos e serviços, incluindo os processos decisórios que antecedem e sucedem estas ações.

Mowen e Minor (2003) definem o comportamento do consumidor como o estudo das unidades compradoras e os processos de troca envolvidos na aquisição, consumo e utilização de mercadorias, serviços, experiências e idéias.

Gade (1998), por outro lado, define o comportamento do consumidor como comportamento de procura, busca, compra, uso e avaliação de produtos e serviços para satisfazer suas necessidades.

A convergência, entretanto, mostra-se evidente entre os diversos autores no que diz respeito ao comportamento do consumidor vincular o consumidor (Ser-humano ou instituição que, em última análise, recai sobre o indivíduo) com o processo pelo qual este ente adquire bens ou serviços.

No contexto deste trabalho, o comportamento do consumidor serve como base para o estudo específico, em que se pretende avaliar o valor percebido de consumidores no setor de hospitalidade. Neste sentido, é essencial que haja uma clara compreensão da teoria de escolha e comportamento de consumo como arcabouço conceitual e qualitativo para 0 modelo quantitativo que se busca no estudo de caso aplicado.

\subsubsection{Teoria econômica de escolha (Economic Choice Theory)}

Segundo McFadden (1986), a teoria econômica moderna parte do pressuposto de que indivíduos ou populações homogêneas de indivíduos possuem um comportamento de mercado que pode ser explicado pela maximização de suas preferências. Estas podem conter componentes aleatórios devido a flutuações nas percepções dos indivíduos, atitudes, ou outros fatores não-mensuráveis. Preferências são definidas por commodities que possuem atributos mensuráveis e não-mensuráveis. Entre essas commodities, estão os hábitos e experiências que entram com o papel de decisões passadas. 
As atitudes podem entrar como variáveis intervenientes, contanto que o modo com que elas são influenciadas pelo mercado também seja levado em consideração. Variáveis sociais, demográficas e econômicas entram como modificadoras das preferências. Assim, a teoria torna-se operacional por meio da junção do modelo aleatório de preferências com as probabilidades de respostas do mercado.

Um modelo axiomático coloca as probabilidades de resposta em famílias estatísticas que tornam práticas a estimação e análise do comportamento de preferências. Este modelo possui duas âncoras. A primeira delas consiste no fato de que as probabilidades de respostas são influenciadas somente por varáveis mensuráveis direta ou indiretamente. A segunda âncora equivale às probabilidades que podem ser validadas por meio de comportamentos reais de mercado.

Para McFadden (1986), esta descrição da teoria econômica é consistente na estrutura do comportamento de escolha de consumo apresentada na figura abaixo, acrescentando que o protocolo de decisões direciona as intenções comportamentais que, por sua vez, maximizam as preferências.

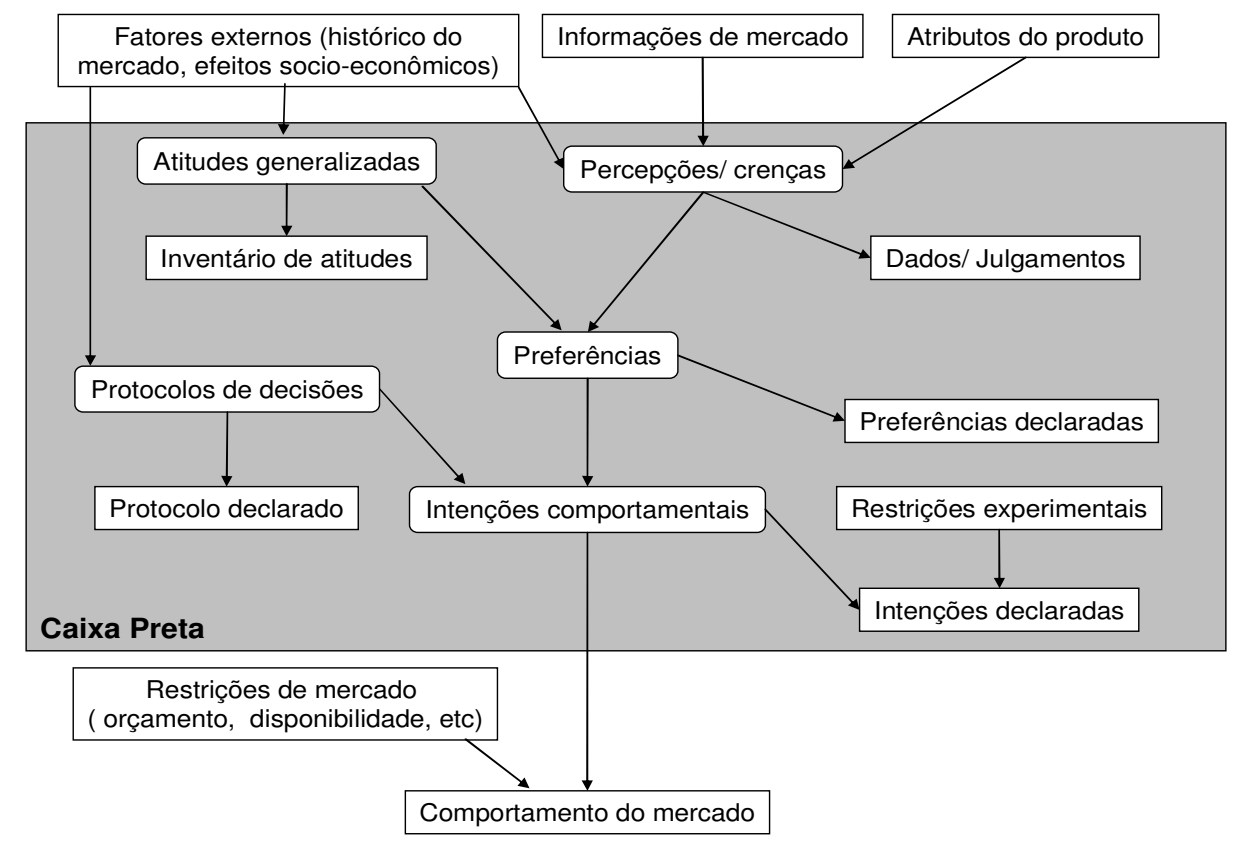

Figura 1: Processo de Escolha de Consumo.

Fonte: McFADDEN, D. (1986) 
O argumento desta proposição é que a disposição do temperamento do indivíduo, que o faz reagir de maneira muito pessoal à ação dos agentes externos (idiossincrasia), pode ser explicada por uma análise completa das preferências que incorporam os efeitos das percepções e atitudes do indivíduo. Esta visão do comportamento de escolha é antiga na economia.

Um objeto não tem valor, a menos que ele tenha utilidade. Ninguém dará nada por um produto, ou serviço, a menos que ele the proporcione satisfação. Sem dúvida, as pessoas agem impulsivamente, e muitas vezes adquirem coisas como se fossem crianças, para realizar algum sonho; mas, no mínimo, elas pensam, neste momento, que um desejo deve ser satisfeito. (TAUSSIG,1912, apud McFADDEN, 2001, p.351)

A teoria econômica clássica postula que o consumidor procura maximizar seus próprios interesses, e que estes interesses são claramente definidos pela consistência de suas posses por meio de diferentes decisões de consumo (McFADDEN, 2001).

McFadden (2001), no artigo em que recebe o prêmio Nobel de Economia, destaca que os economistas consideram heterogêneas as preferências do consumidor, mas ignoram este complicador em seus estudos empíricos de demanda de mercado.

Neste mesmo artigo, o autor define que as preferências de consumo podem ser representadas por uma função utilidade, $U(x)$, formada por um vetor $x$ de níveis de consumo, e que esta função deve ser maximizada para uma restrição orçamentária, $R$, conforme a expressão abaixo:

$$
p \cdot x \leq R
$$

onde, $p$ é o vetor de preços;

$R$ é a renda, e para uma função de demanda, expressa por: 


$$
x=d(R, p)
$$

Somente a função de demanda, $x$, carrega as restrições impostas pela teoria do consumidor ${ }^{4}$.

Esta visão de utilidade como sinônima de comportamento de escolha dominou o meio acadêmico da economia até a formalização da Teoria de Consumo por Hicks e Samuelson, em meados de 1930. Luce (1958) introduz grandes avanços ao estudo do comportamento do consumidor, quando propõe o uso de estudos probabilísticos para explicar a decisão do consumo e, a partir disso, introduz o axioma da Independência das Alternativas Irrelevantes (IIA), que simplificou a coleta de dados experimentais por meio do uso de probabilidades multinomiais. ${ }^{5}$

Ben-Akiva et al. (1999) propõem um modelo para a teoria da escolha (ver figura 2). Este modelo abrange o modelo padrão do processo de escolha da teoria econômica - a teoria racional, na qual os indivíduos coletam informações sobre as alternativas, utilizam-se de probabilidades para converter informações em atributos, e então vão para o processo cognitivo de escolha, em que maximizam a função utilidade dos atributos. Mais do que isso, o modelo ainda abrange fatores psicológicos do processo de escolha. Os conceitos de percepção, preferências e processo aparecem em ambos os modelos, econômicos e psicológicos, mas com visões diferentes.

\footnotetext{
${ }^{4}$ Ver seção 2.2. O conceito de utilidade aplicado neste trabalho será mais explorado na seção referente ao valor percebido.

${ }^{5} \mathrm{O}$ axioma da independência das alternativas irrelevantes (IIA) declara que o processo de escolha de um indivíduo entre um determinado bem ( $p$.ex. um produto da marca $A$ ) versus outro bem (p.ex. um produto da marca B) não é afetado pela presença ou ausência de alternativas (p.ex. um produto da marca $C$, ou D) como escolhas potenciais. Este axioma é também conhecido como axioma de escolha de Luce (LUCE, 1977).
} 


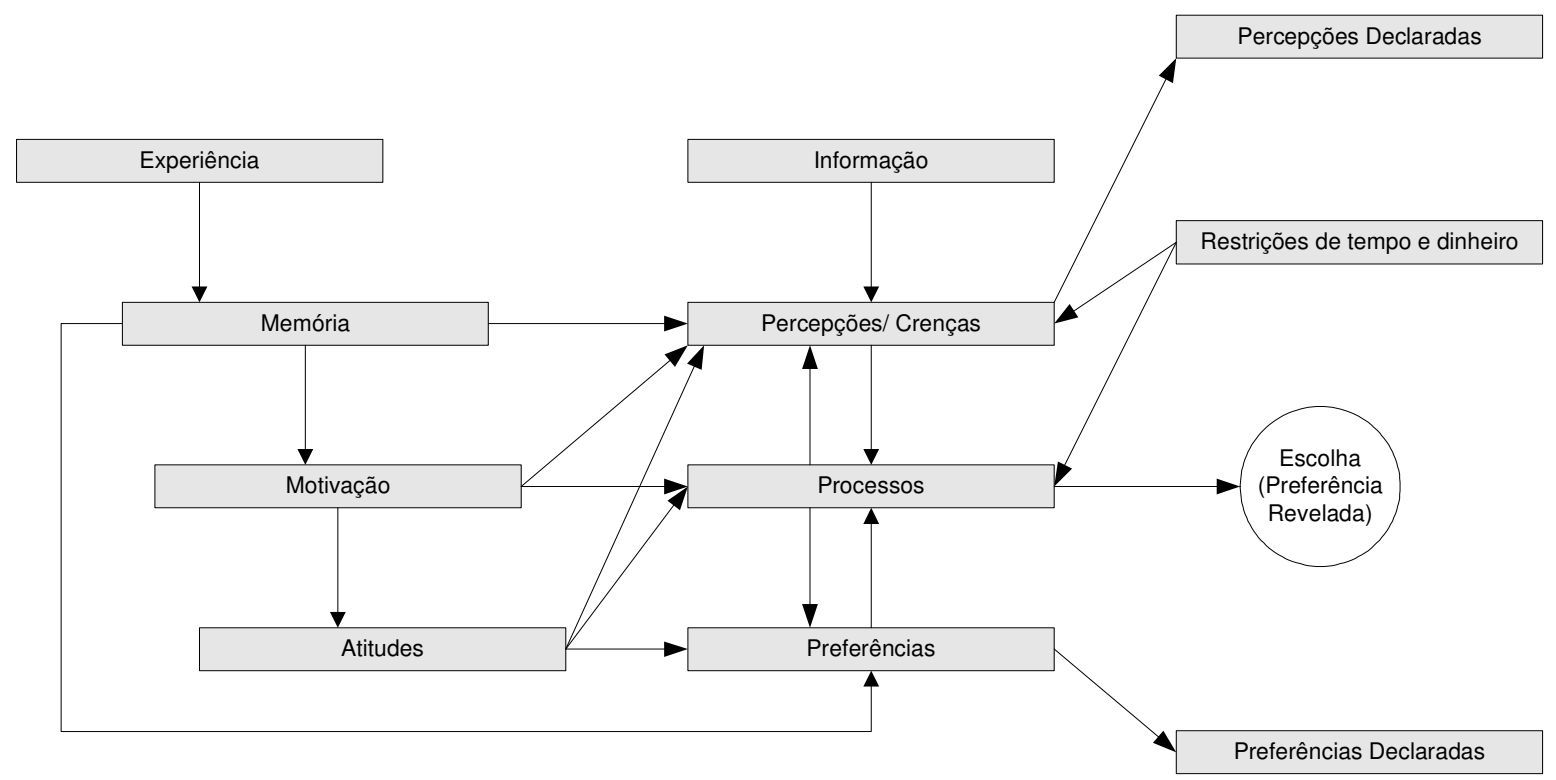

Figura 2: O Processo de Escolha. Adaptado de Ben-Akiva (1999).

Fonte: Mc FADDEN, D. (2000).

Varian (2000) estabelece que, na era vitoriana ${ }^{6}$, os economistas entendiam o conceito de utilidade como medida numérica da felicidade do indivíduo. Na visão neoclássica, eles abandonam esta velha visão e reformulam toda a teoria do comportamento do consumidor com base nas preferências do mesmo. A utilidade passou a ser vista somente como um modo de descrever estas preferências. Para Varian (2000), alguns pressupostos sobre preferências são tão fundamentais que podem ser caracterizados como "axiomas". Dessa forma, ele define três principais axiomas de preferência do consumidor:

1. Preferência Completa: A preferência é completa, ou seja, o consumidor é capaz de escolher entre duas cestas de consumo quaisquer. Dada uma cesta $x$ qualquer e uma cesta $y$ qualquer, $\left(x_{1}, x_{2}\right)>\left(y_{1}, y_{2}\right)$ ou $\left(y_{1}, y_{2}\right)>\left(x_{1}\right.$,

\footnotetext{
${ }^{6}$ A rainha Vitória, da Inglaterra, morreu aos 81 anos de idade no Castelo de Osborne, na llha de Wight. Vitória comandou o império britânico por 63 anos. Durante seu reinado, o império chegou a englobar um quarto do mundo, com colônias em todos os continentes e o domínio de diversas ilhas. Na Era Vitoriana (1838-1901), a Inglaterra viveu o apogeu da burguesia, com as exportações crescendo 450\%. Também nesse período foram criados rígidos códigos de postura, que só foram quebrados no fim do século 20. Edward VII, seu primogênito, assume o trono inglês.
} 
$x_{2}$ ) ou, ainda ambas, caso em que o consumidor é indiferente a ambas. (Utilizaremos o símbolo > (maior) para significar que uma cesta é estritamente preferida a outra).

2. Preferência Reflexiva: Supomos que todas as cestas são pelo menos tão boas quanto elas mesmas: $\left(x_{1}, x_{2}\right) \geq\left(x_{1}, x_{2}\right)$.

3. Preferência Transitiva: Se $\left(x_{1}, x_{2}\right)>\left(y_{1}, y_{2}\right)$ e $\left(y_{1}, y_{2}\right)>\left(z_{1}, z_{2}\right)$, pressupomos então que $\left(x_{1}, x_{2}\right)>\left(z_{1}, z_{2}\right)$. Em outras palavras, se o consumidor acha que $x$ é pelo menos tão boa quanto $y$ e que $y$ é pelo menos tão boa quanto $z$, então ele acha que $x$ é pelo menos tão boa quanto $z$.

Uma relação de preferência só é estabelecida se satisfaz, ao menos, as condições de completitude (axioma 1) e transitividade (axioma 3).

Como notado na figura 1, McFadden (1986) estabelece um diagrama do processo de escolha onde as figuras ovais representam variáveis latentes ou teóricas, enquanto as figuras retangulares representam observações diretas do consumidor (indivíduo) ou medidas experimentais.

As entradas deste processo são os atributos do produto, informações do mercado, propaganda, experiências históricas, fatores socioeconômicos e restrições de mercado, como orçamento e disponibilidade de produto. A saída deste processo de escolha é o próprio comportamento do consumidor.

Os constructos críticos no processo de modelagem da escolha são as percepções e crenças sobre os produtos, as atitudes generalizadas ou valores do indivíduo, as preferências, os protocolos de decisão que mapeiam e direcionam as preferências para escolhas e intenções comportamentais de escolha.

As percepções são influenciadas pelos atributos do produto e por informações do mercado. Percepções, atitudes e protocolos de decisão são influenciados por experiências anteriores e fatores socioeconômicos. As atitudes generalizadas (valores) em conjunto com as percepções determinam as preferências que, por sua vez, se traduzem em intenções comportamentais por meio dos protocolos de decisão. 
Uma forma de os gestores traduzirem este constructo teórico para experimentos práticos que Ihes permitam orientar o processo decisório das estratégias mercadológicas é utilizar dados experimentais das atitudes, percepções, gostos, preferências e protocolos de decisão dos consumidores.

Com estes dados em mãos, pode-se aplicar análises de escalonamentos multidimensionais de dados/ julgamentos para prover medidas para compreender as percepções, enquanto análises fatoriais aplicadas a um conjunto de dados (inventário) de atitudes generalizadas (valores individuais) provêem medidas para os gostos individuais.

Segundo McFadden (1986), o uso de experimentos emparelhados de produtos (dois a dois), escalonamentos de produtos e estímulos envolvendo escolhas entre um conjunto de produtos (conjunto escolha) permitem a análise de preferências declaradas e intenções de comportamento; este conjunto de técnicas forma a análise conjunta.

Os grandes desafios do uso destas ferramentas psicométricas e da análise conjunta ${ }^{7}$ são:

- o desenho de técnicas experimentais (de laboratório) que gerem informações confiáveis sobre o comportamento do consumidor,

- o desenvolvimento de métodos que transformem dados experimentais em modelos de previsões, $\mathrm{e}$

- a validação dos resultados dos modelos preditos.

Os economistas, por sua vez, encaram os mesmos problemas, exceto pelo fato de trabalharem com experimentos naturais no lugar de técnicas de laboratório (McFADDEN, 1986).

Segundo Kerstenetzky (2005), a hipótese do interesse do indivíduo tem desempenhado papel crucial na teoria econômica moderna, desde o pensamento fisiocrata até as perspectivas mais recentes da ciência econômica. ${ }^{8}$ É de se observar a variedade de justificativas, explícitas ou não,

\footnotetext{
${ }^{7}$ Ver seção 3.2. No capítulo três, é apresentado o arcabouço teórico da análise conjunta.

${ }^{8}$ Fisiocracia, advinda da chamada escola fisiocrática, surgiu no século XVIII e é considerada a primeira escola de economia científica. Os fisiocratas consideram o sistema econômico como
} 
para a sua adoção; não há nada de evidente a seu respeito. De fato, é possível identificar um conjunto de funções que o interesse do indivíduo tem cumprido em teorias econômicas, sociais e políticas; podemos citar pelo menos três funções, a saber: explanatória, normativa, representacionista.

Em sua função explanatória, o interesse individual é utilizado para explicar o comportamento humano, tanto individual quanto coletivo, na medida em que os fatos coletivos podem ser analisados em termos dos interesses próprios, motivadores, dos indivíduos. Nesse caso, a teoria deve empenhar-se em descobrir os conteúdos desses interesses, se ela pretende desenvolver predições sobre esse comportamento e sobre seus efeitos no agregado de ações individuais. Nessa função, o interesse individual é freqüentemente acusado de contaminar a explicação com forte reducionismo psicológico ${ }^{9}$.

A segunda é a normativa, cujo interesse operaria como a motivação que deveria guiar as demais motivações e impulsos dos indivíduos e, além disso, seria a única capaz de conduzi-los a uma coordenação espontânea e harmônica de suas ações. As propriedades de equilíbrio e eficiência, associadas a comportamentos interessados, na moderna teoria do bem estar $\mathrm{e}$ da escolha social - ou de equilíbrio, eficiência e justiça nas teorias econômicas contemporâneas sobre a ordem política - testemunham a ativação da função normativa.

Em sua terceira função, o interesse desempenharia um papel meramente representacionista, ou seja, o de permitir a produção de uma teoria coerente que possa representar um comportamento "idealizado" dos indivíduos, controlado por axiomas e passível de extrapolações, na forma de predições e explicações qualificadas. As teorias sobre a tomada de decisão individual, baseadas nas preferências ou, simplesmente, na escolha (como a

um "organismo" regido por leis intrínsecas (pela ordem natural das coisas), sendo elas assim, cientificamente relevantes. (http://pt.wikipedia.org/wiki/Fisiocracia)

${ }^{9}$ Reducionismo psicológico. 1. Descrição ou explicação de fenômenos ou processos humanos coletivos (sociais, culturais ou ecológicos), em termos de fenômenos ou preferências psicológicas dos indivíduos. 
teoria das preferências reveladas de Samuelson), seriam os exemplos mais notáveis.

Em contraste, visões sociopsicológicas tradicionais enfatizam a importância de regras e normas, consideradas práticas sociais que determinam o comportamento dos indivíduos, revelando assim, a ociosidade da noção de escolha individual ${ }^{10}$. Sempre se pode, contudo, apontar a circularidade dessa argumentação, que explica a coordenação entre os indivíduos por meio de práticas sociais e psicológicas pré-existentes. Na verdade, essa forma de explicação holística, ao traduzir escolhas em determinação social, padeceria dos mesmos defeitos da explicação de escolha racional referida.

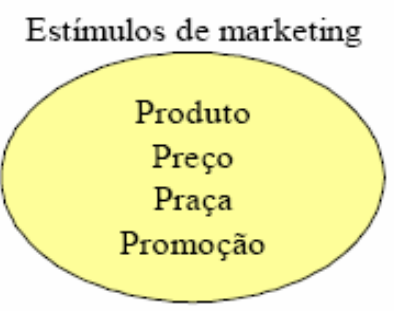

\section{Outros Estímulos}

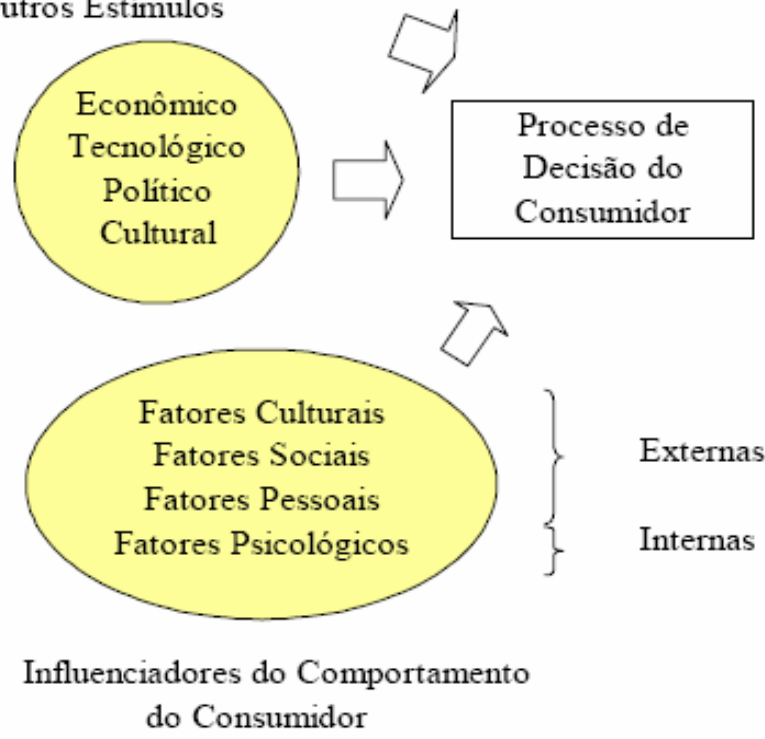

Decisões do Consumidor

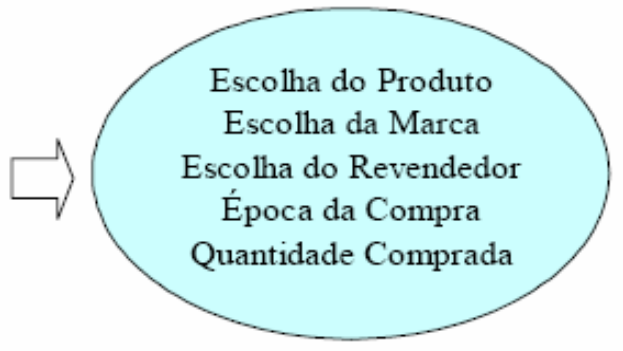

Escolha do Produto

scolha do Revendedor

Epoca da Compra

Quantidade Comprada

Figura 3: Modelo de comportamento do consumidor.

Fonte: Adaptado de KOTLER, P. (1998, p.162)

Na figura 3, adaptada de Kotler (1998, p.162), pode-se observar que muitas características e forças individuais influenciam o comportamento de

\footnotetext{
${ }^{10}$ Ver seções 2.1.3 onde são apresentadas as teorias sócio-psicológicas.
} 
compra. A escolha do consumidor é resultado de um complexo processo interativo de fatores culturais, sociais, pessoais, econômicos, psicológicos, políticos. Muitos destes fatores podem não ser influenciados por estratégias de marketing, entretanto, o conhecimento e influência destes fatores no processo de escolha são essenciais para o gestor hoteleiro.

Das figuras apresentadas, figura 1 - o processo de escolha do consumidor (McFADDEN, 1986), figura 2 - o processo de escolha (McFADDEN, 2000) e figura 3 - o modelo de comportamento do consumidor (KOTLER, 1998), pode-se entender que os estímulos de marketing e outros estímulos influenciam nas características particulares dos indivíduos, a chamada "caixa preta" do consumidor. Esta influência gera resultados traduzidos por meio de escolhas e preferências.

Neste sentido, os pesquisadores e gestores hoteleiros precisam conhecer como estes estímulos são transformados na "caixa preta" do consumidor antes de resultarem na escolha ou preferência de determinado produto.

Para isso, esta "caixa preta" pode ser dividida em duas partes: as características pessoais que influenciam como 0 indivíduo percebe os estímulos e reage a eles e o processo de decisão propriamente dito.

Neste sentido, algumas teorias foram desenvolvidas como forma de explicar estas características pessoais que direcionam o comportamento do indivíduo. Dentre elas, estão: as teorias racionais, nelas incorporadas a teoria econômica, as teorias de motivação, de personalidade e comportamento. Para identificá-las, é apresentado abaixo um breve resumo das suas principais características.

\subsubsection{Teorias racionais}

De um lado, os economistas atribuem ao homem econômico uma racionalidade plena em que as alternativas de comportamento são conhecidas em sua totalidade. As conseqüências de cada uma delas também são, estocástica ou deterministicamente, conhecidas, e as preferências, 
consistentes e completas. $\mathrm{O}$ estudo destas preferências, juntamente com uma capacidade computacional quase que irrestrita, permite a ordenação das alternativas e a seleção de uma escolha entre todas as possíveis. No outro extremo, encontra-se na psicologia social tentativas de reduzir a cognição ao afeto e de demonstrar que os homens não são nem de perto tão racionais quanto gostam de imaginar.

Dentre as teorias racionais que corroboram o lado dos economistas, destaca-se a teoria de avaliação de risco e decisão, segundo a qual o fundamento da decisão de compra estaria relacionado à análise de risco que o sujeito realiza. O risco nada mais é do que a possibilidade do resultado ser alcançado, ou não, considerando os esforços financeiros e psíquicos. O risco tem componentes objetivos (números e estatísticas) definidos exteriormente aos indivíduos, mas também componentes subjetivos (disposição ao risco, p.ex.). O mesmo produto pode ser avaliado com diferentes níveis de risco para diferentes tomadores de decisão.

\subsubsection{Teorias da motivação}

O comportamento que se pode observar entre as pessoas não exibe esta racionalidade plena, tal como descrita no modelo neoclássico, mas antes possui elementos de integração com outras teorias. Partes do comportamento humano exibem uma coerência interna própria que se associa aos elementos da racionalidade para compor o todo. Neste sentido, faz-se necessário o entendimento das principais teorias que interpretam este comportamento.

Talvez o primeiro ponto que há de se entender em relação ao consumidor seja a motivação. Com raras exceções, um ser-humano não consumirá nada se não estiver motivado a comprar. A motivação envolve atividades as quais nos levam a um determinado objetivo. Podemos nos tornar motivados ou estimulados por meio de necessidades internas ou externas, que podem ser de caráter fisiológico ou psicológico. Os principais teóricos da motivação e comportamento foram Maslow, Freud, Herzberg, Jung e Skinner. 
Na seqüência, são apresentadas as principais linhas do pensamento destes autores.

\subsubsection{A Teoria de Maslow}

Segundo Serrano (2003), Maslow e McGregor citam o comportamento motivacional, que é explicado pelas necessidades humanas. Entende-se que a motivação é o resultado dos estímulos que agem com força sobre os indivíduos, levando-os a ação. Para que haja ação ou reação, é preciso que um estímulo seja implementado, seja decorrente de coisa externa ou proveniente do próprio organismo. Esta teoria nos dá idéia de um ciclo, o Ciclo Motivacional. Quando o ciclo motivacional não se realiza, sobrevém a frustração do indivíduo, que poderá assumir várias atitudes:

- Comportamento ilógico ou sem normalidade;

- $\quad$ Agressividade por não poder dar vazão à insatisfação contida;

- Nervosismo, insônia, distúrbios circulatório-digestivos;

- Falta de interesse pelas tarefas ou objetivos;

- Passividade, moral baixo, má vontade, pessimismo, resistência às modificações, insegurança, não colaboração, etc.

Quando a necessidade não é satisfeita e não sobrevêm as situações anteriormente mencionadas, não significa que o indivíduo permanecerá eternamente frustrado. De alguma maneira, a necessidade será transferida ou compensada. Daí percebe-se que a motivação é um estado cíclico e constante na vida pessoal.

A teoria de Maslow é conhecida como uma das mais importantes teorias de motivação. Para ele, as necessidades dos seres-humanos obedecem a uma hierarquia, ou seja, a uma escala de valores a serem transpostos. Isto significa que, no momento em que o indivíduo realiza uma necessidade, surge outra em seu lugar, exigindo sempre que as pessoas busquem meios para satisfazê-la. Poucas ou nenhumas pessoas procurarão 
reconhecimento pessoal e status se suas necessidades básicas estiverem insatisfeitas.

As necessidades humanas estão organizadas e dispostas em níveis, numa hierarquia de importância e de influencia, numa pirâmide, em cuja base estão as necessidades mais baixas (necessidades fisiológicas) e no topo, as necessidades mais elevadas (as necessidades de auto-realização).

Segundo Giglio (2002), a teoria das necessidades básicas de Maslow não estava basicamente interessada em comportamento de consumo senão em criar uma teoria geral de motivação. Sua tese principal é que as pessoas criam cinco planos básicos na sua vida: satisfazer suas necessidades fisiológicas, de segurança, de afeto, de relacionamento e de auto-realização.

Para Kotler (2000), quando uma pessoa consegue satisfazer uma necessidade importante, essa necessidade deixa de ser um motivador corrente e a pessoa tenta satisfazer a próxima necessidade mais importante.

\subsubsection{Teoria de Freud}

Enquanto a teoria de Maslow relaciona-se com a motivação, a teoria de Freud estabelece que motivações seriam responsáveis pela aceitação ou rejeição de produtos ou bens de consumo.

De acordo com Gade (1980), a teoria freudiana é utilizada em marketing a fim não só de estabelecer os motivos intra-psíquicos que levariam o homem ao consumo, assim como o estudo dos apelos mais favoráveis em termos de propaganda. Freud estabelece três instâncias psíquicas responsáveis pelo comportamento: o id, fonte da energia psíquica dos impulsos primitivos, o ego, regulador dos impulsos selvagens do id ligado ao princípio da realidade, e o superego, ao qual cabe a representação interna das proibições sociais.

Freud considerava que a introspecção era insuficiente para alcançar todos os fenômenos da vida mental do "sujet" (paciente estudado). Freud achava que se concentrar somente nos estudos dos aspectos observáveis do comportamento das pessoas era muito pouco e superficial, devendo-se 
aprofundar as observações aos seus lados sombrios interiores, o que mais tarde chamou de inconsciente e subconsciente.

O ponto chave da psicanálise freudiana, ou sua premissa, é a proposição de dividir o psiquismo humano em:

- consciente;

- $\quad$ inconsciente, dividido em: inconsciente latente, capaz de manter a consciência, ou seja, consciente no sentido de sua dinâmica de funcionamento - é o chamado pré-consciente - e inconsciente reprimido, este não consegue manter o nível de consciência.

Os pontos de destaque da psicanálise freudiana, quanto ao comportamento humano, são:

- os impulsos inconscientes e

- $\quad$ as defesas do psiquismo contra estes impulsos inconscientes

Ao estudar o que faz as pessoas comprarem certos produtos, os analistas do consumidor tentaram se utilizar dessas teorias para analisar em termos de personalidade e de estruturação psíquica que componentes e traços do produto teriam maior aceitação. Esses fatores foram estudados com base na premissa de que certos objetos de consumo satisfariam mais a determinadas instâncias psíquicas do que a outras, assim como a satisfação destes desejos pode entrar em conflito com esta ou aquela entidade.

\subsubsection{Teoria Herzberg}

Herzberg desenvolveu uma teoria de dois fatores para distinguir os fatores que causam insatisfação (os insatisfatórios) daqueles que causam a satisfação (os satisfatórios). Para motivar uma compra, não basta, para Herzberg, que os fatores de insatisfação estejam ausentes. Pelo contrário, os fatores de satisfação devem estar bem presentes (KOTLER, 2000)

A teoria de Herzberg apresenta duas sugestões, mais ou menos óbvias: evitar os fatores de insatisfação e apresentar os fatores de satisfação, este último com papel fundamental em relação às marcas que o consumidor comprará. 


\subsubsection{Teoria de Jung}

Jung afirmou que cada indivíduo poderia ser caracterizado como sendo primeiramente orientado para seu interior ou para o exterior. Entretanto, o indivíduo não é totalmente introvertido ou extrovertido. Algumas vezes, a introversão é mais apropriada, em outras ocasiões, a extroversão é mais adequada, mas as duas atitudes se excluem mutuamente, de forma que não se mantêm ambas ao mesmo tempo. Também enfatizou que nenhuma das duas é melhor que a outra, citando que o mundo precisa dos dois tipos de pessoas.

Os introvertidos concentram-se em suas próprias idéias, tendendo à introspecção. O problema de tais consumidores é imergir de forma demasiada em seu mundo interior, perdendo ou tornando tênue o contato com o ambiente externo e com os estímulos que lhe são inferidos.

Os extrovertidos, por outro lado, se envolvem com o mundo externo das pessoas e das coisas. Eles tendem a ser mais sociais e mais conscientes do que acontece à sua volta. Necessitam se proteger para não serem dominados pelos outros e são muito mais facilmente convencidos.

Jung apresenta quatro tipos psicológicos que chama de fundamentais: pensamento, sentimento, sensação e intuição. Cada um desses tipos psicológicos pode ser tanto introvertido quanto extrovertido.

\subsubsection{Teoria do comportamento}

Para Kotler (2000), Skinner questiona o uso de teorias que apresentam conceitos não-observáveis, como inteligência. Em sua teoria do condicionamento, ele diferencia os estímulos que são apresentados antes e depois da compra.

Os primeiros são estímulos eliciadores do comportamento, isto é, que pretendem levar a pessoa a comprar, enquanto os segundos são os condicionantes do comportamento, isto é, estímulos que pretendem que as pessoas continuem a comprar após a primeira vez, ou aumentem a freqüência de compra (GIGLIO, 2002). 
Segundo Kotler (2000), no comportamento de compra complexo, o consumidor desenvolve três etapas no processo de compra. Em primeiro lugar, estabelece crenças sobre o produto; depois, desenvolve atitudes sobre 0 mesmo e, por fim, faz uma escolha refletida. Este comportamento é adotado quando os consumidores estão altamente envolvidos em uma compra e conscientes da diferença significativa entre marcas.

A dissonância cognitiva, segundo Serrano (2003), é o estado psicologicamente incômodo que o indivíduo procurará resolver por meio da reorganização da estrutura cognitiva.

Após a compra, o consumidor pode experimentar alguma dissonância cognitiva advinda da percepção de certos fatores inquietantes ou de ouvir coisas favoráveis sobre outras marcas. O consumidor fica atento às informações que sustentem sua decisão (KOTLER, 2000).

Esta dissonância tenderá a ser dissolvida por meio de mecanismos psicológicos, como apoio social à sua escolha ou informações que confirmem sua validade (SERRANO, 2003).

O comportamento humano e o de consumo, segundo Gade (1998), obedecem em parte a uma psicodinâmica interna e em parte à inter-relação desta dinâmica com fatores externos da sociedade da qual os indivíduos fazem parte. As teorias anteriores tentaram explicitar as influências dos fatores internos do indivíduo, como a psicologia, a motivação, o comportamento.

Um dos fatores externos a considerar, que atua sobre os indivíduos e condiciona seu comportamento, é o desempenho de papéis sociais prescritos, derivados de variáveis pessoais como sexo, idade, posição, sendo que diversos grupos sociais os determinam no contexto das diversas classes sociais.

Dentre os fatores sociais mais diretamente associados ao indivíduo, temos:

- Os grupos de referência: segundo Kotler (2000), os grupos de referência são aqueles que exercem alguma influência direta ou indireta sobre as atitudes ou comportamento dessa pessoa. Os grupos que exercem influência direta são chamados grupos de 
afinidade. As pessoas são também influenciadas por grupos dos quais não são membros. Os grupos aos quais uma pessoa gostaria de pertencer são chamados grupos de aspiração. Um grupo de dissociação é aquele cujos valores ou comportamento são rejeitados por um indivíduo. O mesmo adolescente pode desejar e evitar qualquer relacionamento com "Punks".

- A família: O grupo familiar destaca-se devido a sua importância quanto ao consumo. Por exemplo, o casal pertencente à mesma classe social parece ter um comportamento de consumo em comum, quando pertence à classe social mais alta, ou se encontra no início do casamento. A criança e o consumo infantil também devem ser destacados, pois a criança é tanto consumidora quanto promotora do consumo. Os membros da família constituem o grupo de referência primário mais influente. Para Kotler (2000), podem-se distinguir duas famílias na vida do consumidor: a família de orientação, que consiste dos pais e irmãos e a chamada família de procriação, formada pelo cônjuge e filhos, que oferecem a influência mais direta no comportamento do comprador.

- Os papéis e status sociais: A posição de uma pessoa em cada grupo social a que pertence pode ser definida em termos de papéis e status. Um papel consiste nas atividades que uma pessoa deve desempenhar, e cada papel carrega consigo seu status. Por exemplo, um juiz de direito possui na sociedade um status maior que um advogado, e um advogado maior que um oficial de justiça.

De todo o tratamento do comportamento do consumidor, passando pelas diversas escolas e teorias, tem-se na área do marketing oportunidade de aplicar estes modelos teóricos e transformá-los em modelos práticos que se tornem ferramentas de tomada de decisão do administrador moderno.

Os números resultantes da aplicação dos modelos de previsão de vendas apóiam as decisões mercadológicas. Em todos esses processos, existe o Ser-humano, cujo comportamento está longe de ser previsível (GIGLIO, 2002). 
Se isto é verdade, o entendimento deste comportamento passa a ser uma variável importante de ser conhecida para a elaboração de um modelo matemático. Entretanto, fatores emocionais e sociais não costumam ter espaço em formulações matemáticas.

No seu trabalho entitulado "The Choice theory approach to market research", McFadden (1986, v.5, n4, p.294) conclui:

I have tried in this paper to give a picture of economic choice theory, stressing developments which permit use of data from psychometric and conjoint experiments to produce market demand forecasts. To summarize, consider a marketing problem such as forecasting the market share of a new product. The end objective of the analysis is to simulate market shares as functions of product attributes, and to identify and target demographic groups who are receptive to various marketing strategies. Such a simulation can be built around choice probabilities which are functions of product attributes and demographic characteristics. The probabilities can be estimated using survey data on existing products and/ or data collected from attitude inventories, similarity judgements, and conjoint experiments. Ability to forecast observed choice behavior provides the criterion for specifying the preference model and shaping the utility function. The overall framework of random utility maximization points the way to modifications necessary to handle problems unique to the application, from the dynamics of repeat purchases to response to advertising copy. The ability to forecast product market performance becomes the ultimate yardstick for designing and evaluating each system for consumer data collection and analysis (McFADDEN,1986, v.5, n.4, p.294).

Neste sentido, a teoria do comportamento do consumidor apresenta o referencial teórico necessário para a aplicação de técnicas que possam traduzir este comportamento em modelos matemáticos que expliquem, 
orientem e predigam o comportamento de consumo, e a teoria de escolha do consumidor.

Evoluindo neste campo de pesquisa, em 2001, no artigo em que recebe o prêmio Nobel de economia, McFadden (2001, v. 91, n.3, p.373), complementa [...]

[...] an important interdisciplinary interaction has developed between economic choice analysis and market research. The experimental methods used in market research permit elucidation and measurement of the workings of the decisionmaking process. In particular, it is possible to elicit stated perceptions, stated preferences and attitudes scales; we call these stated preferences (SP) data in contrast to the revealed preference $(R P)$ data obtained from observed choices. Most of these variables and methods used to measure them come from applied psychology. In particular, conjoint analysis, a method for eliciting stated preferences within a classical experiment design, provides data that with proper consumer training and allowance for cognitive illusions can add considerably to the ability to predict consumer decisions (McFADDEN, 2001, v. 91, n.3, p.373).

Neste artigo o autor referencia e propõe a técnica estatística multivariada conhecida como análise conjunta como um método apropriado para capturar e medir as preferências de consumo. Esta técnica será objeto de estudo e aplicação neste trabalho. ${ }^{11}$

A abordagem utilizada para a percepção do valor do comportamento do consumidor, antes da aplicação das técnicas estatísticas, requer uma contextualização teórica que converge para o conceito de valor percebido.

\footnotetext{
${ }^{11}$ A análise conjunta é a metodologia apresentada neste trabalho como ferramental para a medida do valor percebido do consumidor e será mais explorada conceitualmente no capítulo 3.
} 
A teoria de comportamento do consumidor é tão ampla quanto o próprio estudo de indivíduo. Neste sentido, com o objetivo de capturar o valor que $o$ ser-humano atribui a determinadas escolhas, que motivam comportamentos, é necessário entender o que direciona o indivíduo a avaliar positivamente um determinado bem em detrimento de outras opções de escolha.

O capítulo que segue apresenta o conceito de valor percebido, no qual os fatores influenciadores da decisão de escolha tomam parte no processo de preferência do indivíduo. Por meio do conhecimento do valor atribuído a cada fator, poder-se-á aplicar o ferramental matemático para avaliar quantitativamente estas escolhas.

\subsection{Valor Percebido}

Hoje em dia conhecemos o preço de tudo e o valor de nada. (Oscar Wilde)

A noção do comportamento do consumidor traz à luz a importância de entender as premissas dos indivíduos no contexto sócio-econômico das empresas. À continuação deste constructo conceitual, apresenta-se a teoria do valor percebido, ou seja, dado o plano no qual o indivíduo está inserido (ambiente e a sociedade) e suas inter-relações individuais e coletivas, busca-se entender como o indivíduo avalia o bem, produto ou serviço. Existem variações no conceito de valor percebido dentro do contexto de marketing, segundo vários autores.

Para Kotler (1998), o valor percebido indica que uma oferta de marketing para o mercado tem um valor agregado entregue ao consumidor, resultado da diferença entre o valor total esperado (conjunto de benefícios) e o custo total para o consumidor, e que pode ser interpretado como o lucro do consumidor na transação de troca. Dessa forma, o valor percebido é o valor atribuído pelos clientes ao produto ou serviço, baseado na relação entre os 
benefícios que este trará, segundo a ótica do consumidor, e os custos percebidos para sua aquisição, comparativamente à concorrência.

Segundo Zeithmal (1988), o valor percebido é a avaliação total do consumidor sobre a utilidade de um produto, baseada em percepções do que é recebido (benefícios) e do que é dado (sacrifícios). Enfim, o valor percebido é uma função positiva do que se recebe e uma função negativa do que se sacrifica, como uma função de:

$$
\text { valor }=f(\text { recebimentos / sacrificios })
$$

Woodruff (1997) adota o conceito de valor do cliente como sendo a percepção do cliente sobre as preferências e as avaliações dos atributos do produto, do desempenho desses atributos e das conseqüências originadas pelo uso. Os clientes enxergam o produto como um conjunto de atributos e desempenhos desses atributos; quando compram e usam o produto, desenvolvem preferências e desejos por certos atributos, que lhes proporcionam as conseqüências desejadas nas situações de uso (conceito de valor em uso), atendendo seus objetivos e gerando satisfação com o valor recebido. O valor do cliente é a qualidade percebida pelo mercado, ajustada pelo preço relativo de seu produto.

Para Anderson e Narus (1999), numa análise que foca o desempenho industrial, o valor percebido é a importância em termos monetários dos benefícios (técnicos, econômicos, de serviços e sociais) que uma empresa recebe em troca do preço pago por uma oferta de marketing em um dado contexto.

Considerando que existe uma alternativa competitiva de uma dada oferta de marketing (p.ex. fabricar internamente o produto ao invés de comprálo), os autores resumem a essência do conceito do valor percebido por meio da expressão abaixo.

$$
\left(\text { Valor }_{\text {oferta }}-\text { Preço }_{\text {oferta }}\right)>\left(\text { Valor }{ }_{\text {alternativa }}-\text { Preço }_{\text {alternativa }}\right)
$$


Esta expressão compara o valor e o preço da oferta de mercado com o valor e o preço da próxima melhor alternativa. Desta forma, o cliente deve perceber um efetivo diferencial de benefícios superior na oferta (em relação a melhor alternativa concorrente) para optar por ela.

Um ponto de convergência mostra-se evidente entre os diversos autores: o conceito de valor percebido para o cliente está associado ao uso do produto ou serviço (conceito de utilidade), à sua percepção (que determina seu comportamento) e à relação de troca custo por benefício.

Jayanti e Ghosh (1996) reforçam esta convergência, segundo a qual a análise da literatura do valor percebido sob o enfoque do marketing revela duas perspectivas utilizadas no modelo de valor percebido: o conceito de utilidade e o conceito de comportamento.

A literatura sobre valor percebido mostra que a qualidade, a satisfação, o valor de transação e o preço percebido são antecedentes comuns ao valor percebido. O quadro 1 apresenta os principais estudos antecedentes do valor percebido, desenvolvido por diversos autores da literatura da teoria de valor percebido. Em ordem cronológica, com foco na indústria de hospitalidade, tem-se:

- 1996: Jayanti e Gosh, e Sun estudam qualidade, valor e preço percebido, respectivamente, em hotelaria; Bojanic correlaciona satisfação e valor em hotéis; Naylor estuda o impacto da satisfação e do valor na propaganda boca a boca de resorts; Fornell, Johnson, Anderson, Cha e Bryant analisam as relações de qualidade, valor, satisfação e lealdade em hotéis;

- 1999: Petrick estuda o valor percebido relacionado com satisfação e recompra em resorts;

- 2000: Oh, Kashyap e Bojanic aprofundam o estudo de valor percebido em relação à qualidade e intenção de recompra de hotéis. 
Quadro 1: Estudos anteriores sobre valor percebido.

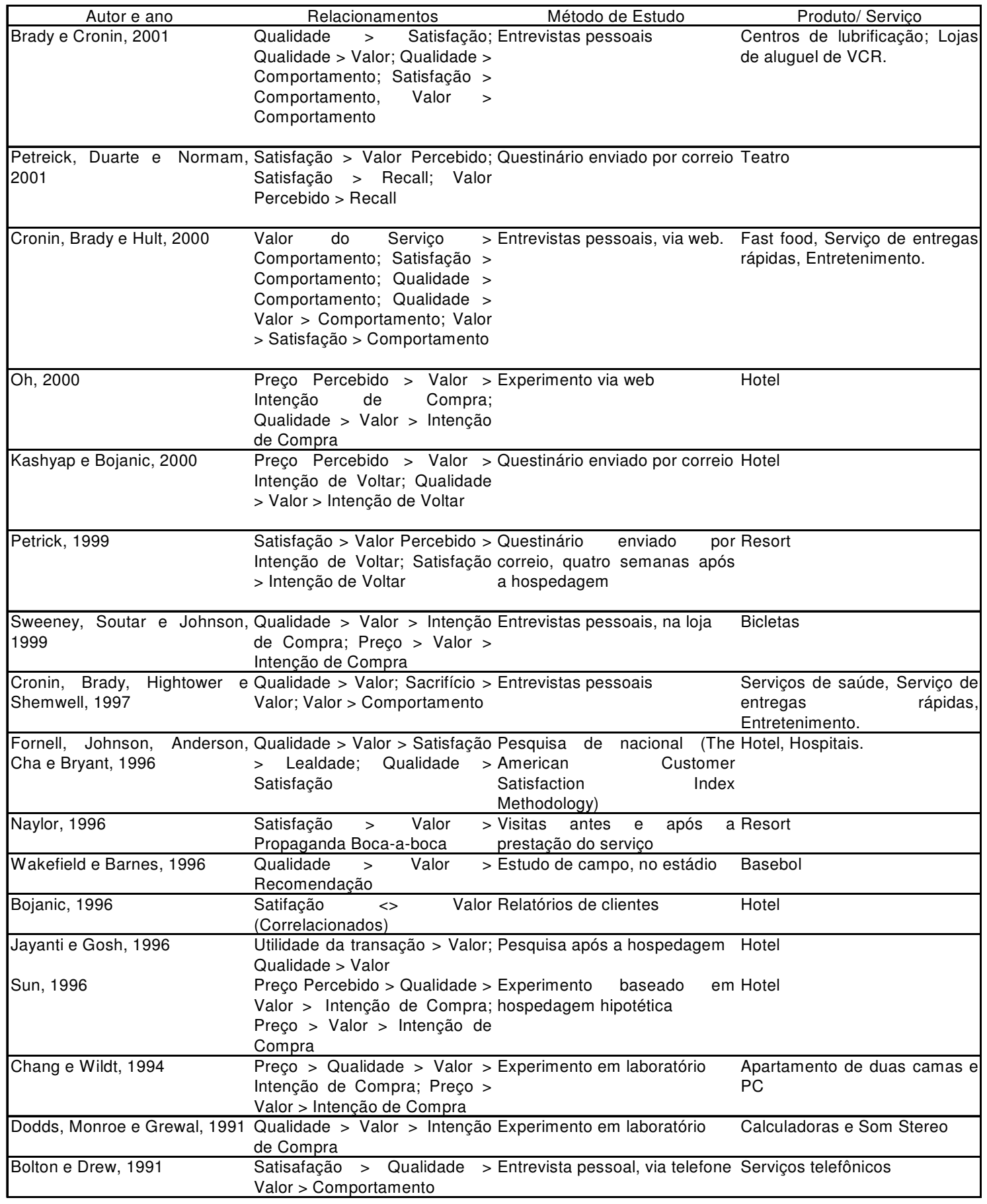

Fonte: Adaptado de DUMAN, T. (2002, p.23-24)

Um dos problemas enfrentado pelos diversos estudos é atribuir um valor quantitativo para a medida de valor percebido. Neste sentido, apresentam-se as propostas de alguns autores no esforço solucionar este 
problema e endereçar a formalização de constructos matemáticos para o valor percebido.

\subsubsection{Medida de valor percebido}

Se considerarmos que o objetivo final do processo de marketing é a satisfação do consumidor, como tratá-la em serviços? Uma das mais poderosas abordagens é o processo segundo o qual os consumidores avaliam os serviços pela comparação da percepção do serviço recebido com as suas expectativas (desconfirmação de expectativas). Se o serviço percebido for igual, ou melhor, que o serviço esperado, então o consumidor está satisfeito.

Este enfoque foi traduzido no modelo SERVQUAL (PARASURAMAN, ZEITHAML e BERRY, 1988) ${ }^{12}$. Esta metodologia foi revista e sintetizada por seus autores em cinco dimensões principais, adotando por base a lógica da desconfirmação entre expectativas e desempenho do serviço, por meio da medida dos atributos de qualidade em serviços: confiabilidade, empatia, assertividade, atributos físicos e garantia. E tornou-se amplamente disseminada e aplicada empiricamente por pesquisadores no campo de qualidade e satisfação em serviços.

O nível de serviço esperado ou desejado é, quase sempre, maior que o nível de percepção do serviço efetivo. Neste sentido, Brown, Churchill Jr. e Peter (1993), ao aplicarem técnicas estatísticas como medida para ampliar a compreensão do constructo de valor percebido para serviços, depararam-se com resultados de baixa confiabilidade matemática.

Cronin Jr., Brady e Hult (2000) examinam a inter-relação de qualidade, satisfação e valor sobre as intenções comportamentais dos consumidores. Basearam-se em síntese dos estudos efetuados neste campo e procuraram ampliar a conceituação destes constructos e o conhecimento a respeito deles, oferecendo um modelo para medição dos mesmos, suas

\footnotetext{
${ }^{12}$ SERVQUAL: Modelo desenvolvido por Valerie A. Zeithaml, A. Parasuraman e Leonard Berry, que mede o desempenho do serviço prestado por uma organização comparado às expectativas (necessidades) de qualidade dos clientes.
} 
relações e seus efeitos sobre o comportamento do consumidor, em termos de intenções. A opção dos autores por esse modelo foi devido a sua simplicidade de aplicação, baseada em metodologia de percepção do desempenho, aliada à definição de poucos itens para mensuração dos constructos.

Lehmann (1999) sugere o uso de abordagens diferentes em pesquisa de comportamento do consumidor, dentre as quais a utilização de múltiplos constructos, comportamento pós-escolha e o efeito de outras pessoas sobre as decisões (fatores externos).

Woodruff (1997) propõe enriquecer a teoria de valor percebido por meio de medidas de desempenho dos produtos em diferentes situações e, a partir disso, concluir a percepção de valor dos consumidores em diferentes contextos. Os critérios utilizados e sua importância relativa, novos métodos de coleta e análise dos dados relacionados a aspectos particulares de valor do consumidor também são considerados para cada situação.

Parasuraman (1997) propõe ampliar a pesquisa conceitual e empírica de valor para o consumidor sobre fatores contextuais, tais como a natureza do produto (p.ex. entre bens ou serviços) e o tipo de consumidor (p.ex. novo ou antigo), desenvolvendo medidas psicométricas consistentes do constructo.

Cronin, Jr., Brady e Hult (2000) dão diversas orientações para pesquisa adicional neste campo, entre as quais se destacam a necessidade de consideração de modelos compostos, ou seja, medições que incluam variáveis adicionais de tomada de decisão, e a replicação dos possíveis efeitos moderadores de características individuais como aversão ao risco, envolvimento e experiência com a categoria de produto.

Monroe (1990) e Thaler (1985) argumentam que o valor percebido do consumidor é resultado de suas comparações entre diferentes estruturas de preços, que incluem o preço de venda anunciado, preço de referência anunciado e o preço de referência interno do consumidor ${ }^{13}$. Segundo Monroe

\footnotetext{
${ }^{13}$ Preço de venda anunciado é igual ao preço que o prestador de serviços comunica ao cliente no momento da compra; preço de referência anunciado é igual ao preço ofertado ao cliente, mas que pode ser alterado em função de variáveis de mercado (p.ex. sazonalidade); e preço
} 
(1990), a introdução de anúncios de preços de venda e preços de referência influencia diretamente a formação de preço de referência interno do consumidor, formado a partir da percepção daqueles. O preço de referência interno permite que o consumidor forme suas expectativas em relação ao preço que deve pagar em determinado produto ou serviço, preparando-o para a negociação (MONROE, 1990). Segundo a perspectiva de utilidade, o valor percebido de um produto ou serviço é formado pela combinação do valor de aquisição e do valor de transação deste produto (ou serviço).

O valor de aquisição é a percepção associada ao benefício líquido (benefícios - sacrifícios) do consumidor no momento do consumo (ALSABBAHY, 2000). Este valor possui estreita relação com os benefícios percebidos em detrimento ao sacrifício associado. Desta forma, é influenciado positivamente pelos benefícios e negativamente pelo preço de aquisição. Alguns autores argumentam que o valor de aquisição é explicado pela qualidade percebida (GREWAL et al.,1998; PARASURAMAN e GREWAL 2000; THALER, 1985).

Parasuraman e Grewal (2000) definem o valor de aquisição como o benefício recebido por um valor monetário despendido, e valor de transação como o prazer do consumidor em realizar um "bom negócio".

O valor de transação é definido como a diferença entre o preço de referência interna do consumidor e o preço de compra (venda) (GREWAL et al.,1998). Assim, o valor de transação é entendido como a satisfação ou prazer na aquisição de um bem ou serviço, por meio de uma vantagem financeira percebida.

A diferença entre o valor de aquisição e de transação é, particularmente, importante quando considerado seu impacto no valor percebido pelo consumidor, no desejo de compra, no comportamento e na comparação entre as alternativas de produtos e serviços disponíveis.

de referência interno é o preço percebido pelo cliente como valor a ser ofertado por determinado bem ou serviço. 
Estas duas estruturas de valor são combinadas na forma de pesos de cada valor para identificar o valor percebido pelo consumidor. Desta maneira, tem-se:

Valor percebido $=\omega_{1} \cdot$ valor de aquisição $+\omega_{2} \cdot$ valor de transação

onde,

$\omega_{1}=$ peso ponderado do valor de aquisição e,

$\omega_{2}=$ peso ponderado do valor de transação.

$\mathrm{Na}$ modelagem do valor percebido, entretanto, o preço é uma variável importante, mas não suficiente para conceituá-lo, já que na maior parte do tempo as decisões de compra são tomadas considerando outros atributos igualmente importantes.

No estudo do valor percebido, tanto os métodos qualitativos quanto os métodos quantitativos têm sido usados para medir o valor percebido. Segundo Woodruff e Gardial (1996), os estudos mais recentes utilizam uma abordagem qualitativa, entretanto, cresce o número de métodos quantitativos a cada dia.

Os autores Zeithmal (1988), Johnston e Clark (2002) sugerem o uso dos métodos qualitativos e entendem que estas ferramentas são as que melhor capturam a essência do comportamento do consumidor e suas percepções, como:

- Grupos focalizados (focus groups) - fóruns de pequenos grupos de pessoas reunidos por aproximadamente duas horas para apresentar suas opiniões sobre determinado assunto. O estudo é conduzido por um moderador, que utiliza um roteiro de entrevista semi-estruturada para gerar as discussões. É seu papel saber formular perguntas, explorar informações, fazer com que os membros do grupo sintam-se à vontade para partilhar suas opiniões e fazer com que todos os participantes opinem; 
- Painéis de clientes - são similares aos grupos focalizados, mas reúnem-se regularmente com uma agenda mais estruturada;

- Análise de reclamações e sugestões (livro de ouro) contribuições voluntárias de clientes, entretanto, tende a ser mais negativa que positiva;

- Técnica do incidente crítico $^{14}$ - identifica as situações que encantam e descontentam os clientes. Incidentes críticos são eventos que contribuem para ou prejudicam o serviço ou o desempenho do produto de maneira significativa.

- Análise de incidentes seqüenciais - combina a análise do incidente crítico, as auditorias passo a passo e o mapeamento dos processos. Os clientes recebem um mapa pré-preparado do processo do serviço e são solicitados a informar suas experiências em cada estágio ou transação do processo. Essa técnica identifica não apenas situações críticas, mas também potencialmente críticas.

Zeithmal (1988) utilizou-se de técnicas de grupos focalizados e entrevistas aprofundadas para identificar as percepções dos consumidores relativas a preços, qualidade e valor de bebidas.

Em métodos quantitativos, geralmente, o valor percebido é medido como uma variável unidimensional. Pelo fato de assumirem que todos os consumidores possuem uma mesma percepção de valor, estes métodos são bastante criticados em relação a sua validade em medir o valor percebido (WOODRUFF E GARDIAL, 1996).

Recentemente, Sweeney e Soutar (2001) desenvolveram uma escala multivariada para medir o valor percebido. Os estudos sugerem uma escala de quatro dimensões e dezenove atributos. Entre as dimensões, estão: qualidade, preço, valor emocional e aspectos sociais que influenciam as decisões de compra do consumidor. Os resultados obtidos sugerem que a

\footnotetext{
${ }^{14}$ Ver seção 3.1, onde a técnica do incidente crítico é melhor detalhada.
} 
escala de quatro dimensões é um melhor prenunciador que os métodos unidimensionais.

Cronin et al. (2000) mediram o valor percebido por meio de uma ferramenta com duas dimensões, compreendidos numa escala de nove pontos. Questionaram os clientes sobre sua impressão geral do serviço e a habilidade do mesmo em atender as suas expectativas. Bolton e Drew (1991) mediram o valor de serviços com uma escala do tipo Likert, de cinco pontos, variando entre muito ruim e muito bom ${ }^{15}$. Chang e Wildt (1994), por sua vez, mediram o valor percebido por meio de um único atributo, numa escala do tipo Likert, de nove pontos. Dodds et al. (1991) testaram um modelo no qual o valor percebido seria função da qualidade percebida e do sacrifício percebido. Neste estudo, utilizaram uma escala do tipo Likert, com cinco atributos e sete pontos.

Dentro deste contexto, o presente trabalho vai ao encontro destas diretivas a respeito dos modelos de medida do valor percebido, no sentido de a interligação e a influência entre $o$ valor percebido $e$ as intenções de comportamento do consumidor serem latentes. Assim, para medir estas relações, o uso de métodos quantitativos como forma de medida deste comportamento convergirá para uma função de utilidade. Nesta função de utilidade, o produto hoteleiro será representado por atributos ponderados em função do grau de utilidade percebido pelo consumidor.

Segundo Silveira (2000), o composto do marketing é o eixo ao redor do qual uma rede de utilidades é percebida pelos mercados num determinado momento. Avaliar, portanto, esta rede é função do administrador. Para solucionar este problema de avaliar as utilidades, há basicamente duas atitudes: estimar subjetivamente os valores de utilidades que o mercado atribui ao produto/serviço/conceito e/ou desenvolver algum método de mensuração indireta da rede de utilidades envolvida no processo decisório do mercado.

\footnotetext{
${ }^{15}$ R.A. Likert (1932) elaborou um procedimento de graduação em que a escala representa um contínuo bipolar. A extremidade inferior representa uma resposta negativa, enquanto a extremidade superior uma positiva, p.ex. 1=Discordo inteiramente; $2=$ Discordo; $3=N a ̃ o$ concordo nem discordo; $4=$ Concordo; $5=$ =Concordo plenamente.
} 
Um método indireto de estimar a rede de utilidades envolvida na decisão de compra é avaliar, cientificamente, o processo de escolha por produtos, construído de maneira que os fatores determinantes de decisão estejam controlados ${ }^{16}$.

Ao se decidir sobre a preferência por um determinado produto ou serviço, o indivíduo não considera as características uma a uma, mas o conjunto de características simultâneas que o produto contém. Além disso, se um produto for decomposto em, por exemplo, dez atributos determinantes, tendo dois níveis cada atributo, teríamos uma combinação fatorial de dez atributos, com duas possibilidades cada $\left(2^{10}=1024\right)$, o que resultaria em 1024 possibilidades de produtos diferentes. Neste caso, há problemas decorrentes da avaliação simultânea de muitos atributos que reside no fato de que a mente humana tem um limite de sete variáveis, em média, que podem ser processadas conjuntamente (MILLER, 1956) ${ }^{17}$.

Dessa forma, no delineamento do experimento, deve-se construir um conjunto mínimo possível de estímulos de marketing apenas com atributos determinantes de decisão para que o consumidor manifeste sua preferência ${ }^{18}$. Em seguida, a partir da escolha, determinar quantitativamente a utilidade que ele atribuiu, não-consciente ou conscientemente, aos produtos e suas características. Este é o constructo proposto pela análise conjunta que será utilizado neste estudo como medida do valor percebido.

\footnotetext{
${ }^{16}$ Fator é uma variável que o pesquisador manipula e que representa um atributo específico. $\mathrm{Na}$ análise conjunta, os fatores (variáveis independentes) são não-métricos. Para fins de esclarecimento, fator e atributo são sinônimos neste trabalho, podendo aparecer em uma ou outra forma ao longo do texto.

${ }^{17}$ MILLER, G. A. (1956). The magical number seven, plus or minus two: some limits on own capacity for processing information. Psychological Review, 63, p.81-97.

${ }^{18}$ Estímulos = Conjunto específico de níveis (um por fator) avaliado pelos respondentes (também conhecido como tratamento). Um método de definir estímulos (delineamento fatorial) é obtido considerando-se todas as combinações possíveis de todos os níveis.
} 
2.2.2 O valor percebido como medida de comportamento

Segundo Zeithaml (1988), a modelagem comportamental do valor percebido envolve um constructo que aborda uma complexidade que transcende a variação de preços e envolve uma maior quantidade de variáveis, como: percepções psicológicas intangíveis. Em seu estudo, Zeithaml (1988) propõe um modelo que integra estas diferentes variáveis e serve de ponto de partida para diversos estudos nesta disciplina.

Zeithaml (1988) define, genericamente, qualidade como uma superioridade ou excelência. Por extensão, a qualidade percebida é o julgamento do consumidor a respeito da excelência ou superioridade de um produto. Qualidade percebida é:

- diferente de qualidade real,

- um nível de abstração, mais do que um atributo,

- uma avaliação geral, que em alguns casos se confunde com uma atitude, e

- um julgamento feito a partir da consciência do cliente.

Neste sentido, os consumidores utilizam-se da percepção de qualidade para formar um julgamento geral sobre o produto. Ela sugere, ainda, que a formação da percepção de qualidade e, conseqüentemente, de valor ocorre segundo uma lógica meio-fim, na qual o meio (valor percebido e qualidade percebida) justifica o fim (aquisição do produto). 


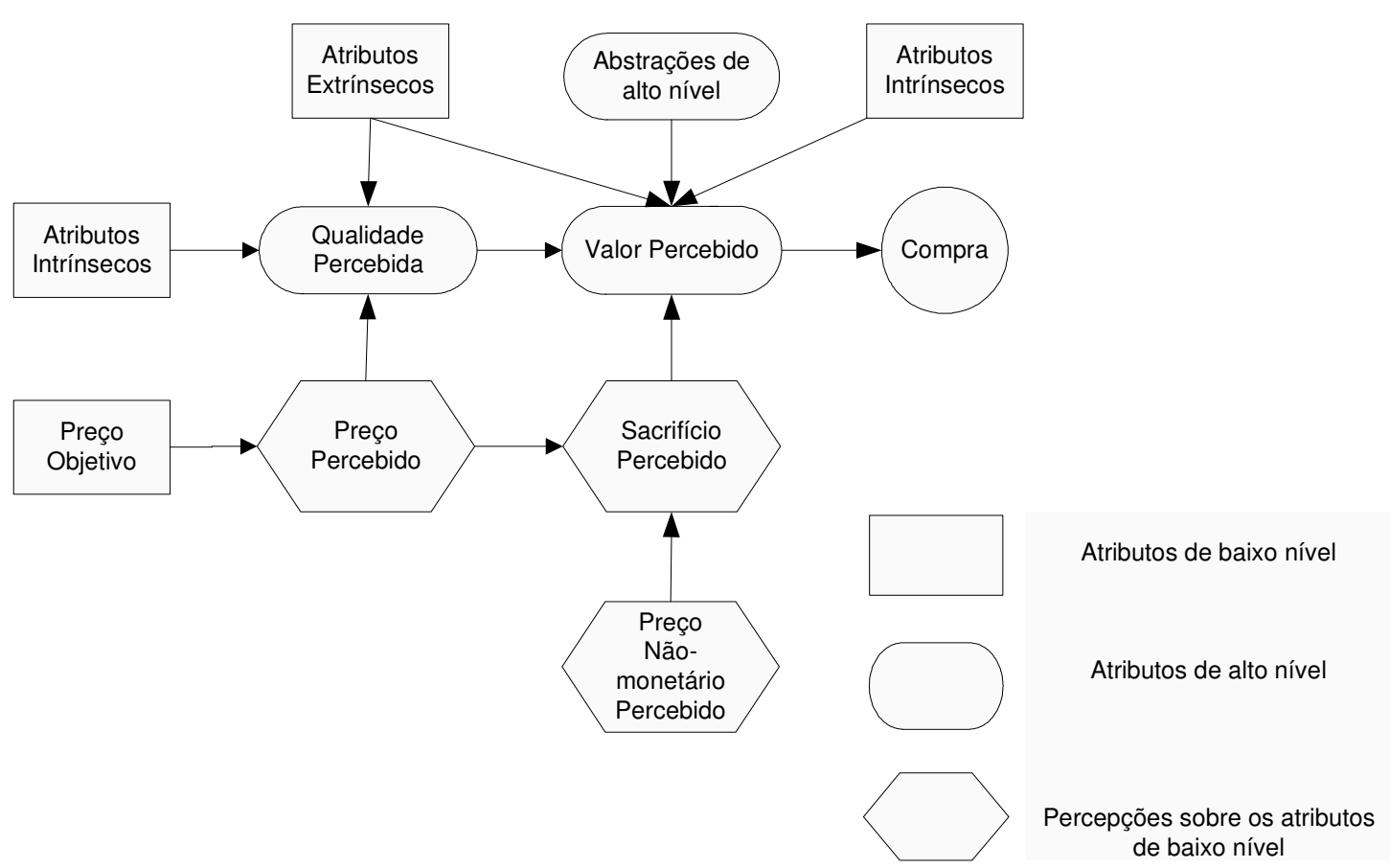

Figura 4: Modelo de relacionamento de preço, qualidade e valor.

Fonte: ZEITHAML, V. A. (1988,.p. 3).

O modelo acima apresentado por Zeithaml (1988) mostra uma visão geral das relações entre os conceitos de preço, qualidade percebida e valor percebido. Neste contexto, os atributos representam o menor nível de hierarquia, enquanto a percepção de qualidade e o valor percebido aparecem como conseqüências daqueles.

Woodruff e Gardial (1996) propõem outro modelo, conforme a figura abaixo, para explicar os níveis de abstração introduzidos por Zeithmal (1988) no modelo anterior. 
Valor Desejado pelo Cliente

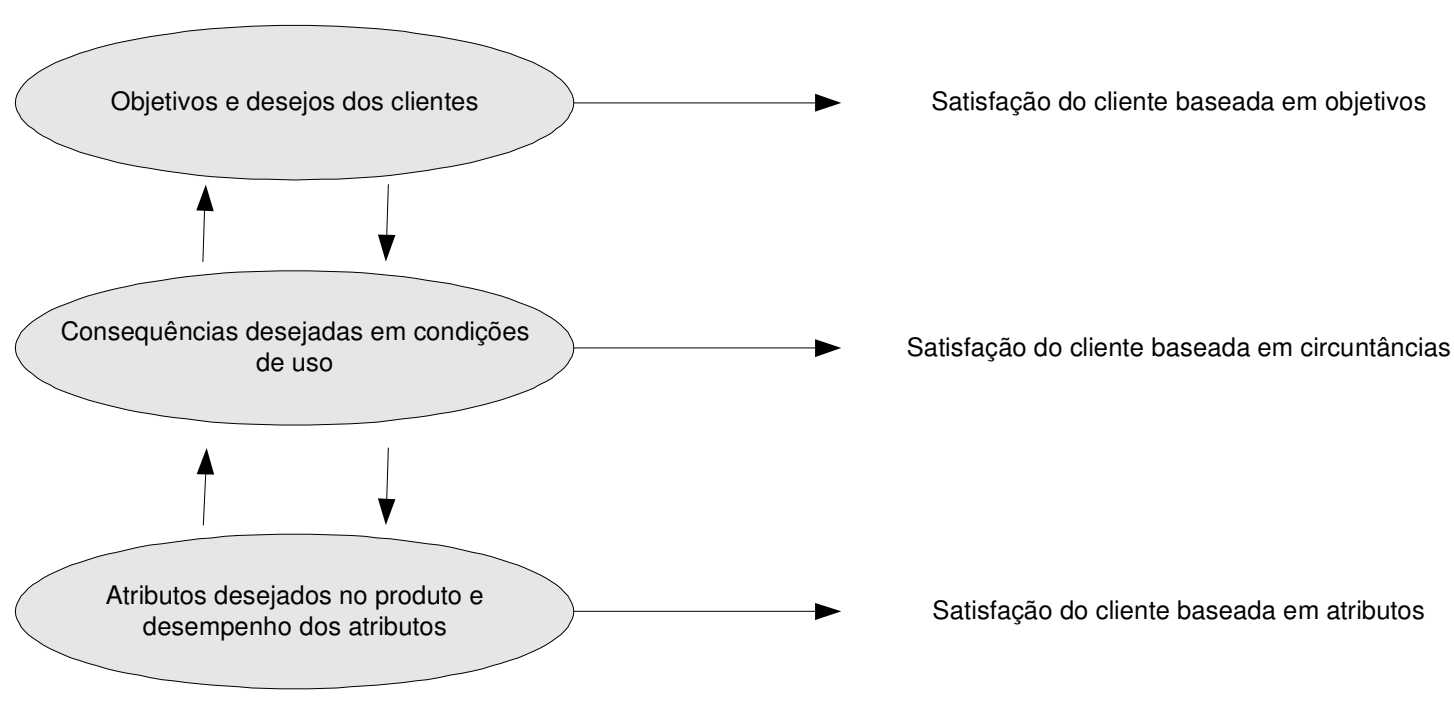

Figura 5: Modelo de Hierarquia de Valor. Adaptado de Woodruff (1997). Fonte: DUMAN, T. (2002, p. 17).

A hierarquia de valor do cliente, conforme Woodruff e Gardial (1996), explica como os consumidores relacionam os atributos dos produtos aos seus objetivos e propostas.

\subsubsection{Atributos de valor}

Atributos são descrições concretas a respeito das características de determinado produto ou serviço. A classificação dos atributos de um produto possui variantes na literatura de marketing. Olson e Jacoby (1972), por exemplo, sugerem a terminologia "intrínseco-extrínseco", enquanto Zeithmal (1988) sugere "tangível-intangível".

Em seu estudo, Zeithmal (1988) exemplifica um produto de consumo - refrigerante - do qual atributos intrínsecos seriam: a cor, a gosto, a textura, a quantidade de açúcar. Atributos extrínsecos são, por exemplo, o preço, a marca, a quantidade de propaganda. Utilizando o modelo de Zeithmal (1988), 
os atributos de um Hotel seriam: o preço, o conforto, o atendimento, a estrutura física, a marca, a localização, etc.

Os serviços são normalmente ofertados por meio de pacotes de atributos representativos para o cliente que visam atender a determinadas necessidades de mercado. Este pacote de serviços é uma combinação de atributos tangíveis (bens) e intangíveis (serviços).

\subsection{Setor de Serviços}

O serviço pode ser considerado "um ato ou desempenho oferecido por uma parte à outra" (LOVELOCK e WRIGHT, 2001, p.5). O serviço é o resultado de um processo que leva um produto ao cliente, composto de uma gama expressiva de intangibilidade. Fitzsimmons e Fitzsimmons (2000) entendem por serviço um pacote de benefícios implícitos e explícitos que são executados em uma instalação de suporte e que utilizam bens facilitadores. Desta forma, o serviço é visto atualmente como um composto de elementos tangíveis e intangíveis.

Os serviços adquirem, pela sua natureza, um alto grau de variabilidade, gerado pelas pessoas, tempo e a própria prestação do serviço. A alta variabilidade concorre diretamente com a padronização dos resultados, 0 que pode ser encarado como uma vantagem ou como um problema. $O$ problema está situado na visão de produção de bens, que durante todo o século passado investiu na padronização dos seus produtos. Por outro lado, a variabilidade pode ser encarada como uma vantagem frente às exigências de flexibilização, permitindo adequar o resultado da produção do serviço às necessidades de cada cliente atendido. As posturas de cada empresa estão ligadas diretamente às suas estratégias de operações.

Outra característica peculiar está na impossibilidade de estocar o produto, fazendo com que as empresas prestadoras de serviços busquem gerenciar suas estratégias ligadas ao equilíbrio entre capacidade produtiva e demanda. A incongruência entre oferta e demanda pode gerar uma capacidade produtiva acima da necessidade, gerando excedentes de recursos e 
equipamentos ou, no outro extremo, uma capacidade muito aquém da demanda que precisa e pode ser atendida.

Os serviços são normalmente ofertados através de pacotes, formado pelo serviço núcleo e serviços periféricos. Os serviços periféricos, também denominados de auxiliares, complementam a oferta e buscam influenciar positivamente nas expectativas dos consumidores, agregando valor ao serviço principal. O pacote de serviços pode ser dividido em:

- instalações de apoio (local e equipamentos usados para prestar o serviço);

- bens facilitadores (elementos que fornecem elementos tangíveis ao serviço);

- serviços explícitos (oferta principal da empresa e fator motivador para o cliente);

- serviços implícitos (serviços auxiliares).

Gianesi e Correa (1994), Gronroos (1990) e outros autores concordam com a idéia de que o pacote de serviço é uma combinação de bens físicos e de serviços. Este entendimento possibilita que possamos desenvolver propostas de melhoria da qualidade, por exemplo, com estratégias para os elementos físicos do processo de serviço, como também estratégias específicas para os elementos intangíveis.

$O$ adequado desenvolvimento do pacote de serviço não assegura sozinho a qualidade do serviço prestado, mesmo que se constitua numa dimensão importante, normalmente se apresentando como elemento de diferenciação. Gronroos (1990) indica que o cliente pode estar interessado não apenas no desempenho do pacote (produto final do serviço), mas também no processo de prestação. Desenvolveu a partir de então o conceito de oferta ampliada, agregando aos componentes básicos do pacote, ponderações relacionadas diretamente ao processo de fornecimento. $O$ conceito de oferta ampliada abrange questões inerentes ao próprio conceito do serviço, à sua acessibilidade, às interações com a organização prestadora e à participação dos clientes. 
O serviço é o resultado de um processo que leva um produto ao cliente, composto de uma gama expressiva de intangibilidade. Fitzsimmons e Fitzsimmons (2000) entendem o serviço como um pacote de benefícios explícitos que são executados em uma instalação de suporte e que utilizam bens facilitadores. Desta forma, o serviço é visto atualmente como um composto de elementos tangíveis e intangíveis. Buscando uma melhor compreensão dos serviços, há várias propostas de classificação.

A partir da visão dos pacotes, Lovelock (1992b) e Fitzsimmons e Fitzsimmons (2000) distinguem nos serviços: um serviço-núcleo e outros serviços periféricos ou secundários. Silvestro (1999) propõe uma visão do processo de prestação de serviço, distinguindo três tipos: serviço profissional, loja de serviço e serviço de massa.

Também, a partir da visão dos processos, Schmenner (1999) classifica os serviços em quatro tipos: fábrica de serviços, loja de serviços, serviços de massa e serviços profissionais. Lovelock (1992a) desenvolveu um esquema de classificação que propõe uma apreciação de possíveis dimensões estratégicas que transcendem as fronteiras da atividade. As classificações são apenas formas de melhor entender este processo em constante mutação.

\subsubsection{As características dos serviços}

Para Kotler (1998), serviço é:

[...] qualquer ato ou desempenho que uma parte pode oferecer a outra e que seja essencialmente intangível e não resulta na propriedade de nada. Sua produção pode ou não estar vinculada ao produto físico (KOTLER, 1998, p.128).

Os serviços possuem algumas características básicas intangibilidade, heterogeneidade, inseparabilidade e perecibilidade - que permitem melhor compreendê-los e que devem ser levados em consideração 
pelas empresas, ao elaborarem suas estratégias de atuação no mercado (KOTLER,1994). Ei-las detalhadas abaixo.

- Intangibilidade: os serviços são essencialmente performances e "não podem ser vistos, provados, sentidos, ouvidos ou cheirados antes de serem comprados" (KOTLER,1998). O grande desafio do prestador de serviço é "administrar a evidência" para tornar "tangível o intangível". É por causa da intangibilidade dos serviços que as empresas encontram dificuldades de entender como os consumidores percebem seus serviços e avaliam a qualidade dos mesmos.

- Heterogeneidade: os serviços têm características de heterogeneidade porque a sua performance sofre influência tanto de aspectos técnicos (conhecimentos, habilidades e suporte material), quanto emocionais (condições e características psicológicas), pelo lado do prestador de serviço. Assim, considerando os serviços altamente variáveis, uma vez que dependem de quem os executa e de onde são prestados, Kotler (1998), aconselha três atitudes para as empresas solucionarem este problema:

- investir em seleção e treinamento de pessoal na prestação de bons serviços;

- padronizar o processo de prestação de serviços por toda a organização;

- monitorar a satisfação do consumidor através do sistema de sugestões, reclamações e comparação de compra, possibilitando que os serviços fracos sejam detectados e corrigidos.

- Inseparabilidade: outra característica peculiar dos serviços, em relação aos produtos físicos, é a inseparabilidade, isto é, os serviços são inseparáveis de quem os executa ou fornece, de tal forma que o prestador do serviço faz parte do próprio serviço. Esta característica, associada ao fato de que os serviços são 
produzidos e consumidos ao mesmo tempo - simultaneidade, conforme Kotler e Armstrong (1998) -, faz com que, nos serviços em que o cliente esteja presente, haja uma interação entre cliente e prestador de serviços, de modo que o cliente também passa a fazer parte do serviço e, conseqüentemente, a interferir em sua qualidade.

- Perecibilidade: a última das quatro características marcantes dos serviços é a perecibilidade. Os serviços são perecíveis, segundo Kotler e Armstrong (1998), porque não podem ser estocados para venda ou uso posterior. Isto pode representar um sério problema para a empresa prestadora quando a demanda é flutuante, como acontece nas empresas que lidam com serviços de demanda cíclica, sazonal ou irregular. Montam-se estruturas capazes de suportar os picos da demanda, naturalmente terão capacidade ociosa (e custos mais elevados) nos momentos em que a demanda estiver mais baixa. Se, por outro lado, decidem montar uma estrutura para atender ao mínimo necessário, prestarão serviços precários quando a demanda estiver mais elevada. Dessa forma, ao montarem sua estrutura, devem levar em consideração as flutuações e adotar estratégias flexíveis e adequadas para enfrentar cada situação (Kotler e Armstrong 1998).

\subsubsection{As competências em serviços}

Entende-se por competência em serviços a eficiência no atendimento ao cliente. Os novos cenários e mercados trazem como característica a exigência para que as empresas tenham nos consumidores uma importante fonte de competência. O conceito de competência segundo Prahalad e Ramaswamy (2000b) constitui-se 
[...] como fonte de vantagem competitiva, teve origem em estudos sobre diversificação que começaram a conceber as organizações como uma série de competências e não mais como uma carteira de diferentes negócios (PRAHALAD e RAMASWAMY, 2000b, p.43).

Esta nova situação propiciou a identificação de novos ativos intelectuais da empresa. Estes ativos apresentam-se como oportunidades de negócios, além de formas inovadoras de uso estratégico, mas existe a dificuldade no aproveitamento da competência do cliente. A empresa terá que:

[...] dominar quatro habilidades fundamentais para aproveitar tais competências. Ela terá de engajar seus clientes em um diálogo ativo, claro e constante; terá de administrar consumidores; terá de administrar as diferenças entre eles e, por fim, terá de criar experiências personalizadas junto com os clientes (PRAHALAD; RAMASWAMY, 2000b, p.44)

A incessante busca pela competência é um fenômeno das últimas décadas, incluindo todas as etapas do processo de produção, ampliando-se, desta forma, na direção dos fornecedores e distribuidores. O quadro 2 mostra a evolução dos diversos níveis de abordagens das competências fundamentais. Neste sentido, as empresas devem migrar para um patamar no qual as suas estratégias atinjam muito mais do que a empresa em si, abrangendo a "empresa ampliada" (sistema empresa-fornecedores-parceiros-clientes). Assim, a empresa vista como um sistema tem sua organização central sustentada e integrada a um conjunto de redes de organizações.

O gerenciamento da competência do cliente tem início na gestão do processo de interação entre a empresa e seus clientes. Neste processo, é preciso aprender com as experiências destes, muito mais do que as suas experiências com os produtos oferecidos pela empresa. Isso quer dizer que as empresas devem quebrar paradigmas dos produtos e efetivamente fomentar um diálogo aberto com o cliente, a fim de compreender quais as suas reais 
percepções a cada experiência com a empresa, desde a pré-venda à pósvenda.

Neste sentido, é preciso desenvolver produtos que se adaptem às necessidades do consumidor e não manter a estratégia ultrapassada de que o consumidor é quem deve adaptar-se ao serviço oferecido. Com essas novas exigências do mercado, as empresas precisam fazer uma mudança no modelo de gestão, para que consigam aproveitar a competência do cliente.

Esta mudança passa também por uma mudança na estrutura organizacional da empresa, pois os novos padrões exigem que se leve em conta também o capital intelectual e humano. As novas estratégias das empresas precisam estar focadas em uma nova empresa que aproveite a competência de todos os envolvidos no processo, incluindo o cliente. A personalização dos serviços, por exemplo, implica na participação ativa do cliente com toda a sua experiência acumulada.

Além disso, segundo Prahalad e Ramaswamy (2000b), o maior desafio ainda é desenvolver estruturas que sejam capazes de sustentar uma rede de distribuição de vários canais. Dessa forma, manter este novo cenário de auto-exigência, mantendo um custo baixo na nova economia, exigirá a combinação de tecnologia de comunicação e logística de serviços.

A mudança do foco na abordagem das competências proposta pelos autores e apresentada no quadro 2 abaixo é o grande desafio para as organizações neste novo cenário de acirrada competitividade. Sair do paradigma da empresa e orientar a organização para a rede ampliada; buscar recursos ao longo da cadeia de valor via competências dos fornecedores e clientes; aumentar a infra-estrutura de diálogo, migrando da atual estrutura de processos para uma permanente abertura de comunicação; assumir a necessidade da busca de novos conhecimentos por meio da colaboração versus o paradigma da auto-suficiência, enfim, estas são algumas das novas competências que as organizações deverão buscar para se posicionar no novo ambiente de negócios. 
Quadro 2: A mudança do foco na abordagem das competências fundamentais.

\begin{tabular}{|c|c|c|c|}
\hline & Empresa & $\begin{array}{l}\text { Rede/ Família de } \\
\text { Empresas }\end{array}$ & Rede ampliada \\
\hline Unidade de análise & Empresa & $\begin{array}{l}\text { Empresa ampliada: a } \\
\text { empresa, seus } \\
\text { fornecedores e parceiros }\end{array}$ & $\begin{array}{l}\text { O sistema como um todo } \\
\text { a empresa, seus } \\
\text { fornecedores, parceiros e } \\
\text { clientes }\end{array}$ \\
\hline Recursos & $\begin{array}{l}\text { Disponíveis atualmente } \\
\text { na empresa }\end{array}$ & $\begin{array}{l}\text { Acesso a recurso e } \\
\text { competências de outras } \\
\text { organizações }\end{array}$ & $\begin{array}{l}\text { Acesso a recurso e } \\
\text { competências de outras } \\
\text { organizações; e acesso } \\
\text { às competências e } \\
\text { recursos dos clientes, } \\
\text { seu tempo e esforço. }\end{array}$ \\
\hline $\begin{array}{l}\text { Acesso às } \\
\text { competências }\end{array}$ & Processos internos & $\begin{array}{l}\text { Acesso privilegiado à } \\
\text { rede de parceiros }\end{array}$ & $\begin{array}{l}\text { Infra-estrutura de diálogo } \\
\text { contínuo com os clientes }\end{array}$ \\
\hline $\begin{array}{l}\text { Valor agregado pela } \\
\text { gestão }\end{array}$ & Construir competências & $\begin{array}{l}\text { Gerência da colaboração } \\
\text { com os parceiros }\end{array}$ & $\begin{array}{l}\text { Aproveitamento das } \\
\text { competências dos } \\
\text { clientes; gerência de } \\
\text { experiências } \\
\text { personalizadas; modelar } \\
\text { as expectativas dos } \\
\text { clientes }\end{array}$ \\
\hline Criação de valor & Autonomia da empresa & $\begin{array}{l}\text { Colaboração com } \\
\text { empresas parceiras }\end{array}$ & $\begin{array}{l}\text { Colaboração com } \\
\text { empresas parceiras e } \\
\text { clientes ativos }\end{array}$ \\
\hline $\begin{array}{l}\text { Recursos de tensão } \\
\text { gerencial }\end{array}$ & $\begin{array}{l}\text { Autonomia das Uns vs } \\
\text { criação de novas } \\
\text { competências }\end{array}$ & $\begin{array}{l}\text { O parceiro é, ao mesmo } \\
\text { tempo, colaborador e } \\
\text { competidor pela criação } \\
\text { de valor }\end{array}$ & $\begin{array}{l}\text { O cliente é, ao mesmo } \\
\text { tempo, colaborador e } \\
\text { competidor pela criação } \\
\text { de valor }\end{array}$ \\
\hline
\end{tabular}

Fonte: Adaptado de PRAHALAD; RAMASWAMY, 2000a.

Em geral, a literatura específica do turismo e em especial a da hotelaria busca adaptar idéias e conceitos gerais de marketing e do estudo do setor de serviços às particularidades do produto ou serviço turístico. Assim, dos principais atributos da prestação de serviços, a hotelaria apresenta, igualmente, as características de:

- Intangibilidade

- Heterogeneidade

- Perecibilidade

- Simultaneidade entre produção e consumo

- Variabilidade 
Sintetizando o produto ou serviço turístico, para Vilafradera (1969, apud VALDÉS, 2003, p.127), turismo "é um bem de consumo abstrato, imaterial, inapreensível que está integrado por elementos materiais, visíveis, apreensíveis entre outros". Como tal, apesar de estar inserido no escopo da prestação de serviços, demanda um estudo específico de suas particularidades e características.

Neste sentido, destaca-se a seguir o referencial teórico do turismo e hotelaria que servirá para contextualizar o estudo de caso deste trabalho.

\subsubsection{Turismo e hotelaria}

O conceito atual de turismo se refere a um fenômeno que surge explicitamente no século XX, normalmente ligado ao desenvolvimento industrial de regiões ou países. Teve sua gênese ligada à revolução Industrial, ao desenvolvimento dos meios de comunicação, ao transporte e à ascensão da classe média.

Amplamente aceito, o conceito de turismo mais utilizado é o da Organização Mundial de Turismo (OMT), que se refere ao turismo como

[...] as atividades realizadas por pessoas durante suas viagens e estadas em lugares diferentes de sua moradia habitual, por um período de tempo consecutivo, inferior a um ano, com fins de férias, por negócios e outros motivos" (SANCHO, 2001, p.3).

Segundo a Enciclopédia Livre Universal em Espanhol, turismo é o movimento migratório, por terra, mar ou ar que desloca as pessoas de um ponto geográfico a outro. Ou ainda, turismo é a atividade de viajar por prazer; numa viagem turística, o deslocamento e o destino são os fins. Um turista pode estar interessado na beleza geográfica do lugar, em seu povo, em sua gastronomia, em sua cultura, ou em outros atrativos. 
Para Wahab (1977), turismo é uma atividade humana intencional que serve como meio de comunicação e como elo de interação entre os povos, tanto dentro de um mesmo país como fora dos limites geográficos dos países. Envolve o deslocamento temporário de pessoas para outra região, país ou continente, visando à satisfação de necessidades outras que não o exercício de função remunerada. Para o país receptor, o turismo é uma indústria cujos produtos são consumidos no local, formando "exportações invisíveis". Os benefícios originários deste fenômeno podem ser verificados na vida econômica, política, cultural e social da comunidade.

Para a EMBRATUR, em uma visão econômica, turismo é a atividade econômica representada pelo conjunto de transações turísticas (compra e venda de bens e serviços).

Para Andrade (1998), turismo pode ser entendido como um complexo de atividades e serviços relacionados aos deslocamentos, transportes, alojamentos, alimentação, circulação de produtos típicos, atividades relacionadas aos movimentos culturais, visitas, lazer e entretenimento. Este conceito enfatiza as diversas atividades que compõe o turismo, o que os autores definem como trade turístico. Um exemplo disto, e talvez o mais importante, é a hotelaria, sem a qual não haveria como os turistas se alojarem.

Segundo Éfron (1994), o turismo pode ser classificado segundo vários critérios, e dependendo do objetivo final do estudo que se queira fazer, utiliza-se uma ou outra classificação. Neste sentido, apresentaremos alguns dos principais critérios, como segue:

- Por sua natureza: turismo ativo, aquele formado pelos turistas propriamente ditos; e turismo receptivo, constituído pelos bens e serviços que uma localidade oferece para receber os turistas;

- Pela nacionalidade dos turistas: turismo local (nacional) ou estrangeiro, turismo interior, exterior ou internacional;

- Por seu volume: turismo de minorias, indica um turismo seletivo, seja por preferências, cultura, ou nível econômico, que se diferencia da maioria; ou turismo de massa, caracterizado por 
meios de transporte mais econômicos, viagens coletivas, reduzido gasto diário;

- Por sua composição social: turismo de classes privilegiadas (elevados gastos diários, geralmente gastos supérfluos, utilização de meios de transporte e de hospedagem luxuosos, preferência por viagens internacionais, em especial lugares de tipo cosmopolita ou exótico e indiferença no nível de preços); da burguesia (constituído em geral pela classe média, que utiliza serviços considerados de primeira categoria, sem ser luxuosos, viagens por meio de agências de turismo, preferência por centros turísticos, lugares típicos, e viajam, geralmente, com a família); da juventude (formado por estudantes, caracteriza-se por gastos muito reduzidos e pela utilização de serviços econômicos); de classes populares (com vantagens especiais em meios de hospedagem ${ }^{19}$ e transportes, como colônias de férias);

- Por sua duração: excursionismo, deslocamento inferior a 24 horas; de fim de semana; de férias; residencial, longa temporada; esporádicos, congressos, encontros, seminários;

- Por objetivo de viagem: de descanso, cura, desportivo, religioso, a negócios. Este último é o foco do estudo deste trabalho, já que o hotel escolhido para a aplicação do estudo de caso trabalha fortemente com este público, ou seja, viajantes que se deslocam por motivo de trabalho para realizar negócios na cidade de destino.

- $\quad$ Pelo modo de viajar: particular ou coletivo.

\footnotetext{
19 Meios de Hospedagem de Turismo. Conforme o decreto no. 84.910/ 90, da EMBRATUR, em seu artigo 20., alínea a, entende-se por meio de hospedagem os empreendimentos ou estabelecimentos destinados a prestar serviços de hospedagem em aposentos mobiliados e equipados, com alimentação e outros serviços necessários aos usuários.
} 
2.3.3.1 Turismo de Negócios

Segundo dados da Embratur (EMBRATUR, 2004), o segundo maior motivo para o turismo de estrangeiros no Brasil são os negócios - categoria que compreende negócios, congressos e convenções.

O turismo de negócios, como é chamada esta categoria de turismo, abrange as viagens dos profissionais das empresas e corporações, inclusive governamentais, para o desenvolvimento dos negócios referentes aos diversos setores de suas atividades, sejam elas comerciais, industriais ou de serviços. Estabelecer contatos e reuniões, abrir novos mercados, comprar ou vender bens e serviços, firmar convênios e contratos, são alguns dos motivos que fazem com que os funcionários e os dirigentes de uma organização se desloquem para longe de suas sedes.

Além disso, os profissionais viajam para participar de eventos, tais como: congressos, feiras, seminários, exposições, simpósios, encontros esportivos e religiosos, dentre outras tantas modalidades. Muitos destes eventos buscam o aprimoramento técnico e a atualização das pessoas envolvidas nas organizações, bem como a divulgação das marcas de produtos novos ou em expansão.

O estudo promovido pelo Fórum Brasileiro dos Convention \& Visitors Bureaux, em conjunto com o Sebrae (Serviço de apoio à micro e pequena empresa) (SEBRAE, 2001), revelou que, entre janeiro e novembro de 2001, aconteceram no Brasil mais de 330 mil eventos, com o envolvimento de 79,9 milhões de pessoas. Somando-se os gastos dos participantes, a receita das locações e das empresas organizadoras, chega-se a uma renda total de $R \$ 37$ bilhões por ano, o que representa 3,1\% do produto interno bruto (PIB) brasileiro daquele mesmo período. Assim, fica patente a importância deste segmento na economia brasileira e, em maior proporção, no setor turístico brasileiro. 
2.3.3.2 O Turismo e o seu Cliente

Taylor (2001, p.283) diz que "[...] há muito tempo que o turismo se preocupa com o consumo e não com os consumidores". As decisões de mudança nas empresas, para acompanhar as tendências do mercado, precisam estar relacionadas tanto à incidência quanto ao estilo dos consumidores hoteleiros, analisados de forma conjunta. Isso indicará com maior segurança a direção das melhorias do processo de prestação de serviços. Neste sentido, Taylor (2001) insiste na idéia de que [...]

[...] o turismo não pode se permitir descuidar das implicações desses dados como meio de melhorar o conhecimento dos mercados e de aumentar as oportunidades de satisfação do cliente (TAYLOR, 2001, p.291).

No turismo, os serviços de hospedagens e de alimentação são questões básicas, pois estas são necessidades de todo ser-humano e, naturalmente se aplicam ao turista, especialmente quando entendemos por turista aquele que passa pelo menos uma noite no destino visitado. Desta forma, pode-se "compreender a importância do alojamento e da alimentação no conjunto da experiência turística, pois esse turista deve fazer suas necessidades básicas quando estiver fora de casa" (SANCHO, 2001, p.79). A hospedagem, em si, representa uma condição para o turista entrar em contato com o atrativo.

O hotel, no entanto, pode também se tornar um atrativo, colocandose como motivador da viagem. Sancho (2001, p.79) define a hotelaria como "[...] o sistema comercial de bens materiais e inatingíveis dispostos para satisfazer às necessidades básicas de descanso e alimentação dos usuários fora do domicílio".

Tecnicamente utiliza-se a oferta turística como termo para se referir ao produto alojamento. A hotelaria seria uma oferta básica, enquanto os serviços de alimentação fariam parte da oferta complementar. Da mesma 
forma, são ofertas complementares as excursões, os museus, os parques temáticos, etc.

O deslocamento do turista de seu lugar de residência até o destino turístico é motivado pelo desejo de conhecer os atrativos no destino turístico. Desta forma, a hotelaria e o transporte derivam do desejo dos viajantes. Portanto, nestes casos, serviços de hospedagem, alimentação e transporte ficam limitados a serviços facilitadores do contato entre turistas e atrativos. Todos esses elementos da oferta turística se inter-relacionam, e a ineficiência de um deles prejudicará a avaliação do processo como um todo. Convém salientar, porém, que o atrativo é o elemento ativo do processo de serviço turístico.

Os meios de hospedagens de lazer normalmente se adaptam às necessidades dos seus clientes, de forma que a hotelaria que atende ao lazer está próxima dos locais de diversões, mais acessíveis em relação aos preços, sendo a questão da rapidez dos serviços uma questão secundária. Para a hotelaria de negócios, a rapidez dos serviços oferecidos pelo hotel aliado ao acesso constitui os principais elementos que caracterizam este segmento. Cumpre salientar que a questão da localização é primordial para 0 oferecimento dos serviços hoteleiros, quer seja ligado a negócios ou a lazer.

Talvez o principal problema que hoje a hotelaria enfrenta diz respeito à falta de padronização nas classificações, dificultando a comunicação com os clientes $^{20}$. Como os critérios não estão bem definidos e adequados, a possibilidade de frustração quanto aos serviços oferecidos é muito alta.

Tendo a qualidade como ponto central do desenvolvimento de estratégias competitivas, as empresas hoteleiras podem propiciar profundas transformações na cultura empresarial. Nestas empresas, onde são simultâneos produção e consumo, implicando um maior contato entre empresa e cliente, é fundamental para a qualidade do serviço uma gerência eficaz. Tal relacionamento se constitui uma variável fundamental para a qualidade do serviço.

\footnotetext{
${ }^{20}$ Ver anexo 3: Classificação hoteleira (ABIH, EMBRATUR, 2002).
} 
Relacionado à questão da qualidade, cabe enfatizar que, diferentemente dos produtos tangíveis, a qualidade final é derivada tanto dos resultados quanto das relações envolvidas durante o processo de fornecimento (MENDES; TOLEDO, 2001). Dessa forma, a determinação da qualidade dos serviços inclui elementos materiais e comportamentais, este último muito vinculado à questão da cultura da empresa.

Nesta questão da qualidade, o modelo das cinco falhas (ou cinco lacunas), desenvolvido por Parasuraman et al. (1990), é considerado como o mais consistente modelo da qualidade em serviço. Este nome advém das cinco lacunas identificadas entre o sistema de prestação do serviço e a qualidade esperada pelo consumidor.

Neste modelo, a qualidade do serviço é resultante das referências do cliente, formada pelas suas experiências anteriores, com a empresa prestadora do serviço, pelas suas necessidades pessoais, assim como pelas informações obtidas por meio de outras pessoas. Desta forma, a qualidade do serviço percebida pelo cliente representa a forma como ele vê o resultado e o esforço da empresa no atendimento de suas necessidades.

Assim sendo, a avaliação deste processo está diretamente ligada a questões subjetivas, desde o momento da formação das expectativas por parte do cliente, até na forma como consegue perceber o desempenho da empresa em prestar o serviço. A discrepância entre expectativa do cliente e percepção da gerência sobre esta expectativa é entendida como a primeira falha. Isto ocorre quando a prestadora de serviço não capta corretamente as expectativas de seus clientes, criando atributos ao pacote diferentes das necessidades dos consumidores.

A segunda lacuna acontece quando o sistema de serviços da empresa não atende todas as necessidades e expectativas dos clientes por vários motivos, como escassez de recursos, condições de mercado ou incompetência da gerência. Essa lacuna explicita o problema da empresa entre os requisitos do processo de produção e o seu sistema de fornecimento.

A terceira lacuna está ligada ao elemento humano do processo. Mesmo que todo o sistema de prestação do serviço esteja correto, a alta 
influência do fator humano produz diferenças entre o desempenho projetado e o desempenho real. A quarta lacuna, por sua vez, é ligada à formação de falsas expectativas dos serviços oferecidos.

Poderá haver discordâncias entre o conceito do serviço e os sistemas de comunicação. Enquanto se vende a idéia de um serviço com determinados requisitos, o processo real produz serviços com atributos diferentes.

A quinta lacuna retrata discrepância entre a qualidade esperada e a qualidade percebida pelo cliente, causada pelas demais lacunas apresentadas no modelo. Os problemas nos processos de serviços precisam ser enfrentados com o desenvolvimento de sistemas cada vez mais estruturados. A competição, a inovação, a sazonalidade, a redução de riscos e o aproveitamento de oportunidades são metas que precisam ser seguidas por toda a organização de serviços.

As lacunas demonstram a dificuldade de conseguir captar a real necessidade dos clientes. A satisfação do cliente deve ser o foco da empresa, que deve buscar constantemente conhecer as suas necessidades, preferências e prioridades, criando mecanismos que controlem o grau de progresso em relação às expectativas dos clientes. Assim feito, utilizará as informações sobre os clientes para inovações, tanto nos produtos quanto nos processos de produção, avaliando constantemente a concorrência e o desempenho interno.

Visando entregar serviços de alta qualidade para seus clientes, a gestão hoteleira deve entender a visão de qualidade sob a perspectiva do cliente. No modelo exposto de "Análise de Lacunas (Gap Analysis)", que Parasuraman et al. (1985) conceituaram para estudar a qualidade na prestação de serviços, uma das principais lacunas refere-se à diferença entre as expectativas dos clientes e a percepção da gestão acerca destas expectativas.

Para que este modelo seja útil para a indústria hoteleira, é necessária a identificação dos atributos que caracterizam a visão de qualidade percebida do cliente. Pesquisas mostram que, em serviços como na hotelaria, a qualidade na interação interpessoal entre clientes e empregados influencia diretamente a satisfação do cliente (BITNET et al., 1994). O novo "paradigma" 
diz respeito ao relacionamento de longo prazo como ferramenta para a retenção de clientes (GRÖNROOS, 1997). Indo além, o bom relacionamento na prestação de serviços é considerado um fator de vantagem competitiva para o negócio (WEBSTER, 1992).

\subsubsection{Atributos Hoteleiros}

Lewis (1995) apresenta os atributos em duas dimensões, a saber: os atributos determinantes - qualidade de serviços, segurança, silêncio, reservas e recepção, condições do quarto e banheiro, imagem do hotel, amenidades, alimentos e bebidas, e localização - e os atributos importantes - qualidade de serviços, segurança, silêncio, condições do quarto e banheiro, imagem do hotel, alimentos e bebidas, e localização.

Knutson (1988) e Cadotte e Turgeon (1988) reconhecem os componentes intangíveis do serviço hoteleiro. Em particular: a limpeza, o conforto, a manutenção dos apartamentos, a localização, a segurança, assim como a cortesia e presteza no atendimento como componentes determinantes da satisfação do cliente. No estudo de Saleh e Ryan (1992) sobre atributos importantes ou determinantes na escolha de um hotel, foram identificados: limpeza, tamanho do apartamento, conforto da cama, disponibilidade e preço da alimentação, cortesia da equipe de atendimento e eficiência na prestação de serviço, estacionamento, assim como decoração de interiores e aspecto exterior do Hotel. Preço ou valor para o dinheiro são fatores fortemente associados à retenção de clientes e ao faturamento do Hotel (SHIFFLET et al, 1997)

Ao longo dos anos, inúmeras pesquisas foram realizadas visando identificar os fatores que influenciam os hóspedes na escolha de um hotel. Callan (1996), apud Lockyer (2003), em seus estudos, identificou 166 atributos seguindo atributos-chave, como: localização, imagem, competência, acesso, segurança, serviços adicionais, conforto da cama, facilidades de lazer e atendimento. 
Dube e Renaghan (1999), apud Lockyer (2003), entrevistaram 469 usuários freqüentes de hotéis e identificaram como o mais citado benefício a tranqüilidade, no sentido de não-perturbação, seguido pelo conforto. Dois itens empataram em terceiro lugar de preferência dos hóspedes: a "experiência agradável" e a "sensação de satisfação".

Outros estudos orientaram sua análise para pontos mais específicos dos meios de hospedagem. Ananth et al. (1992), apud Lockyer (2003), pesquisaram as necessidades dos viajantes, enquanto outros consideraram as necessidades dos turistas a negócios (GUNDERSEN et al., 1996; MCCLEARY et al., 1993; WEAVER e OH, 1993; LOCKYER, 2000, apud LOCKYER, 2003). Goldberg et al. (1984) identificaram como atributos-chave na hotelaria, com respectivos níveis: atmosfera do ambiente, considerando: o tamanho do hotel, a paisagem, corredores, localização da piscina, tipo de piscina, arquitetura do edifício; o apartamento, considerando: temperatura do quarto, qualidade da decoração, tamanho, entretenimento, tipo de equipamentos (TV, vídeo, rádio), banheiro, banheira; o lazer, considerando: salas de jogos, playground, quadras, salas de ginástica, sauna, jacuzzi; a recepção, considerando: tipo das pessoas, atmosfera e localização; e a segurança, considerando: sistemas de alarmes, sistemas integrados de TV, detectores de fumaça e incêndio e equipe de seguranças.

Segundo Schall (2003), seus estudos indicam que os hóspedes avaliam três principais pontos de um hotel: o apartamento, a comida e os empregados. No apartamento, os elementos-chave são: a limpeza, o funcionamento dos equipamentos e o conforto (silêncio e sensação de limpeza). Para hóspedes de negócios, pode-se considerar também o espaço para trabalho dentro do quarto. Na alimentação, os pontos-chave são: o gosto, a aparência e a temperatura da comida. E os empregados são avaliados por sua presteza, cuidado, amizade e prontidão.

Gundersen et al. (1996), baseados em seu experimento com turistas de negócios, recomendam que os gestores hoteleiros concentrem sua atenção e recursos na melhoria dos aspectos tangíveis do departamento de governança 
(limpeza) e dos aspectos intangíveis da recepção para, assim, aumentarem a satisfação da experiência de seus clientes.

De todos estes experimentos, há uma forte indicação de que a limpeza é um atributo de grande importância, senão o mais importante fator na escolha de uma acomodação (CALLAN, 1996; WEAVER e OH, 1993; SALEH e RYAN, 1992; MCCLEARY e WEAVER 1992; MEHTA e VERA, 1990; LEWIS, 1987, apud LOCKYER, 2003).

Em resumo, as pesquisas anteriores na indústria de hospitalidade enfatizam: a construção de relacionamentos, as características de design, preço e diversos outros aspectos tangíveis e intangíveis sobre o apartamento, localização, facilidades e restaurante.

Destes estudos, pode-se concluir que saber quais os atributos que diferenciam a escolha de um hotel é de extrema importância. Pelo entendimento do que o cliente percebe como importante e de como determina sua preferência na escolha, os hoteleiros podem direcionar seus serviços para a maximização da satisfação de seus hóspedes e para onde direcionar esforços e recursos em sua propriedade.

Para o nosso estudo, em particular, foi conduzido um estudo qualitativo, segundo a técnica do incidente crítico, além de entrevistas com executivos do setor, para a definição dos atributos de valor e, conseqüentemente, de qualidade, como fatores decisivos na escolha $e$ posterior satisfação do cliente hoteleiro.

\subsubsection{Mercado Hoteleiro Brasileiro}

Para Costa (2004), pode-se conceber o hotel como uma organização de prestação de serviços, onde se alugam quartos ou apartamentos mobiliados a pessoas (hóspedes) e/ou organizações (clientes), por um período de tempo, podendo esse aluguel estar acompanhado de serviços de alimentação, arrumação, diversão, segurança, entre outras atividades inerentes à operação hoteleira. Hotel é muito mais do que isso, 
[...] é uma empresa de prestação de serviços, dotada de recursos que deve atender a clientela, atual e potencial, com qualidade e segurança para satisfazê-la, encantá-la e fidelizála, obtendo com isso lucros para sobreviver e crescer (COSTA, 2004, p.1).

Ao definir hotel dentro deste escopo, consolida-se o "cliente" como elemento central do conceito e de todo processo organizacional.

Segundo Lewis (1995), há três elementos que são considerados importantes, em iguais proporções, na compra de um produto hoteleiro (ou meio de hospedagem): os itens tangíveis, o ambiente e os serviços intangíveis.

- Itens Tangíveis: Incluem as camas, mobília, instalações dos banheiros, elevadores, tevês, coisas que não trabalham, mas têm valor. Para o cliente, o preço também é um item tangível na decisão de compra. Assim, em hospitalidade, estes itens determinam a satisfação ou não das necessidades básicas dos consumidores.

- Ambiente: Os valores ambientais podem ser ou não tangíveis, estão, geralmente associados aos sentimentos e percepções do cliente. Uma fechadura eletrônica é, de fato, um item tangível, mas que não é vendido ao cliente. O que é vendido neste caso é a sensação de segurança, um atributo intangível na visão do cliente. Entre outros atributos desta categoria estão: a decoração, o conforto, a arquitetura, localização.

- Serviços: Os serviços estão relacionados diretamente aos recursos humanos de um Hotel. Cordialidade, rapidez, eficiência, atitudes, profissionalismo e respeito são características deste atributo. Entretanto, existem fatores que estão sujeitos ao sistema, que dependem estritamente das decisões gerenciais de como este serviço será oferecido, como o sistema de reservas.

Na década de 90, com o crescimento do turismo interno e externo, novas cadeias internacionais aportam no Brasil; as já existentes se expandem, 
assim como as redes nacionais, provocando grandes transformações na hotelaria brasileira. As mudanças ambientais nesta década foram realmente abruptas. Desde o Plano Collor em 1990, incontáveis mudanças ocorreram no ambiente econômico, político, social, cultural, legal, tecnológico, dentre outros. Iniciou-se, assim, uma perceptível alteração no mercado hoteleiro.

Tabela 1: Crescimento da oferta hoteleira no Brasil.

\begin{tabular}{lcccc}
\hline & \multicolumn{2}{c}{ Crescimento da oferta de hotéis e unidades habitacionais no Brasil } \\
\cline { 2 - 3 } & $\mathbf{2 0 0 0}$ & & Projetos & $\mathbf{2 0 0 3}$ \\
\hline Empreendimentos & 4.828 & 244 & 5.072 \\
Unidades habitacionais & 225.186 & & 49.435 & 274.621 \\
\hline
\end{tabular}

Fonte: Database Marketing, Accor Brasil, 2000.

O crescimento na oferta de unidades habitacionais $(\mathrm{UH})$, mostrada na tabela 3 , de cerca de $22 \%$, demonstra claramente a tendência de incremento da oferta de hotéis no Brasil e a conseqüente modernização da mesma. Outra grande tendência que podemos constatar na hotelaria brasileira é a concentração de mercado, com a expansão das redes e o conseqüente e contínuo aumento na participação de mercado pelas mesmas. A análise da tabela 4 nos mostra o impressionante crescimento das redes de hotéis no Brasil.

Tabela 2: Crescimento da oferta de hotéis de Rede.

\begin{tabular}{|c|c|c|c|}
\hline \multirow{2}{*}{ Motivo da viagem } & \multicolumn{3}{|c|}{ Crescimento da oferta de hotéis e unidades das Redes no Brasil } \\
\hline & 2000 & Projetos & 2003 \\
\hline Empreendimen & 249 & 228 & 477 \\
\hline Unidades habitacionais & 35.303 & 45.482 & 80.785 \\
\hline
\end{tabular}

Fonte: Database Marketing, Accor Brasil, 2000

Segundo dados da EMBRATUR (EMBRATUR, 2003), o mercado hoteleiro brasileiro é composto de aproximadamente 5.000 hotéis, divididos entre as categorias que vão de luxo à super-econômica ${ }^{21}$. A maior parte desses

21 Existem basicamente quatro tipos de classificação hoteleira: por números - 1aa $2^{\underline{a}}, 3^{\underline{a}}$ categoria; por letras - A, B, C, etc; misto: A1, A, B, etc.; e por símbolos: estrelas. (ÉFRON, 
hotéis se encontra na Região Sudeste, onde se situa a população com maior poder aquisitivo no país.

Houve um aumento significativo da oferta hoteleira. Em razão deste aumento, a ocupação em 1999 diminuiu em relação a 1998, tendo apresentado valores de 59,3\% e 61,7\%, respectivamente. Esta queda se dá principalmente nas regiões Sudeste e Nordeste, regiões com fluxo de turistas estrangeiros. As diárias médias, em Reais, aumentaram 16,6\% entre 1998 e 1999, porém, em Dólares, as diárias diminuíram significativamente, de US $\$ 92,00$ para US\$ 68,80 . Este declínio de $25 \%$ é diretamente atribuível à desvalorização do Real que ocorreu em janeiro de 1999.

Do total de 5.509 estabelecimentos, conforme apresenta a tabela 3, os quarenta e três maiores grupos hoteleiros contribuem com uma participação de 10,60\%, correspondente a 584 (quinhentos e oitenta e quatro) empreendimentos. Isso significa que $89,40 \%$ do mercado é formado por hotéis independentes que operam sem administradoras ou bandeiras ${ }^{22}$.

Tabela 3: Total de hotéis e flats no Brasil.

\begin{tabular}{lcccc}
\hline \multirow{2}{*}{ Tipo de estabelecimento } & \multicolumn{2}{c}{ 2004* $^{\boldsymbol{*}}$} & \multicolumn{2}{c}{ 2005 $^{\text {** }}$} \\
\cline { 2 - 5 } & Hotéis & UH & Hotéis & UH \\
\hline Independentes & 4.925 & 202.600 & 4.950 & 203.500 \\
Hotéis e flats de cadeias nacionais & 312 & 39.010 & 330 & 41.340 \\
Hotéis e flats de cadeias internacionais & 272 & 47.866 & 313 & 54.900 \\
Total & 5.509 & 289.476 & 5.593 & 299.740
\end{tabular}

* Inclui hotéis e flats existentes até setembro de 2004.

** Estimativa

Fonte: GORNI e RODRIGUES, 2004.

1994). No Brasil, a EMBRATUR, por meio da Deliberação no 429, de 23 de Abril de 2002, adotou a classificação por estrelas (ver apêndice).

${ }^{22}$ Não há nenhum dado oficial atualizado sobre o número total de hotéis no Brasil. Estes números representam o total de hotéis e flats afiliados a cadeias hoteleiras. No caso dos hotéis independentes, baseou-se em guias de turismo e no conhecimento da indústria (GORNI e RODRIGUES, 2004) 
O incremento da oferta hoteleira vem ocorrendo nos principais centros comerciais do país, especialmente no setor de flats. Embora não sejam considerados hotéis, a nova geração de flats se torna um forte competidor direto dos hotéis mid-scale. Isto se deve à sofisticação das suas instalações, configuração dos apartamentos, infra-estrutura para convenções e afiliação a cadeias hoteleiras.

\subsubsection{Hotéis de Negócios}

Hotel de negócios é o meio de hospedagem que reúne as facilidades necessárias ao abrigo de pessoas em deslocamento resultante de sua atividade econômica. Entre seus clientes, estão incluídas também as pessoas que se hospedam para participar de eventos com vistas ao seu aprimoramento profissional, tais como: convenções, feiras e exposições, treinamentos ou congressos. Os hotéis de negócio geralmente estão localizados nos centros urbanos e urbano-industriais, diferentemente dos hotéis de lazer, prioritariamente situados próximos a atrativos naturais, desportivos ou socioculturais.

Conforme a tabela 4, os hotéis classificados com três, quatro e cinco estrelas, isto é, pertencentes às categorias turística, turística superior e luxo, concentram grande número de hóspedes em viagens de trabalho ou treinamento. Essa preferência nos permite considerar essas categorias constituídas predominantemente por hotéis de negócios.

O diferencial nos hotéis de negócio está na adequação de suas instalações às necessidades de seus clientes e na eficiência dos serviços prestados. Um sistema de comunicações eficiente, a prestação de serviços expressos como: entrada (check-in), saída (check-out), serviços de quarto (room service) e lavanderia (laundry service) 24 horas, são exemplos de alguns serviços ou atendimentos que repercutem de forma positiva na imagem de um hotel de negócios. Ambientes que reproduzam escritórios virtuais, equipados com material de última geração e espaços preparados especialmente para a 
realização de eventos e congressos, apresentam elevado nível de competitividade e têm a preferência dos hóspedes.

De acordo com o conteúdo apresentado, pode-se verificar que o mercado hoteleiro apresenta um modelo atual de crescimento no Brasil e, mais do que isso, um crescimento orientado para a qualidade e produtividade. Neste cenário, o diferencial competitivo está fortemente associado ao entendimento do cliente e à efetiva entrega de produtos e serviços que acrescentem valor e mais onde o cliente realmente reconheça este valor por meio da sua percepção e preferência.

Tabela 4: Segmentação da demanda de hotéis segundo o motivo da viagem e a categoria do estabelecimento (1997/1999)

\begin{tabular}{|c|c|c|c|c|c|c|c|c|c|}
\hline \multirow{3}{*}{$\begin{array}{c}\text { Motivo da } \\
\text { viagem }\end{array}$} & \multicolumn{9}{|c|}{ Categoria do Estabelecimento } \\
\hline & \multicolumn{3}{|c|}{ Luxo } & \multicolumn{3}{|c|}{ Superior Turística } & \multicolumn{3}{|c|}{ Turística } \\
\hline & 1997 & 1998 & 1999 & 1997 & 1998 & 1999 & 1997 & 1998 & 1999 \\
\hline Lazer & 27,6 & 40,9 & 29,5 & 31,1 & 44,6 & 44,1 & 40,9 & 37,3 & 49,6 \\
\hline Negócios & 42,2 & 37,0 & 44,8 & 44,1 & 31,1 & 34,9 & 41,8 & 43,9 & 31,0 \\
\hline Congressos & 20,1 & 13,7 & 15,9 & 16,1 & 12,7 & 12,6 & 8,8 & 11,5 & 12,0 \\
\hline Outros & 10,1 & 8,4 & 9,8 & 8,7 & 11,7 & 8,4 & 8,5 & 8,2 & 7,4 \\
\hline
\end{tabular}

Fonte: Horwath Consulting (2000).

Com o objetivo identificar como o cliente hoteleiro classifica e avalia sua percepção a respeito dos principais atributos dos serviços recebidos, fazse necessária a adoção de uma metodologia para que se possa mensurar o valor percebido pelo cliente na prestação de serviços hoteleiros.

No capítulo seguinte, será descrito o instrumental utilizado na aplicação do presente trabalho, desde a análise qualitativa à quantitativa. 


\section{METOdOLOGIA DE PESQUISA: DESENHO E DESCRIÇÃO DA ANÁLISE CONJUNTA}

Este capítulo tem por objetivo apresentar o ferramental metodológico adotado para a aplicação do estudo de caso. As técnicas de análise qualitativa e quantitativa utilizadas são explicadas e justificadas baseadas no referencial teórico das disciplinas, respectivamente, técnica do incidente crítico e análise conjunta.

\subsection{Técnica do incidente crítico}

Nos anos 50, muitos pesquisadores orientaram seus estudos para o comportamento humano. Os behavioristas, como eram chamados, procuravam analisar e sintetizar suas observações num conjunto de relacionamentos que pudesse ser quantificado, válido e generalizado, independentemente do experimento. Benjamim Bloom (1956), educador, escreveu "Taxonomia dos Objetivos Educacionais" em 1956, em que descreve categorias cognitivas e termos comportamentais que representam o processo de aprendizado. $\mathrm{Na}$ seqüência, outros pesquisadores orientaram seus estudos no comportamento humano, tentando estruturar maneiras de mensurá-lo. Neste contexto, surge a técnica do incidente crítico (TIC), apresentando que o método científico pode facilitar a observação e categorização de todos os comportamentos humanos.

A abordagem da técnica do incidente crítico é atribuída a John C. Flanagan (1954), com a primeira publicação - "The Critical Incident Technique" 
- em 1954 no "Psychological Bulletin"23". Estas observações, em tempo, são utilizadas para solucionar problemas práticos e desenvolver princípios de psicologia.

A TIC foi desenvolvida durante a $2^{a}$. Guerra Mundial, quando Flanagan, então chefe do programa de psicologia da Força Aérea Americana, identificou uma alta taxa de falha nos treinamentos dos pilotos. Análises de traços de personalidade visando identificar os de predição do sucesso dos treinamentos falharam. Como alternativa, Flanagan analisou os incidentes reais de sucesso e falha no treinamento e trabalhou inversamente para explicar o comportamento que direcionava os resultados positivos e negativos. A técnica foi amplamente estudada e desenvolvida por outros psicólogos, como Borman e Dunnette (1975), Campbell, Dunnette, Lawler e Weick (1970) e Campbell, Dunnette, Arvey e Hellervick (1973). Para se ter uma idéia da penetração e aplicação da TIC, o artigo original de Flanagan (1954) tem sido o mais citado do que qualquer outro artigo de psicologia industrial e organizacional durante os últimos quarenta anos (ANDERSON e WILSON, 1997).

A técnica do incidente crítico (T.I.C.) tem sido extensivamente usada na literatura de qualidade em serviços e administração. Eles são definidos como incidentes interativos, nos quais o cliente percebe ou reconhece um incidente como positivo ou negativo, quando questionado a respeito. Os clientes os reconhecem e os contam por suas experiências como se fossem histórias (FLANAGAN, 1954; BITNER, 1990).

A definição do incidente crítico vem mudando ao longo dos anos. Flanagan (1954) primeiro descreveu esta técnica como um conjunto de procedimentos para a coleta de dados observáveis, diretamente por meio do comportamento do consumidor, com vista a facilitar o uso da pesquisa para a solução de problemas práticos e, para isso, explicar princípios psicológicos.

Por meio do incidente crítico, percebe-se qualquer atividade humana observável que seja suficiente para compreendê-la por si só, permitindo

\footnotetext{
${ }^{23}$ John C. Flanagan foi um psicólogo que trabalhou no Instituto Americano de Pesquisa e na Universidade de Pittsburgh. Ele descreveu a TIC como um conjunto de procedimentos utilizados para coletar observações do comportamento humano.
} 
interferências e previsões sobre a ação humana. Para ser crítico, um incidente deve ocorrer em situações em que a intenção da ação parece claramente identificada pelo observador e suas conseqüências são suficientemente definidas, sem dúvidas sobre seus efeitos (FLANAGAN, 1954).

Bitner et al. (1989, p.97) definem os incidentes críticos como "interações entre consumidores e funcionários de empresas de serviços que são satisfatórias, ou não, de algum modo".

Flanagan (1954) estabeleceu cinco passos cruciais na aplicação desta técnica:

- Estabelecimento do objetivo geral do estudo;

- Desenvolvimento de um plano de coleta de dados;

- Coleta de dados;

- Análise dos dados;

- Interpretação dos dados.

\subsubsection{Estabelecimento do objetivo geral do estudo}

O primeiro passo é determinar o propósito do estudo (isto é, uma breve declaração do objetivo da pesquisa). Por exemplo, um objetivo num estudo hipotético poderia ser determinar os deveres da função de enfermeiras em situações cirúrgicas. Segundo Flanagan (1954), este passo é essencial, o planejamento e a avaliação que seguem são impossíveis sem antes estar claro o propósito do estudo.

\subsubsection{Desenvolvimento de um plano de coleta de dados}

O segundo passo da TIC é planejar e especificar como os incidentes relacionados ao objetivo definido serão coletados. No nosso exemplo hipotético, para entender os deveres das enfermeiras, o pesquisador precisa identificar incidentes práticos que ocorrem numa situação típica entre as enfermeiras e os demais membros da equipe de cirurgia, bem como a relação destas com os pacientes. Este entendimento direcionará o desenvolvimento 
dos critérios a serem utilizados na observação e coleta de dados das interações.

\subsubsection{Coleta de dados}

O terceiro passo é a coleta de dados. Esta coleta pode ser por meio de entrevistas ou por um relatório realizado pelo próprio observador. No exemplo hipotético, o pesquisador deve entrevistar as enfermeiras ou observar o seu comportamento nos dias subseqüentes à cirurgia. Segundo Flanagan (1954), os dados devem ser objetivos para validarem o comportamento das pessoas.

\subsubsection{Análise dos dados}

O quarto passo na TIC é a análise dos dados. Esta análise deve estar resumida, e os dados descritos de tal forma a serem utilizados para efeitos práticos. No nosso exemplo, a análise pode ocorrer por meio de um relatório ou pela identificação de temas característicos do comportamento. Flanagan (1954) reconhece que este é o passo que apresenta menor objetividade entre os demais.

\subsubsection{Interpretação dos dados}

O quinto passo é a interpretação dos resultados e o relatório final do estudo. No caso acima, pode ser uma lista de deveres das enfermeiras que emergiram das entrevistas ou observação dos incidentes críticos durante as cirurgias.

Uma característica da TIC é clareza nos aspectos das melhores e piores práticas de cada estudo, ou seja, busca os extremos positivo e negativo do comportamento em estudo.

Um grupo de pesquisadores identificou três suposições normalmente associadas à TIC. Primeiro, o termo incidente crítico refere-se a uma cena 
claramente demarcada do que se quer medir. Segundo, caso não se consiga obter uma detalhada medida para o comportamento real, o incidente não será válido. E terceiro, o incidente crítico por si é uma unidade básica de análise.

Estabelecido o entendimento da técnica qualitativa do incidente crítico, na seqüência, introduz-se o método da técnica estatística multivariada da análise conjunta, definida como ferramenta de coleta e análise de dados quantitativos sobre o comportamento do consumidor.

\title{
3.2 Análise Conjunta
}

O termo conjoint é derivado de duas palavras, a saber: considered joinlty, ou seja, cuidadosamente agregados (conjuntos). Enquanto a origem deste tema remonta a década de 20 do século passado, o início da análise conjunta é atribuído ao ano de 1964, com o artigo escrito por: R. Duncan Luce (1964), um psicólogo e matemático, em conjunto com John W. Tukey (1964), estatístico. Logo após esta data, diversas contribuições teóricas e o desenvolvimento de algoritmos apareceram (GREEN E SRINIVASAN, 1978).

Em Kotler (1995, p.139), a análise conjunta é definida da seguinte forma:

\begin{abstract}
A análise conjunta é uma técnica estatística pela qual as preferências dos respondentes por diferentes ofertas são decompostas para determinar a função utilidade suposta pelos mesmos para cada atributo e sua importância relativa. Por exemplo, uma linha aérea pode determinar a utilidade total prestada por diferentes combinações de serviços a seus passageiros (KOTLER, 1995, p.139).
\end{abstract}

A análise conjunta procura estabelecer funções de valor parcial ou de utilidade, que descrevem o grau de utilidade que os consumidores associam aos níveis de cada atributo.

Neste sentido, segundo Green e Srinivasan (1978) e Engel et al. (2000) , o modelo de expectativa-valor de Fishbein-Rosenberg e a nova teoria 
econômica de consumo esclarecem, ainda que hipoteticamente, o modelo de preferência de consumo baseado em análises multiatributo (multivariada).

De acordo com Mowen e Minor (2003), o modelo de atitude em relação ao objeto, apresentado por Fishbein-Azjen, é um dos diversos modelos de multiatributos desenvolvidos para descrever o modo como os consumidores combinam suas crenças sobre os atributos do produto, para formar atitudes a respeito das alternativas de marcas ou empresas. Esse modelo identifica três importantes fatores precursores das atitudes.

O primeiro fator considera as crenças visíveis de uma pessoa como influenciadoras da formação de atitude acerca de um objeto, representam conhecimento a respeito de atributos do mesmo. O segundo fator considera a força das crenças da pessoa de que um objeto possui o atributo específico em questão. $O$ terceiro fator é a avaliação positiva ou negativa de cada um dos atributos visíveis.

$\mathrm{Na}$ análise conjunta, os pesquisadores descrevem produtos e serviços por meio de um conjunto de atributos e seus níveis e, a partir disso, medem o interesse de consumo para cada produto ou serviço (Mc CULLOUGH, 2002).

Para Malhotra (2001), a análise conjunta procura determinar a importância relativa que os consumidores dão a atributos relevantes e a utilidade que eles associam aos níveis de atributos. Os entrevistados se deparam com estímulos que consistem em combinações de níveis de atributos e devem avaliar esses estímulos em termos de sua conveniência.

A análise conjunta é um método estatístico utilizado para coletar dados primários por experimentação. É também uma técnica estatística descritiva multivariada de dependência, utilizada para analisar a preferência de indivíduos por objetos que possuam os mesmos atributos (SILVEIRA, 2000).

Para Kotler (1995),

A pesquisa mais válida cientificamente é a experimental. Ela exige a seleção de grupos de assuntos (unidades experimentais) semelhantes, que são submetidos a 
tratamentos diferentes, ao controle das variáveis extrínsecas e à checagem se as diferenças entre as respostas observadas são estatisticamente significativas. $\mathrm{Na}$ medida em que as variáveis extrínsecas são eliminadas ou controladas, os efeitos observados podem ser relacionados às variáveis de tratamentos. O propósito da pesquisa experimental é capturar relacionamentos de causa-efeito, eliminando as explanações conflitantes das descobertas observadas (KOTLER,1995, p.234).

De acordo com Green e Srinivasan (1978), o principal objetivo de um estudo empírico é identificar uma combinação de métodos que maximizem o poder de predição do modelo, associado ao sempre escasso orçamento da pesquisa e a sua limitação temporal.

Ao longo dos anos, surgiram diversos trabalhos desenvolvendo 0 estudo da análise conjunta, mais propriamente a evolução de novos modelos e procedimentos para estimação dos parâmetros envolvidos na análise. A figura 6, adaptada de Green, Krieger e Schaffer (1993), oferece uma visão clara da evolução destes estudos e suas diferentes abordagens.

A parte extrema esquerda da figura 6 apresenta três técnicas estatísticas tradicionais para a análise do perfil completo de estímulos. $O$ principal método de estimação de parâmetros para esta abordagem é a MONANOVA (Monotonic analysis of variance) (KRUSKAL, 1965); para variáveis de resposta não-métricas, o modelo PREFMAP (CARROLL, 1973) e LINMAP (SHOCKER e SRINIVASAN, 1977). Mais do que isso, também se utilizam as regressões pelo Método de Mínimos Quadrados (M.M.Q.) para o ajuste dos parâmetros, nestes casos. 


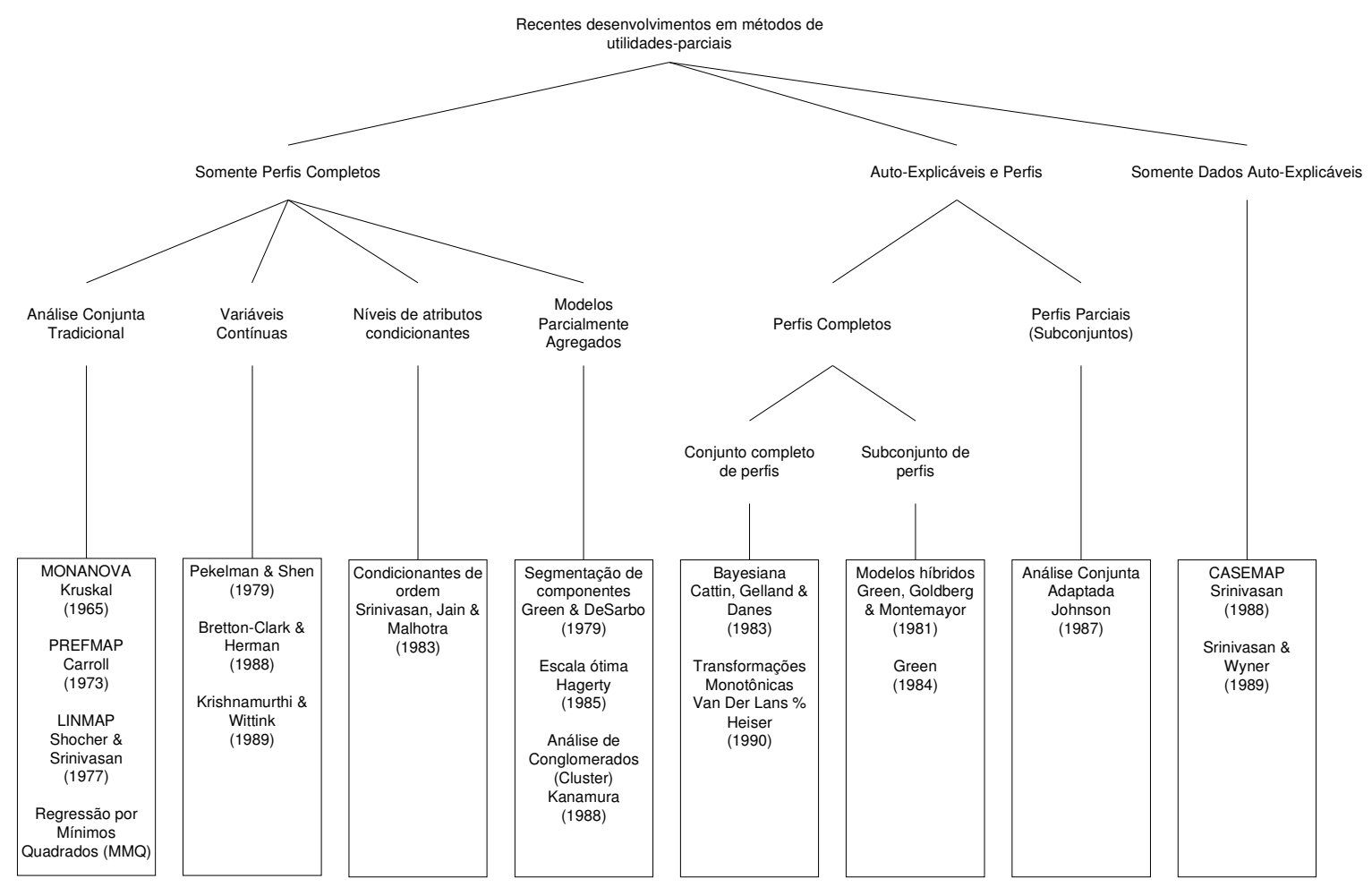

Figura 6: Recentes desenvolvimentos em métodos de utilidades-parciais.

Fonte: CARROL, J.D.; GREEN, P.E. (1995, p.386.)

Conforme Carroll e Green (1995), o modelo de perfil completo se beneficia das outras abordagens, por exemplo, alguns pesquisadores (HERMAN, 1988; KRISHNAMURTHI e WITTINK, 1989; PEKELMAN e SEM, 1979) expandiram a abordagem tradicional dos valores parciais por meio da inserção de parâmetros lineares e quadráticos aos valores parciais da função de utilidade. Ganhos na confiabilidade e na validade do modelo podem ser obtidos por meio de transformações monotônicas das utilidades-parciais (SRINIVASAN, JAIN e MALHOTRA, 1983) ou métodos de agregação (GREEN e DeSARBO, 1979; HAGERTY, 1985, KAMAKURA, 1988).

Segundo Battesini (2002), a análise conjunta é uma vasta e mal definida família de técnicas, que tem em comum a modelagem estatística das avaliações dos respondentes, em relação aos cenários experimentalmente projetados para produzir utilidades. 
A técnica da análise conjunta baseia-se na estimativa da função utilidade por meio da percepção dos entrevistados frente a estímulos obtidos através da pesquisa de campo. Esta função permite avaliar quais os cenários que mais agradam aos entrevistados e, através dela, calcular a utilidade de cada atributo representativo do produto ou serviço. Neste sentido, a função utilidade é melhor abordada na seção seguinte.

\subsubsection{A função utilidade na análise conjunta}

A utilidade é um valor que um determinado indivíduo pode atribuir a um produto ou serviço por meio de uma combinação de fatores, sendo que este valor seja máximo para a escolha realizada dentro de um conjunto de opções. A escolha discreta de produtos, por meio da análise de seus atributos determinantes, por exemplo, pode ser vista como função das características sócio-econômicas do consumidor, assim como da atratividade por ela exercida, quando comparada a qualquer outra e representa uma probabilidade.

A utilidade, quando quantificada matematicamente por meio da função de utilidade, permite exprimir preferências dos usuários. Ela é normalmente representada como um modelo linear do tipo aditivo (BEN-AKIVA E LERMAN, 1985, SMALL, 1992, APUD SCHIMITZ, 2001):

$$
U_{i n}=\sum_{k=1}^{k} \beta_{k} \cdot X_{i n}^{K}
$$

em que:

$U_{\text {in }}$ : representa a utilidade da alternativa $i$.

$X_{\text {in }}^{K}=\left[X_{\text {in }}^{1}+X_{\text {in }}^{2}+, \ldots,+X_{\text {in }}^{K}\right]$ : é o vetor de atributos ou fatores da alternativa i.

$\beta_{k}=\left[\beta_{1}, \beta_{2}, \ldots, \beta_{k}\right]$ : é um vetor de $k$ parâmetros, no qual cada

$\beta_{k}$ : denota a importância relativa, ou peso de cada atributo $k$.

A função utilidade devidamente ajustada permite:

- $\quad$ estabelecer a importância relativa entre atributos de interesse; 
- a determinação dos valores marginais de substituição entre os vários atributos e dinheiro, mesmo para aqueles de difícil quantificação;

- $\quad$ sua utilização na predição de modelos de demanda;

- determinação da elasticidade da demanda.

A utilidade em análise conjunta pode ser vista segundo duas abordagens:

- primeira abordagem: é aquela que considera simplesmente a utilidade das alternativas constantes ou fixas, sendo escolhida a alternativa que ofereça uma utilidade Ui maior que o valor de uma utilidade $U_{j}\left(U_{i}>U_{J}\right)$. Assim, a probabilidade de escolha de um respondente $(n)$ para uma dada alternativa $(I)$, em um conjunto de escolhas $\left(\mathrm{C}_{n}\right)$, com um número $(m)$ de alternativas, pode ser dada por uma expressão do tipo:

$$
P_{i n}=P\left(i / C_{n}\right)
$$

onde, $0 \leq P_{i n} \leq 1$ e $\sum_{1}^{m} P_{i n}=1$

- segunda abordagem: é considerado não apenas o aspecto determinístico, mas também as inconsistências comportamentais do indivíduo. Em geral, usuários, quando expostos a um mesmo conjunto de atributos, nem sempre tomam a mesma decisão, apresentando características mensuráveis de cada escolha diferente. Admite-se assim a existência de características da jornada que influenciam a escolha, mas que não são medidas ou possivelmente não-mensuráveis (SCHIMITZ, 2001). A escolha entre alternativas, representada pela expressão abaixo, é probabilística, em que a probabilidade de escolha do usuário $n$ para uma alternativa $i$, em um conjunto de escolhas $C_{n}$, com $m$ alternativas, pode ser dada pela expressão abaixo, considerando a parcela da probabilidade das utilidades menor do que a de escolha em função das inconsistências comportamentais. 


$$
P_{i n}=P\left(i / C_{n}\right)>P\left(U_{i n} \geq U_{j n}\right) \quad \text { para } i \neq j
$$

A utilidade pode ser representada ainda como um modelo linear aditivo de utilidades aleatórias, composto de duas parcelas distintas, de acordo com a seguinte expressão:

$$
U_{i n}=V_{i n}+\varepsilon_{i n}
$$

em que, $V_{\text {in }}$ representa a utilidade sistemática ou determinística.

$\varepsilon_{\text {in }}$ é a parcela aleatória ou desconhecida da utilidade que captura a dispersão de escolhas, que pode estar relacionada aos fatores não controláveis ou desconhecidos do modelador, tais como (BOVY e STERN, 1990, apud SCHIMITZ, 2001):

- $\quad$ atributos relevantes não incluídos na função utilidade;

- $\quad$ erros na medição dos atributos feitos pelo pesquisador;

- $\quad$ erros de percepção feitos pelo respondente;

- diferenças não observáveis na avaliação, etc.

Ao selecionar qual alternativa tem máxima utilidade, o pesquisador tem de atribuir uma probabilidade que considere o caráter da parcela de utilidade não observável (DALVI, 1978, HEGGIE, 1978, APUD SCHIMITZ, 2001). A probabilidade de que a alternativa $i$ é mais atrativa que as demais pode ser representada por uma expressão abaixo, que é a equação fundamental dos modelos de utilidade aleatória e que satisfaz as exigências da função escolha (DAGANZO, 1979, APUD SCHIMITZ, 2001).

$$
P\left(i / C_{n}\right)=P\left(U_{i n} \geq U_{j n}, \forall_{j} \in C_{n}\right)
$$


Aplicando a expressão 3.4 na expressão 3.5, temos:

$$
\begin{aligned}
& P\left(i / C_{n}\right)=P\left(V_{i n}+\varepsilon_{i n} \geq V_{j n}+\varepsilon_{j n}, \forall_{j} \in C_{n}\right) \\
& P\left(i / C_{n}\right)=P\left(V_{i n}-V_{j n} \geq \varepsilon_{j n}-\varepsilon_{i n}, \forall_{j} \in C_{n}\right)
\end{aligned}
$$

Como a diferença $\varepsilon_{j n}-\varepsilon_{i n}$ não é conhecida, o pesquisador não sabe se ela é maior, menor ou igual à diferença $V_{i n}-V_{j n}$; assim, poderá apenas sugerir uma probabilidade de ocorrência.

A forma funcional do modelo de utilidade aleatória depende da distribuição do erro $\varepsilon$ sobre a população e de suposições da aleatoriedade do mesmo. O componente estocástico, quando modelado por um conjunto de variáveis independentes e identicamente distribuídas, resulta no Modelo Logit Multinomial (MNL), representado pela expressão abaixo (DAGANZO, 1979, BEN AKIVA e LERMAN, 1985 e ORTUZAR, 1997, apud SCHIMITZ, 2001, p.103):

$$
P_{i n}=\frac{\exp \left(V_{i n}\right)}{\sum_{j \in C_{n}}^{J} \exp \left(V_{j n}\right)}
$$

A expressão 3.8 acima representa a probabilidade de escolha da alternativa $i$ pelo indivíduo $n$, considerando um conjunto de escolhas $C n$ que possui $J$ alternativas.

O pressuposto mais importante que se faz para o modelo é o da propriedade independência das alternativas irrelevantes (IIA), ou seja, a utilidade de uma alternativa não é influenciada por utilidades de quaisquer alternativas que estejam ou não dentro do conjunto de escolhas, ou a razão entre uma alternativa 1 e uma alternativa 2, por exemplo, deve permanecer constante, independentemente se alternativas existentes ou novas se apresentem ou não ${ }^{24}$.

\footnotetext{
${ }^{24} \mathrm{O}$ axioma de escolha de Luce declara que o processo de escolha de um indivíduo entre um determinado bem (p.ex. um produto da marca $A$ ) versus outro bem (p.ex. um produto da marca B) não é afetado pela presença ou ausência de alternativas (p.ex. um produto da marca $C$, ou
} 
3.2.2 Planejamento de um experimento em análise conjunta

Existem diversos métodos de análise conjunta, conforme foi apresentado na seção anterior. Independentemente do método, as pesquisas são planejadas para produzir um modelo de preferência que seja capaz de representar o comportamento do consumidor. Neste sentido, o tema implícito às pesquisas de análise conjunta é modelar o comportamento do consumidor.

Em função de suas características, uma pesquisa de análise conjunta deve ser cuidadosamente planejada. Boyd et al. (1989) e Kotler (2000), apud Battesini (2002), sugerem o uso do método científico em pesquisas de marketing.

Neste sentido, a estrutura de etapas de uma pesquisa de análise conjunta deve ser compatível com às do método científico de uma pesquisa de marketing e de um planejamento experimental, apresentando as diversas etapas de cada um destes experimentos, conforme aparece no quadro abaixo. Esta compatibilidade pode ser obtida a partir da integração das etapas já estabelecidas na literatura, representado no quadro 3, para as duas áreas de conhecimento que são a base de qualquer pesquisa de análise conjunta: Pesquisa de Marketing e Projeto de Experimento. A partir desta abordagem, é possível caracterizar um método que seja consistente com os diversos métodos de análise conjunta apresentados na literatura.

D) como escolhas potenciais. Este axioma é também conhecido como a propriedade da independência das alternativas irrelevantes (LUCE, 1977). 
Quadro 3: Etapas do Método Científico de uma Pesquisa de Marketing e de um Planejamento Experimental.

\begin{tabular}{|c|c|c|c|}
\hline \multirow[t]{2}{*}{ Etapas } & \multicolumn{3}{|c|}{ Métodos } \\
\hline & Método científico & Pesquisa de marketing & Planejamento experimental \\
\hline 1 & Definição do objeto de observação & - & - \\
\hline 2 & Observação do problema & $\begin{array}{l}\text { Definição do problema e dos objetivos } \\
\text { da pesquisa }\end{array}$ & $\begin{array}{l}\text { Identificação e estabelecimento do } \\
\text { problema } \\
\text { Escolha dos fatores e seus níveis }\end{array}$ \\
\hline 3 & Formulação de hipóteses & Desenvolvimento do plano de pesquisa & $\begin{array}{l}\text { Seleção da variável resposta } \\
\text { Escolha do projeto experimental }\end{array}$ \\
\hline 4 & Experimentação & Coleta de informações & Execução do experimento \\
\hline 5 & Análise de resultados experimentais & Análise das informações & Análise dos dados \\
\hline 6 & $\begin{array}{l}\text { Conclusão sobre a validade das } \\
\text { hipóteses }\end{array}$ & Apresentação das conclusões & Conclusões e recomendações \\
\hline 7 & $\begin{array}{l}\text { Generalizações a respeito das } \\
\text { conclusões }\end{array}$ & - & - \\
\hline
\end{tabular}

Fonte: Adaptado de Amaral (2000), SLONGO (2000), KOTLER (2000) E MONTGOMERY (1976) apud BATTESINI (2002, p.66)

Segundo Hair et al. (2005), o pesquisador deve tomar várias decisões-chave ao planejar o experimento e analisar seus dados. A figura 7 apresenta os passos gerais, seguidos no delineamento e execução de um experimento de análise conjunta.

O processo de decisão inicia com uma especificação dos objetivos da análise conjunta. Depois que os objetivos foram definidos, as questões relacionadas ao verdadeiro plano de pesquisa são abordadas e as suposições validadas. O processo de decisão então considera a real estimação dos resultados conjuntos, a interpretação dos resultados e os métodos usados para validar os resultados. 


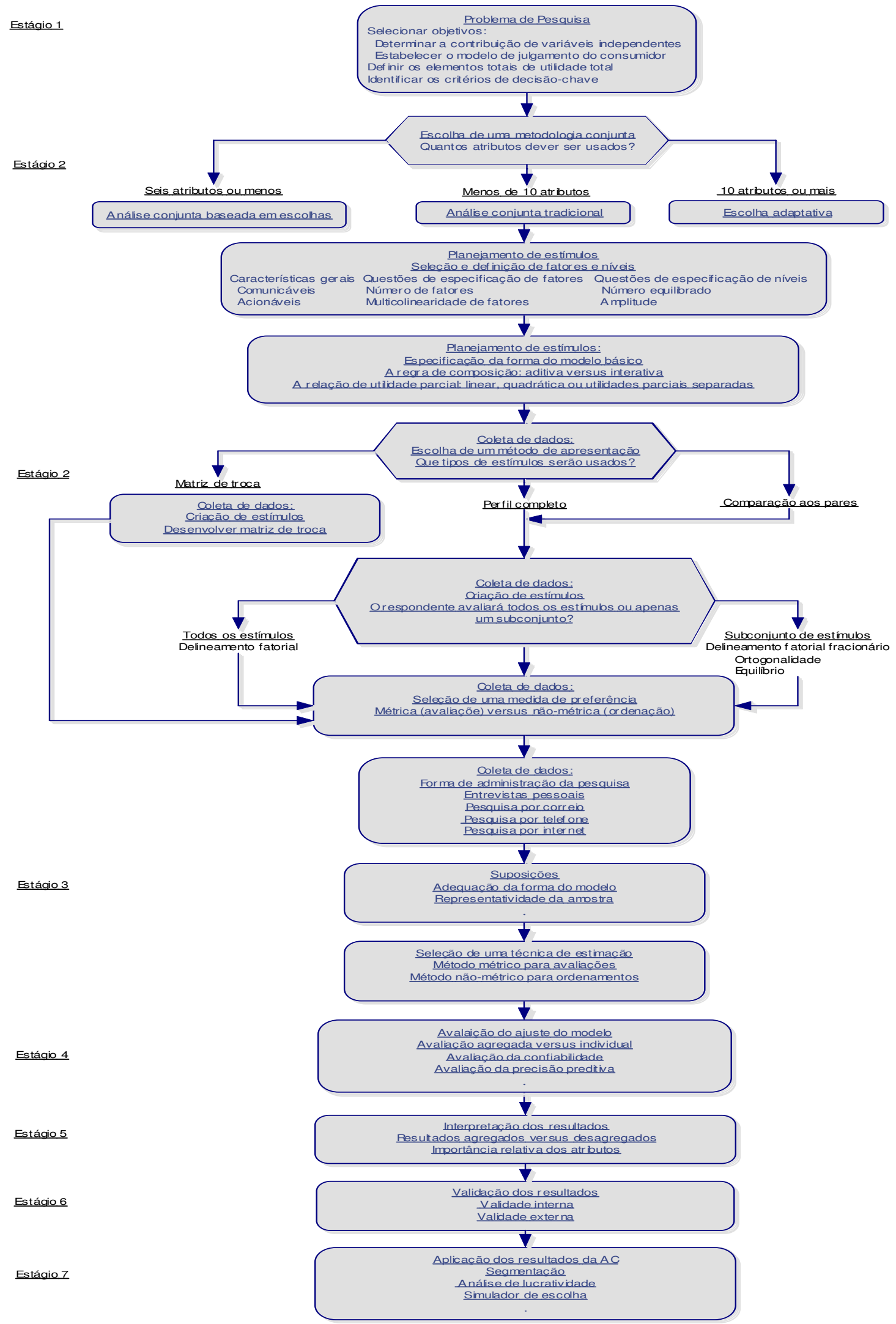

Figura 7: Estágios 1-7 do diagrama de decisão da análise conjunta.

Fonte: HAIR et al.(2004) 
3.2.2.1 Estágio 1: os objetivos da análise conjunta

Esta é uma etapa genérica a toda pesquisa de marketing, na qual é definida a necessidade do uso de uma pesquisa experimental como a análise conjunta como opção às outras análises multivariadas de dados. Uma vez estabelecido o problema de marketing, é preciso definir o problema de pesquisa e identificar com precisão o seu objetivo. Para isto, o pesquisador deve compreender a situação específica de marketing na qual o problema de marketing está inserido. Segundo Yin (1994), são necessários tempo e paciência para a definição da questão da pesquisa, uma vez que este é provavelmente o mais importante passo a ser dado.

O objetivo geral da análise conjunta é estimar um modelo de preferência, baseado nas importâncias de cada atributo, por meio das respostas dadas pelos respondentes aos estímulos apresentados (EVRARD et al., 1993, apud BATTESINI, 2002). O modelo gerado deve ser capaz de representar as preferências dos consumidores. Neste sentido, em pesquisas de análise conjunta, a variável de resposta é a sua preferência pelos produtos ou serviços, objeto da pesquisa.

Segundo Hair et al. (2005), em análise conjunta, o delineamento experimental na análise das decisões do consumidor tem dois objetivos:

- Determinar as contribuições de variáveis de predição e seus níveis na determinação de preferências do consumidor.

- Estabelecer um modelo válido de julgamentos do consumidor.

Assim, a questão de pesquisa deve ser contextualizada em torno de duas questões-chave. A primeira é se é possível descrever todos os atributos que conferem utilidade ou valor ao produto ou serviço em estudo. A segunda é determinar quais são os critérios-chave de decisão envolvidos no processo de escolha para esse tipo de produto ou serviço.

Essas questões precisam ser resolvidas antes de prosseguir para a fase de delineamento de uma análise conjunta, pois elas fornecem uma orientação fundamental para as decisões-chave em cada estágio. 
No estudo em questão, os atributos de utilidade ou valor foram determinados pela técnica do incidente crítico, enquanto os critérios-chave e o processo de escolha foram abordados na discussão sobre o comportamento do consumidor.

Nesta etapa, o pesquisador deve, primeiramente, se assegurar em definir a utilidade total do objeto. Para representar o processo de julgamento do respondente com precisão, todos os atributos que potencialmente criam ou destroem a utilidade geral do produto ou serviço dever ser incluídos (HAIR et al, 2005).

Apesar de a definição dos atributos e de seus níveis não ser tão complexa quanto as demais etapas do planejamento, ela é uma das mais importantes de uma pesquisa de análise conjunta (BATTESINI, 2002). Os atributos selecionados devem ser capazes de representar o objeto de pesquisa, além de influenciar a decisão de compra do consumidor. A incorreta seleção dos atributos pode determinar que os resultados da pesquisa não sejam válidos e, desta forma, não estejam adequados aos propósitos inicialmente estabelecidos.

Para Hair et al. (2005), a meta é incluir os fatores determinantes que diferenciam melhor o produto ou serviço, objeto de estudo. Muitos atributos podem ser importantes, mas também podem não diferenciar as escolhas.

Em alguns casos, o conhecimento anterior do gestor aliado ao do pesquisador é suficiente para selecionar os atributos e seus níveis. Na maioria das vezes, este raciocínio é uma tarefa arriscada que pode levar a resultados incorretos. Uma pesquisa qualitativa preliminar, por meio de questionamentos aos clientes sobre quais são os atributos que melhor identificam o produto, ou serviço, é de particular utilidade nesta fase (GREEN e SRINIVASAN, 1978). Este procedimento tende a produzir uma maior robustez nos resultados obtidos. 
3.2.2.2 Estágio 2: o projeto de uma análise conjunta

Resolvida a questão relativa ao objetivo da pesquisa, o pesquisador passa a analisar questões específicas no delineamento e execução do experimento de análise conjunta.

O ponto inicial é definir qual dentre os diversos métodos conjuntos alternativos deve ser escolhido. Com o tipo de modelo selecionado, o pesquisador especificará as combinações (estímulos), que atributos incluir, com quantos e quais os níveis para cada atributo, como medir a preferência e coletar os dados, e qual o procedimento de estimação a ser empregado (HAIR et al, 2005).

Depois que o pesquisador determinou os atributos básicos que constituem a utilidade do produto ou serviço (objeto), uma questão fundamental dever ser resolvida: Qual metodologia básica de análise conjunta, a saber: tradicional, adaptativa ou baseada em escolha, deve ser utilizada?

Os critérios usados para definição da metodologia levam em consideração três principais variáveis:

- $\quad$ Número de atributos

- $\quad$ Nível de análise

- Forma do modelo

Quadro 4: Uma comparação de metodologias conjuntas alternativas.

\begin{tabular}{|lccc|}
\hline \multicolumn{1}{|c}{ Característica } & \multicolumn{3}{c|}{ Metodologia conjunta } \\
\cline { 2 - 4 } & Tradicional & Adaptativa & Baseada em escolha \\
\hline Número máximo de atributos & 9 & 30 & 6 \\
Nível de análise & Individual & Individual & Agregada \\
Forma do modelo & Aditiva & Aditiva & Aditiva+efeitos de interação \\
\hline
\end{tabular}

Fonte: HAIR et al (2005)

O quadro 4 compara as três metodologias em relação a estas variáveis. A análise tradicional é caracterizada por um modelo aditivo simples que contém até nove fatores estimados para cada indivíduo.

O método adaptativo foi desenvolvido para acomodar um grande número de fatores (muitas vezes, acima de 30) que não seriam praticáveis na 
análise conjunta tradicional (HAIR et al, 2005). A terceira metodologia, a abordagem baseada em escolha, não apenas emprega uma única forma para apresentar os estímulos, como também difere no sentido de incluir interações diretamente e, portanto, deve ser estimada em nível agregado.

Com a metodologia, o número de atributos, a forma do modelo e o nível de análise definidos, o pesquisador deverá planejar os estímulos ou conjunto de atributos representativos de produtos ou serviços reais ou hipotéticos para proceder a coleta de dados.

Do ponto de vista teórico, devem ser selecionados fatores relevantes em relação a sua influência na escolha do consumidor. Do ponto de vista administrativo, os fatores devem ser manejáveis, por exemplo, não adianta concluir que os consumidores preferem um automóvel esporte ao invés de um conservador, ao menos que os automóveis sejam definidos em termos de fatores sobre os quais o administrador tem controle, tais como com/sem tração nas quatro rodas ou tipo de pintura (MALHOTRA, 2001).

O pesquisador deve levar em consideração que uma quantidade muito grande de fatores gera uma quantidade grande de estímulos, o que confunde os respondentes e pode afetar a eficiência estatística e a validade dos resultados (BITTENCOURT, 1999). Três regras podem ser utilizadas para identificar quais fatores incluir na pesquisa de análise conjunta:

1. escolher fatores importantes para o respondente em situação de compra,

2. escolher fatores que ainda possam ser alterados (dependendo do estágio de planejamento do produto) e

3. escolher fatores que sejam facilmente comparados com os de produtos concorrentes.

Na busca de um número razoável de fatores, o pesquisador deve ter em mente o pouco tempo que os respondentes estão dispostos a gastar analisando os estímulos. Em análise conjunta, normalmente limita-se o número de fatores a seis ou um pouco menos, desta forma, a sua aplicação é mais apropriada nas fases finais do desenvolvimento de um novo produto ou serviço. 
Pesquisas com nove ou mais fatores podem ser extensas e cansativas, sendo comum a utilização de algum elemento de motivação, como um brinde.

Ao incluir o preço como atributo, o pesquisador deve considerar que ele não se relaciona da mesma forma que os demais fatores, o que pode levar o pesquisador a utilizar um método de análise conjunta capaz de modelar interações. Quando o preço é utilizado como atributo, ele possui um alto grau de correlação com outros fatores, podendo levar a estímulos irreais (muito caros ou baratos quando comparados com os do mercado), além de interagir com fatores intangíveis como a marca (HAIR et al, 2005).

Segundo Green e Srinivasan (1990), a correlação ou multicolinearidade entre fatores não acontece em função da combinação propriamente dita dos fatores, mas pelo fato de algumas combinações gerarem estímulos irreais. A correlação pode ser positiva ou negativa.

Um exemplo de correlação negativa ocorre quando, num caso hipotético de um carro, os fatores potência, em seu nível alto, e consumo de combustível, em seu nível baixo, aparecem no mesmo cenário. Para resolver este problema, podem ser utilizadas duas abordagens.

A primeira seria a inclusão de "superatributos" para substituir conceitualmente aqueles fatores que estão correlacionados, como por exemplo, os fatores potência e consumo de combustível podem ser substituídos pelo "superatributo" desempenho do veículo. $\mathrm{Na}$ segunda abordagem, o pesquisador exclui os estímulos irreais, renunciando os conceitos de ortogonalidade, tolerando assim que alguns fatores estejam correlacionados ${ }^{25}$.

Segundo Johnson et al. (1998), apud Green e Srinivasan (1990), as correlações negativas normalmente ocorrem no mercado, pois na prática não existem produtos que dominem totalmente os demais, uma vez que, quando um produto é superior em um atributo, é provável que ele seja inferior em algum outro. Segundo Green e Srinivasan (1990), a presença de correlações entre fatores por si não viola as hipóteses da análise conjunta, pois não é

\footnotetext{
${ }^{25}$ Ortogonal: independência matemática (sem correlação) de eixos fatoriais um em relação ao outro (ou seja, em ângulos retos) (HAIR et al., 2005).
} 
assumida a hipótese de que as variáveis independentes (fatores) são perfeitamente ortogonais.

Os níveis de um fator são os diferentes modos de presença dos fatores no estudo e se referem às quantidades ou qualidades específicas dos fatores. Eles são selecionados a partir da identificação das faixas de variação críticas dos fatores. Para Hair et al. (2005), além de acionáveis e comunicáveis, a pesquisa tem mostrado que o número de níveis, o equilíbrio de níveis entre fatores e os intervalos dos fatores têm efeitos diferentes sobre as avaliações dos respondentes.

A qualidade das conclusões da pesquisa depende da inclusão somente dos níveis necessários. Devido à sobrecarga no número de estímulos, a qualidade dos dados pode diminuir, sendo necessário aumentar o número de respondentes que avalia determinado conjunto de estímulos. Este aumento do número de respondentes pode gerar uma menor confiabilidade nas estimativas.

Os níveis dos fatores devem ser viáveis e ter relevância prática. Eles podem ser fixados em intervalos um pouco maiores do que os normalmente encontrados na prática, desde que não produzam estímulos irreais. Segundo Malhotra (2001), a utilização de níveis de fatores que estejam fora do intervalo normalmente encontrado no mercado diminui a credibilidade da pesquisa, mas aumenta a precisão da estimativa dos parâmetros.

Deve ser dada uma atenção quando o número de níveis entre fatores não é balanceado, uma vez que um número maior de níveis de um atributo, em relação aos demais, pode influenciar na importância atribuída pelo respondente àquele atributo $\mathrm{e}$, desta forma, levar a um aumento irreal no valor das utilidades parciais (HAIR et al, 2005). Entretanto, se a importância relativa de fatores é conhecida a priori, o pesquisador pode expandir os níveis dos fatores mais importantes para evitar uma diluição de importância e capturar informação adicional sobre os fatores mais importantes (WITTINK et al, 1992 apud HAIR et al., 2005).

Com a finalidade de explicar a estrutura de preferência de um respondente a partir de avaliações gerais de um conjunto de estímulos, o pesquisador deve tomar outras duas decisões-chave referentes ao modelo de 
análise. A primeira decisão é definir a regra de composição, e a segunda, selecionar a relação de utilidades parciais.

Segundo Sheth et al. (1999), apud Battesini (2002), os respondentes normalmente adotam estratégias para reduzir o seu esforço quando estão diante de um processo de decisão. Ao definir sobre a regra de composição, o pesquisador deve considerar dois aspectos.

O primeiro é que, em função do número de estímulos a serem avaliados e da quantidade de tempo disponível para a pesquisa, os respondentes podem utilizar comportamentos compensatórios ou nãocompensatórios. O segundo é que, em função do seu grau de conhecimento sobre o objeto da pesquisa, os respondentes podem ter maior ou menor facilidade nas suas avaliações.

A regra de composição adotada para analisar a estrutura de preferência pode ser simplesmente aditiva ou então também incluir efeitos de interação. Nesta etapa, o pesquisador deve, com base no conhecimento adquirido nas etapas anteriores, estimar qual é a regra de composição mais adequada para modelar as preferências dos consumidores.

O modelo aditivo é regra de composição mais comum, com o qual o respondente "soma" as utilidades parciais de cada atributo para obter o valor total de um conjunto de atributos (o produto, ou serviço propriamente dito). (HAIR et al, 2005)

Quando é utilizado o modelo aditivo, é necessário um número menor de estímulos para avaliar as utilidades parciais do que quando o modelo inclui efeitos de interação. Neste sentido, a necessidade de avaliar efeitos de interação reduz o grau de fracionamento possível do número total de estímulos (BATTESINI, 2002; HAIR et al., 2005)

Quanto às relações entre os seus níveis, conforme a figura abaixo, elas podem ser:

- Linear;

- Quadrática; ou

- Utilidade parcial. 


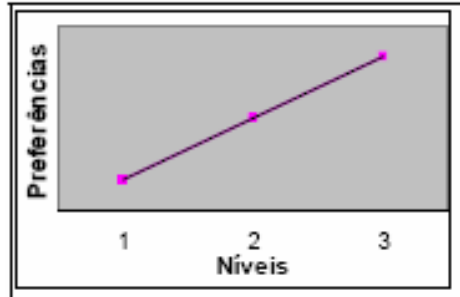

Linear

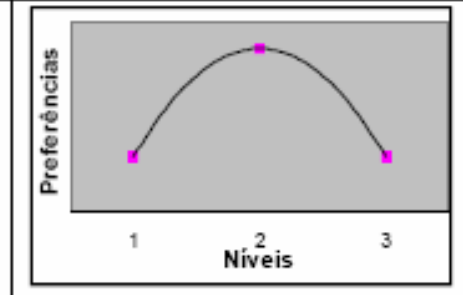

Quadrático ou Ideal

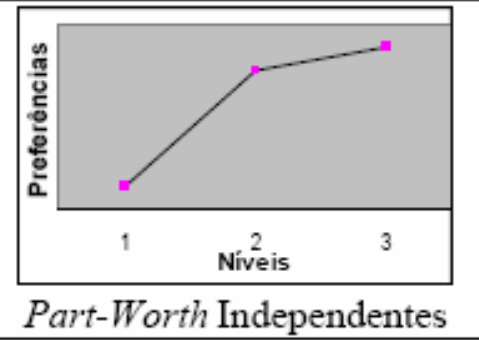

Part-Worth Independentes

Figura 8: Os três tipos básicos de relações entre níveis fatoriais em análise conjunta.

Fonte: HAIR et al. (2005)

Para Battesini (2002), quando é assumido um relacionamento linear, é gerado um único coeficiente para todos os níveis de determinado fator, sendo suficiente investigar apenas dois níveis. Já a estimação de efeitos do tipo utilidade parcial separada exige mais de dois níveis de cada atributo, sendo que é gerada uma utilidade parcial diferente para cada um dos níveis de determinado atributo.

A investigação de relacionamentos do tipo utilidade parcial pode ser útil, quando o efeito dos níveis dos atributos se comporta de forma instável (crescente e decrescente). Com o uso de relacionamentos do tipo utilidade parcial, a capacidade de estimação do modelo pode ser melhorada, porém é necessária a existência de graus de liberdade suficientes ${ }^{26}$. Esta definição deve ocorrer antes da etapa de definição da estimulação da coleta de dados, uma vez que o número de parâmetros a ser estimado interfere na definição do número de cenários.

A última etapa do estágio de projeto da análise conjunta é transmitir ao respondente as combinações de atributos (estímulos) da maneira mais realista e eficiente possível, ou seja, a coleta de dados. Neste sentido, a estimulação a ser utilizada na coleta de dados envolve a definição da

${ }^{26}$ Graus de liberdade - Valor calculado a partir do número total de observações menos o número de parâmetros estimados. Essas estimativas de parâmetros são restrições sobre os dados porque, uma vez calculadas, definem a população da qual se supõe que os dados tenham sido extraídos. Os graus de liberdade nos dão uma medida de quão restritos estão os dados para alcançar certo nível de previsão (HAIR et al., 2005) 
combinação dos atributos para a composição dos estímulos, da escala de resposta e do método de apresentação dos estímulos.

Os métodos de apresentação mais amplamente utilizados na pesquisa de análise conjunta, conforme ilustrado na tabela abaixo, são: matriz de troca (escolha), perfil completo e comparação aos pares.

Tabela 5: Comparação dos métodos de apresentação na análise conjunto, pela variável resposta.

\begin{tabular}{lcc}
\hline Método de apresentação & \multicolumn{2}{c}{ Métodos } \\
\cline { 2 - 3 } & Científico & Não-métrica \\
\hline Perfil completo & $\mathrm{x}$ & $\mathrm{x}$ \\
Matriz de escolha & $\mathrm{x}$ & $\mathrm{x}$ \\
Combinação entre pares & $\mathrm{x}$ & $\mathrm{x}$ \\
\hline
\end{tabular}

Fonte: GOUVEA, M. (2003)

A matriz de escolha compara os atributos aos pares, classificando todas as combinações de níveis. Suas vantagens são: facilidade de apresentação e administração, já que são apresentados apenas dois atributos por vez. Entre suas limitações tem-se: (1) sacrifício do realismo em função de apresentar apenas dois fatores por vez, (2) grande número de julgamentos, (3) tendência à confusão dos respondentes, (4) falta de habilidade de empregar estímulos pictóricos, (5) uso somente de respostas não-métricas, (6) falta de capacidade de usar delineamentos fatoriais fracionários para redução do número de comparações.

O método do perfil completo é o mais popular entre os três, pelo seu realismo e habilidade de reduzir o número de estímulos pelo uso do delineamento fatorial fracionário. Suas principais vantagens são, além das citadas: uma descrição mais explícita das trocas entre os diversos fatores, possível uso de mais tipos de julgamentos de preferência, como intenções de compra, chances de troca, uso experimental. Entre suas limitações tem-se: o número elevado de fatores, que dificulta a administração dos estímulos e torna cansativo o processo de entrevista, quando pessoal, e a ordem na qual são apresentados os estímulos, que pode ter impacto na avaliação dos respondentes. 
Por último, o método de combinação entre pares combina os dois métodos anteriores, no qual dois perfis incompletos são comparados e a resposta é a intensidade com que um perfil é preferido ao outro (GOUVEA, 2003).

Definido o método de apresentação, o pesquisador passa para a etapa de construção dos estímulos. Ao definir a estimulação, é necessário que o pesquisador compreenda qual o seu impacto nas etapas seguintes, já que a coleta e a análise dos dados ficarão condicionadas a estas decisões.

Segundo Battesini (2002), especialmente nesta etapa, o pesquisador deve ter em mente a perspectiva do respondente, uma vez que estará definindo o nível de complexidade ao qual o respondente será submetido. O nível de complexidade influencia a consistência (confiabilidade) das respostas e depende do tipo e do número de cenários a serem avaliados.

A escala de medida é um instrumento utilizado pelo pesquisador para converter as preferências (variável de resposta) em avaliações. Ao definir a escala de medida da variável de resposta, o pesquisador precisa ter em mente a perspectiva do respondente, uma vez que o tipo de variável de resposta adotado interfere no esforço ao qual o respondente será submetido, no realismo da situação de pesquisa e na análise dos dados.

Segundo Hair et al. (2005), o pesquisador deve escolher entre ordenação ou avaliação. Apesar de o método de troca empregar apenas dados de ordenação, a comparação aos pares pode avaliar a preferência, obtendo uma avaliação de preferência de um estímulo sobre outro ou apenas uma medida binária (medida de dois elementos, por exemplo, 0 ou 1, sim ou não) do qual é preferido. O método do perfil completo acomoda as duas formas de medida.

Cada medida de preferência possui vantagens e limitações. Quando o pesquisador opta pela ordenação, deve considerar que esta é uma medida confiável, pois é mais fácil do que a avaliação quando o número de estímulos é pequeno (inferior a 20) e ela fornece maior flexibilidade para estimar diferentes regras de composição (aditiva ou efeitos de interação). Por outro lado, não se deve esquecer que é uma medida de difícil administração, pelo fato de exigir o 
processo de entrevistas individuais, que consistem num processo mais demorado e custoso em relação aos outros meios de coleta de dados, por exemplo, pesquisas por correio, ou internet.

Sempre que possível, deve ser dada preferência às entrevistas pessoais. Desta forma, o respondente pode contar com o auxílio do entrevistador para elucidar alguma dúvida e, neste sentido, podem ser mais facilmente contornadas deficiências em relação ao entendimento do instrumento de coleta de dados.

Nos casos em que o meio de contato é telefônico ou postal, o pesquisador deve dar atenção especial em relação à complexidade do instrumento de coleta de dados. Um instrumento de coleta complexo pode ocasionar dificuldades no seu preenchimento, afetando a taxa de retorno e a confiabilidade da pesquisa.

Para estes meios de contato com os respondentes, Hair et al. (2005) sugerem o uso da avaliação de preferência por escalas métricas. Elas são facilmente analisadas e administradas, mesmo por correio, e permitem que a análise conjunta seja realizada por regressão multivariada.

Nos casos de grande número de estímulos, em que também se recomenda o uso de medidas métricas, é útil expandir a categoria de respostas em relação ao que se vê na maioria de entrevistas a clientes (por exemplo, escalas do tipo Likert de 1 a 5). Uma norma prática é ter 11 intervalos para a escala de medida (ou seja, avaliar 0-10, 0-100, com incrementos de 10) quando o experimento possuir 16 ou menos estímulos. Caso o experimento apresente mais de 16 estímulos, o pesquisador deve expandir a escala para 21 intervalos (LOUVIERE et al, 1988, apud HAIR et al., 2005).

\subsubsection{Estágio 3: pressupostos da análise conjunta}

O estágio 3 apresenta as hipóteses ou pressupostos estatísticos da análise conjunta. Dentre as técnicas de análise multivariada, a análise conjunta é a que apresenta o menor conjunto restritivo de pressupostos que envolvem a estimação do modelo conjunto. 
Segundo Gouvêa (2003), não há a necessidade de testes estatísticos para a normalidade, a homocedasticidade e a independência, geralmente realizados para outras técnicas de dependência ${ }^{27}$.

Ainda que tenha menos restrições estatísticas, os pressupostos conceituais da análise conjunta são, talvez, em maior número do que em qualquer outra técnica multivariada.

O planejamento de uma análise conjunta deve ser coerente com a forma do modelo considerada. Isso "sustenta" essa decisão e torna impossível testar modelos alternativos logo que a pesquisa é delineada e os dados coletados (GOUVEA, 2003; HAIR et al., 2005).

3.2.2.4 Estágio 4: estimação do modelo da análise conjunta e qualidade do ajuste

Hair et al. (2005) sustentam que as opções disponíveis ao pesquisador em termos de técnicas de estimação aumentaram dramaticamente nos últimos anos, em conjunção com métodos especializados de apresentação de estímulos (por exemplo, análise conjunta adaptativa ou a análise conjunta baseada em escolhas).

O pesquisador, dependendo da escala da variável resposta, se por ordenação ou medida métrica de preferência (avaliação), deverá optar por determinada técnica de estimação.

27 Normalidade: Esse pressuposto é chave para toda a estatística paramétrica. Contudo, quando a amostra for suficientemente grande $(n>30)$, dependendo do formato da distribuição, o Teorema Central do Limite garante a convergência da média amostral para a normalidade. Homocedasticidade ou igualdade de variâncias: Este pressuposto exige que o nível de dispersão da variável dentro dos grupos seja similar.

Independência: Este pressuposto é chave para a maioria das estatísticas. Isto significa que o resultado de uma observação não interfere no resultado de outra observação. Já esse pressuposto é quebrado para amostras relacionadas. Neste caso, deve-se utilizar o teste para dados emparelhados, ou ANOVA (análise de variância) com medidas repetidas (HAIR et al., 2005). 
As medidas de preferência definidas por ordenações de estímulos exigem uma forma modificada da análise de variância especificamente planejada para dados ordinais. Entre os programas de computador mais populares e conhecidos estão o MONANOVA (análise monotônica de variância) $^{28}$ (JOHNSON, 1975; KRUSKAL, 1965 apud HAIR et al., 2005) e o LINMAP (SCHOECKER e SRINIVASAN, 1977 apud HAIR et al., 2005).

Estes programas fornecem estimativas de utilidades parciais de atributos, de modo que a ordem de classificação de sua utilidade total para cada tratamento está correlacionada tanto quanto possível com a ordem observada.

Para os casos de medidas métricas de preferência, muitos métodos, inclusive a regressão múltipla, podem estimar as utilidades parciais para cada nível de fator (HAIR et al. 2005). Em ambos os casos, qualquer tipo de relação, seja linear, ponto ideal (quadrática) ou utilidade parcial, pode ser estimada.

Para a avaliação da qualidade de ajuste, Hair et al. (2005) e Gouvêa (2003) consideram que os resultados da análise conjunta podem ser avaliados em precisão tanto em nível individual quanto agregado. O objetivo neste caso é avaliar o quão consistente é o modelo em prever o conjunto de avaliações de preferência dado por cada respondente. A avaliação da qualidade do modelo difere para respostas métricas (avaliação) e não-métricas (ordenamentos).

Testes estatísticos não-paramétricos podem ser utilizados para esta avaliação de respostas não-métricas ou ordenamentos. Os modelos nãoparamétricos implicam ordenação ascendente das variáveis, sendo suas principais vantagens o fato de as variáveis não dependerem da distribuição da população e não serem afetadas pela presença de valores aberrantes. $\mathrm{Na}$

28 MONANOVA (análise monotônica de variância) é um procedimento de transformação de dados em experimentos fatoriais. Ele busca por todas as transformações monotônicas crescentes (ou seja, crescente durante todo o intervalo de transformação) dos dados e entrega aquela considerada a "melhor", isto é, a transformação monotônica que resulta na maior porcentagem de variância gerada pelos efeitos principais. 
análise estatística, são utilizados o coeficiente de correlação de Spearman e a regressão de Kendall.

O grau de associação entre duas variáveis é observado a partir da análise de correlação. A correlação de Spearman baseia-se na ordenação de duas variáveis sem qualquer restrição quanto à distribuição de valores. $O$ primeiro passo é a ordenação de uma variável e o segundo, a transformação dos valores absolutos em valores ordenados.

As diferenças entre dois postos (previstos e observados), di, são calculadas, e o coeficiente de correlação, $R$, é determinado por meio da expressão abaixo:

$$
R=1-\frac{6 \cdot \sum_{i=1}^{n} d_{i}^{2}}{n \cdot\left(n^{2}-1\right)}
$$

Neste caso, queremos altos valores para estes coeficientes, já que eles representam a correlação entre os postos previstos e os postos observados, demonstrando assim a qualidade do ajuste do modelo. A regressão de Kendall assume que uma série de pontos $(X 1, Y 1)$, (X2, Y2)... $(X n, Y n)$, é ajustada para uma reta, expressão abaixo, com a forma:

$$
Y=b \cdot X+a
$$

É análoga à regressão linear paramétrica, mas com ordenada na origem e coeficiente angular calculado a partir da transformação das variáveis ordenadas. O primeiro passo consiste na ordenação dos valores da variável $X$ por ordem crescente, para $n$ observações. O coeficiente de inclinação da reta, $b_{i j}$, é determinado para cada par de valores de $X_{i}$ e $X_{j}$.

$$
b_{i j}=\frac{Y_{j}-Y_{i}}{X_{j}-X_{i}}
$$

em que $i$ varia de 1 a $n-1$ e $j>i$. O coeficiente de inclinação da reta, $b$, é a mediana dos valores $b_{i j}$. 
A ordenada de cada par de valores $\left(X_{i}, Y_{i}\right), a_{i}$ é determinada utilizando-se a expressão:

$$
a_{i}=Y_{i}-b \cdot X_{i}
$$

A ordenada na origem, $a$, é a mediana dos valores $a_{i}$. Este método tem três vantagens distintas relativamente ao método paramétrico: não assume que todos os erros ocorrem na direção de $Y$; não assume que todos os erros são normalmente distribuídos e o resultado não é afetado pela presença de valores aberrantes.

Se uma classificação métrica é obtida, então o coeficiente de correlação de Pearson simples, como a utilizada em regressão, é adequado juntamente com uma comparação entre as classificações reais e previstas.

O índice $r^{2}$ de Pearson é um índice que descreve o quanto um conjunto de dados pode representar ou ter um comportamento de uma reta. A relação linear entre duas variáveis pode ser indexada por um único número, o coeficiente de correlação de Pearson, indicado pela letra $r$.

Este coeficiente indica o grau de vínculo e a direção da relação entre duas variáveis, podendo variar de -1 (relação perfeitamente negativa) a 1 (relação perfeitamente positiva). ${ }^{29}$ Neste caso, queremos altos valores para estes coeficientes, já que eles representam a correlação entre os postos previstos e os postos observados, demonstrando assim a qualidade do ajuste do modelo.

\footnotetext{
${ }^{29}$ Coeficiente de correlação $(r)$ - Coeficiente que indica a força de associação entre quaisquer duas variâncias métricas.

Coeficiente de determinação $\left(R^{2}\right)$ - Medida da proporção da variância da variável dependente em torno de sua média, que é explicada pelas variáveis independentes ou de predição. Se o modelo de regressão é propriamente aplicado e estimado, o pesquisador pode assumir que, quanto maior o valor de $R^{2}$, maior o poder de explicação da equação de regressão e, portanto, melhor a previsão da variável independente. (HAIR et al., 2005)
} 
Segundo Gouvêa (2003), estímulos validação ${ }^{30}$ (ou amostra holdout) são utilizados para respondentes para estimar a qualidade do ajuste. Isso ocorre porque, na maioria dos experimentos conjuntos, o número de estímulos não excede substancialmente a quantia de parâmetros, e sempre existe potencial para "super-ajustar" os dados. A amostra de validação permite ao pesquisador uma oportunidade para uma avaliação direta de estímulos de interesse para o estudo da pesquisa.

\subsubsection{Estágio 5: interpretação dos resultados}

O estágio 5 do método de análise conjunta apresenta a interpretação dos resultados do experimento. Para isso, dois tópicos principais são abordados: a análise agregada versus a desagregada e a avaliação da importância relativa dos atributos. A análise conjunta permite que as utilidades parciais sejam calculadas em nível:

- individual (desagregado),

- agregado e

- $\quad$ agregado por estrato.

A abordagem mais comum nos estudos de análise conjunta, segundo Hair et al. (2005), é a individual, na qual cada respondente é modelado separadamente. Ela é mais precisa, mas também é de difícil uso por parte dos gerentes no desenvolvimento das estratégias de marketing.

A análise agregada falha ao não reconhecer a heterogeneidade das preferências dos indivíduos, uma vez que é gerado um único modelo para representar todos os indivíduos. Na análise em nível agregado por estrato, é gerado um modelo para representar a preferência de um grupo de indivíduos. Quando a análise ocorre por estrato, os modelos possuem uma melhor

\footnotetext{
${ }^{30}$ Estímulos de validação (ou amostra holdout) - Conjunto de estímulos que são usados na estimação das utilidades parciais (HAIR et al., 2005)
} 
capacidade de previsão (CHURCHILL e NIELSEN, 1996 apud BATTESINI, 2002).

Segundo Malhotra (2001), quando a análise ocorre em nível agregado sem prévia determinação dos estratos, é preciso estabelecer uma estratégia para agrupar os respondentes. Uma abordagem comum consiste em estimar modelos em nível individual e após agrupar os respondentes com base na semelhança de suas utilidades parciais.

Para Hair et al. (2005), o pesquisador deve considerar o propósito do estudo ao escolher o nível de análise, uma vez que ele deve optar entre a clareza dos modelos agregados e a precisão dos métodos desagregados. A análise em nível agregado proporciona meios de reduzir a tarefa dos respondentes, uma vez que cada um pode ser solicitado a responder apenas uma parte dos estímulos e a estimação de interações. ${ }^{31}$

Como as estimativas de utilidades parciais geralmente são convertidas em uma escala comum, a maior contribuição para a utilidade geral - e, portanto, o fator mais importante - é o fator com a maior amplitude. ${ }^{32}$

Segundo Gouvêa (2003), a razão entre os valores absolutos da amplitude das suas utilidades parciais e a soma dos valores absolutos das utilidades parciais de todos os fatores representa o valor da importância de cada fator numa escala percentual. Isso viabiliza a comparação entre os respondentes em uma escala comum, bem como dá significado à magnitude do escore de importância.

${ }^{31}$ Estímulo - Conjunto específico de níveis (um por fator) avaliado pelos respondentes (também conhecido como tratamento). Um método de definir estímulos (delineamento fatorial) é obtido considerando-se todas as combinações possíveis de todos os níveis.

Efeitos de interação - Efeitos de uma combinação de características relacionadas, também conhecidas como termos de interação. (HAIR et al., 2005)

${ }^{32}$ Utilidade Parcial - Estimativa da análise conjunta da preferência ou utilidade geral associada a cada nível de cada fator usado para definir o produto ou serviço. 
3.2.2.6 Estágio 6: validação dos resultados

Os resultados de um experimento de análise conjunta podem e devem ser validados interna e externamente (GOUVEA, 2003). A validação interna abrange a confirmação de que a regra de composição selecionada (aditiva ou com efeitos de interação) é apropriada ao modelo em estudo. Neste caso, o uso de estímulos de validação, ou amostra holdout, para avaliar a precisão de predição para a amostra individual ou no nível agregado, é uma saída apropriada.

Hair et al. (2005) apontam que a validação externa envolve a habilidade da análise conjunta em prever escolhas reais; em termos específicos, isto significa a questão da representatividade da amostra. A despeito disso, o amplo uso e estudo da análise conjunta pouco têm se desenvolvido no âmbito da validação da representatividade da amostra.

Apesar de não haver avaliação do erro de amostra nos modelos de nível individual, e nem faz sentido, pois o indivíduo é a própria população, o pesquisador deve, nos estudos agregados, garantir que a amostra seja representativa da população do estudo. Para Gouvêa (2003), isto é particularmente importante quando o uso da análise conjunta servirá para fins de segmentação e simulação.

\subsubsection{Usos e aplicações gerenciais}

Resultados de experimentos conjuntos agregados podem representar grupos de indivíduos e fornecer um meio de prever suas decisões para inúmeras situações reais de mercado; enquanto que, com os resultados no nível individual, as preferências individuais podem ser empregadas empiricamente. Assim, os modelos conjuntos são empregados em uma série de áreas de suporte à decisão. As aplicações mais comuns da estrutura de preferência do cliente incluem:

- Segmentação: as utilidades parciais conjuntas estimadas são usadas sozinhas ou em combinação com outras variáveis (como 
as variáveis ambientais e sócio-demográficas) para deduzir agrupamentos de respondentes;

- Análise de lucratividade: sabendo-se o custo de cada nível de fatores aplicados num experimento conjunto, pode-se, a partir dos resultados de preferência, e combinando com a participação do mercado e o volume de vendas esperados, prever a viabilidade de um produto ou serviço.

- Simulação: o papel de um simulador de escolha é permitir ao pesquisador responder a seguinte pergunta: o que aconteceria se o produto ou serviço [...]?, para prever a participação de preferência que um estímulo, real ou hipotético, está apto a capturar em cenários competitivos de mercado. Para isso, Gouvêa (2003) apresenta três passos principais a serem seguidos:

- Estimar e validar modelos conjuntos para cada respondente ou grupo de respondentes;

- Selecionar um conjunto de estímulos para testar, de acordo com os cenários competitivos;

- Simular as escolhas de todos os respondentes ou grupos para conjuntos específicos de estímulos e predizer o share (a fatia) de preferência para cada estímulo pela agregação das escolhas.

Com o propósito de testar a praticidade do conjunto de procedimentos apresentados neste capítulo, a contribuição metodológica é aplicada no caso específico de um hotel de categoria econômica no interior de São Paulo, visando atribuir o valor percebido pelos clientes do hotel aos serviços oferecidos. 


\section{UMA APLICAÇÃO NA INDÚSTRIA HOTELEIRA}

Este capítulo tem por objetivo considerar a aplicabilidade da metodologia proposta, tomando para estudo de caso o Habitat Hotel de Leme. O hotel em estudo pretende definir uma estratégia de marketing para atender melhor às demandas de seus hóspedes e direcionar as suas ações e investimentos, de forma a incrementar a taxa de ocupação e a diária média do empreendimento.

Neste contexto, o problema de pesquisa estabelecido é a definição de quais as atributos do produto hoteleiro são percebidos com maior valor para os hóspedes, por meio de uma função de utilidade e a partir disso direcionar a estratégia de serviços e orientar os esforços na melhoria destes atributos.

A aplicação é dividida basicamente em duas etapas:

1. Análise qualitativa dos atributos de valor percebido pelo cliente da indústria de hospitalidade, utilizando a técnica do incidente crítico;

2. Apresentação da função de utilidade dos atributos de valor percebido, bem como suas utilidades parciais, por indivíduo e agregada; e apresentação dos resultados de ajuste do modelo de preferência, utilizando a análise conjunta.

\subsection{Descrição do objeto de estudo: o Habitat Hotel}

O Habitat Hotel, empresa de pequeno porte, prestadora de serviços de hospedagem localizada na cidade de Leme, interior de São Paulo, foi fundado em Junho de 1976. O município de Leme está localizado na quinta 
Região Administrativa do Estado de São Paulo, cuja sede é Campinas ${ }^{33}$. O município possui uma área urbana total de $36,76 \mathrm{~km}^{2}$ e uma extensão territorial de 430,55 km². A cidade de Leme dista 189 km de São Paulo e 93 km de Campinas, e o principal acesso ao município é feito pela via Anhanguera SP330. A Rodovia dos Bandeirantes, agora em extensão até Cordeirópolis, representa um importante acesso a Campinas e São Paulo. A localização privilegiada do Município de Leme, na região centro-norte do Estado, junto à Via Anhangüera e a meia distância entre Campinas e Ribeirão Preto, corresponde à linha de um dos vetores de crescimento mais importantes do país.

A excelente condição de transporte da Via Anhangüera (registra-se um fluxo diário de 19.000 veículos nos dois sentidos: Capital-Interior e viceversa) induz a uma integração muito forte ao longo do seu curso, no sentido de ligação norte-sul. Tal característica, per si, autoriza que seja visualizada uma série de benefícios significativos que os municípios da microrregião podem ter com a referida ligação.

O que caracteriza o hotel é a prestação de serviços hoteleiros com foco no turismo de negócios. Em função da excelente localização do município e da grande quantidade de empresas na microrregião, há um fluxo de pessoas pela cidade que pernoita na região em função dos negócios realizados. Assim, visando atender este público, o Habitat Hotel dispõe da seguinte infra-estrutura:

- 44 unidades habitacionais (UH), distribuídas entre modelos standard, luxo e especial, equipados com ar-condicionado, TV a cabo, mini-bar, circulador de ar, telefone;

\footnotetext{
${ }^{33}$ A região administrativa corresponde a um território que se distingue dos demais por possuir características (clima, produção, etc.) próprias, e que são assim, divididas para organizar as políticas de administração pública dos estados. Desde 1970, por sucessivas leis estaduais, foram criadas e alteradas regiões administrativas e regiões de governo, estabelecidas com o objetivo de centralizar as atividades das secretarias estaduais. O estado de São Paulo possui, atualmente, treze regiões administrativas (Araçatuba, Barretos, Bauru, Campinas, Central, Franca, Marília, Presidente Prudente, Registro, Ribeirão Preto, São José do Rio Preto, São José dos Campos e Sorocaba), mais as regiões metropolitanas da Baixada Santista, Campinas e São Paulo.
} 
- Sala de Café;

- Sala de Estar;

- 1 Sala de Reuniões para 30 pessoas;

- 1 Sala de Reuniões para 50 pessoas;

- Estacionamento.

Dentre os serviços prestados, além da hospedagem, o Hotel possui lavanderia, café da manhã e recepção 24 horas. O cliente do Habitat Hotel, como citado, é em grande parte representado por turistas de negócios. Segundo os gestores, mais de $50 \%$ das hospedagens são oriundas deste segmento compreendido por: vendedores, representantes comerciais, executivos de empresas locais, promotores de venda, enfim pessoas que viajam a trabalho.

Além das pessoas físicas representadas pelos hóspedes, também são clientes do hotel empresas locais cadastradas que enviam seus clientes, fornecedores e funcionários; além do aluguel de salas para treinamento e eventos. Há ainda as operadoras e agências de turismo que fazem parte do trade turístico e representam importante fonte de renda para o Hotel.

Para este trabalho, entretanto, será considerado como cliente somente o hóspede, aquele que efetivamente recebe a prestação dos serviços nas instalações do hotel e que mais facilmente é afetado pelo bom ou mau serviço prestado pela organização, e que, em última análise, é responsável pela escolha do produto hoteleiro. Como visto anteriormente, o turista de negócios é definido como o cliente que utiliza os serviços hoteleiros para conduzir seu trabalho em determinada cidade ou região.

Todos os esforços da empresa são dirigidos para um só objetivo: satisfazer os hóspedes e os clientes em geral. A condição principal para essa satisfação é que o produto ofertado atenda às necessidades dos clientes, principalmente naqueles fatores ou atributos que são mais importantes para o hóspede.

Neste sentido, a aplicação da metodologia proposta no capítulo anterior visa obter uma função de utilidade destes hóspedes, em relação aos atributos dos serviços oferecidos pelo Habitat Hotel. Inicia-se a aplicação, 
identificando estes principais atributos; para isso foi aplicada a técnica do incidente crítico.

\subsection{Técnica do Incidente Crítico}

O capítulo 3 introduziu o conceito e descreveu o método de aplicação da técnica do incidente crítico (TIC). Neste momento, procede-se a aplicação desta técnica com o objetivo de identificar os atributos determinantes na escolha de um produto hoteleiro.

Tendo em vista a opção metodológica, tanto de coleta quanto de tratamento dos dados, ser de natureza qualitativa, a própria apresentação das informações adquiridas já se constitui em uma etapa da análise. Assim, ao longo da apresentação desta seção, algumas relações e até mesmo conclusões já serão levantadas sobre os atributos de valor percebido pelos clientes do hotel.

No presente trabalho, o objetivo estabelecido para a TIC foi o de identificar incidentes satisfatórios ou insatisfatórios, de acordo com a visão dos consumidores de serviços hoteleiros. Os incidentes servirão de insumo na definição dos atributos ou fatores determinantes na escolha do hotel, que serão objetos do experimento da etapa quantitativa da pesquisa, a análise conjunta.

\subsubsection{Obtenção e coleta de dados}

Para a aplicação desta técnica, foi estabelecido um roteiro de entrevista individual, constituído pela seguinte questão: durante sua estadia neste hotel, aconteceu algum fato que o fez sentir-se muito satisfeito, ou insatisfeito? Descreva entre cinco e dez possíveis aspectos que aconteceram em ambos os casos.

Segundo Hayes (2001), o número recomendado de clientes a serem entrevistados para a aplicação da técnica do incidente crítico deve variar de 10 a 20 pessoas. Este número relativamente alto de entrevistados é recomendado para que a possibilidade de ocorrência de informações deficientes ou com 
baixa avaliação de um entrevistado possa ser compensada pelas informações de outro.

A coleta de dados desenvolveu-se por meio de entrevistas individuais do pesquisado com os clientes do hotel. Foram realizadas dezesseis entrevistas durante uma semana no mês de abril de 2003.

A escolha dos indivíduos que participaram das entrevistas foi aleatória entre os hóspedes presentes no Hotel. $\mathrm{O}$ entrevistador abordou os hóspedes no salão de café, durante o desjejum, convidando-os a participar voluntariamente na pesquisa, após uma breve apresentação e contextualização do experimento. Os hóspedes que concordaram em participar constituíram a amostra qualitativa.

No decorrer da entrevistas, os hóspedes (ver tabelas 9, 10 e 11, ANEXO 1) foram, um a um, demonstrando sua opinião, estimulados pela pergunta acima. Dos depoimentos pessoais destes entrevistados, pode-se extrair 93 incidentes críticos, caracterizados por frases representativas do evento, positivo ou negativo, ocorrido na prestação de serviços. Como declarações de incidentes críticos (IC) houve, entre outras:

- O pessoal é atencioso em todos os momentos.

- O apartamento tem mau cheiro.

- A TV poderia ser maior.

- O banheiro é bom, é grande.

- A limpeza é satisfatória. ${ }^{34}$

A partir destas 93 declarações de IC, realizou-se o processo de classificação dos incidentes críticos em itens de satisfação ${ }^{35}$. Segundo Hayes (2001), a lista de incidentes críticos contém incidentes que são semelhantes entre si. Estes incidentes semelhantes devem ser agrupados. A chave para a

\footnotetext{
${ }^{34}$ Declarações de incidentes críticos feitas pelos entrevistados.

${ }^{35}$ Ver ANEXO 1, tabela 12 e quadro 8 referente aos incidentes críticos e itens de satisfação, respectivamente.
} 
classificação destes incidentes críticos é a concentração nos verbos e adjetivos específicos que são comuns entre determinados incidentes.

Depois de formados os grupos, escreve-se uma frase para cada grupo que reflete o conteúdo dos incidentes críticos, esta frase é chamada de item de satisfação. Por exemplo, os incidentes críticos: "A limpeza e a roupa de cama estão boas." e "A limpeza é importante e está boa" são semelhantes e podem ser agrupados no seguinte item de satisfação, "As roupas de cama estavam limpas." Assim, a partir dos 93 incidentes críticos identificados nas entrevistas, pode-se chegar a um conjunto de itens de satisfação.

Uma vez que os incidentes críticos foram classificados em seus respectivos itens de satisfação, repetiu-se o processo, usando os itens de satisfação. A começar destes itens de satisfação e aproveitando experiências do mercado hoteleiro por meio de entrevistas com a gerência e diretoria do hotel, levando-se em consideração as pesquisas anteriores realizadas neste setor, foram agrupados os itens de satisfação semelhantes para formar uma necessidade do cliente ou um atributo de valor.

Assim, os fatores ou atributos do modelo foram definidos em:

- Atendimento

- Localização

- Apartamento

- Equipamentos

- Banheiros

- Estacionamento

- Limpeza

- Reservas

- Preços

- Café da manhã

Pode-se observar que os resultados da aplicação da técnica do incidente crítico em muito se aproximam do referencial teórico estudado, confirmando que, mesmo em diferentes locais e sob influências ambientais distintas, os consumidores hoteleiros apresentam certa homogeneidade de 
comportamento de consumo. Vale dizer que esta é uma etapa preliminar exploratória e que assim deve ser levada em consideração na limitação de suas conclusões.

A seguir, tendo definido os principais atributos determinantes do produto hoteleiro, passa-se à apresentação da formulação da função de utilidade característica do valor percebido dos clientes para os atributos qualificados, por meio do método da análise conjunta.

\subsection{Análise Conjunta}

No capítulo três, buscou-se introduzir o referencial teórico que dá suporte a esta técnica estatística multivariada. Esta etapa apresenta o delineamento do experimento e a aplicação da análise conjunta, considerando como entrada os atributos de valor identificados na técnica do incidente crítico, visando estabelecer a função de utilidade dos atributos representativos do produto hoteleiro.

Para a aplicação das técnicas de análise conjunta, faz-se necessário o desenvolvimento de algum tipo de projeto experimental. Considerando que a aplicação envolve a abordagem dos clientes (hóspedes), optou-se por um número reduzido de atributos, visando um delineamento mais simples para a obtenção de respostas mais confiáveis, a fim de evitar o risco da aplicação de delineamentos mais complexos para determinadas classes de usuários.

Como observado por Hair et al. (2005), o perigo que se incorre ao se apresentar aos entrevistados tarefas muito complicadas é bem conhecido pelos modeladores de um modo geral, e esta consciência tem geralmente assegurado que tarefas não sejam por demais longas e não incluam muitas variáveis. $O$ projeto de experimento adotado teve como referência 0 apresentado por Hair et al. (2005) e está desenvolvido em sete estágios. 


\subsubsection{Estágio 1: os objetivos da análise conjunta}

O objetivo principal desta etapa é estabelecer a estrutura da utilidade total do objeto e os fatores determinantes no experimento, para definir o modelo de preferência do consumidor hoteleiro. Para isso, há duas considerações.

A primeira delas é que, em última análise, o objetivo do experimento conjunto é definir uma função de utilidade que melhor represente o modelo de preferência de consumidor. Além disso, os dados levantados no experimento qualitativo da técnica do incidente crítico representam os principais fatores determinantes da satisfação e, portanto, escolha dos consumidores hoteleiros. A partir desses dois fatores, define-se, a priori, uma utilidade total por meio da expressão 4.1:

$$
U_{i n}=\sum_{k=1}^{k} \beta_{k} \cdot X_{i n}^{K}
$$

em que,

$U_{\text {in }}$ representa a utilidade da alternativa $i$.

$X_{\text {in }}^{K}=\left[X_{\text {in }}^{1}+X_{\text {in }}^{2}+, \ldots,+X_{\text {in }}^{K}\right]$ é o vetor de atributos ou fatores da alternativa $i$.

$\beta_{k}=\left[\beta_{1}, \beta_{2}, \ldots, \beta_{k}\right]$ é um vetor de $k$ parâmetros, no qual cada

$\beta_{k}$ denota a importância relativa de cada atributo $k$.

A partir dos resultados da análise qualitativa apresentada na técnica do incidente crítico descritos na seção anterior, e considerando o conceito de atributos determinantes para este experimento, foram considerados os seguintes fatores ou atributos $X^{k}$ :

- Equipamentos: Equipamentos disponíveis no apartamento visando seu maior conforto (TV, Frigobar, Ar-condicionado, Telefone); 
- Conforto do Apartamento: Tamanho, tipo de cama e área de trabalho;

- Serviços Disponíveis: Serviços disponíveis no hotel relativos à alimentação e limpeza;

- Café da Manhã: Café da manhã em termos de variedade e sortimento de alimentos (completo ou simples);

- Conforto do Banheiro: Ducha/ Chuveiro.

\subsubsection{Estágio 2: o projeto de uma análise conjunta}

Uma vez definidos os principais atributos e a função utilidade, passase para a definição da metodologia no delineamento do experimento da análise conjunta.

Para isso, o quadro 5 ilustra as três principais características que devem ser consideradas na definição da metodologia do experimento, a saber:

- O número de atributos: conforme observamos na seção anterior, o número de atributos identificados para o estudo é cinco;

- O nível de análise: há duas opções de nível de análise em análise conjunta, a individual e a agregada. Neste caso, optou-se pela análise em nível individual, com posterior agregação das utilidades parciais de cada indivíduo;

- A forma do modelo: na seleção da regra de composição, optouse pelo modelo aditivo simples (sem efeito de iterações), no qual o respondente "soma" os valores das utilidades parciais de cada atributo.

Quadro 5: Uma comparação de metodologias conjuntas alternativas.

\begin{tabular}{|lccc|}
\hline \multicolumn{1}{|c}{ Característica } & \multicolumn{3}{c|}{ Metodologia conjunta } \\
\cline { 2 - 4 } & Tradicional & Adaptativa & Baseada em escolha \\
\hline Número máximo de atributos & 9 & 30 & 6 \\
Nível de análise & Individual & Individual & Agregada \\
Forma do modelo & Aditiva & Aditiva & Aditiva+efeitos de interação \\
\hline
\end{tabular}

Fonte: HAIR et al (2005) 
Os atributos acima foram definidos a partir da consolidação dos atributos identificados na etapa da análise qualitativa da técnica do incidente crítico, partindo de dez atributos iniciais para cinco atributos representativos e importantes para qualificar o produto hoteleiro, conforme o quadro 6 .

Quadro 6: Atributos e níveis do experimento.

\begin{tabular}{|c|c|c|}
\hline Atributos & Níveis & Descrição \\
\hline \multirow{4}{*}{ Equipamentos } & A & $\begin{array}{l}\text { TV } 20 " \text { a cabo, Telefone com discagem direta, } \\
\text { Frigobar e Ar-Condicionado. }\end{array}$ \\
\hline & B & $\begin{array}{l}\text { TV } 14 " \text { a cabo, Telefone com discagem direta e } \\
\text { Frigobar. }\end{array}$ \\
\hline & $\mathrm{C}$ & TV 14", Telefone com discagem direta. \\
\hline & A & $\begin{array}{l}\text { Amplo(20m2), Cama Box-Spring, Bancada de } \\
\text { Trabalho com acesso a Internet. }\end{array}$ \\
\hline \multirow[t]{2}{*}{ Conforto do apartamento } & B & $\begin{array}{l}\text { Mediano (17m2), Colchão de espuma densidade } 33 \\
\text { (D33), Bancada de Trabalho. }\end{array}$ \\
\hline & $\mathrm{C}$ & $\begin{array}{l}\text { Pequeno (12m2), Colchão de espuma densidade } 33 \\
\text { (D33). }\end{array}$ \\
\hline \multirow{3}{*}{ Serviços disponíveis } & $A$ & $\begin{array}{l}\text { Recepção e Room -Service } 24 \mathrm{~h} \text {, troca diária das } \\
\text { roupas de cama e banho. }\end{array}$ \\
\hline & B & $\begin{array}{l}\text { Recepção } 24 \mathrm{~h} \text {, Room-Service das } 15 \mathrm{~h} \text { às } 22 \mathrm{~h} \text {, troca } \\
\text { das roupas de cama e banho a cada } 2 \text { dias. }\end{array}$ \\
\hline & $\mathrm{C}$ & $\begin{array}{l}\text { Recepção } 24 \mathrm{~h} \text {, troca das roupas de cama e banho a } \\
\text { cada } 3 \text { dias. }\end{array}$ \\
\hline \multirow{2}{*}{ Conforto do banheiro } & A & Ducha \\
\hline & B & Chuveiro \\
\hline \multirow{2}{*}{ Café da manhã } & A & Ampla variedade e sortimento \\
\hline & $\mathrm{B}$ & Variedade e sortimento limitados \\
\hline
\end{tabular}

Para isso, uma análise crítica foi realizada pelo pesquisador em conjunto com a equipe do hotel objeto do estudo, visando reduzir a complexidade da coleta de dados sem perder a característica e análise dos atributos identificados na etapa anterior.

- Os atributos atendimento, limpeza e reservas foram considerados conjuntamente num atributo único chamado serviços disponíveis. 
- O atributo localização foi eliminado da análise, em função do estudo de caso ter sido realizado num hotel já existente, onde este fator não pode ser alterado.

- O atributo apartamento foi considerado como conforto do apartamento.

- O atributo equipamentos foi mantido.

- O atributo banheiro foi considerado como conforto do banheiro (entendido como qualidade do chuveiro).

- O atributo estacionamento foi excluído, pelo fato de ser uma condição de hospedagem, ou seja, os respondentes deferiram ser este item uma condicionante para a hospedagem. Considerando que o hotel possui estacionamento, a condição está cumprida e, portanto, não há mais análises a serem feitas relativas a este fator.

- O atributo preço apresenta multicolinearidade fatorial com os demais atributos ${ }^{36}$. Desta forma, realizou-se um ajuste para incorporar este atributo no modelo: estabeleceu-se um delineamento fatorial fracionário entre os níveis dos cinco atributos e, para cada estímulo, em conjunto com a equipe do hotel, realizou-se uma análise de custos e posterior atribuição de preço. Para cada estímulo, foi calculado o valor real $(R \$)$ associado, conforme a sua composição de níveis dos atributos definido pelo aplicativo utilizado ${ }^{37}$. Desta forma, para tornar a avaliação do respondente o mais real possível, o preço foi apresentado juntamente com os demais atributos que compõem os estímulos. Em função do acordo de confidencialidade firmado com o hotel, não será apresentado 0 modelo de custeio utilizado na

\footnotetext{
${ }^{36}$ Correlação interatributo ou ambiental.

${ }^{37}$ O software utilizado para o delineamento do experimento foi o SPSS, versão 9.0. A definição dos cartões por meio da função ORTHOGONAL DESIGN, a preparação dos estímulos, a execução do modelo e a definição da função de utilidade e importância relativa dos atributos foram geradas por este sistema.
} 
composição dos preços de cada estímulo apresentado aos respondentes.

- O atributo café da manhã foi mantido e apresentou dois níveis.

\subsubsection{Coleta de dados}

Em função da disponibilidade do pesquisador e da preocupação da gestão do hotel em facilitar o trabalho, o método de contato para coleta de dados foi a entrevista pessoal, realizada pelo pesquisador e pelo subgerente do hotel. A amostra considerada foi representada por turistas de negócios, aqueles cuja viagem é motivada pelo trabalho.

Após a abordagem dos hóspedes na recepção, seguida da identificação do entrevistador, e explicado o motivo da entrevista, procedeu-se a aplicação de um questionário sócio-demográfico. Duas eram as perguntas que determinavam a amostra do experimento: o número de viagens realizadas por mês, sendo que o critério estabelecido era de no mínimo três viagens, e o motivo da viagem, cujo critério era o motivo de viagens de negócios.

Os entrevistados que preenchiam os requisitos necessários passavam então a uma segunda etapa, em que era apresentada uma seqüência de dezoito cartões-escolha. Era sugerido que eles escolhessem dentro deste bloco a sua alternativa preferida; solicitava-se em seguida a ordenação das demais alternativas, como forma de garantir dados adicionais. Cada seqüência era devidamente anotada.

Os resultados obtidos das entrevistas, e codificados de forma apropriada, foram posteriormente transferidos para planilhas eletrônicas do programa computacional utilizado para ajustes da função utilidade. De um total de 33 entrevistados, já eliminados aqueles que deram respostas discrepantes ou não preencheram os critérios de elegibilidade para a amostra, resultaram 594 observações, sendo 18 observações por respondente.

A condução do projeto experimental, o tipo de material apresentado e explicações adicionais durante as entrevistas permitiram colocar o problema de forma bastante clara e objetiva, mesmo para usuários com diferentes graus 
de instrução, contribuindo decisivamente para a obtenção de informações consistentes estatisticamente.

A definição dos níveis e atributos foi uma etapa importante para a definição do tipo de experimento projetado. Neste trabalho, optou-se pelo modelo de perfil completo com delineamento fatorial fracionário.

As alternativas que resultaram do delineamento proposto foram distribuídas não aleatoriamente, mas em blocos completos, balanceados e ortogonais denominados de perfil completo. Os atributos e níveis definidos, se considerados por meio de um planejamento fatorial, apresentariam 108 (= $3 \times 3 \times 3 \times 2 \times 2$ ) possibilidades de estímulos para o método de coleta de perfil completo, conforme apresenta a tabela 6.

Assim, os dados dos atributos e níveis foram inseridos no aplicativo computacional, gerando os dezoito estímulos (cartões) utilizados na coleta de dados $^{38}$. Destes dezoito estímulos, dezesseis representam o modelo de preferência e dois são estímulos de validação do modelo ou amostra holdout.

Tabela 6: Planejamento fatorial.

\begin{tabular}{lc}
\hline \multicolumn{1}{c}{ Atributos } & Planejamento fatorial \\
\cline { 2 - 2 } & Níveis \\
\hline Equipamentos & 3 \\
Conforto do apartamento & 3 \\
Serviços disponíveis & 3 \\
Café da manhã & 2 \\
Conforto do banheiro & 2 \\
Total de estímulos & 108 \\
\hline
\end{tabular}

Para melhorar o entendimento dos entrevistados sobre as diferentes propostas de produtos apresentadas e reforçar a visualização espacial durante o processo de escolhas, cada alternativa foi apresentada no formato do cartão representado pela figura 9 , que deu origem aos cartões apresentados no anexo 2.

A variável resposta deste experimento é a preferência do consumidor aos estímulos, hipotéticos ou não, apresentados nos cartões de

\footnotetext{
${ }^{38}$ Ver ANEXO 2, cartões de entrevista.
} 
pesquisa. A medida escolhida para modelar esta variável foi a ordenação dos cartões. Ou seja, nas instruções das entrevistas pessoais com os respondentes, solicitou-se que o mesmo ordenasse os cartões (estímulos) por preferência de consumo.

\section{: Projeto de Mestrado em Engenharia de Produção}

\section{Exemplo de Formato do Cartão}
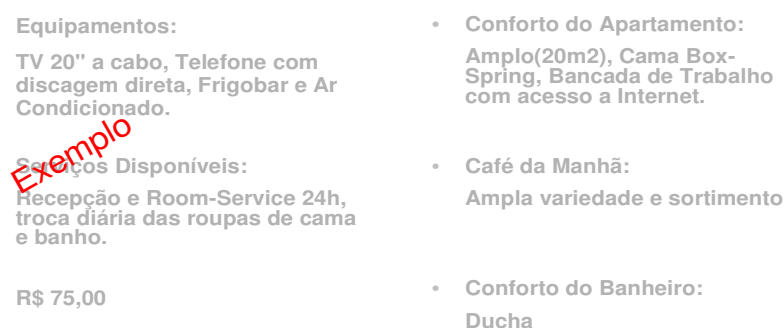

Figura 9: Exemplo do formato de apresentação dos cartões.

Realizada a coleta de dados, passou-se para a etapa de definição dos pressupostos da análise, ou seja, as restrições ou hipóteses estatísticas a serem consideradas no delineamento do experimento, visando garantir a qualidade final do ajuste do modelo.

\subsubsection{Estágio 3: pressupostos da análise conjunta}

Como vimos no capítulo três, não há a necessidade de testes estatísticos para a normalidade, homocedasticidade e independência, geralmente realizadas para outras técnicas de dependência. Entretanto, os dezoito estímulos do planejamento fatorial fracionário gerados são ortogonais e equilibrados, conforme apresenta a figura 18 (ANEXO 2) .

O universo de amostra do experimento constitui os possíveis hóspedes do hotel onde foi realizado o estudo de caso. Segundo dados oferecidos pela gerência do hotel, o número médio de hóspedes por mês está em torno de 500, variando entre os diversos motivos de hospedagem. $O$ 
escopo deste estudo são os hóspedes em viagens de negócios que representam, em média, cinqüenta por cento da ocupação do hotel.

Foram apresentados 94 questionários, sendo respondidos 33 de acordo com os critérios estabelecidos pela pesquisa, que são:

- Número mínimo de hospedagem por mês de 3 diárias;

- Motivo de viagem: negócios.

Atendidos os pressupostos da análise conjunta, a etapa seguinte diz respeito à estimação do modelo, ou seja, definir para cada atributo qual o modelo de ajuste especificado.

\subsubsection{Estágio 4: estimação do modelo da análise conjunta}

$\mathrm{Na}$ estimação do modelo da análise conjunta, há quatro modelos disponíveis. Dentre as opções apresentadas pela técnica da análise conjunta, estão:

- O modelo discreto: não estabelece relação direta entre os níveis do atributo.

- O modelo linear crescente: define uma relação linear crescente entre os níveis do atributo, do tipo quanto maior, melhor;

- O modelo linear decrescente: define uma relação linear decrescente entre os níveis do atributo, do tipo quanto menor, melhor;

- O ponto ideal: define uma relação quadrática com preferência decrescente entre os níveis do atributo;

- O ponto antiideal: define uma relação quadrática com preferência crescente entre os níveis do atributo.

O quadro 6 apresenta os atributos representativos do produto hoteleiro e seus respectivos níveis. Dele observa-se que os níveis dos fatores são categóricos, não havendo relação linear ou quadrática entre os mesmos. 0 respondente pode atribuir utilidades diferentes para cada nível de atributo sem 
seguir um comportamento linear crescente ou decrescente em função dos níveis de cada atributo apresentado.

Neste sentido, este estudo considerou a relação discreta para todos os atributos do modelo.

O quadro 7 ilustra o modelo definido. A primeira coluna apresenta os atributos do delineamento experimental, a coluna do meio apresenta o modelo definido para cada atributo (discreto) e a terceira coluna, o número de níveis de cada fator.

Quadro 7: Relação dos atributos e número de níveis.

\begin{tabular}{|llc|}
\hline Atributo & Relação & Número de níveis \\
\hline Equipamentos & Discreta & 3 \\
Conforto do apartamento & Discreta & 3 \\
Serviços disponíveis & Discreta & 3 \\
Café da manhã & Discreta & 2 \\
Conforto do banheiro & Discreta & 2 \\
\hline
\end{tabular}

$\mathrm{Na}$ seqüência, tendo o delineamento do experimento completo, com atributos e níveis, função de utilidade definida, estímulos gerados, dados coletados e organizados em planilhas, pressupostos e modelo de estimação definidos, executou-se o aplicativo de análise estatística e obtiveram-se os resultados apresentados abaixo.

\subsubsection{Estágio 5: interpretação dos resultados}

Esta etapa apresenta os resultados do experimento de análise conjunta aplicado no Habitat Hotel, segundo a metodologia descrita no capítulo 3 e detalhada nas seções anteriores.

Os dados sobre as preferências dos usuários para diferentes opções de produtos hoteleiros foram devidamente analisados por meio de um programa computacional desenvolvido para ajustes de modelos de análise 
conjunta. A tabela 7 apresenta os dados de saída aplicativos utilizados após a execução do experimento ${ }^{39}$.

Tabela 7: Tabela de sumário dos resultados da estimação do modelo

\begin{tabular}{|c|c|c|c|c|}
\hline \multicolumn{5}{|c|}{ Sumário dos resultados do experimento - Adaptação do arquivo de saída do SPSS } \\
\hline Atributo & Nível do Atributo & Descrição & Utilidade & Importância medida \\
\hline \multirow{3}{*}{ Equipamentos } & A & $\begin{array}{l}\text { TV 20" a cabo, Telefone com discagem } \\
\text { direta, Frigobar e Ar-Condicionado. }\end{array}$ & 1,6162 & \multirow{3}{*}{$27,60 \%$} \\
\hline & B & $\begin{array}{l}\text { TV } 14 " \text { a cabo, Telefone com discagem } \\
\text { direta e Frigobar. }\end{array}$ & $-0,3308$ & \\
\hline & C & TV 14", Telefone com discagem direta. & $-1,2854$ & \\
\hline \multirow{3}{*}{ Conforto do apartamento } & A & $\begin{array}{l}\text { Amplo(20m2), Cama Box-Spring, } \\
\text { Bancada de Trabalho com acesso a } \\
\text { Internet. }\end{array}$ & 0,5505 & \multirow{3}{*}{$32,39 \%$} \\
\hline & B & $\begin{array}{l}\text { Mediano (17m2), Colchão de espuma } \\
\text { densidade } 33 \text { (D33), Bancada de } \\
\text { Trabalho. }\end{array}$ & 1,0543 & \\
\hline & C & $\begin{array}{l}\text { Pequeno (12m2), Colchão de espuma } \\
\text { densidade } 33 \text { (D33). }\end{array}$ & $-1,6048$ & \\
\hline \multirow{4}{*}{ Serviços disponíveis } & A & $\begin{array}{l}\text { Recepção e Room-Service } 24 \mathrm{~h} \text {, troca } \\
\text { diária das roupas de cama e banho. }\end{array}$ & 0,7273 & \multirow{4}{*}{$17,15 \%$} \\
\hline & & Recepção $24 \mathrm{~h}$, Room-Service das $15 \mathrm{~h}$ às & $-0,0530$ & \\
\hline & B & $\begin{array}{l}22 \mathrm{~h} \text {, troca das roupas de cama e banho a } \\
\text { cada } 2 \text { dias. }\end{array}$ & & \\
\hline & C & $\begin{array}{l}\text { Recepção } 24 \mathrm{~h} \text {, troca das roupas de cama } \\
\text { e banho a cada } 3 \text { dias. }\end{array}$ & $-0,6742$ & \\
\hline \multirow{2}{*}{ Café da manhã } & A & Ampla variedade e sortimento & $-0,5076$ & \multirow{2}{*}{$12,77 \%$} \\
\hline & B & Variedade e sortimento limitados & 0,5076 & \\
\hline \multirow{2}{*}{ Conforto do banheiro } & A & Ducha & 0,6136 & \multirow{2}{*}{$10,19 \%$} \\
\hline & B & Chuveiro & $-0,6136$ & \\
\hline
\end{tabular}

4.3.5.1 Análise agregada - importância dos atributos e utilidades parciais

A figura 10, bem como a tabela 7, apresenta os valores de importância obtidos para cada fator para os resultados agregados. Os resultados demonstram que o atributo conforto do apartamento é considerado como sendo o de maior importância, quando comparado com os demais atributos do experimento.

$\mathrm{Na}$ ordem de preferência, seguem os atributos equipamentos, serviços disponíveis, café da manhã e conforto do banheiro.

Os valores de importância indicados são determinados pela amplitude de cada atributo. Entende-se por amplitude a soma dos valores

${ }^{39}$ Ver ANEXO 2, figura 18. 
absolutos das utilidades parciais de maior e menor valor para cada atributo.

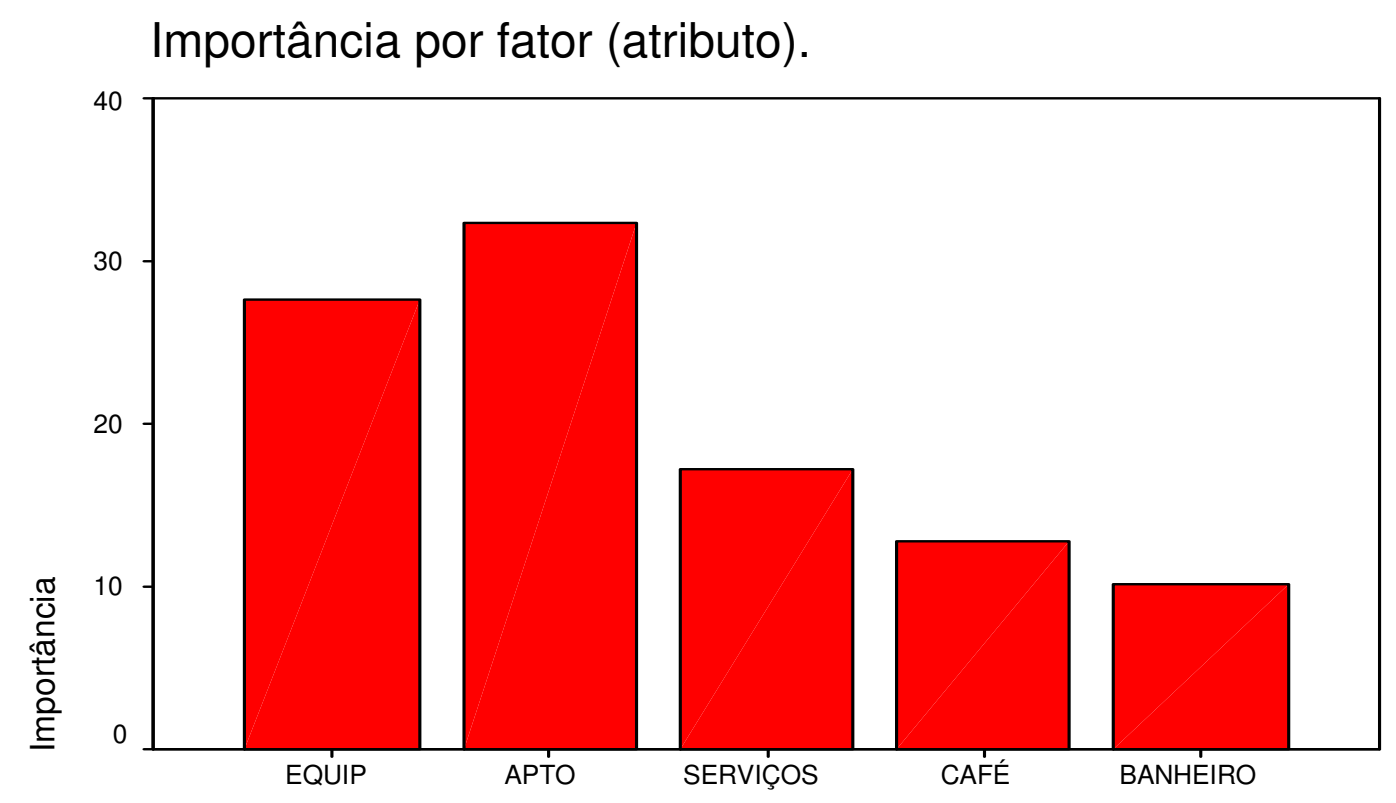

Fator (Atributo)

Figura 10: Importância dos atributos.

Fonte: Arquivo de saída do SPSS.

Neste sentido, tomando-se a coluna das utilidades parciais da tabela 7, obtêm-se os valores das amplitudes de cada atributo do modelo, apresentados abaixo:

- Equipamentos:

Nível A: 1, 6162;

Nível B: -0,3308;

Nível C: $-1,2854$.

Amplitude $=1,6162-(-1,2854)=2,9016$

- Conforto do apartamento:

Nível A: 0,5505;

Nível B: 1,0543;

Nível C: $-1,6048$.

Amplitude $=1,0543-(-1,6048)=2,6591$

- Serviços disponíveis:

Nível A: 0,7273; 
Nível B: - 0,0530;

Nível C: - 0,6742.

Amplitude $=0,7273-(-0,6742)=1,4015$

- Qualidade do café da manhã:

Nível A: -0,5076;

Nível B: 0,5076;

Amplitude $=0,5076-(-0,5076)=1,0152$

- Conforto do banheiro

Nível A: 0,6136

Nível B: - 0,6136

Amplitude $=0,6136-(-0,6136)=1,2272$

O experimento conjunto estabelece as importâncias relativas $(I R)$ por meio da expressão 4.2 .

$$
I R=\frac{\text { valor absoluto das amplitudes das utilidades parciais do atributo } i}{\sum_{i=1}^{n}(\text { valor absoluto das amplitudes das utilidades parciais do atributo } i)}
$$

4.3.5.2 Análise desagregada - importância dos atributos e utilidades parciais

Apesar de observar-se uma consistência com os resultados desagregados, conforme tabela 15, anexo 2, cada respondente possui aspectos únicos e distintos dos demais e dos resultados agregados.

Como exemplo da importância relativa dos atributos em nível individual, tomou-se os dados da tabela 15, para o respondente 1 e 29, consolidados respectivamente nas tabelas 8 e 9, para comparar como os dados agregados do modelo.

A partir das utilidades parciais de cada nível de atributo, foram calculadas as amplitudes por atributo. A amplitude é determinada pela somas dos valores absolutos do maior e o menor valor de utilidade parcial. 
No exemplo da tabela 8 (respondente 1), para 0 atributo equipamentos, tem-se as seguintes utilidades parciais, por nível: $A=-1,500$; $B$ $=-0,375 ; C=1,875$.

Tabela 8: Exemplo de cálculo de importância relativa para o respondente 1

\begin{tabular}{|c|c|c|c|c|c|}
\hline Atributo & Nível & Indívíduo 1 & Absoluta & Amplitudes & Importância relativa \\
\hline \multirow[t]{2}{*}{ Resíduo } & & 9,750 & & & \\
\hline & A & $-1,500$ & 1,500 & 3,375 & $19,01 \%$ \\
\hline \multirow[t]{2}{*}{ Equipamentos } & B & $-0,375$ & 0,375 & & \\
\hline & C & 1,875 & 1,875 & & \\
\hline \multirow{3}{*}{ Conforto do Apto } & A & $-3,000$ & 3,000 & 7,000 & $39,44 \%$ \\
\hline & B & 4,000 & 4,000 & & \\
\hline & C & $-1,000$ & 1,000 & & \\
\hline \multirow{3}{*}{ Serviços Disponíveis } & A & $-0,500$ & 0,500 & 1,125 & $6,34 \%$ \\
\hline & B & $-0,125$ & 0,125 & & \\
\hline & C & 0,625 & 0,625 & & \\
\hline \multirow{2}{*}{ Café da Manhã } & A & $-2,750$ & 2,750 & 5,500 & $30,99 \%$ \\
\hline & B & 2,750 & 2,750 & & \\
\hline \multirow{3}{*}{ Conforto do Banheiro } & A & $-0,375$ & 0,375 & 0,750 & $4,23 \%$ \\
\hline & B & 0,375 & 0,375 & & \\
\hline & & & Total & 17,750 & \\
\hline
\end{tabular}

A amplitude, neste caso, é calculada pela soma do valor absoluto da do nível A, 1,500, ao valor do nível C, 1,875, totalizando 3,375.

Repetindo este procedimento para os demais atributos, conforme a tabela 8, tem-se o valor de amplitude total, representado pela soma das amplitudes dos fatores, neste caso, 17,750.

Por fim, o valor da importância relativa dos atributos em nível individual é obtido pela razão entre a amplitude do atributo e a soma dos valores absolutos das amplitudes das utilidades parciais de todos os fatores (expressão 4.2). Voltando no exemplo acima, a importância relativa $(I R)$ do atributo equipamentos para o respondente 1, será:

$$
I R=\frac{3,375}{17,750}=19,01 \%
$$

O mesmo raciocínio vale para os demais atributos, que apresentam respectivamente as importâncias relativas de: 


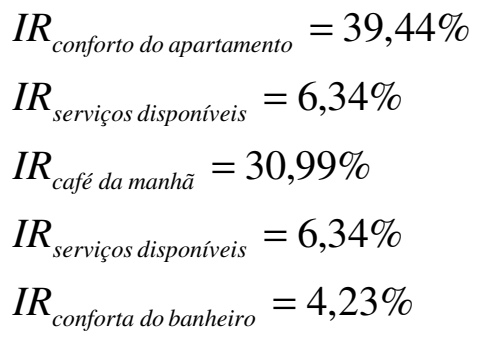

No exemplo da tabela 9 (respondente 29), para o atributo equipamentos, há as seguintes utilidades parciais, por nível: $A=1,833$; $B=$ 0,$292 ; \mathrm{C}=-1,542$.

Tabela 9: Exemplo de cálculo de importância relativa para o respondente 29.

\begin{tabular}{|c|c|c|c|c|c|}
\hline Atributo & Nível & Indívíduo 1 & Absoluta & Amplitudes & Importância relativa \\
\hline \multirow[t]{2}{*}{ Resíduo } & & 6,667 & & & \\
\hline & A & 1,833 & 1,833 & 3,375 & $21,95 \%$ \\
\hline \multirow[t]{2}{*}{ Equipamentos } & B & $-0,292$ & 0,292 & & \\
\hline & C & $-1,542$ & 1,542 & & \\
\hline \multirow{3}{*}{ Conforto do Apartamento } & A & 5,333 & 5,333 & 10,000 & $65,04 \%$ \\
\hline & B & $-0,667$ & 0,667 & & \\
\hline & C & $-4,667$ & 4,667 & & \\
\hline \multirow{3}{*}{ Serviços Disponíveis. } & A & 0,167 & 0,167 & 1,250 & $8,13 \%$ \\
\hline & B & $-0,708$ & 0,708 & & \\
\hline & C & 0,542 & 0,542 & & \\
\hline \multirow{2}{*}{ Café da Manhã } & A & 0,250 & 0,250 & 0,500 & $3,25 \%$ \\
\hline & B & $-0,250$ & 0,250 & & \\
\hline \multirow{2}{*}{ Conforto do Banheiro } & A & 0,125 & 0,125 & 0,250 & $1,63 \%$ \\
\hline & B & $-0,125$ & 0,125 & & \\
\hline
\end{tabular}

A amplitude, neste caso, é calculada pela soma do valor absoluto da do nível A, 1,833, com o valor do nível C, 1,542, totalizando 3,375.

Repetindo este procedimento para os demais atributos, conforme a tabela 9, há o valor de amplitude total, representado pela soma das amplitudes dos fatores, neste caso, 15,375.

Por fim, o valor da importância relativa dos atributos em nível individual é obtido pela razão entre a amplitude do atributo e a soma dos valores absolutos das amplitudes das utilidades parciais de todos os fatores (expressão 4.2). Voltando no exemplo acima, a importância relativa $(I R)$ do atributo equipamentos para o respondente 29 , será: 


$$
I R=\frac{3,375}{15,375}=21,95 \%
$$

O mesmo raciocínio vale para os demais atributos, que apresentam respectivamente as importâncias relativas de:

$$
\begin{aligned}
& I R_{\text {conforto do apartamento }}=65,04 \% \\
& I R_{\text {serviços disponíveis }}=8,13 \% \\
& I R_{\text {café da manhã }}=3,25 \% \\
& I R_{\text {conforto do banheiro }}=1,63 \%
\end{aligned}
$$

Os resultados desagregados do respondente 1 e 29 demonstram claramente a unicidade e diferença dos indivíduos. O indivíduo 29, em termos de preferências, apresentou um forte alinhamento com a análise agregada, enquanto o indivíduo 1 apresentou uma função de utilidade diferente do modelo agregado.

Ou seja, há uma diferença nas preferências individuais versus a agregada. Isso não invalida o modelo e, na etapa de validação dos resultados, apresenta-se a qualidade do ajuste de predição do experimento. Entretanto, é importante na análise dos resultados levar em consideração estas particularidades, para que a tomada de decisão com base nestas informações esteja suficientemente respaldada pelos modelos gerados.

\subsubsection{A função de utilidade estimada}

A partir dos dados das utilidades parciais apresentadas na tabela 7, o modelo aditivo simples representativo da estrutura de preferência do produto hoteleiro objeto do estudo, com base nos cinco atributos de valor (conforto do apartamento, equipamentos, serviços disponíveis, café da manhã e conforto do banheiro), é definido pela função de utilidade da expressão 4.5. (considerando um nível de significância de $\alpha=10 \%$ ). 
$U=(1,6162) \cdot X_{\text {equip }}^{A}+(-0,3308) \cdot X_{\text {equip }}^{B}+(-1,2854) \cdot X_{\text {equip }}^{C}+$

$(0,5505) \cdot X_{\text {apto }}^{A}+(1,0543) \cdot X_{\text {apto }}^{B}+(1-1,6048) \cdot X_{\text {apto }}^{C}+$

$(0,7273) \cdot X_{\text {serviço }}^{A}+(-0,0530) \cdot X_{\text {serviço }}^{B}+(-0,6742) \cdot X_{\text {serviço }}^{C}+$

$(-0,056) \cdot X_{\text {café }}^{A}+(0,056) \cdot X_{\text {café }}^{B}+$

$(0,6136) \cdot X_{\text {banheiro }}^{A}+(-0,6136) \cdot X_{\text {banheiro }}^{B}+$

7,7765

em que,

$U$ representa a utilidade total do serviço hoteleiro,

$X^{a}{ }_{i}$ representa os níveis dos atributos, em que a representa o nível $(A, B$, ou $C)$

e $i$ representa o atributo (equipamentos, serviços disponíveis, conforto do apartamento, café da manhã e conforto do banheiro).

As utilidades parciais dos atributos por indivíduo e consolidadas são apresentadas no anexo 2 deste trabalho.

Dos resultados do experimento, tem-se que o resíduo é igual a 7,7765. Este valor representa os erros de ajuste do modelo, sendo eles:

- $\quad$ atributos relevantes não incluídos na função utilidade;

- $\quad$ erros na medição dos atributos feitos pelo pesquisador;

- $\quad$ erros de percepção feitos pelo respondente;

- diferenças não observáveis na avaliação.

É importante observar que os valores apresentam consistência lógica com os dados do questionário prévio de análise sócio-demográfica.

Tendo apresentado os resultados agregados em nível individual da análise conjunta, estes devem ser validados por meio de testes estatísticos não-paramétricos, já que o modelo apresenta variáveis categóricas, com ordenação de estímulos.

\subsubsection{Estágio 6: validação dos resultados}

A validação dos resultados da análise conjunta é definida pelos coeficientes $R$ de Pearson e $\tau($ tau $)$ de Kendall do experimento, como 
apresentado nos resultados no modelo, no anexo 2. Estas estatísticas são indicações de quão bem o modelo se ajusta à realidade. Ou seja, elas são medidas de correlação entre os dados observados (postos observados) e as preferências estimadas (postos estimados ou previstos). Assim, é esperado que estes coeficientes apresentem valores altos, próximos de um.

O coeficiente de $R$ de Pearson, neste caso, no qual a variável de resposta é não métrica, representa o coeficiente de correlação de Spearman. Ou seja, nos casos em que os dados não pertencem a uma escala de medida métrica, mas existe uma ordenação clara, o coeficiente de Spearman é utilizado no lugar do coeficiente $R$ de Pearson, conforme visto na seção de qualidade de ajuste do capítulo três.

Este é um método não-paramétrico que usa somente os postos e não faz quaisquer suposições. Essencialmente o que faz é calcular o coeficiente de correlação de Pearson nos postos. Uma fórmula que é relativamente fácil de usar é:

$$
r=1-\frac{6 \cdot \sum_{i} d_{i}^{2}}{\left(n^{3}-n\right)}
$$

em que:

$n$ representa o número de pares (postos previstos, postos observados)

$d_{i}$ representa a diferença (posto de previsto i dentre os postos previstos) (posto observado i dentre os postos observados). Note-se que, se os postos observados forem iguais aos postos previstos, então $d_{i}$ é zero e, portanto, $r$ será igual a 1.

Como apontado anteriormente, espera-se altos valores para este coeficiente, já que ele representa a correlação entre os postos previstos e os postos observados, demonstrando assim a qualidade do ajuste do experimento conjunto.

$\mathrm{Na}$ estimação do ajuste do modelo, foi estabelecido um teste de hipóteses no qual a hipótese nula $H_{0}$ representa a correlação entre os postos 
observados e previstos, em que se espera que seja igual a zero, e a hipótese alternativa $H_{1}$, na qual a correlação entre os postos é diferente de zero.

$$
\begin{aligned}
& H_{0}: \text { correlação entre os postos }=0 ; \\
& H_{1}: \text { correlação entre os postos } \neq 0 ; \\
& \text { para } \alpha=0,10 \text { (nível de significância } 10 \% \text { ). }
\end{aligned}
$$

Dos resultados do experimento conjunto, obteve-se o valor do $R$ de Pearson (Spearman) de 0,949, um valor excelente, considerando que, para um nível de significância de $10 \%$, o valor de $s$ é igual 0,0000, de tal forma que devemos rejeitar a hipótese nula $\left(H_{0}\right)$.

O coeficiente de Kendall também apresenta valores desejáveis. No experimento, o resultado do coeficiente $\tau(\operatorname{tau})$ de Kendall apresentou um valor de 0,783 para o conjunto de estímulos do experimento, com significância 0,0000, para um nível aceitável de 10\%.

No caso da amostra de validação (amostra holdout), observaram-se valores ainda melhores para o modelo, no qual o coeficiente $\tau(\operatorname{tau})$ de Kendall apresentou valor igual a 1,00, com significância igual 0,0000, num nível aceitável de até 0,10 (10\%).

Neste sentido, o modelo experimental sugerido na aplicação do estudo de caso apresenta-se fortemente consistente estatisticamente, demonstrando seu poder explicativo e de predição das variáveis observadas.

Desta forma, qualquer que seja a estratégia utilizada pelo gestor hoteleiro, os atributos conforto do apartamento $(32,29 \%)$, equipamentos $(27,60 \%)$ e serviços disponíveis (17,15\%), representando juntos $77,04 \%$ da função de utilidade do produto hoteleiro, devem merecer destaque. 


\section{$5 \quad$ CONCLUSÕES}

Este trabalho apresentou uma breve revisão da literatura sobre comportamento do consumidor, valor percebido e o setor de serviços. Em cada seção, buscou-se apresentar a teoria à luz do problema de pesquisa, a avaliação do valor percebido.

O estudo apresentou ainda uma breve revisão da literatura do método utilizado no experimento, a técnica do incidente crítico, tratando a análise qualitativa e a análise conjunta como modelos de análise de preferência do consumidor hoteleiro.

A medida de valor percebido dos consumidores hoteleiros por meio da análise conjunta propôs: (i) uma estruturação de etapas (método) que procura integrar a análise qualitativa e quantitativa para uma pesquisa de marketing, integrando a pesquisa de marketing ao planejamento de experimentos; (ii) uma abordagem pouco trivial e incipiente na indústria hoteleira, na qual os respondentes são orientados a expor sua real preferência dos atributos determinantes na escolha do produto hoteleiro, num método exploratório, que se demonstrou eficiente e viável economicamente para o estudo do valor percebido.

A fim de ilustrar o método proposto neste estudo, foi conduzida uma aplicação da metodologia proposta no Habitat Hotel de Leme. O modelo gerado apresentou adequada capacidade de previsão da preferência de consumo, permitindo determinar a influência dos atributos determinantes, sua importância e utilidade.

Os resultados obtidos no capítulo de aplicação mostraram que as principais variáveis da função de utilidade, como medida do comportamento do consumidor, na aquisição de serviços hoteleiros, são: o conforto do 
apartamento, com 32,29\% de importância, seguido da qualidade dos equipamentos nos apartamentos, com 27,60\% de importância, os serviços disponíveis, com 17,15\% de importância, o café da manhã, com 12,77\% de importância e o conforto do banheiro, com 10,19\% de importância. Esta é a efetiva medida de valor percebido colocada como objetivo do estudo e permitirá ao gestor hoteleiro um suporte ao processo de decisão.

A disponibilidade e riqueza de informações obtidas como resultado dos ajustes das diferentes funções-utilidade agregadas e individuais são utilizadas também para explorar outras questões de interesse dos gestores, tais como os impactos sobre a remuneração dos investimentos, a priorização de investimentos em determinados itens de maior utilidade, a formulação e desenvolvimento de novos produtos, etc.

Neste sentido, e como principal ferramenta de suporte à decisão, a função de utilidade calculada representa uma oportunidade para o gestor hoteleiro ponderar sobre quais atributos orientar sua estratégia. A aplicação do método proposto se mostrou útil no estudo de caso apresentado e permite concluir que é uma ferramenta importante no apoio ao processo de tomada de decisão do gestor hoteleiro, no que tange ao direcionamento da aplicação de recursos e esforços, orientados ao cliente.

\subsection{Recomendação de estudos futuros}

No capítulo 1, foi apresentado que este trabalho estava delimitado em compreender o valor percebido dos consumidores na indústria hoteleira, utilizando técnicas qualitativas para identificar os atributos de valor e quantitativas para mensurá-los.

Sobre a continuidade deste trabalho, é recomendado seguir por temas não abordados nele, mas que estão fortemente associados às disciplinas de valor percebido e análise conjunta.

Entre os principais temas de continuidade, pode-se citar: 
- a estratégia de formação de preços, na qual a análise conjunta tem demonstrado grande aplicabilidade (GREEN e SRINIVASAN, 2000)

- a análise do valor percebido na etapa anterior à compra do produto ou serviço hoteleiro (pré-venda)

- a análise de clientes corporativos que, atualmente na indústria hoteleira com foco no turismo de negócios, representam uma classe altamente compradora no setor;

- utilizar a análise conjunta orientada para a simulação de novos produtos hoteleiros. 


\section{REFERÊNCIAS BIBLIOGRÁFICAS}

ALBRECHT, K. (1992). Revolução nos Serviços.São Paulo: Pioneira, p.254.

AL-SABBAHY, H.Z. (2000). An Examination of Perceived Value Dimensions in the Hospitality Industry. School of Management Studies for the Service Sector, University of Surrey, Guildford, UK.

AL-SABBAHY, H.Z. ; EKINCI, Y.; RILEY, M. (2004). An Investigation of Perceived Value Dimensions: Implications for Hospitality. Journal of Travel Research, Vol. 42, n.3, p. 226-234.

ANDERSON, J.; NARUS, J. (1999). Business Market Management: understanding, creating and delivering value. New Jersey: Prentice-Hall.

ANDERSON, J. C.; JAIN, D. C.; CHINTAGUNTA, P. K. (1993). Customer Value Assessment in Business Markets: A State-of-Practice Study. Journal of Business-to-Business Marketing, vol.1, n.1, p. 3-29.

ANDRADE, J.V. (1988). Turismo - fundamentos e dimensões. 8.ed. São Paulo: Ática.

ANJOS, S. J. D. (2004). Serviços integrados no turismo: um modelo de gestão para o setor de hotelaria. Tese (Doutorado em Engenharia de Produção), Programa em Engenharia de Produção, Universidade Federal de Santa Catarina, Florianópolis. 2004.

ATELJEVIC, I. (2000). Tourist Motivation, Values and Perceptions. Em A. G. Woodside; G. I. Crouch; J. A. Mazanec; M. Oppermann; M. Y. Sakai (Eds.), Consumer Psychology of Tourism, Hospitality, and Leisure (p. 193209). Wallingford and New York: CABI Publishing. 
BATTESINI, M. (2002). Método de análise conjunta com estimulação em duas etapas. Dissertação (Mestrado em Engenharia de Produção), Escola de Engenharia, Universidade Federal do Rio Grande do Sul, Porto Alegre. 2002.

BEN-AKIVA, R. (1999). Extendend Framework for modeling Choice Behaviour. Marketing Letters, v.10, n.3, p. 187-203.

BITNER, M.J.; BOOMS, B.H.; MOHR, L. A. (1994). Critical service encounters: the employee's viewpoint, Journal of Marketing, v. 58, No. 4, pp. 95-106.

BITNER, M.J. (1990). Evaluating service encounters: the effects of physical surroundings and employee responses. Journal of Marketing, v. 54, p. 6982.

BITNER, M.J.; BOOMS, B.H; TETREAULT, M.S. (1989). Critical incidents in service encounters, em BITNER, MJ. e CROSBY, L.A. (1989), Designing a Winning Service Strategy, American Marketing Association, Chicago, IL, p. 89-99.

BOJANIC, D. C. (1996). Consumer Perceptions of Price, value, and Satisfaction in the Hotel Industry: An Exploratory Study. Journal of Hospitality \& Leisure Marketing, v. 4, n.1, p.5-22.

BOLTON, R.N.; DREW, J.H. (1991). A Multistage Model of Customers' Assessments of Service Quality and Value. Journal of Consumer Research, v.17, p. $375-384$.

BOULTON, R.E.S. ; LIBERT, B.D.; SAMEK, S.M. (2001).Decifrando o código de valor. Rio de Janeiro, Campus, p.302. 
BYRNE, M. (2001). Critical incident technique as a qualitative research method -Research Corner. AORN Journal, Disponível em: <http://www.findarticles.com/p/articles/mi m0FSL/is 4 74/ai 80159552>. Acesso em: 01 mar. 2005

CADOTTE, E.R.; TURGEON, N. (1988). Key factors in guest satisfaction. The Cornell Hotel and Restaurant Administration Quarterly, v. 28, n. 4, p. 44-51. CARROL, J.D.; GREEN, P.E. (1995). Psychometric Methods in Marketing Research: Part I, Conjoint Analysis. Journal of Marketing Research. v. 32, p.385-391.

CHANG, T.Z.; WILDT, A.R. (1994). Price, Product Information, and Purchase Intention: An empirical study. Journal of the Academy of Marketing Science, v.22, n.1, p.16-27.

COOPER, D.R.; SCHINDLER, P.S. Métodos de pesquisa em administração. 7.ed. Porto Alegre: Bookman.

COSTA, M. Disponível em: <http://www.ceseth.com.br/artigos 03.htm>. Acesso em: 05 jul. 2004

CRONIN, Jr. J.J.; BRADY, M.K.; HULT, G.T.M. (2000). Assessing the effects of quality, value, and customer satisfaction on consumer behavioral intentions in service environments. Journal of Retailing, v. 76, n.2, p.193-218.

DOODS, W.B; MONROE, K.B.; GREWAL,D. (1991). The effects of price, brand, and store information on buyers' product evaluations. Journal of Marketing Research, v. 28, p.307-319. 
DUBÉAND, L.; RENAGHAN, L.M.(2000). Creating visible customer value: how customers view best-practice champions. Cornell Hotel and Restaurant Administration Quarterly.

DUMAN, T. (2002). A Model of perceived value for leisure travel products. The Pennsylvania State Unniversity, College of Health and Human Development, A Thesis in Leisure Studies.

EDVARDSSON, B.; ROSS, I. (2001). Critical incident techniques: Towards a framework for analysing the criticality of critical incidents. International Journal of Service Industry Management, Bradford.

EFRÓN, A.J. (1995). Indústria hoteleira em Balneário Camboriú: Uma visão por meio de modelos de preferência declarada. Dissertação de mestrado, programa de pós-graduação em engenharia de produção, UFSC, Florianópolis.

EMBRATUR (2003). Dados da Hotelaria. Brasília: Ministério do Turismo/ Instituto Brasileiro de Turismo/ Diretoria de Estudos e Pesquisas. 6 p. dados de 2002.

EMBRATUR (2004). Anuário Estatístico da Embratur. Brasília: Ministério do Turismo/ Instituto Brasileiro de Turismo/ Diretoria de Estudos e Pesquisas. V. 31.180 p. dados de 2003.

ENGEL, J. F.; BLACKWELL, R. D.; MINIARD, P.W. (2000). Comportamento do Consumidor, 8. ed. Rio de Janeiro: LTC. 
FITZSIMMONS, J. A.; FITZSIMMONS, M. J.(1998) Service management: operations, strategy, and information technology. 2.ed. USA: Irwin/McGrawHill.

.(2000). Administração de serviços: operações, estratégias e tecnologia de Informação. 2. ed. Porto Alegre: Bookman.

FLANAGAN, J.C. (1954). The critical incident technique. Psychological Bulletin, v. 51, n. 4, p. $327-58$.

GADE, C. (1998). Psicologia do consumidor e da propaganda. São Paulo. EPU. GIANESI, I.G.N; CORREA, H.L. (1994). Administração Estratégica de Serviços. São Paulo: Atlas.

GIGLIO, E. (2002). O Comportamento do Consumidor. 2a . ed. São Paulo: Pioneira -Thomson Learning.

GOLDBERG, S.M; GREEN, P.E.; WIND, Y. (1984). Conjoint analysis of price premiums for hotel amenities. The Journal of Business, v.57, n.1, p.s111s132.

GORNI, M., RODRIGUES, R. M. (2004). Hotelaria em números - Brasil. São Paulo: HIA.

GOUVÊA, M. A. (2003). Notas de aula da disciplina EAD 5938 - Análise multivariada aplicada à administração II. São Paulo: FEA-USP.

GREEN, P.E.; SRINIVASAN, V. (1978). Conjoint Analysis in Consumer Research: Issues and outlook. The Journal of Consumer Research, v.5, n.2, p.103-123. 
GREEN, P. E., SRINIVASAN V. (1990). Conjoint Analisys in Marketing: New Developments With Implications for Research and Practice. Journal of Marketing. v. 54, p.3-19.

GREEN, P.E.; WIND, Y. (2000). Novas maneiras de medir os julgamentos dos consumidores. Revista Harvard-Exame, Grandes Decisões-Marketing, p.39-48.

GREEN, P.E.; KRIEGER, A.M. (2002). What's right with conjoint analysis? Marketing Research, Março-Maio, p.24-27.

GREWAL, D., MONROE, K. B.; KRISHNAN, R. (1998). The Effect of PriceComparison Advertising on Buyers' Perception of Acquisition Value, Transaction Value, and Behavioral Intentions. Journal of Marketing, v. 62, p. 46-59.

GRÖNROOS, C. (1997). From marketing mix to relationship marketing: towards a paradigm shift in marketing. Management Decision, v. 35, n..3, p. 322339.

GUERRINI, F.M. (2002). Planejar e redigir textos científicos em Engenharia de Produção. EESC - USP. São Carlos.

GUNDERSEN, M.G.;HEIDE, M.; OLSSON, U.H.(1996). Hotel guest satisfaction among business travelers. What are the important factors?. Cornell Hotel and Restaurant Administration Quarterly, v.36, n.2, p.72-81.

HAIR, J.F.; ANDERSON, R.E.; TATHAM, R.L.; BLACK, W.C. (1995). Multivariate data analysis. Upper Saddle River: Prentice Hall, p.387-441.

HAIR, J.F.; ANDERSON, R.E.; TATHAM, R.L.; BLACK, W.C. (2005). Análise multivarida de dados. Porto Alegra: Bookman, p.319-360. 
HAEMOON, O. (1999). Service quality, customer satisfaction, and customer value: A holistic perspective. International Journal of Hospitality Management.

HAYES, B.E. (2001). Medindo a satisfação do cliente. Rio de Janeiro: Ed. Qualitymark.

HOLBROOK, M.B. (1999). Consumer value: a framework for analysis and research. New York: Routledge, p.203.

HUBER, F.; HERRMANN, A.; MORGAN, R. E. (2001). Gaining Competitive Advantage through Customer Value Oriented Management. Journal of Consumer Marketing, v. 18, n.1, p. 41-53.

JAYANTI, R.K.; GHOSH, A.K. (1996). Service Value Determination: An integrative perspective. Journal of Hospitality and Leisure Marketing, v. 3, n. 4, p. 5-25.

JOHNSTON, R.; CLARK, G. (2002). Administração de Operações de Serviço. São Paulo: Editora Atlas.

KASHYAP, R. ; BOJANIC, D. C. (2000). A Structural Analysis of Value, Quality, and Price Perceptions of Business and Leisure Travelers. Journal of Travel Research, v. 39, August, p. 45-51.

KERSTENETZKY, C. L (2005). What is the value of self-interest?. Revista de Economia Política, v.25, n.3, julho/setembro, p.254-276.

KIM, W.C.; MAUBORGNE, R. (2005). A estratégia do oceano azul: como criar novos mercados e tornar a concorrência irrelevante. Rio de Janeiro: Elsevier. 
KNUTSON, B.J. (1988). Frequent travelers: making them happy and bringing them back. The Cornell Hotel and Restaurant Administration Quarterly, v. 29, n.1, p. 83-87.

KOTLER, P. (1998). Administração de Marketing: análise, planejamento, implantação e controle. São Paulo: Atlas. . (2000). Administração de Marketing. São Paulo: Prentice Hall.

KOTLER, P., ARMStRonG, G. (1998). Princípios de Marketing. Rio de Janeiro: Prentice Hall do Brasil.

KOTLER, P.; BOWEN, J.; MAKENS, J..(1998). Marketing for hospitality and tourism. 2. ed. Upper Saddle River: Prentice Hall, p.800. (2002). .3. ed. Upper Saddle River: Prentice Hall.

LAFIS (2002). Estudo de mercado de Hotéis e Turismo.

LEWIS, R. C. (1985), Predicting Hotel Choice, Cornell Hotel and Restaurant Adm. Quarterly, p.81.

LOCKYER, T. (2003). Hotel cleanliness-how do guests view it? Let us get specific. A New Zealand study. International Journal of Hospitality Management, v. 22, p.297-305.

LOVELOCK, C.H. (1992a). Managing Services - Marketing, Operations and Human Resources. 2. ed. New Jersey: Prentice Hall International Editions. . (1992b). A basic toolkit for service managers Managing Services Marketing, Operations and Human Resources. 2. ed. New Jersey: Prentice Hall International Editions. 
LOVELOCK, C. ; WRIGT, L.(2001). Serviços: marketing e gestão. São Paulo: Saraiva.

LUCE, R. (1958). A Probabilistic Theory of Utility. Econometrica, v.26, n.2, p.193-224.

MALHOTRA, N.K. (1999). Marketing Research: An Applied Orientation. Prentice-Hall, p. 647-657. . (2001). Pesquisa de Marketing - Uma Orientação Aplicada.

3.ed. Porto Alegre: Bookman.

MATTILA, A. (1999). Consumers' Value Judgments. Cornell Hotel and Restaurant Administration Quarterly. Cornell University, NY, v. 4, n. 1, p. 40-46.

McCUllough, D. (2002). A User's Guide to Conjoint Analysis. Journal of Marketing Research. Summer 2002, p.19-23.

McFADDEN, D. (1986). The Choice Theory Approach to Market Research. Marketing Science, v.5, n.4, p.275-297.

McFADDEN, D. (2001). Economic Choices. The American Economy Review, v.91, n.3, p351-378.

MONROE, K.B. (1990). Pricing: Making profitable decisions. New York: McGraw Hill.

MOWEN, I.C.; MINOR, M.S. (2003). Comportamento do Consumidor. São Paulo: Prentice Hall. 
NAUMANN, E. (1995). Creating Customer Value: The Path to Sustainable Competitive Advantage. Ohio: Thomson Executive Press.

NOVAES, A.G. et al (1996). Técnicas de preferência declarada na análise do nível de serviço hoteleiro. Gestão \& Produção, v.3, n.2, p. 188-203.

OH, H. (1999). Service Quality, Customer Satisfaction, and Customer Value: $A$ Holistic Perspective. International Journal of Hospitality Management, vol. 18 , p. $67-82$.

OLSON, J.; JACOBY,J. (1972). Cue utilization in the quality perception process. Proceedings of the third annual conference of the association for consumer research, USA, 167-179.

PARASURAMAN, A. (1997). Reflections on Gaining Competitive Advantage through Customer Value. Journal of the Academy of Marketing Science, v. 25, n.2, p.154-161.

PARASURAMAN, A.; GREWAL, D. (2000). The impact of technology on the quality-value-loyalty chain: A research agenda. Journal of the Academy Marketing Science, v. 28, n.1, p.168-74.

PARASURAMAN, A.; ZEITHAML, V.A.; BERRY, L.L. (1985). A conceptual model of service quality and its implications for future research. Journal of Marketing, v. 49, n. 4, pp. 41-50.

PRAHALAD, C.K.; RASMAWANY,V. (2000a). Co-optming customer competence. Harvard Business Review, jan./fev., p. 79-87. (2000b). Como incorporar as competências do cliente. HSM Management, maio/junho, p. 42-52. 
PETRICK, J. F. (2001). Development of a Multi-Dimensional Scale for Measuring the Perceived Value of a Service. Artigo apresentado na $32^{\mathrm{a}}$ Annual Conference of the Travel and Tourism Research Association, Fort Myers, Florida.

RIBEIRO, S.V.P. (2003). Benchmarketing: alternativa para os administradores de hotéis independentes. Revista Eletrônica Humanae. http://www.esuda.com.br/revista humanae/artigo sandro.php. Acesso em 08.07.2005.

SALEH, F.; RYAN, C. (1992). Client perceptions of hotels, a multi-attribute approach. Tourism Management, v. 13, n. 2, p. 163-168.

SANCHO, A (2001). Introdução ao Turismo. São Paulo: Roca.

SCHALL, M. (2003) Best practices inthe assessment of hotel guest-attitudes. Cornell Hotel and Restaurant Administration Quarterly, v.44, n.2, p.51-65.

SCHMENNER, R.W. (1999). Administração de Operações de Serviços. São Paulo: Editora Futura.

SEBRAE, FBC\&VB,CTI (2001). Dimensionamento Econômico do Setor de Eventos do Brasil. Elaboradores: IGNARRA, L.R.; SANTOVITO,T. C.; OLIVEIRA, J.C; SOUZA,M.V.; BIBANCO, T.S.; SCHIASCHIO,M.; SANTOS,F.R.; VAZ,T.; GHELLER,T. (Pesquisa)

SEMON, T. T. (1998). Existing Measures Make Value Hard to Quantify. Marketing News, v. 32, n. 11, p.18.

SERRANO, D. (2003). Comportamento do Consumidor. www.softclick.com.br, acesso em 17.03.2003. 
SHIFFLET, D.K.; BHATIA, P. (1997). Perception of value often leads to loyalty. Hotel \& Motel Management, v. 211, n. 14, p. 22.

SILVESTRO, R. (1999) Positioning services along the volume-variety diagonal. The contingencies of service design, control and improvement. International Journal of Operations e Production Management, v.19, n.4, p. 399-42.

SOLOMON, M. R. (1999). Consumer Behavior: Buying, Having, and Being (4th ed.). Upper Saddle River, New Jersey: Prentice-Hall.

SPSS, INC (1997). SPSS Conjoint 8.0. Chicago: SPSS.

STAHL, M. J.; BARNES, W. K.; GARDIAL, S. F.; PARR, W. C.; Woodruff, R. B. (1999). Customer Value Analysis Helps Hone Strategy. Quality Progress, v. 32 , n. 4 , p. 53-58.

SWEENEY, J. C.; SOUTAR, G. N.; JOHNSON, L. W. (1997). Retail Service Quality and Perceived Value: A Comparison of Two Models. Journal of Retailing and Consumer Services, v. 4, n.1, p. 39-48.

SWEENWEY, J.C.; SOUTAR, G.N. (2001). Consumer perceived value: The development of multiple item scale. Journal of Retailing, v. 77, p. 203-220.

TAUSSIG, F. (1912). Principles of economics. New York: Macmillan.

THALER, R. (1985). Mental Accounting and Consumer Choice. Marketing Science, v. 4, n. 3, p.199-214.

VARIAN, H.R. (2000). Microeconomia: Princípios Básicos. Rio de Janeiro: Campus. 
WAHAS, S.A. (1977). Introdução à administração do turismo. São Paulo: Editora Pioneira, p.26.

WEBSTER Jr, F.E. (1992). The changing role of marketing in the corporation. Journal of Marketing, v. 56, n. 2, p. 54-61.

WOODRUFF, R. B. (1997). Customer value: the next source for competitive advantage. Journal of the Academy of Marketing Science, v. 25, n. 2, p. 139-153.

WOODRUFF, R. B.; GARDIAL, S.F. (1996). Know your customer: New approaches to understanding customer value and satisfaction. Cambridge, MA: Blackwell Publishers.

ZEITHAML, V. A. (1988). Consumer perceptions of price, quality, and value: a means-end model and synthesis of evidence. Journal of Marketing, v. 52, p. 2-22.

ZEITHAML, V. A.; BITNER, M.J. (2003). Marketing de serviços: a empresa com foco no cliente. Porto Alegre: Bookman.

ZEITHAML, V. A.; PARASURAMAN, A.; BERRY, L.L. (1990). Delivering Quality Service. New York: The Free Press. . (1991). Understanding customer expectations of service. Cambridge, EUA: Sloan Management Review. 


\section{GLOSSÁRIO}

Abordagem conjunta baseada em escolha - Forma alternativa de coleta de respostas e estimação do modelo conjunto. A diferença principal é que os respondentes selecionam um único perfil completo, a partir de um conjunto de estímulos (conhecido como conjunto de escolhas), em vez de avaliar ou ordenar cada estímulo separadamente.

Análise conjunta adaptativa - Metodologia para conduzir uma análise conjunta que conta com informações de respondentes (p.ex., importância dos atributos), para adaptar o delineamento conjunto, de modo a realizar a tarefa de maneira mais simples. Exemplos são os modelos auto-explicados e adaptativos ou híbridos.

Análise conjunta tradicional - Metodologia que emprega os princípios "clássicos" da análise conjunta, usando um modelo aditivo de preferência de consumidor e métodos de apresentação de comparação aos pares ou perfil completo.

Conjunto escolha - Conjunto de estímulos de perfil completo, construído por meio de princípios de delineamento de experimentos.

Correlação interatributo - Correlação entre atributos, também conhecida como correlação ambiental, que torna as combinações de atributos inacreditáveis ou redundantes.

Delineamento balanceado - Delineamento de estímulos no qual cada nível dentro de um fator aparece um número igual de vezes.

Delineamento fatorial fracionário - Abordagem como uma alternativa a um delineamento fatorial que emprega apenas um subconjunto dos possíveis estímulos necessários para estimar os resultados, com base na regra de 
composição assumida. Sua tarefa primária é reduzir o número de avaliações coletadas, embora ainda mantenha a ortogonalidade entre os níveis e as estimativas subseqüentes das utilidades parciais.

Delineamento fatorial - Método para planejar estímulos para avaliação, gerando todas as possíveis combinações de níveis de atributos.

Delineamento ótimo - Delineamento de estímulos que é ortogonal e balanceado.

Delineamento - Conjunto específico de estímulos conjuntos criado para exibir as propriedades estatísticas específicas de ortogonalidade e balanço.

Estrutura de preferência - Representação da importância ou utilidade relativa de cada fator e do impacto de níveis individuais que afetam a utilidade.

Fator - Variável que o pesquisador manipula e que representa um atributo específico. $\mathrm{Na}$ análise conjunta, os fatores (variáveis independentes) são nãométricos.

Método do perfil completo - Método de apresentação de estímulos aos respondentes para avaliação que consiste em uma descrição completa dos estímulos com todos os atributos.

Modelo adaptativo - Técnica para simplificar a análise conjunta, combinando os modelos conjuntos auto-explicados e tradicionais. O exemplo mais comum é a Análise Conjunta Adaptativa da Sawtooth Software.

Modelo aditivo - Modelo baseado na regra de composição aditiva, que considera que indivíduos apenas "adicionam" as utilidades parciais para calcular um escore geral ou "valor total" que indica a utilidade ou preferência. 
Nível - Valor específico que descreve um fator. Cada fator deve ser representado por dois ou mais níveis, mas o número de níveis jamais excede quatro ou cinco.

Ortogonal - Restrição matemática que exige que as estimativas das utilidades parciais sejam independentes uma das outras.

Parâmetro - quantidade característica da população. Por exemplo, média e variância são parâmetros populacionais. Estes parâmetros são estimados a partir de dados de uma amostra em que a média e a variância da amostra são utilizadas para estimar os parâmetros da população.

Utilidade - Um julgamento subjetivo de preferência por um indivíduo que representa o valor ou utilidade holística de um objeto específico. Em análise conjunta, utilidade é assumida como sendo formada pela combinação de estimativas de utilidades parciais para qualquer conjunto especificado de níveis, com o uso de um modelo aditivo.

Variável categórica (não-métrica) - Apresenta uma qualidade (ou atributo) da unidade pesquisada. Com elas, não podem ser feitos cálculos matemáticos, como soma e médias, mas apenas contagem de respostas por categorias (ex. sim ou não; $A, B$ ou C).

Variável estatística conjunta - Combinação de variáveis (conhecida como fatores) especificadas pelo pesquisador que constituem o valor ou utilidade total dos estímulos. O pesquisador também especifica todos os possíveis valores para cada fator, sendo estes valores conhecidos como níveis.

Variável métrica - Apresenta números resultantes de uma contagem ou mensuração, pode ser usada para cálculos matemáticos (somas e médias). 


\section{ANEXO 1 - RESULTADOS DA TÉCNICA DO INCIDENTE CRÍTICO}


Tabela 10: Faixa etária da amostra qualitativa.

\begin{tabular}{|c|c|}
\hline Idade & Percentual \\
\hline Entre 16-24 & $0,00 \%$ \\
\hline Entre 25-34 & $35,71 \%$ \\
\hline Entre $35-44$ & $42,86 \%$ \\
\hline Entre 45-54 & $0,00 \%$ \\
\hline Entre 55-64 & $7,14 \%$ \\
\hline Mais de 64 & $14,29 \%$ \\
\hline
\end{tabular}

Fonte: Pesquisa de campo

Tabela 11: Distribuição por sexo da amostra qualitativa.

\begin{tabular}{lr}
\hline \multicolumn{1}{c}{ Sexo } & Percentual \\
\hline Masculino & $56,25 \%$ \\
Feminino & $43,75 \%$ \\
\hline
\end{tabular}

Fonte: Pesquisa de campo

Tabela 12: Distribuição por estado civil da amostra qualitativa.

\begin{tabular}{|c|c|}
\hline Estado Civil & Percentual \\
\hline Solteiro & $37,50 \%$ \\
\hline Casado & $62,50 \%$ \\
\hline
\end{tabular}

Fonte: Pesquisa de campo 
Tabela 13: Tabela de Incidentes Críticos

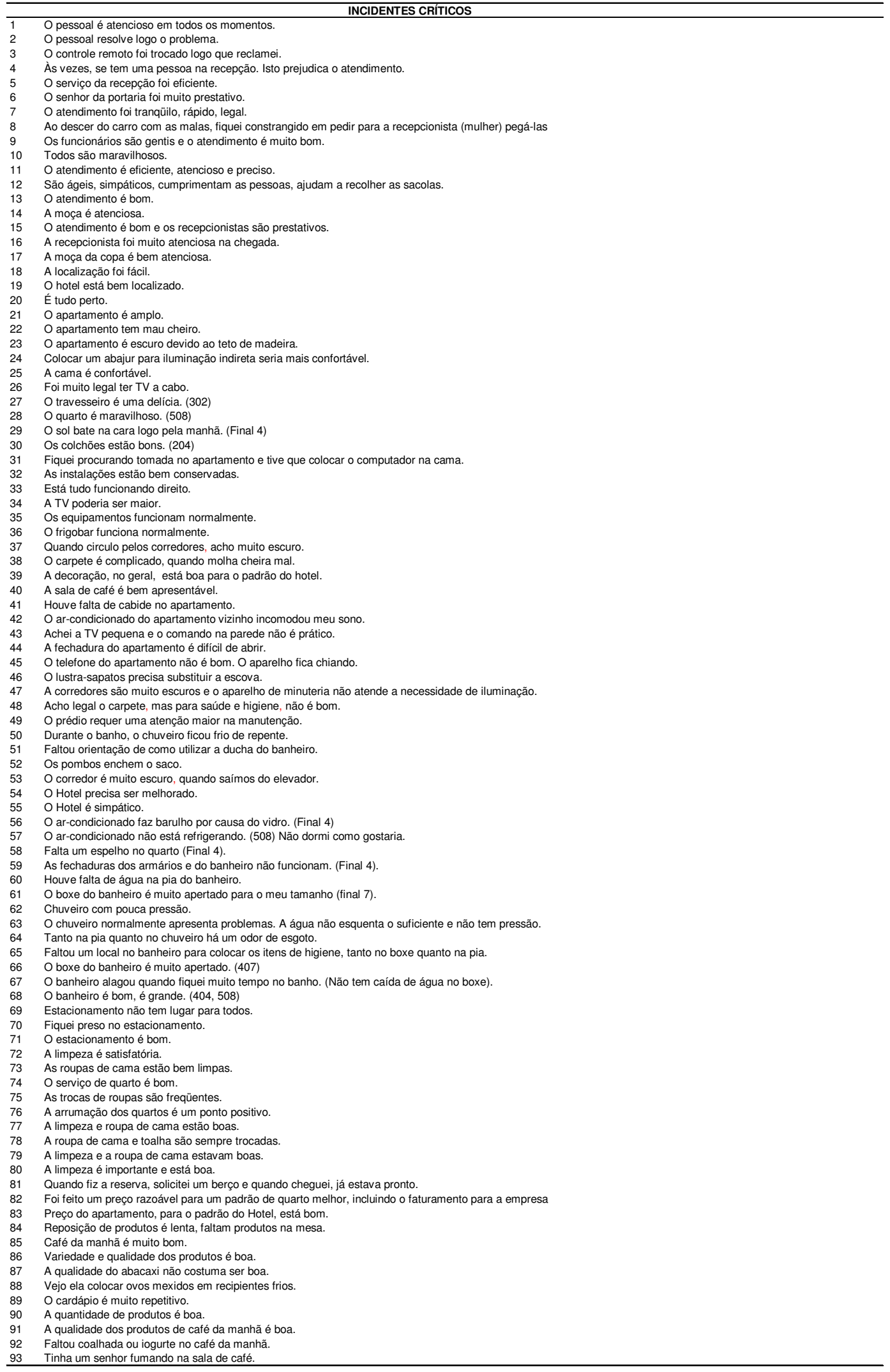




\section{Quadro 8: Quadro de itens de satisfação e seus respectivos incidentes críticos}

\section{ITENS DE SATISFACÃO}

\section{Atendimento \\ $\mathrm{O}$ atendimento foi eficiente}

Esperei pouco tempo para ser atendido

Atenderam-me com agilidade

Atenderam-me com simpatia

Meus problemas / solicitações foram resolvidos

Resolveram meus problemas/ solicitações em pouco tempo

Os funcionários do hotel foram prestativos às minhas necessidades

Localização

Cheguei com facilidade no Hotel

Foi fácil encontrar o Hotel

$\mathrm{O}$ acesso aos diferentes pontos da cidade foi rápido a partir do Hotel

Encontrei sinalização com facilidade

Estou perto de onde preciso ir

Apartamento

Meu apartamento era amplo

A iluminação estava adequada para leitura

A temperatura do apartamento estava agradável

A colchão estava confortável

Encontrei o apartamento limpo quando cheguei

Quando precisei, o apartamento estava adequado ao uso para o meu trabalho

Gostei da decoração

Senti "cheiro" de limpeza quando entrei no apartamento

A iluminação estava adequada ao meu descanso

\section{Equipamentos}

Consegui assistir à tv com clareza de imagem

$\mathrm{O}$ ar-condicionado/ ventilador deixaram a temperatura agradável

Fiz minhas chamadas telefônicas sem ruídos

Abri e fechei as portas com facilidade

Pude dormir sem ser incomodado por ruídos

Quando precisei, havia tomadas à minha disposição

O frigobar estava gelando bem

O carpete estava em boas condições

A iluminação dos corredores era adequada

O silêncio do apartamento permitiu que eu dormisse com tranqüilidade

A conservação geral dos equipamentos estava boa

A decoração era agradável

Tive orientação adequada para o uso dos equipamentos (ar, tv, chuveiro,etc))

Banheiro

O tamanho do banheiro era adequado

O banheiro tinha "cheiro de limpeza"

A pressão de água era confortável para meu banho

O tamanho do boxe era adequado

A temperatura da água do chuveiro era adequada

$\mathrm{O}$ banheiro era higiênico

Estacionamento

O estacionamento tinha vaga para meu carro

Senti-me seguro ao deixar meu carro no estacionamento

\section{Limpeza e arrumação}

As roupas de cama estavam limpas

Os corredores estavam limpos

As toalhas estavam limpas

Reserva

$O$ atendente tratou-me com atenção

Tudo que solicitei na reserva estava pronto quando cheguei ao Hotel

Fui informado dos serviços e produtos do Hotel para poder fazer minha reserva adequadamente Preço

O preço estava adequado às instalações

custo $\mathrm{x}$ benefício é adequado

Comparado a outros Hotéis, o preço do Hotel Flórida é adequado

Café da Manhã

O buffet estava sempre com produtos

A variedade de produtos era adequada

O cardápio foi bem variado ao longo da semana

A quantidade de produtos era adequada

O ambiente era agradável para alimentação

Quando precisei, a atendente foi prestativa

Os produtos eram de boa qualidade

Fonte: Pesquisa de campo. 
ANEXO 2 - RESULTADOS DA ANÁLISE CONJUNTA 


\section{Equipamentos}

1) TV 20" a cabo, Telefone com discagem direta, Frigobar e Ar Condicionado.

2) TV 14" a cabo, Telefone com discagem direta e Frigobar.

3) TV 14", Telefone com discagem direta.

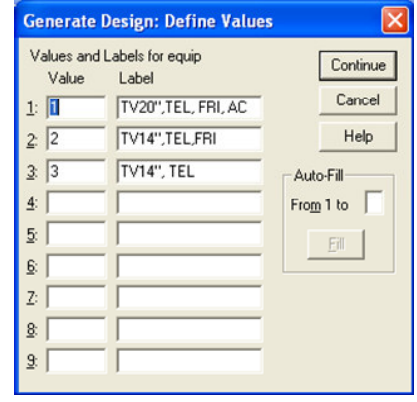

Figura 11: Fatores e Níveis no SPSS 9.0. (segue).

Fonte: Pesquisa de campo

\section{中 Projeto de Mestrado em Engenharia de Produção}

\section{Conforto do Apartamento}

1) Amplo(20m2), Cama Box-Spring, Bancada de Trabalho com acesso a Internet.

2) Mediano (17m2), Colchão de espuma densidade 33 (D33), Bancada de Trabalho.

3) Pequeno (12m2), Colchão de espuma densidade 33 (D33).

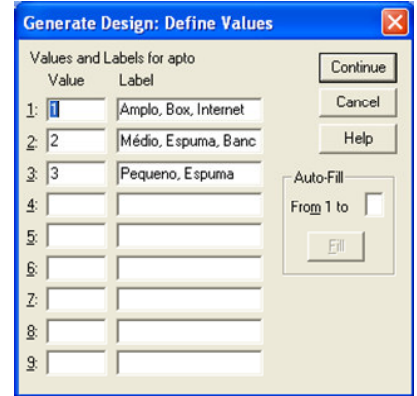

Figura 11: Fatores e Níveis no SPSS 9.0. (continuação).

Fonte: Pesquisa de campo 


\section{Serviços Disponíveis}

1) Recepção e Room-Service $24 \mathrm{~h}$, troca diária das roupas de cama e banho.

2) Recepção $24 \mathrm{~h}$, Room-Service das $15 \mathrm{~h}$ às $22 \mathrm{~h}$, troca das roupas de cama e banho a cada 2 dias.

3) Recepção $24 \mathrm{~h}$, troca das roupas de cama e banho a cada 3 dias.

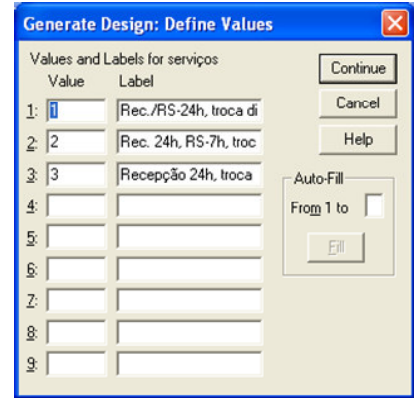

Figura 11: Fatores e Níveis no SPSS 9.0. (continuação).

Fonte: Pesquisa de campo

\section{nf Projeto de Mestrado em Engenharia de Produção}

\section{Café da manhã}

1) Ampla variedade e sortimento

2) Variedade e sortimento limitados

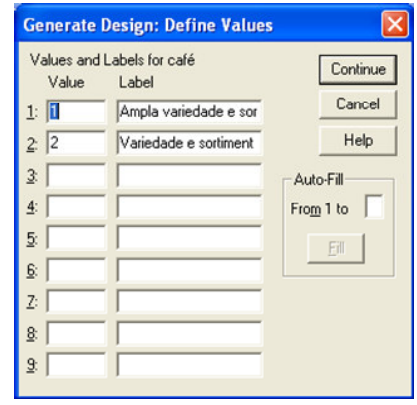

Figura 11: Fatores e Níveis no SPSS 9.0. (continuação).

Fonte: Pesquisa de campo 


\section{Conforto do Banheiro \\ 1) Ducha \\ 2) Chuveiro}

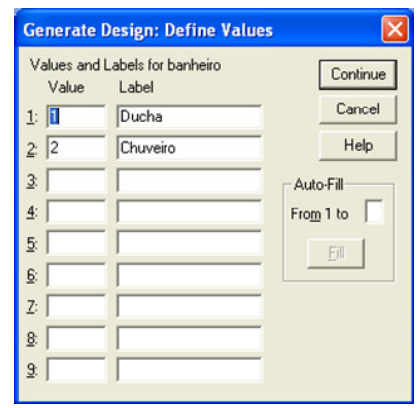

Figura 11: Fatores e Níveis no SPSS 9.0. (continuação).

Fonte: Pesquisa de campo

\section{Projeto de Mestrado em Engenharia de Produção}

\section{Desenho Ortogonal}

\section{1) Inclusão dos fatores e níveis}

2) Definição da amostra hold-out
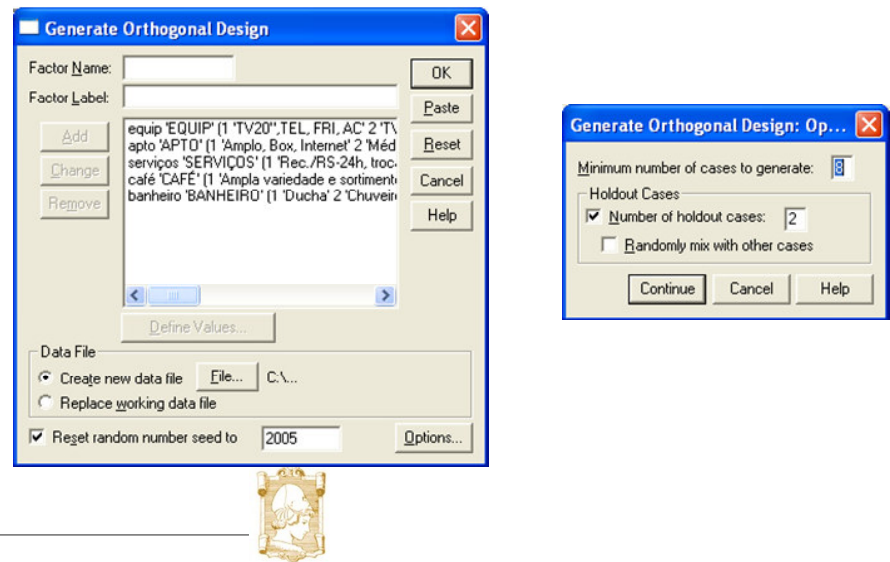

Figura 12: Delineamento fatorial fracionário no SPSS 9.0, com estímulos de validação.

Fonte: Pesquisa de campo 


\section{* Projeto de Mestrado em Engenharia de Produção}

\section{Desenho Ortogonal}

\begin{tabular}{|c|c|c|c|c|c|c|c|}
\hline & equip & apto & serviços & café & banheiro & status_ & card_ \\
\hline 1 & 1,00 & 1,00 & 3,00 & 2,00 & 2,00 & 0 & 1 \\
\hline 2 & 2,00 & 3,00 & 1,00 & 2,00 & 1,00 & 0 & 2 \\
\hline 3 & 1,00 & 3,00 & 1,00 & 2,00 & 2,00 & 0 & 3 \\
\hline 4 & 3,00 & 1,00 & 2,00 & 2,00 & 1,00 & 0 & 4 \\
\hline 5 & 3,00 & 2,00 & 1,00 & 2,00 & 1,00 & 0 & 5 \\
\hline 6 & 1,00 & 1,00 & 1,00 & 1,00 & 1,00 & 0 & 6 \\
\hline 7 & 2,00 & 2,00 & 2,00 & 1,00 & 2,00 & 0 & 7 \\
\hline 8 & 1,00 & 2,00 & 3,00 & 1,00 & 1,00 & 0 & 8 \\
\hline 9 & 1,00 & 1,00 & 2,00 & 2,00 & 2,00 & 0 & 9 \\
\hline 10 & 1,00 & 3,00 & 2,00 & 1,00 & 1,00 & 0 & 10 \\
\hline 11 & 2,00 & 1,00 & 3,00 & 2,00 & 1,00 & 0 & 11 \\
\hline 12 & 3,00 & 3,00 & 3,00 & 1,00 & 2,00 & 0 & 12 \\
\hline 13 & 1,00 & 2,00 & 1,00 & 2,00 & 2,00 & 0 & 13 \\
\hline 14 & 2,00 & 1,00 & 1,00 & 1,00 & 2,00 & 0 & 14 \\
\hline 15 & 1,00 & 1,00 & 1,00 & 1,00 & 1,00 & 0 & 15 \\
\hline 16 & 3,00 & 1,00 & 1,00 & 1,00 & 2,00 & 0 & 16 \\
\hline 17 & 3,00 & 3,00 & 3,00 & 2,00 & 1,00 & 1 & 17 \\
\hline 18 & 2,00 & 1,00 & 3,00 & 2,00 & 2,00 & 1 & 18 \\
\hline
\end{tabular}

Figura 13: Resultado de delineamento fatorial fracionário.

Fonte: Pesquisa de campo 
Estímulos gerados pelo planejamento fatorial fracionário da função ORTGHONAL DESIGN do software estatístico SPSS, versão 9.0.

Cartão 1

EQUIP TV20",TEL, FRI, AC

APTO Amplo, Box, Internet

SERVIÇOS Rec. 24h, RS-7h, troca a cada 2 dias

CAFÉ Variedade e sortimento limitados

BANHEIRO Chuveiro

Cartão 2

EQUIP TV14", TEL

APTO Amplo, Box, Internet

SERVIÇOS Rec./RS-24h, troca diária de roupa

CAFÉ Ampla variedade e sortimento

BANHEIRO Chuveiro

Cartão 3

EQUIP TV14",TEL,FRI

APTO Amplo, Box, Internet

SERVIÇOS Rec. 24h, RS-7h, troca a cada 2 dias

CAFÉ Ampla variedade e sortimento

BANHEIRO Chuveiro

Cartão 4

EQUIP TV14",TEL,FRI

APTO Médio, Espuma, Bancada

SERVIÇOS Rec./RS-24h, troca diária de roupa

CAFÉ Variedade e sortimento limitados

BANHEIRO Ducha 
Cartão 5

EQUIP TV20",TEL, FRI, AC

APTO Pequeno, Espuma

SERVIÇOS Recepção 24h, troca a cada 3 dias

CAFÉ Variedade e sortimento limitados

BANHEIRO Chuveiro

Cartão 6

EQUIP TV20",TEL, FRI, AC

APTO Pequeno, Espuma

SERVIÇOS Rec./RS-24h, troca diária de roupa

CAFÉ Ampla variedade e sortimento

BANHEIRO Ducha

Cartão 7

EQUIP TV14", TEL

APTO Médio, Espuma, Bancada

SERVIÇOS Recepção 24h, troca a cada 3 dias

CAFÉ Ampla variedade e sortimento

BANHEIRO Chuveiro

Cartão 8

EQUIP TV14",TEL,FRI

APTO Pequeno, Espuma

SERVIÇOS Rec./RS-24h, troca diária de roupa

CAFÉ Ampla variedade e sortimento

BANHEIRO Chuveiro 
Cartão 9

EQUIP TV20",TEL, FRI, AC

APTO Médio, Espuma, Bancada

SERVIÇOS Rec./RS-24h, troca diária de roupa

CAFÉ Variedade e sortimento limitados

BANHEIRO Chuveiro

Cartão 10

EQUIP TV14",TEL,FRI

APTO Amplo, Box, Internet

SERVIÇOS Recepção 24h, troca a cada 3 dias

CAFÉ Variedade e sortimento limitados

BANHEIRO Ducha

Cartão 11

EQUIP TV14", TEL

APTO Amplo, Box, Internet

SERVIÇOS Rec./RS-24h, troca diária de roupa

CAFÉ Variedade e sortimento limitados

BANHEIRO Ducha

Cartão 12

EQUIP TV20",TEL, FRI, AC

APTO Amplo, Box, Internet

SERVIÇOS Recepção 24h, troca a cada 3 dias

CAFÉ Ampla variedade e sortimento

BANHEIRO Ducha 
Cartão 13

EQUIP TV14", TEL

APTO Pequeno, Espuma

SERVIÇOS Rec. $24 \mathrm{~h}, \mathrm{RS}-7 \mathrm{~h}$, troca a cada 2 dias

CAFÉ Variedade e sortimento limitados

BANHEIRO Ducha

Cartão 14

EQUIP TV20",TEL, FRI, AC

APTO Amplo, Box, Internet

SERVIÇOS Rec./RS-24h, troca diária de roupa

CAFÉ Variedade e sortimento limitados

BANHEIRO Chuveiro

Cartão 15

EQUIP TV20",TEL, FRI, AC

APTO Amplo, Box, Internet

SERVIÇOS Rec./RS-24h, troca diária de roupa

CAFÉ Ampla variedade e sortimento

BANHEIRO Ducha

Cartão 16

EQUIP TV20",TEL, FRI, AC

APTO Médio, Espuma, Bancada

SERVIÇOS Rec. $24 \mathrm{~h}, \mathrm{RS}-7 \mathrm{~h}$, troca a cada 2 dias

CAFÉ Ampla variedade e sortimento

BANHEIRO Ducha 
Cartão 17

EQUIP TV14", TEL

APTO Pequeno, Espuma

SERVIÇOS Rec./RS-24h, troca diária de roupa

CAFÉ Ampla variedade e sortimento

BANHEIRO Chuveiro

Cartão 18

EQUIP TV20",TEL, FRI, AC

APTO Médio, Espuma, Bancada

SERVIÇOS Recepção 24h, troca a cada 3 dias

CAFÉ Variedade e sortimento limitados

BANHEIRO Ducha 
Tabela 14: Dados demográficos da amostra do experimento conjunto.

\begin{tabular}{lcc}
\hline & Sexo & Amostra \\
\cline { 2 - 3 } & & Percentual \\
\hline Homens & Idade & $81,82 \%$ \\
Mulheres & $18,18 \%$ \\
\hline & \\
\hline Entre 16-24 & $15,15 \%$ \\
Entre 25-34 & $39,39 \%$ \\
Entre 35-44 & $21,21 \%$ \\
Entre 45-54 & $15,15 \%$ \\
Entre 55-64 & $9,09 \%$ \\
Maiores de 65 & $0,00 \%$ \\
\hline
\end{tabular}

Grau de escolaridade

\begin{tabular}{lc}
\hline Ensino fundamental & $6,06 \%$ \\
Ensino médio & $36,36 \%$ \\
Ensino superior & $30,30 \%$ \\
Pós graduação & $27,27 \%$ \\
\hline
\end{tabular}

\begin{tabular}{lc}
\hline \multicolumn{1}{c}{ Renda familiar } \\
\hline Não responderam & $48,48 \%$ \\
Entre 1 e 10 salários & $15,15 \%$ \\
Entre 11 e 20 salários & $9,09 \%$ \\
Entre 21 e 30 salários & $18,18 \%$ \\
Acima de 31 salários & $9,09 \%$ \\
\hline & \\
\hline \multicolumn{1}{c}{ Escolha do hotel } \\
\hline Não responderam \\
Entre 1 e 10 salários \\
Entre 11 e 20 salários \\
Entre 21 e 30 salários \\
Acima de 31 salários \\
\hline
\end{tabular}

Fonte: Pesquisa de campo 


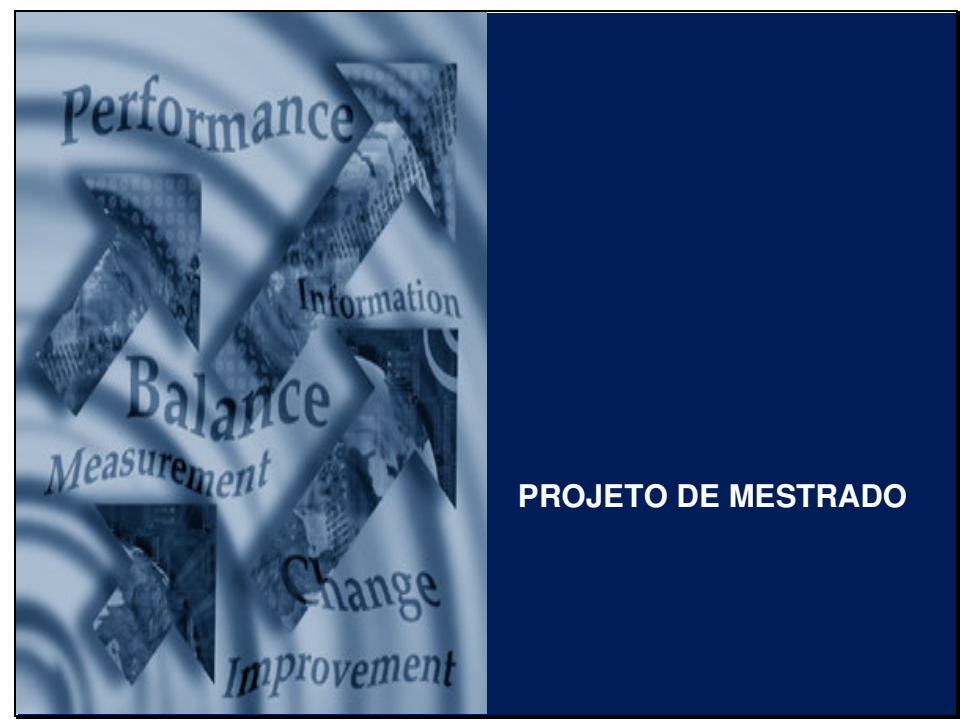

Figura 14: Instruções das entrevistas pessoais de coleta de dados e questionários. (segue)

Fonte: Pesquisa de campo

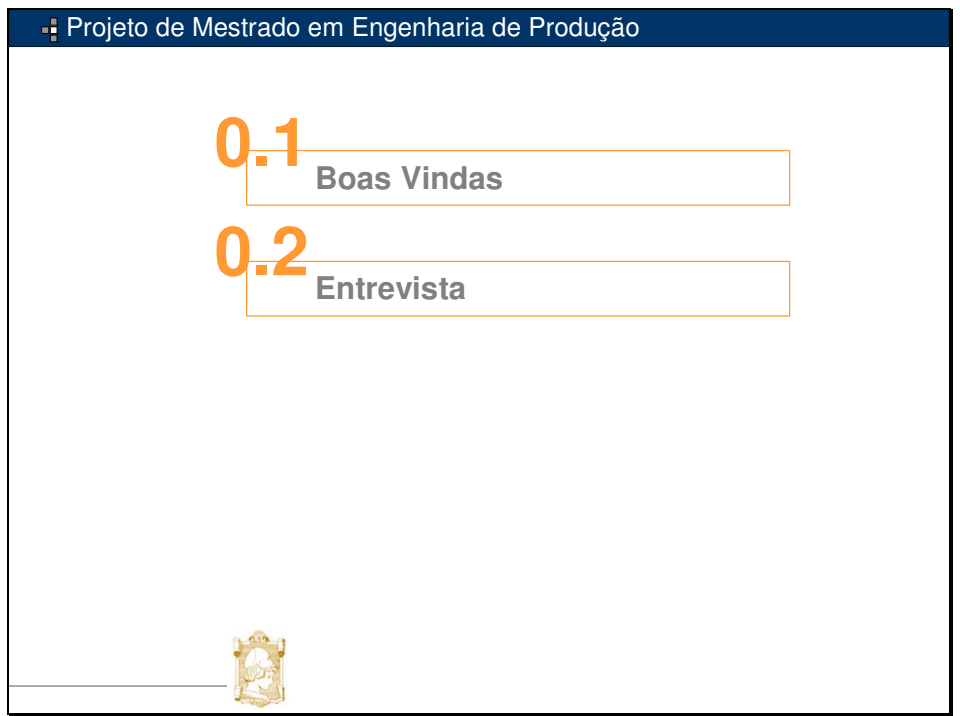

Figura 14: Instruções das entrevistas pessoais de coleta de dados e questionários. (continuação)

Fonte: Pesquisa de campo 


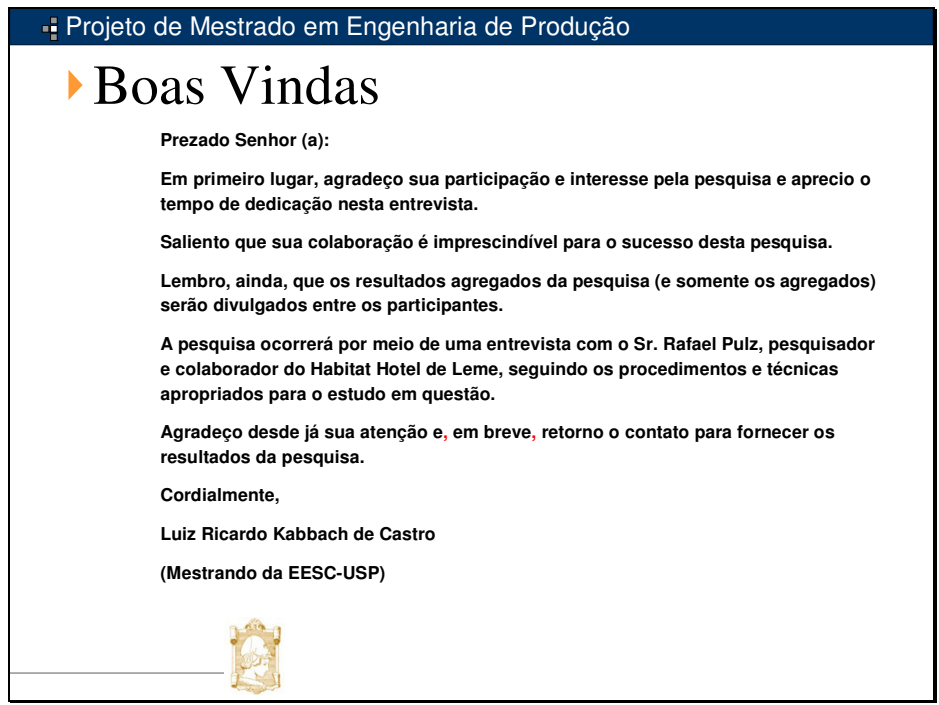

Figura 14: Instruções das entrevistas pessoais de coleta de dados e questionários. (continuação)

Fonte: Pesquisa de campo

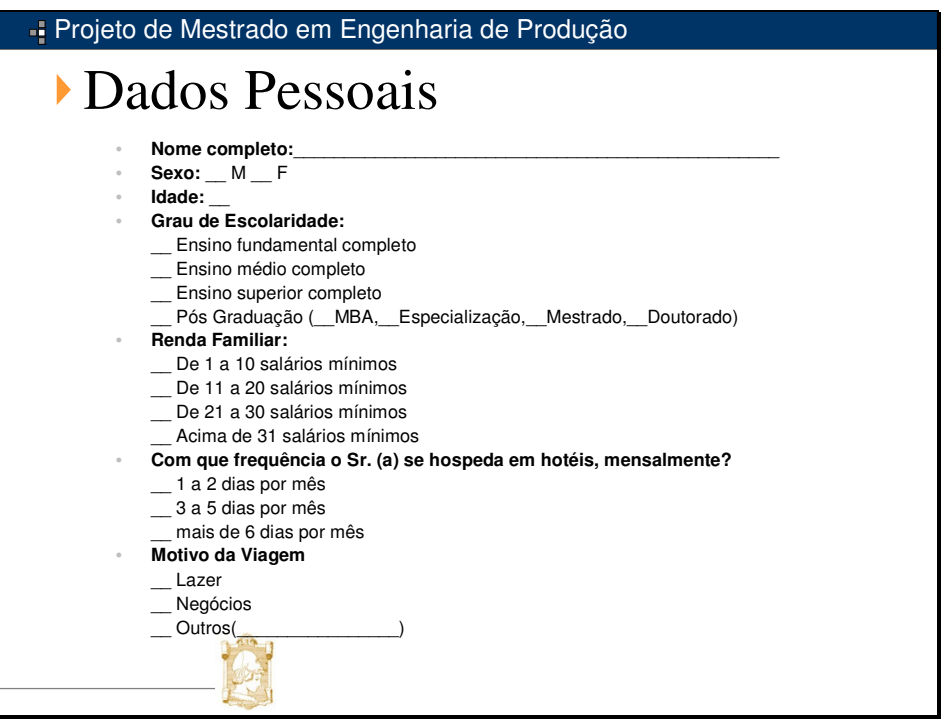

Figura 14: Instruções das entrevistas pessoais de coleta de dados e questionários. (continuação)

Fonte: Pesquisa de campo 


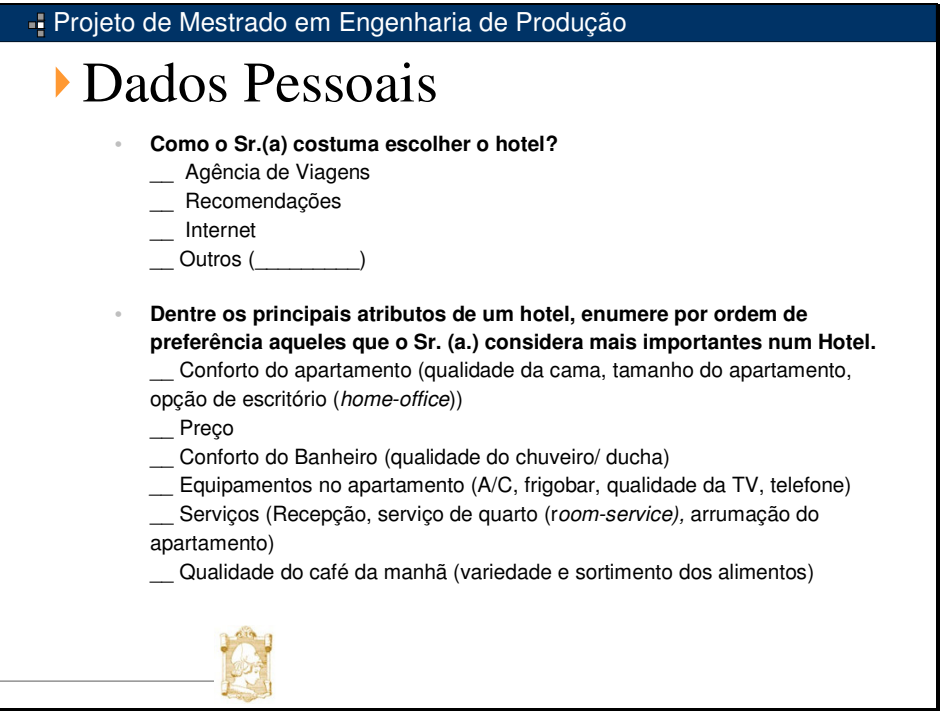

Figura 14: Instruções das entrevistas pessoais de coleta de dados e questionários. (continuação)

Fonte: Pesquisa de campo

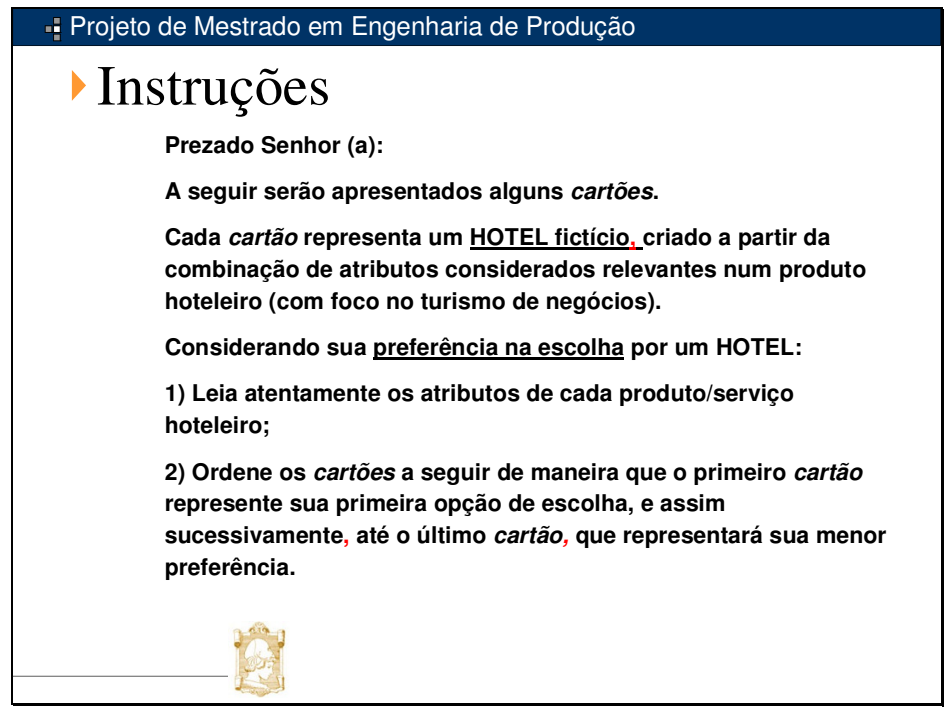

Figura 14: Instruções das entrevistas pessoais de coleta de dados e questionários. (continuação)

Fonte: Pesquisa de campo 


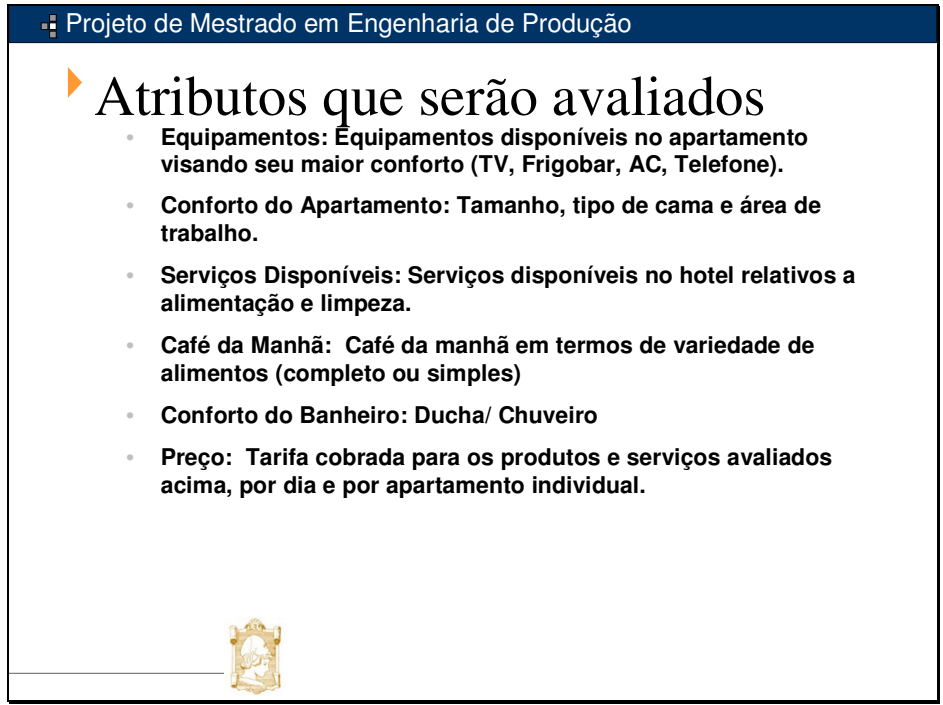

Figura 14: Instruções das entrevistas pessoais de coleta de dados e questionários. (continuação)

Fonte: Pesquisa de campo

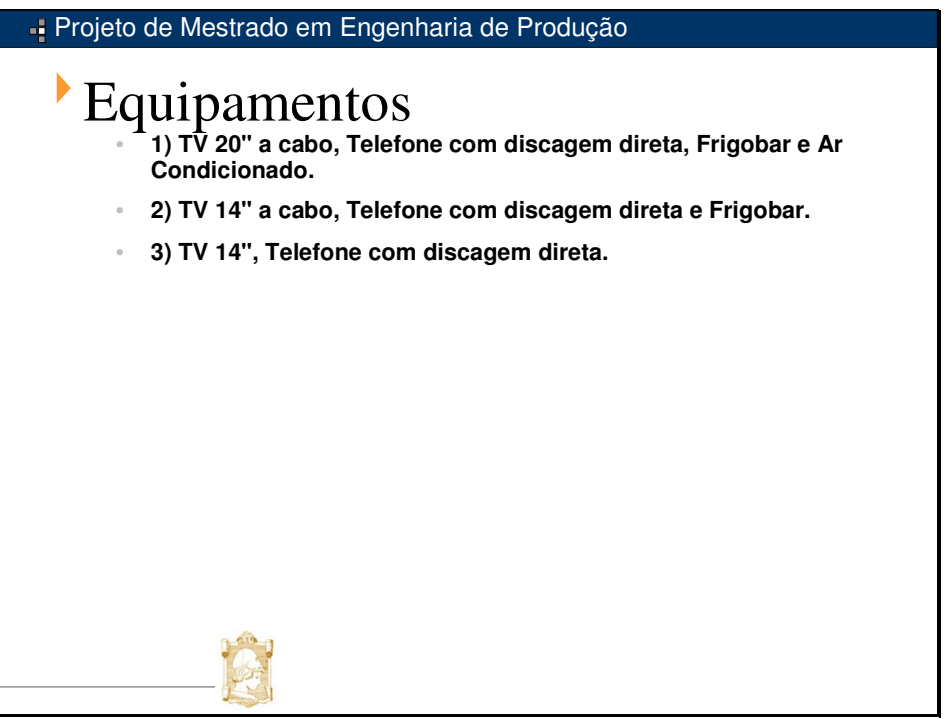

Figura 14: Instruções das entrevistas pessoais de coleta de dados e questionários. (continuação)

Fonte: Pesquisa de campo 


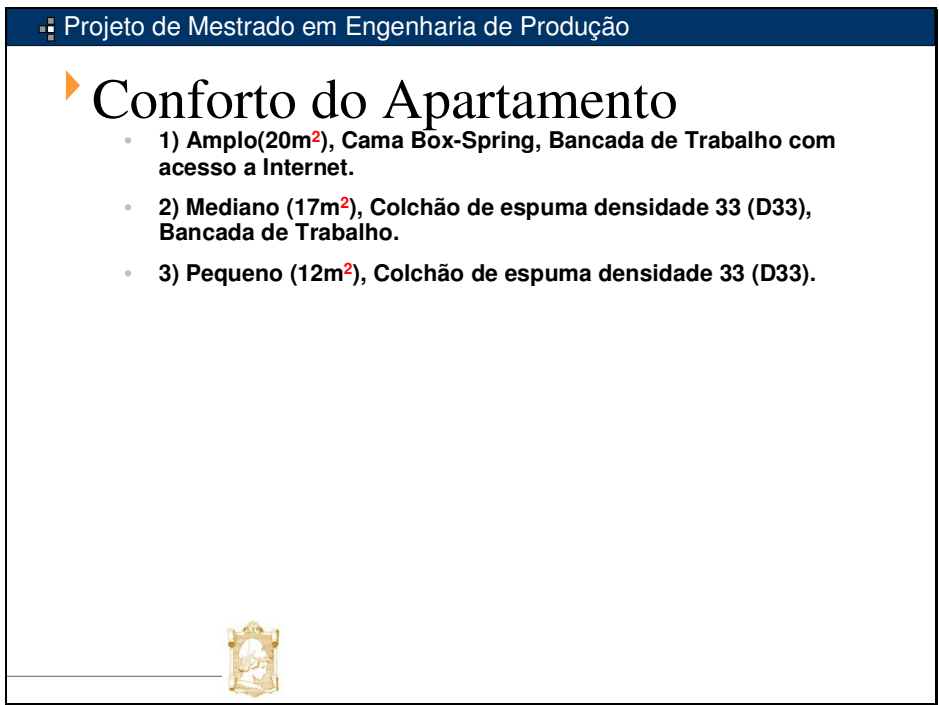

Figura 14: Instruções das entrevistas pessoais de coleta de dados e questionários. (continuação)

Fonte: Pesquisa de campo

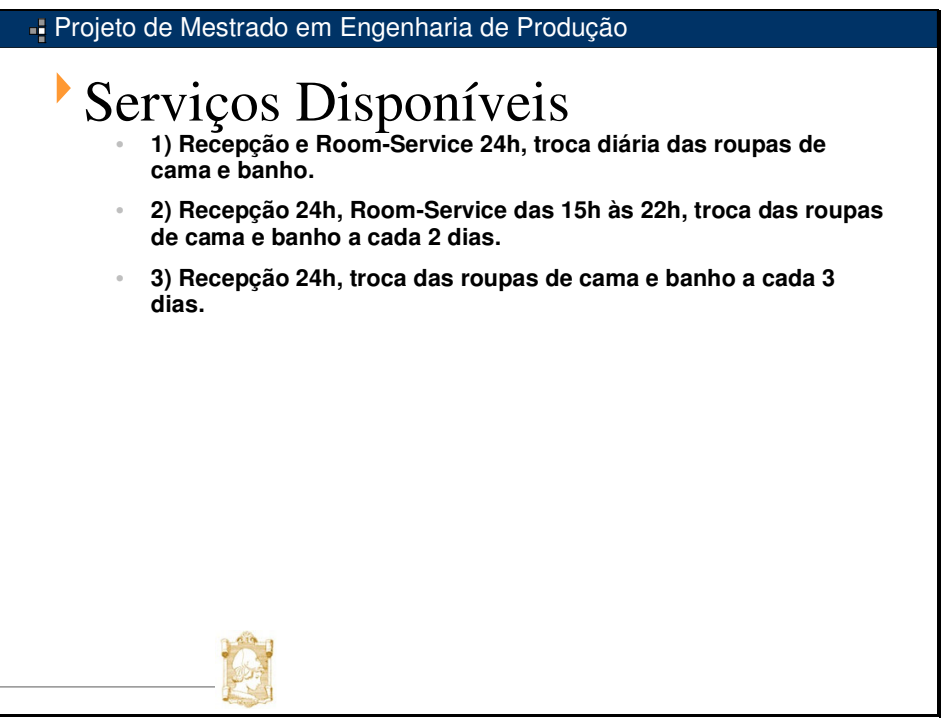

Figura 14: Instruções das entrevistas pessoais de coleta de dados e questionários. (continuação)

Fonte: Pesquisa de campo 


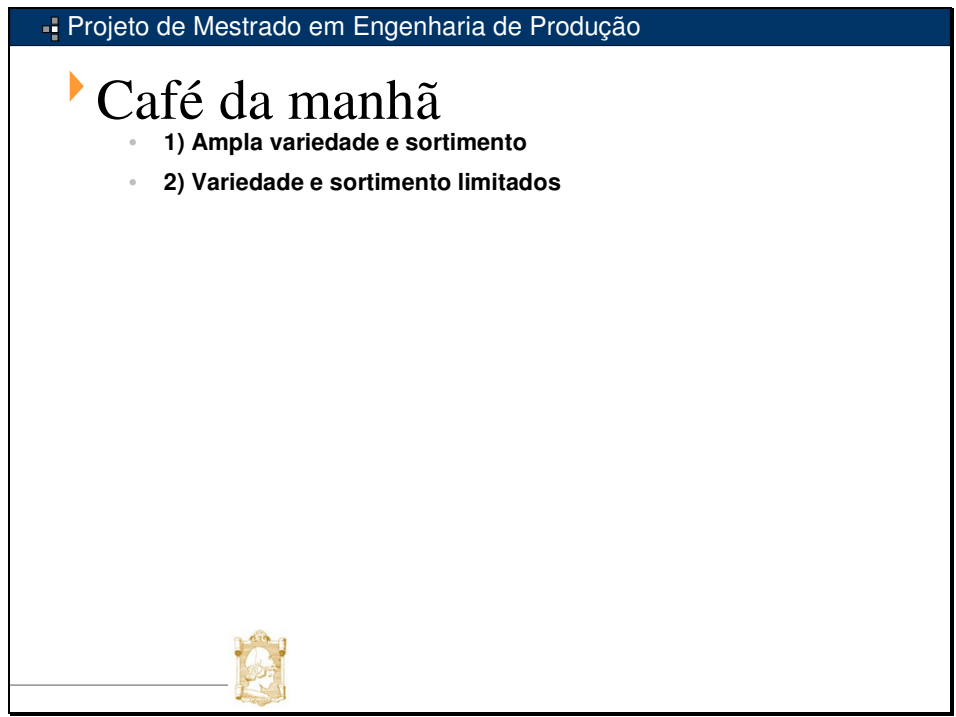

Figura 14: Instruções das entrevistas pessoais de coleta de dados e questionários. (continuação)

Fonte: Pesquisa de campo

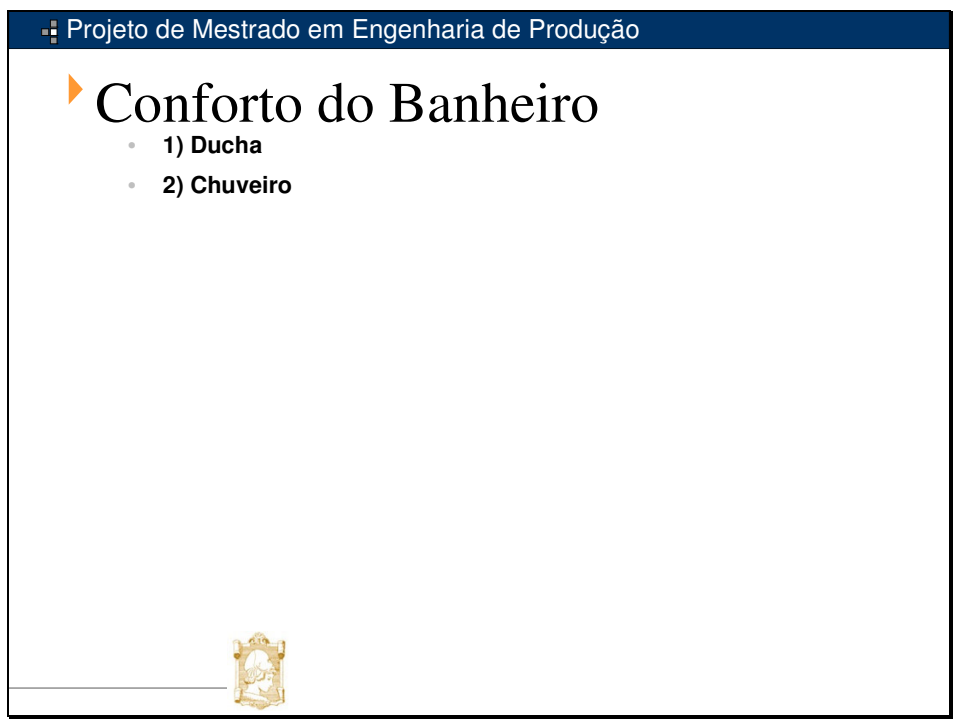

Figura 14: Instruções das entrevistas pessoais de coleta de dados e questionários. (continuação)

Fonte: Pesquisa de campo 


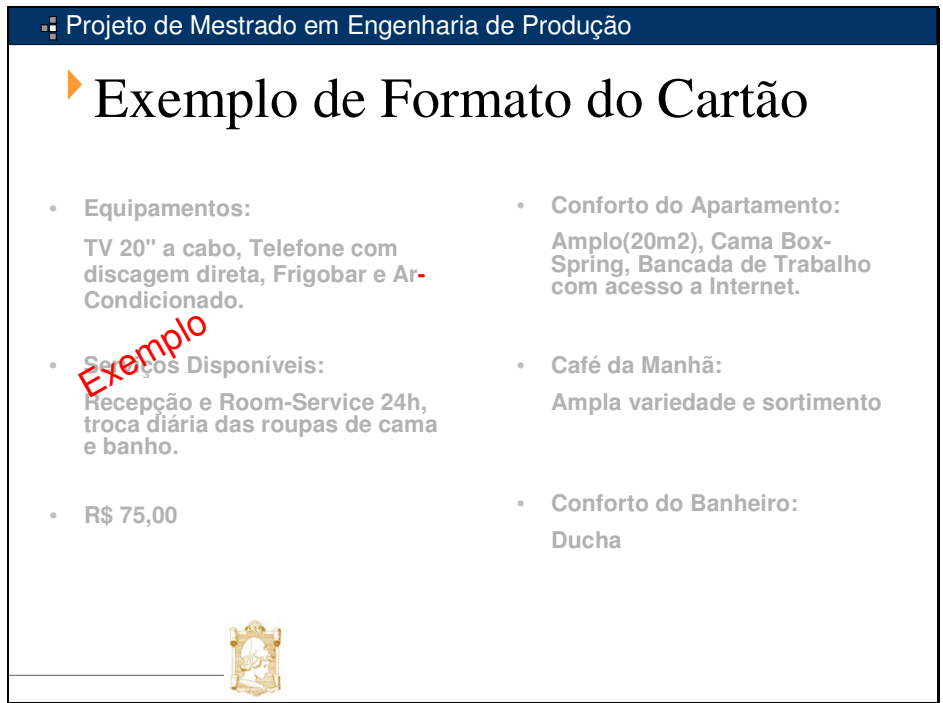

Figura 14: Instruções das entrevistas pessoais de coleta de dados e questionários. (continuação)

Fonte: Pesquisa de campo 


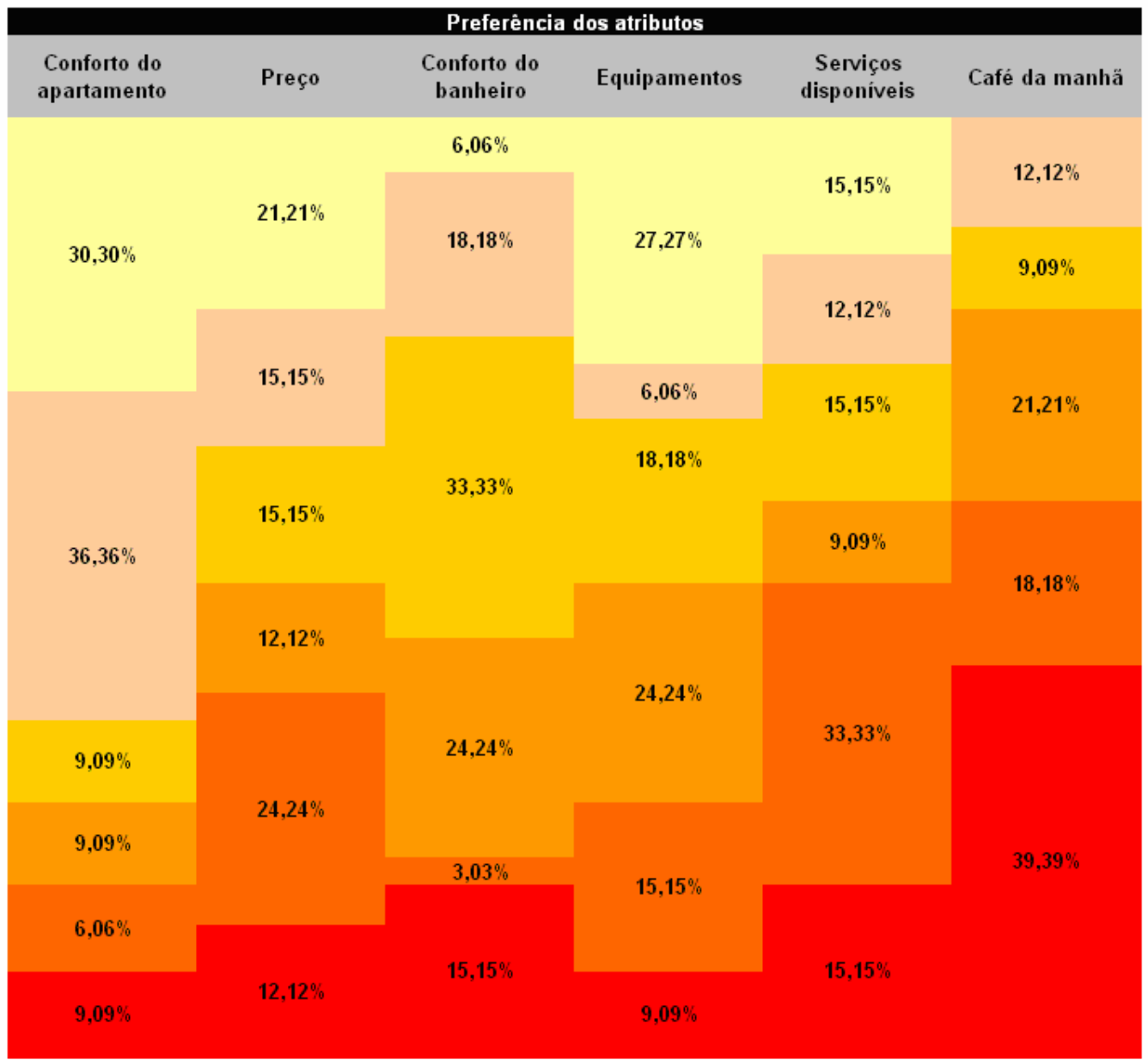

Ordem de preferência

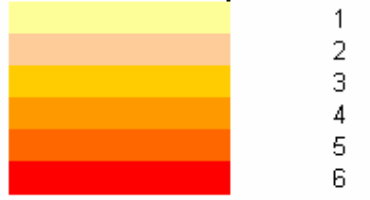

Figura 15: Preferência dos atributos pelos respondentes no questionário preliminar.

Fonte: Pesquisa de campo 
CONJOINT PLAN='C:IProgram FilesiSPSSMestradolCampołDesenho_Ortogonal_111205_V2_EXP.sav'

IDATA='C: $:$ Program FilesiSPSSMestradoiCampołDados_090106_D33. sav'

/SEQUENCE=PREF1 TO PREF18

ISUB.JECT=ID

/FACTORS= EQUIP (DISCRETE) APTO (DISCRETE) SERVIÇOS (DISCRETE) CAFÉ (DISCRETE) BANHEIRO (DISCRETE)

/PRINT=SUMMARYONLY

/UTILITY='RESULTADO_090106_UTIL_D33.SAV'

SAVE OUTFILE='RESULTADO RANK_ 090106.SAV'.

Figura 16: Sintaxe do planejamento do experimento. 

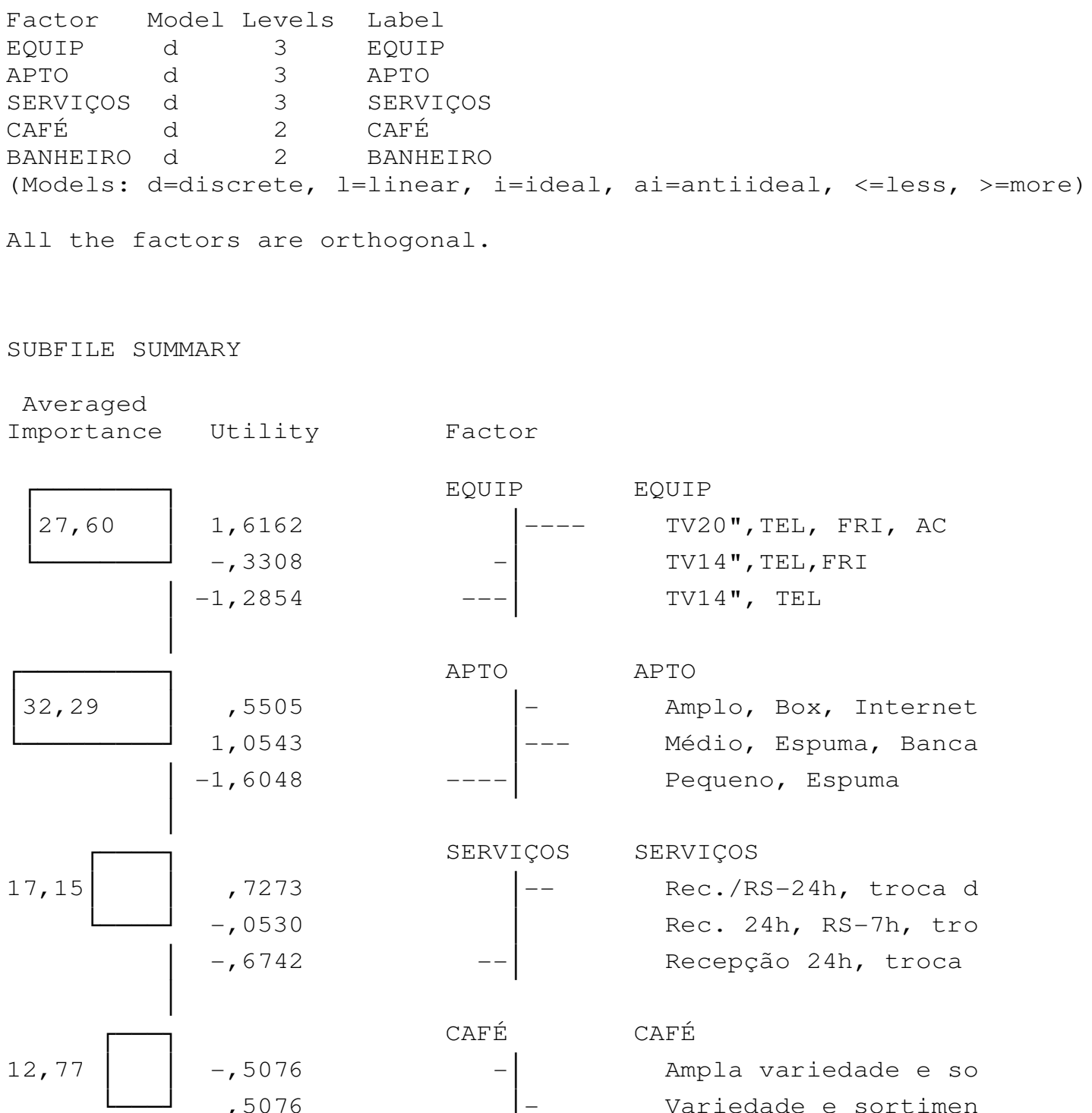

$-, 5076$ , 5076

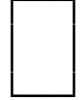

, 6136

$-, 6136$

7,7765

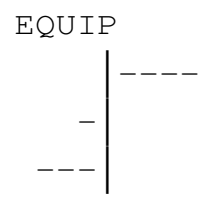

EQUIP

TV20", TEL, FRI, AC

TV14", TEL, FRI

TV14", TEL

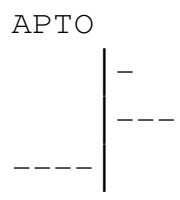

APTO

Amplo, Box, Internet Médio, Espuma, Banca

Pequeno, Espuma

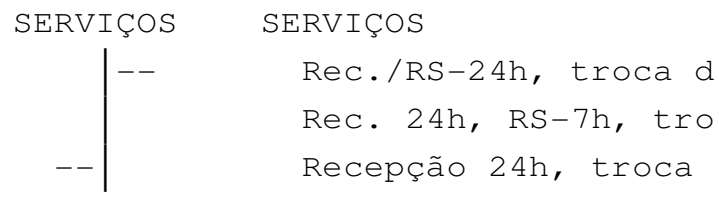

CAFÉ<smiles>[I-][I-]</smiles>

CAFÉ

Ampla variedade e so Variedade e sortimen

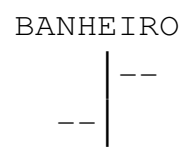

BANHEIRO

Ducha

Chuveiro

CONSTANT

Pearson's $\mathrm{R}=, 949$

Kendall's tau $=, 783$

Kendall's tau $=1,000$ for 2 holdouts

Significance $=, 0000$

Significance $=, 0000$

Significance $=$

SUBFILE SUMMARY

No reversals occured in this split file group.

Figura 17: Arquivo de saída do SPSS, versão 9.0.

Fonte: Pesquisa de campo 


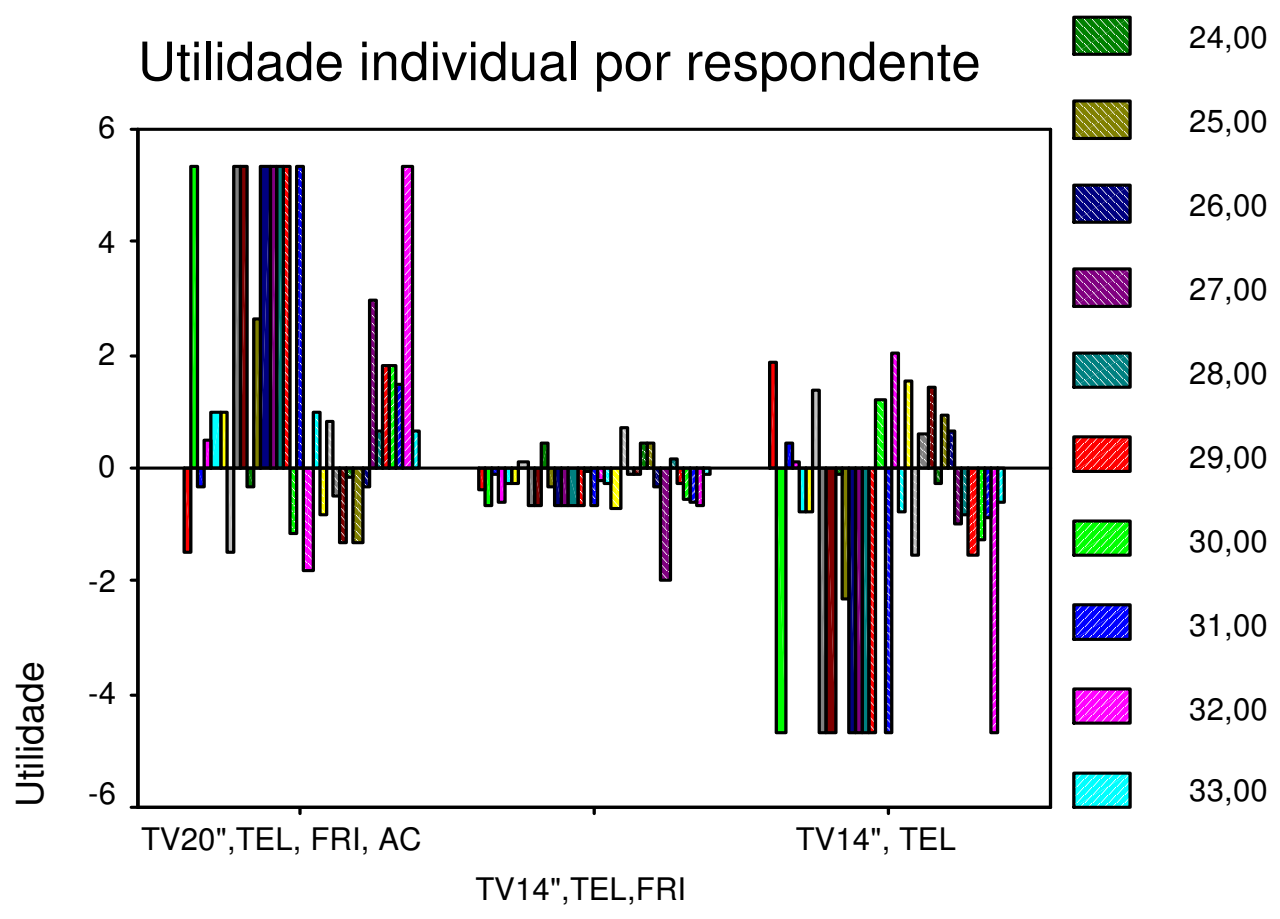

Atributo: Equipamentos

Figura 18: Utilidade individual do atributo equipamentos.

Utilidade individual por respondente

24,00

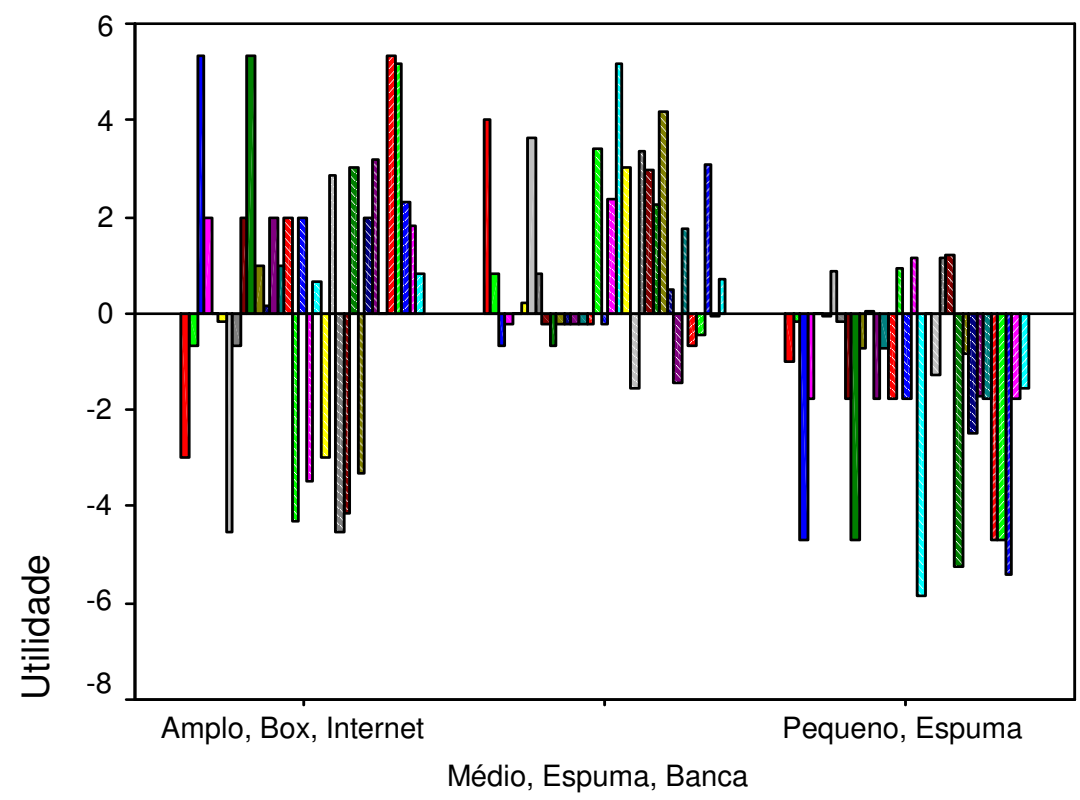

25,00

26,00

27,00

28,00

29,00

30,00

U1, 31,00

32,00

Atributo: Conforto do apartamento

Figura 19: Utilidade individual do atributo conforto do apartamento. 


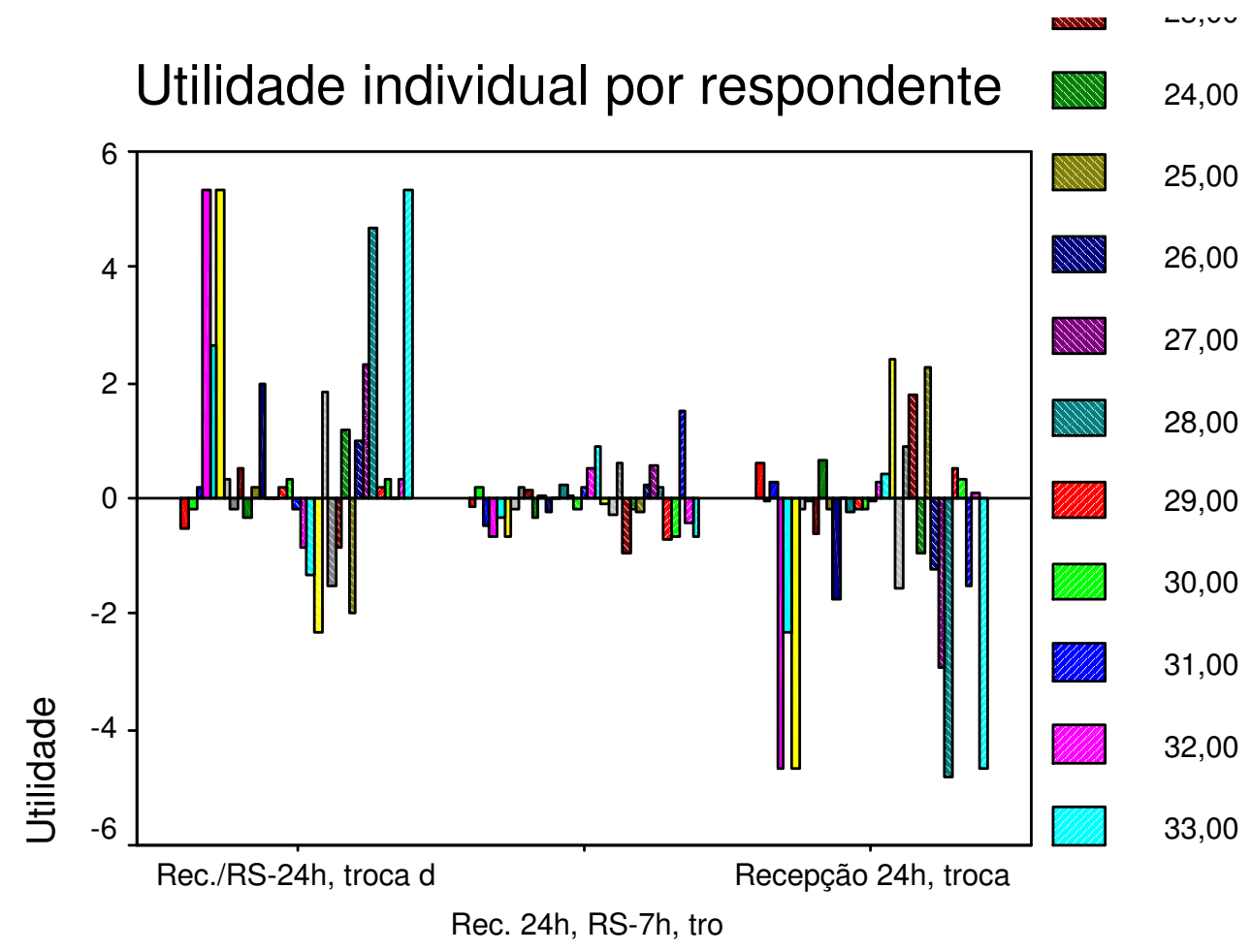

Atributo: Serviços disponíveis

Figura 20: Utilidade individual do atributo serviços disponíveis.

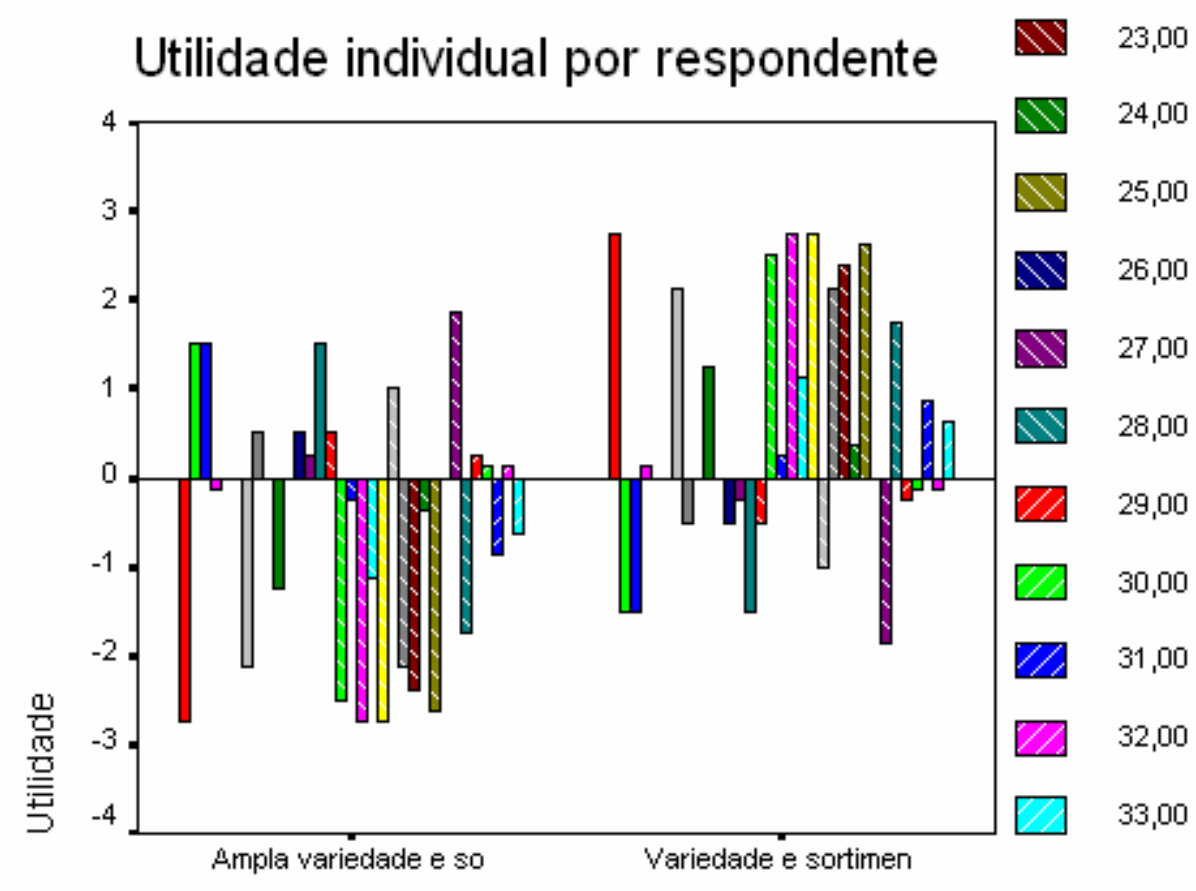

Atributo: Café da manhẫ

Figura 21: Utilidade individual do atributo café da manhã. 


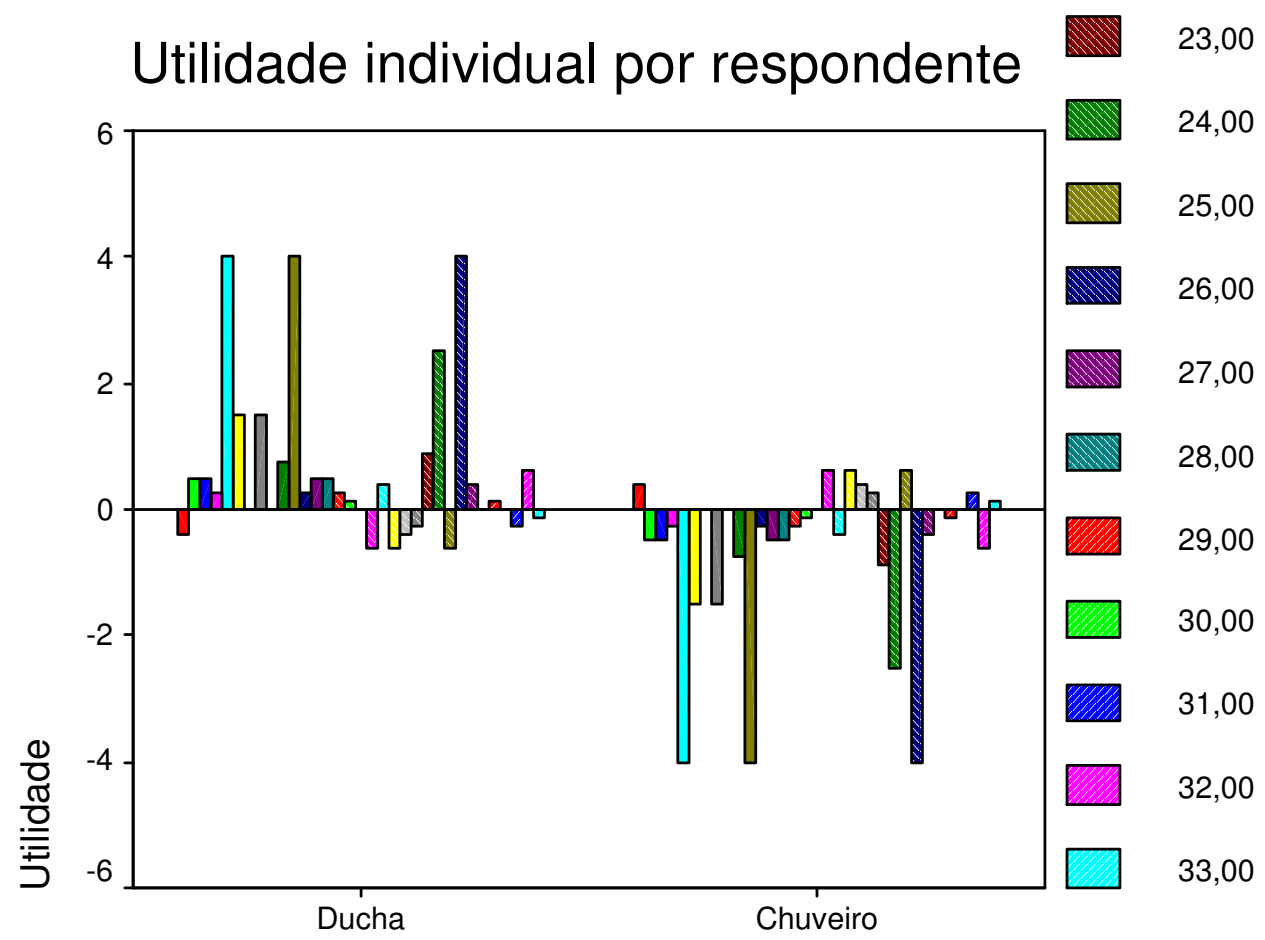

Atributo: Conforto do banheiro

Figura 22: Utilidade individual do atributo conforto do banheiro.

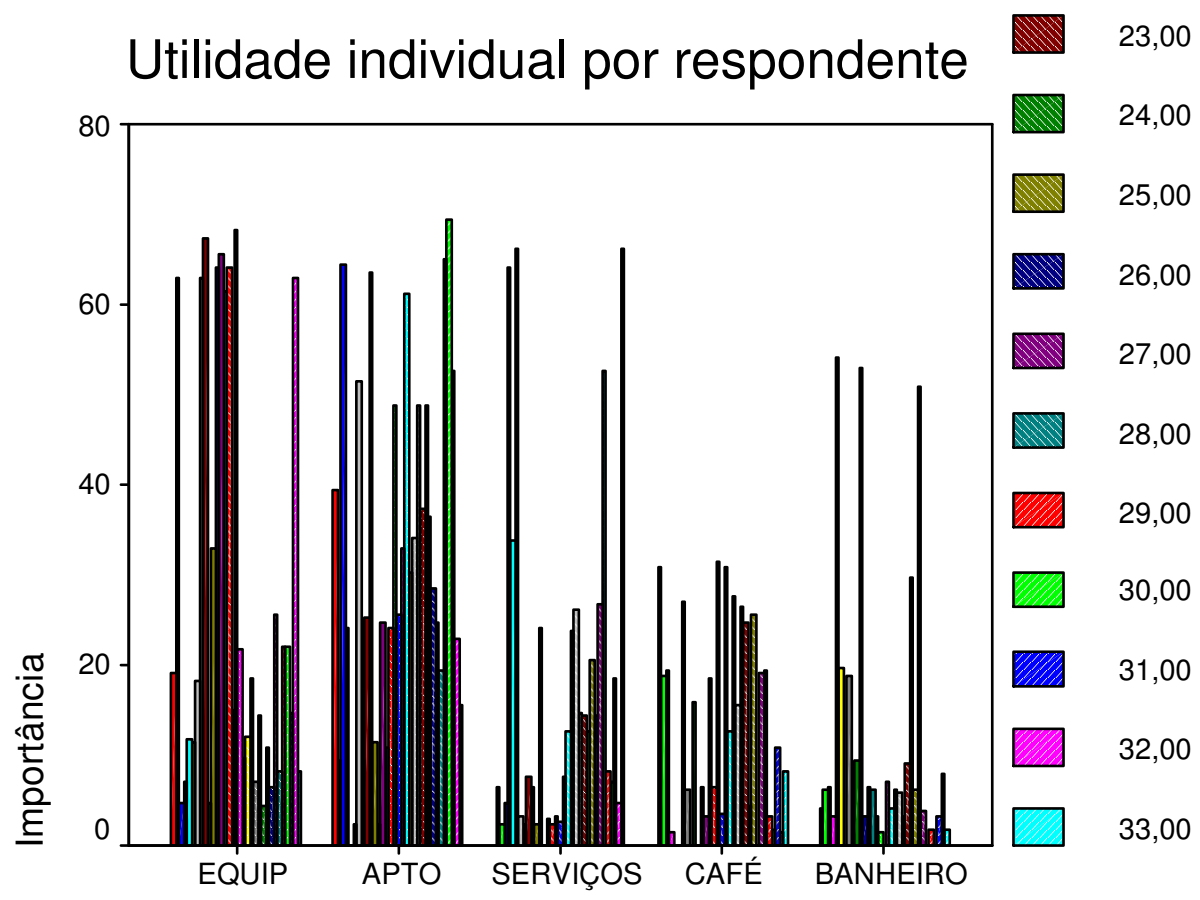

Fator (Atributo)

Figura 23: Utilidade individual consolidada dos atributos do experimento. 
Utilidade agregada por nível de fator.

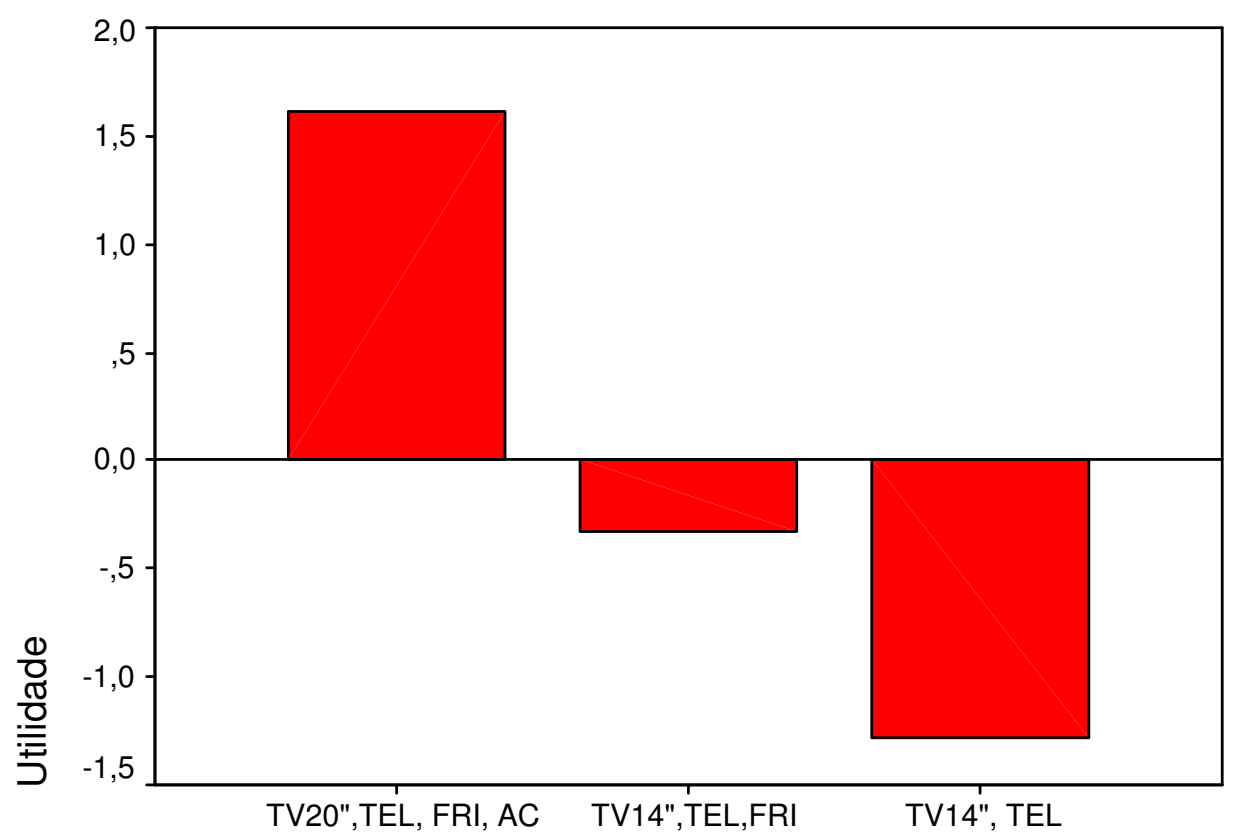

Atributo: Equipamentos

Figura 24: Utilidade agregada do atributo equipamentos.

Utilidade agregada por nível de fator.

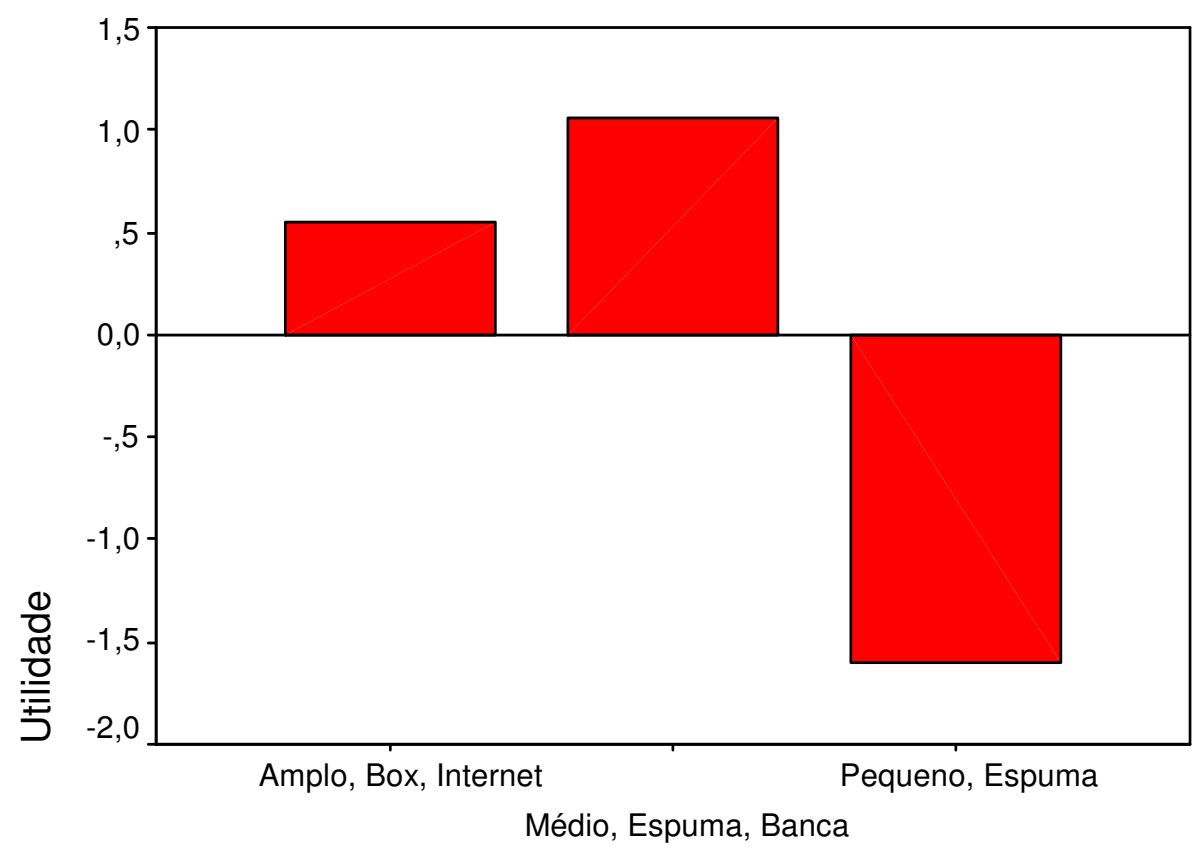

Atributo: Conforto do apartamento

Figura 25: Utilidade agregada do atributo conforto do apartamento. 
Utilidade agregada por nível de fator.

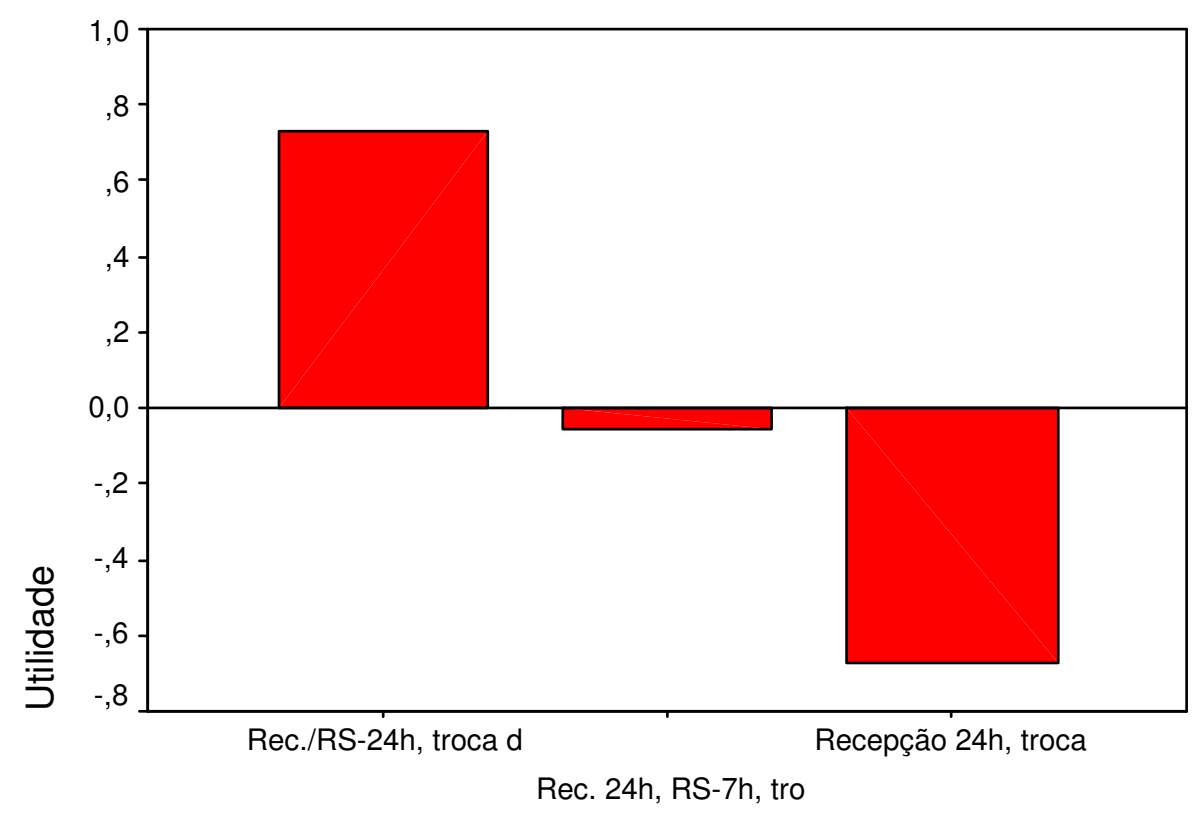

Atributo: Serviços disponíveis

Figura 26: Utilidade agregada do atributo serviços disponíveis.

Utilidade agregada por nível de fator.

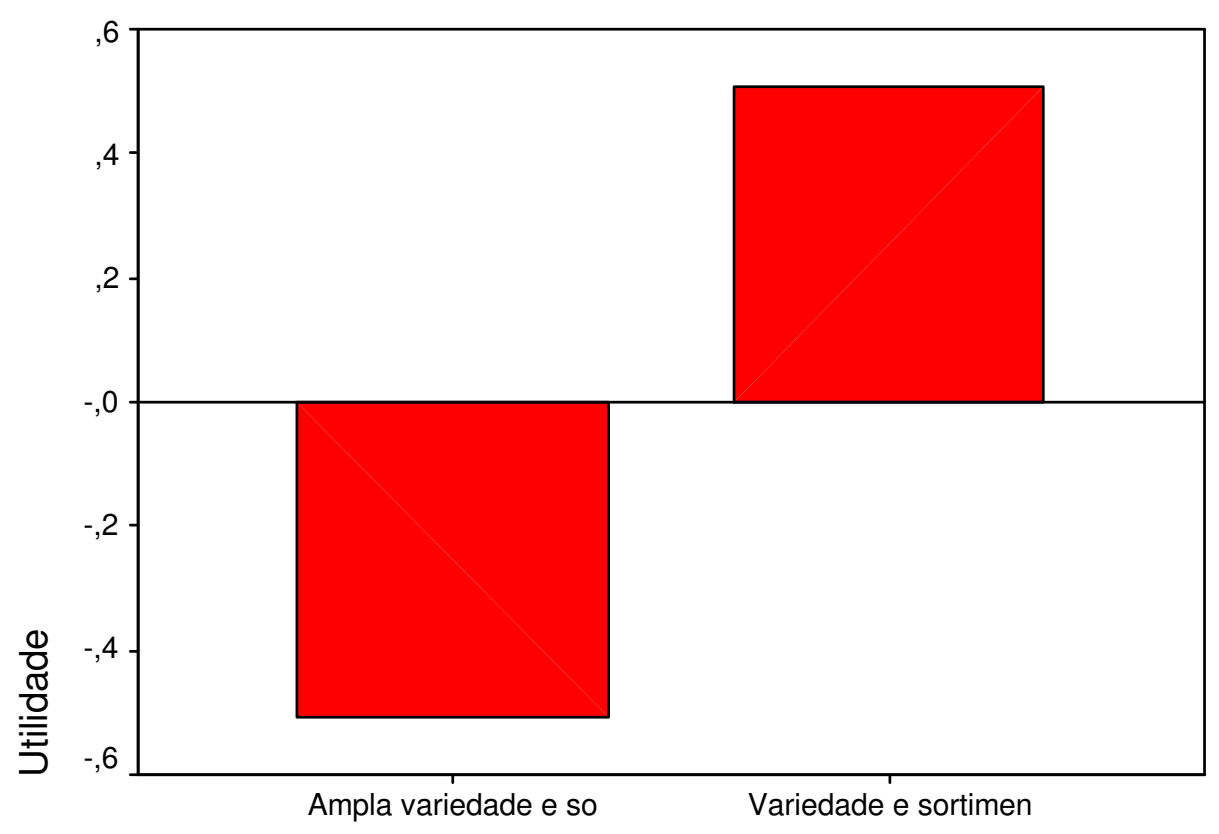

Atribtuto: Café da manhã

Figura 27: Utilidade agregada do atributo café da manhã. 
Utilidade agregada por nível de fator.

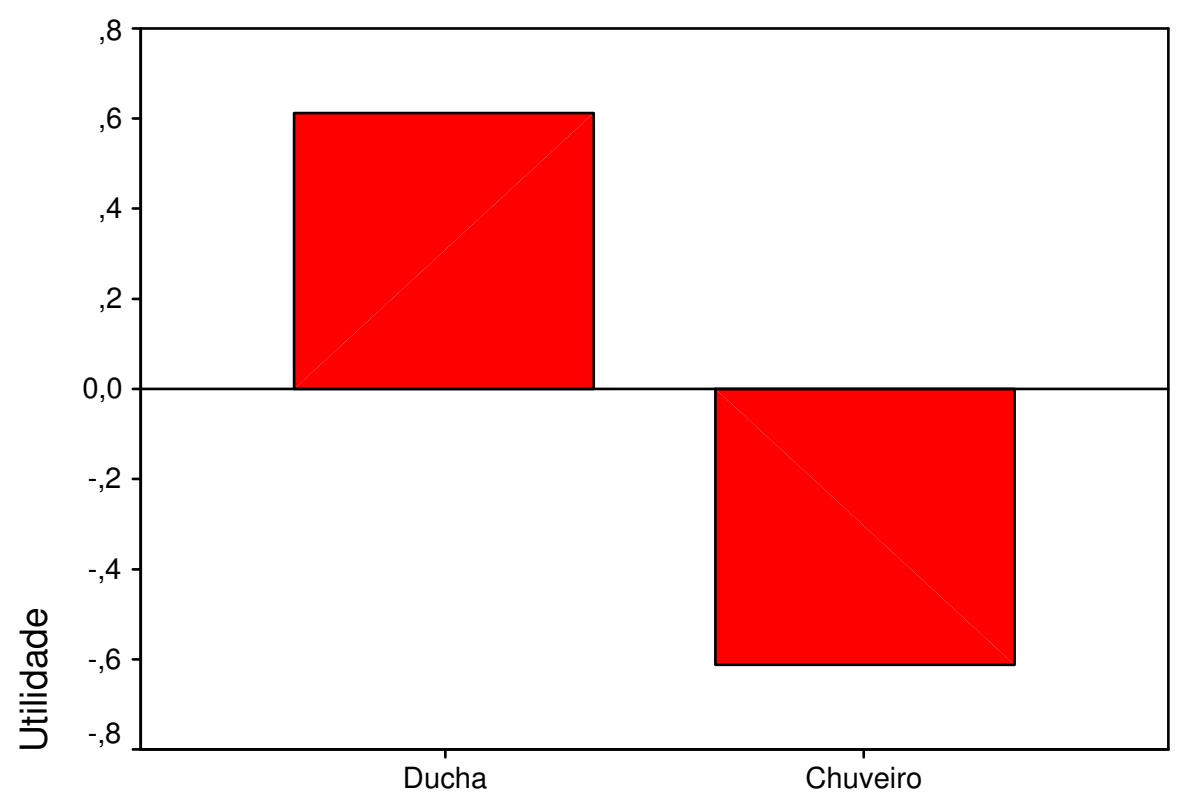

Atributo: Conforto do banheiro

Figura 28: Utilidade agregada do atributo conforto do banheiro.

Importância por fator (atributo).

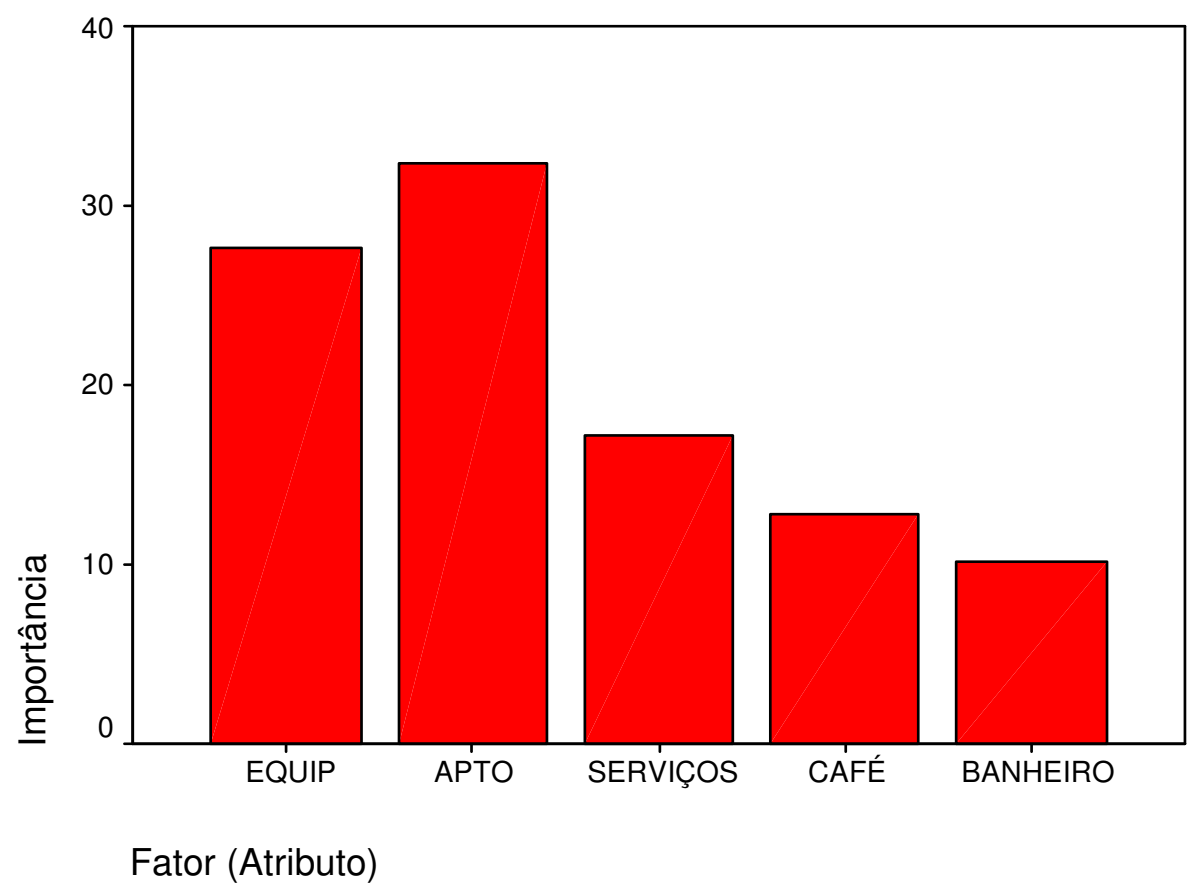

Figura 29:Utilidade agregada do experimento. 
Tabela 15: Resultado das utilidades parciais e escores por respondente.

\begin{tabular}{|c|c|c|c|c|c|c|c|c|c|c|c|c|c|c|c|c|c|c|c|c|c|c|c|c|c|c|c|c|c|c|c|c|}
\hline & NSTANT & EQUUP1 & EQUTP2 & EQUIP3 & 901 & IPTO2 & T03 & SERVIÇ1 & SERVIÇ2 & SERVIÇC3 & CAFE1 & CAFÉ2 & BANABI1 & BANHEI2 & SCORE1 & SCORE2 & SCORE3 & SCORE4 & SCORE5 & SCORE6 6 & SCORE7 & SCORE8 & SCORES & CORE10 & CORE1 & CORE1 & CORE1 & ORE1 & COREI & COREI & CORE11 & $\cos$ \\
\hline 1,00 & 9,75 & $-1,50$ & $-0,38$ & 1,88 & $-3,00$ & 4,00 & $-1,00$ & $-0,50$ & $-0,12$ & 0,62 & $-2,75$ & 2,75 & $-0,37$ & 0,37 & 8,25 & 5,75 & 3,88 & 15,25 & 11,00 & 3,63 & 13,88 & 5,50 & 14,88 & 9,38 & 10,50 & 2,75 & 12,88 & 7,88 & 1,63 & 9,00 & 7,75 & 15,25 \\
\hline 2,00 & 7,38 & 5,33 & 0,67 & 4.67 & $-0,67$ & 0.83 & $-0,17$ & $-0,17$ & 0.21 & $-0,04$ & 1.50 & $-1,50$ & 0,50 & $-0,5$ & 10,2 & 2,88 & 7.25 & 38 & 10,50 & & 4,50 & 7,38 & 11,38 & 5,00 & 0,87 & 14,00 & &, 88 & 13,88 & 5.75 & 37 & 2,50 \\
\hline 3,00 & 7,21 & 0,33 &, 08 & 0,42 & 5,33 & 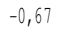 & 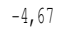 & 0,17 & $-0,46$ & 0,29 & 1,50 & $-1,50$ & 0,50 & -0, & & 14,13 & 13,00 & 5,63 & 5 & 4,38 & 8,25 & 3,63 & 4,38 & 11,75 & 12,13 & 14,50 & 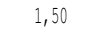 & 10,38 & 14,38 & 87 & 13 & 5,50 \\
\hline 4,00 & 6,54 & 0,50 & & & & $-0,25$ & $-1,75$ & 5,33 & $-0,67$ & $-4,67$ & $-0,13$ & 013 & 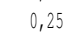 & & & 13,63 & 688 & 11,38 & & 10,75 & 138 & 13 & 12,00 & 63 & 14,38 &, 50 & 4,63 & 14,25 & 50 & 25 & 88 & 50 \\
\hline 5,00 & 7,58 & 1,00 & 25 & 0,75 & 0,00 & 0,00 & 0,00 & 2,67 & $-0,33$ & $-2,33$ & 0,00 &, 00 & 00 & -4 & 4,25 & 5.50 & 3,00 & 14,00 & 2, & 15,25 & 0,50 & 6,0 & 70 & 9,00 & 13,50 & 10,25 & 10,50 &, 25 & 15,25 & 12,25 & 5,50 & 10,25 \\
\hline 6,00 & 6, & 1,0 & & 75 & $-0,17$ & 0,21 & -0, & 5,33 & $-0,67$ & $-4,67$ & 000 & 0,00 & in & & & & 4 & & 1 & & 0.25 & 10.50 & 120 & 3.38 & 12,88 & 4,63 & 700 & 63 & 63 & 9,00 & 10,00 & 5,00 \\
\hline 7,00 & 9,9 & $-1,50$ & 13 & 1,38 & & 369 & & 0,33 & $-0,17$ & $-0,17$ & $-2,13$ & 2,13 & & & & & & 16.13 & 112 & & & & & & 9.25 & 1.63 & 14.13 & & & (1) & 0,38 & 14,00 \\
\hline 8,00 & & 5,3 & & & & 0, & 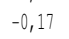 & $-0,17$ & 21 & $-0,04$ & 0, & 1,50 & & & & & & & & 14, & & & & & & & & & & 15,75 & & 4,50 \\
\hline 9,00 & 6,3 & 5,33 & -0, & & 2, & -0, &, 75 & 0,50 & 0,13 & $-0,63$ & 0,00 & 0,00 & 0,00 & & & 37 & 8,0 & & 9,9 & 10,63 & & 4,6 & 13 & 7,25 &, \pm 37 & 13,25 &, 25 & 14,38 & 4,38 & 11,75 & 62 & 11,00 \\
\hline 0 & & 0.33 & & & & & 67 & $-0,33$ & $-0,33$ & 0,67 & $-1,25$ & & & & & & & & & & & & & & & & & & & 5,50 & & 9,00 \\
\hline 00 & 7,5 & 2,6 & & & 1,0 & 25 & $-0,75$ & 0,17 & 0,04 & $-0,21$ & 0,00 & 00 & 00 & -4, & 25 & 38 & & 11,1 & & 13,63 & 0, & 2, & 611 & 2,00 & 38 & 15 &, 50 &, 38 &, 38 & 14,00 & 62 & 13,75 \\
\hline 00 & & 5 & & & & & & 28 & $-0,2$ & $-1,75$ & & & & & & & & & & & & & & & & & & & & $x$ & &, 75 \\
\hline 13 & 6,8 & 5,3 & & & & & & 0,0 & 0,0 & 0,00 & & & & & & & & & & & & & & & & & & & & 50 & ou & 12,00 \\
\hline 14,00 & 6, & 5,3 & & & 1,00 & $-0,25$ & $-0,75$ & 0,00 & 0,25 & $-0,25$ & 1,50 & -1, & 50 & -0, & & 25 & & & & 13, & & 6, & & 6, & 2,25 & & 0,75 & .25 & 15,2 & 14,25 & 50 & 10,75 \\
\hline & 6,6 & 5,33 & & & & $-0,25$ & -1, & 0,1 & 0,04 & $-0,21$ & & & & & & & & & & & & & & & & & & & & 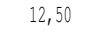 & 02 & 11,25 \\
\hline 16 & 9, & & & 1 & & 2 & 0, & 0,3 & $-0,17$ & $-0,17$ & -2 & & & & & & & & & & & & & & $1,6$. & 1,75 & 38 & 7,00 & 25 &, 50 & 63 & 14,50 \\
\hline & & & & & & & & & & & & & & & & & & & & & & & & & & & & & & (1) & & \\
\hline 18 & ,04 & & & & & & & & & 0,29 & & & & & & & & & & & & & & & & & & & & 7,75 & 1,25 & 13,00 \\
\hline & & & & & & & -5, & -1, & & & -1 & & & & & & & & & & & & & & & & & & & 4,75 & & 16,50 \\
\hline 00 &, 04 & & & & & & 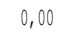 & $-2,33$ & & & & & & & & & & & & & & & & & & & & & & 8,75 & 13 & 16,75 \\
\hline & & & & & & & & 1 & & & & & & & & & & & & & & & & & & & & & & 75 & & 3,50 \\
\hline & & & & & & & & & & & & & & & & & & & & & & & & & & & & & & t. & & \\
\hline & & & & & & & & -0, & $-0,9$ & 1, & -2, & & & & & & & & & & & & & & & & & & & 9,25 & & 16,75 \\
\hline & & & & & & & & 1, & & -0, & -0 & & & & & & & & & & & & & & & & & & & 50 & 25 & - \\
\hline & 10,17 & & & & -3, & & & -2, & -0, & & -2 & & & & & & & & & & & & & & & & & & & 9,50 & & 7,25 \\
\hline & & & & & & & & & & -1 & & & & & & & & & & & & & & & & & & & & 12,25 & & 10,75 \\
\hline & & & & & & & & & & 2 & & & & & & & & & & & & & & & & & & & & 1,15 & & 3,50 \\
\hline & & & & & & & & & & -4 & & & & & & & & & & & & & & & & & & & & 8,00 & & \\
\hline & & 1, & 0,29 & & & $-0,8$ & 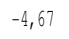 & 0, & $-0,7$ & 0,5 & . & & & -0 & & & & & & & & & & & & & $-0,38$ & & & 50 &, 75 & 8,25 \\
\hline & & & & & & -0 & & & & & & & & & & & & & & & & & & & & & & & & & & \\
\hline & & & & & & 3, & & 0,0 & 1, & -1, & . & & $v_{1}, t_{1}$ & & & & 10, & & & & & & & & & & & & & 50 & .62 & 1,25 \\
\hline & 6, & 5, & $-0,6$ & & 1, & -0, &, 79 & 0,3 & $-0,4$ & 0,0 & 0, & $-0,1$ & 0, & -0, & 121 & & 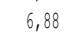 & & & $111_{1}$ & & & & & & & & 10, & & 12,25 & 00 & 12,50 \\
\hline 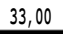 & 6,79 & 0,67 & $-0,08$ & -0.58 & 0,83 & 0,71 & $-1,54$ & 5,33 & $-0,67$ & $-4,67$ & $-0,63$ & 0,63 & $-0,13$ & 0.1 & 8,3 & 11,88 & 63. & 13 & 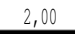 & 10.5 & 1,75 & 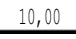 & & 3,38 & 12,8 & 2,88 & 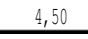 & 14,38 & 12,8 & 6,75 &, 50 & 4,00 \\
\hline
\end{tabular}


ANEXO 3 - MATRIZ DE CLASSIFICAÇÃO HOTELEIRA 


\section{1- POSTURAS LEGAIS}

1.1.1 - Posturas municipais, estaduais e federais aplicáveis, comprovadas pelos registros, inscriçôes e documentações exigidos, especialmente com referência a "Habite-se", "Alvará de Localizaçăo e Funcionamento",registro como empresa hoteleira e prova de regularidade perante as autoridades ambientais, sanitárias e concessionárias de serviços públicos.

1.1.2 - Legislaçâo quanto à proteçấo contra incêndio, dispondo de equipamentos e instalaçôes exigidos pelas autoridades competentes $e$ prevendo rotas de fuga, iluminaçâo de emergência e providências em situações de pánico

1.1.3 - Elevadores para passageiros e para carga/serviço em prédio de quatro ou mais pavimentos, inclusive otérreo, ou conforme as posturas municipais

1.1.4 - Exigências da legislaçăo trabalhista, especialmente no que se refere a vestiários, sanitários e local de refeiçōes de funcionários e Comissőes de Prevençấo de Acidentes - CIPA

1.1.5 - Exigências da EMBRATUR, constantes da legislaçâo de turismo, referentes $\mathrm{a}$ :

a) registro do hóspede, por intermédio de Ficha Nacional de Registro de Hóspedes - FNRH

b) fornecimento mensal do Boletim de Ocupação Hoteleira - $\mathrm{BOH}$, preenchido

c) fornecimento de Cartão do Estabelecimento com o nome do hóspede e periodo de hospedagem

d) placa de classificaçâo fixada no local determinado pela ABIHIEMBRATUR

e) divulgaçăo e explicitação dos compromissos recíprocos para com o hóspede através de:

e.1) Regulamento Interno, com direitos e deveres do hóspede

e.2) Serviços e preços oferecidos, incluídos, ou não, na diária, divulgados na forma da legislaçăo

f) Meios para pesquisar opiniōes e reclamações dos hóspedes e solucioná-las

1.1.6 - Facilidades construtivas, de instalações e de usa, para pessoas com necessidades especiais, de acordo com a

NBR 9050 - 1984, em prédio com projeto de arquitetura aprovado pela

Prefeitura Municipal, como meio de hospedagem, após 12 de agosto de 1987.

NOTA: No caso de projetos anteriores, o meio de hospedagemdeverá dispor de sistema especial de atendimento.

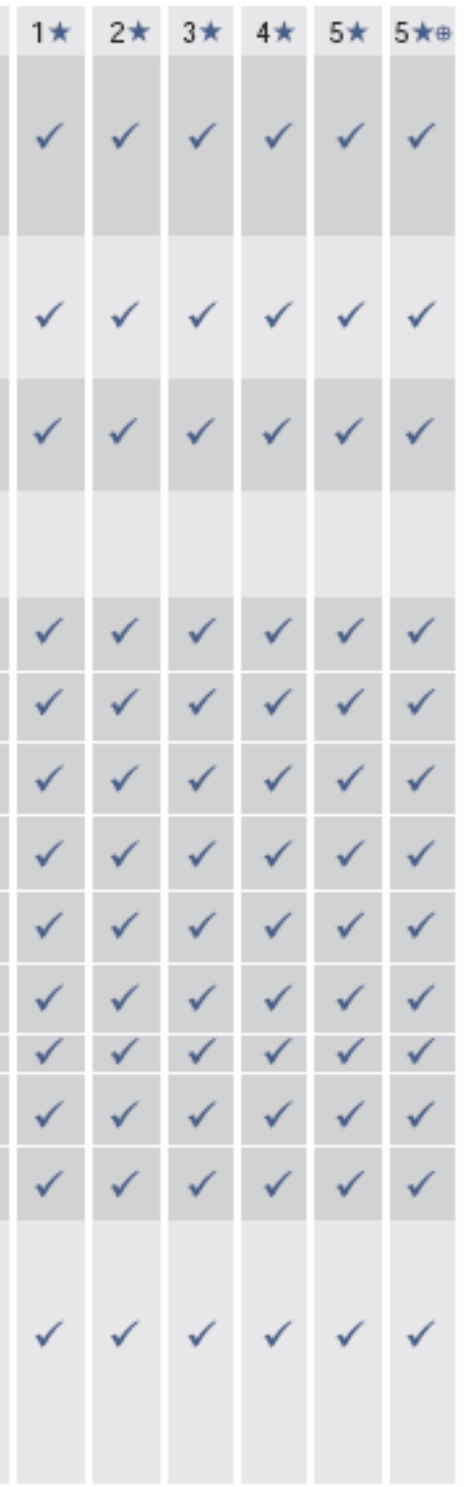

Figura 30: Matriz de classificação hoteleira (segue).

Fonte: ABIH e EMBRATUR 


1.2 - SEGURANÇA
1.2.1 - Meios para controle do uso dos cofres
1.2. - Circuito interno de TV ou equipamento de segurança
1.2.3 - Gerador de emergência com partida automática
1.2.4 - Rotas de fuga sinalizadas nas áreas sociais e restaurantes
1.2.5 - Serviço de segurança no estabelecimento, por intermédio de:
a) pessoal com formaçấo adequada, próprio ou contratado, e com
dedicaçấo exclusiva
b) porteiro (admite-se acúmulo de funçöes)
1.2.6 - Preparo para Iidar com situações de incêndio e pânico (assalto,
explosão, inundação e outros)
a) com equipes predeterminadas, com treinamento específico (Brigadas)
b) com treinamento geral do pessoal
1.2.7 - Cobertura contra roubos, furtos e responsabilidade civil
1.3 - SAÚDE / HIGIENE
1.3.1 - Serviço de atendimento médico de urgéncia
1.3.2 - Tratamento de resíduos
1.3.3 - Imunizaçäo permanente contra insetos e roedores
1.3.4 - Higiene do ambiente, das pessoas e dos serviços
1.3.5 - Higienização do alimento "in natura" antes do armazenamento
1.3.6 - Higienização adequada de equipamentos (roupas de cama / mesa/
banho; louças e talheres; sanitários)
1.3.7 - Tratamento de água

1.4 - CONSERVAÇAOO / MANUTENÇÅAO

1.4.1 - Todas as áreas, equipamentos e instalaçôes em condiçôes adequadas de conservaçâo/manutençâo
1.3.7 - Tratamento de água

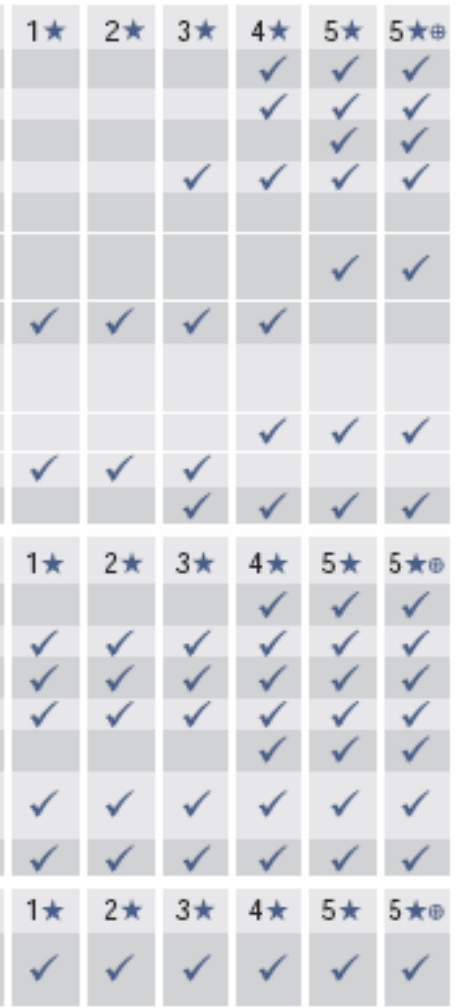

Figura 30: Matriz de classificação hoteleira (continuação).

Fonte: ABIH e EMBRATUR 

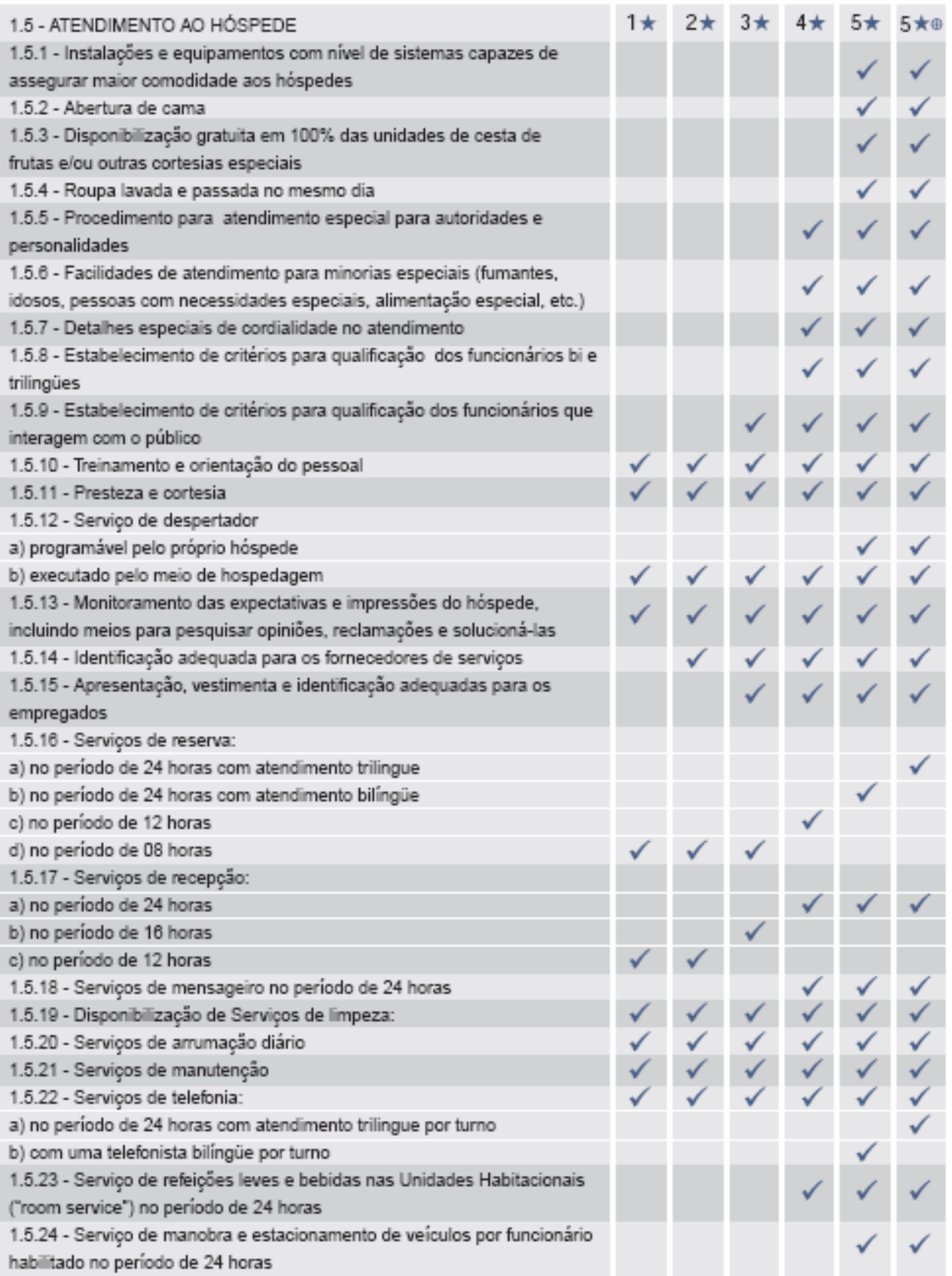

Figura 30: Matriz de classificação hoteleira (continuação).

Fonte: ABIH e EMBRATUR 


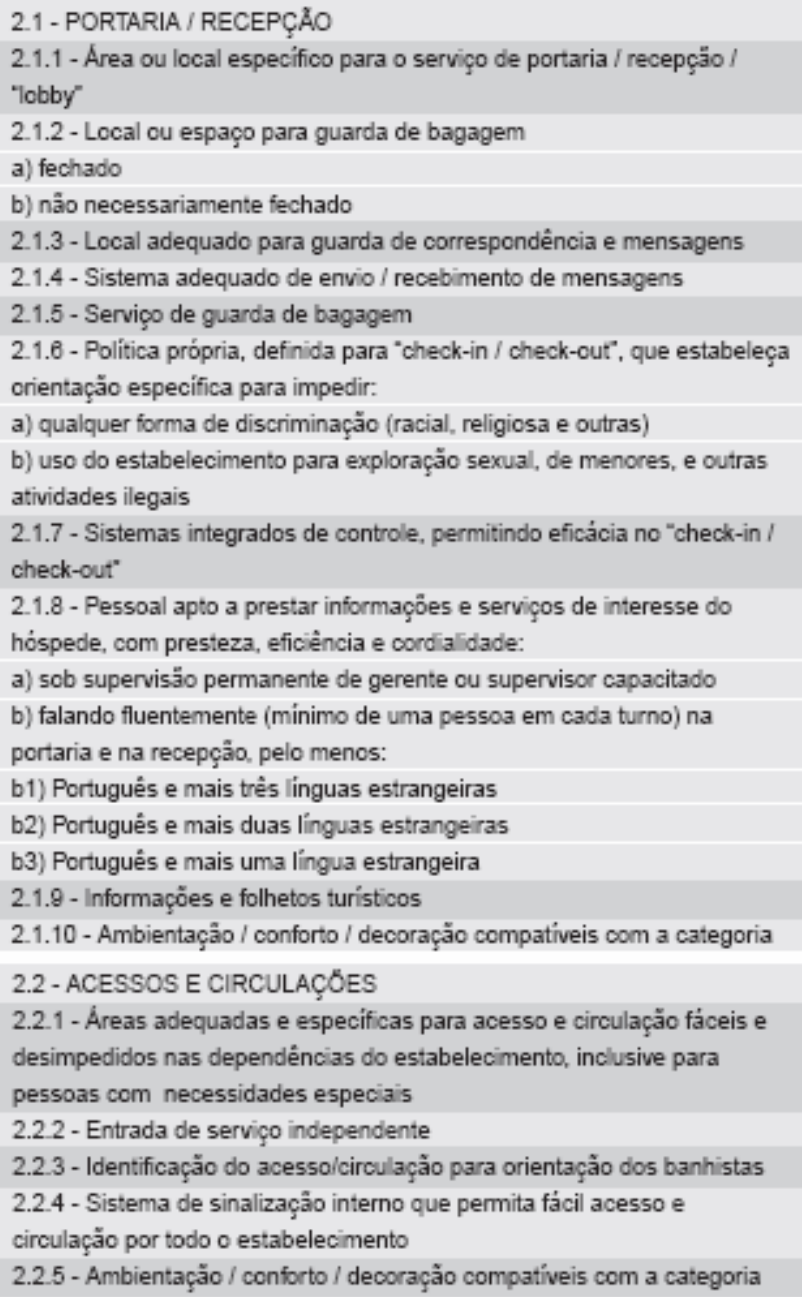

a) sob supervisäo permanente de gerente ou supervisor capacitado

b) falando fluentemente (mínimo de uma pessoa em cada turno) na portaria e na recepçâa, pelo menos:

b1) Português e mais três línguas estrangeiras

b2) Português e mais duas línguas estrangeiras

b3) Português e mais uma lingua estrangeira

2.1.8 - Informaçōes e folhetos turísticos

2.1.10 - Ambientaçâo / conforto / decoraçăo compativeis com a categoria

2.2 - ACESSOS E CIRCULAÇĆES

2.2.1 - Areas adequadas e específicas para acesso e circulaçăo fáceis e desimpedidos nas dependências do estabelecimento, inclusive para pessoas com necessidades especiais

2.2 .2 - Entrada de serviço independente

2.2.3 - Identificaçăo do acesso/circulação para orientação dos banhistas

2.2.4 - Sistema de sinalizaçâo interno que permita fácil acesso e circulação por todo o estabelecimento

2.2 .5 - Ambientação / conforto / decoração compativeis com a categoria

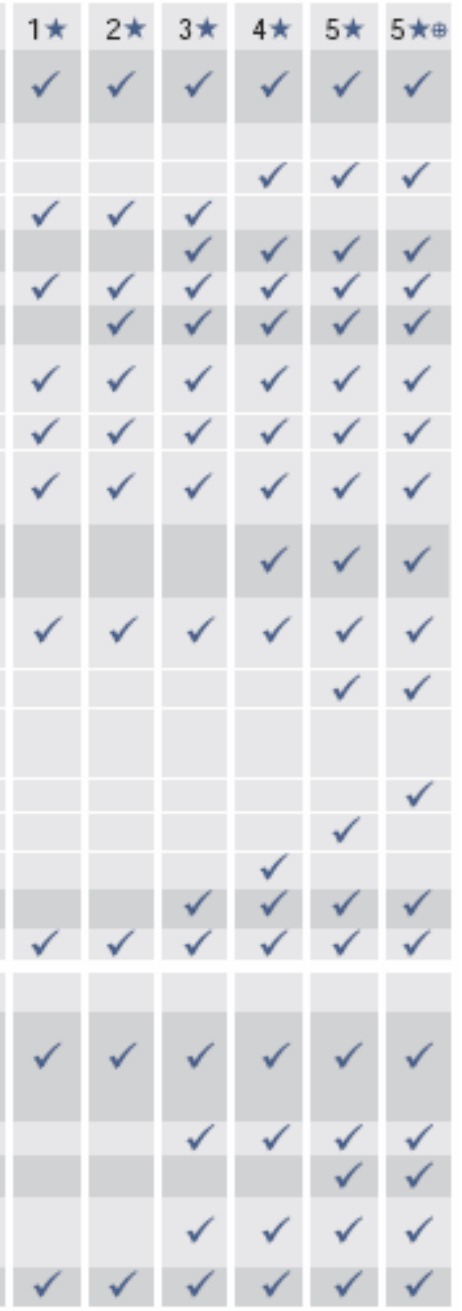

Figura 30: Matriz de classificação hoteleira (continuação).

Fonte: ABIH e EMBRATUR 
2.3 - SETOR HABITACIONAL

2.3.1 - Todas as salas e quartos das UH com iluminaçăo e ventilaçăo de acordo com as normas vigentes para edificaçöes

2.3.2 - Todas as UH deverâo ter banheiros privativos com ventilaçăo direta para o exterior ou através de duto

2.3.3 - Facilidades de informatizaçâo / mecanizaçăo, nas UH

2.3.4 - Quarto de dormir com menor dimensão igual ou superior a $2.50 \mathrm{~m}$ $e$ área igual ou superior $a$ :
a) $16,00 \mathrm{~m} 2$ ( $100 \%$ das UH)
b) $16,00 \mathrm{~m} 2$ (em no mínimo $90 \%$ das $U \mathrm{H}$ )
c) $14,00 \mathrm{~m} 2$ (em no mínimo $80 \%$ das UH)
d) $12,00 \mathrm{~m} 2$ (em no mínimo $70 \%$ das $U H$ )
e) $10,00 \mathrm{~m} 2$ ( em no mínimo $65 \%$ das UH)
f) $9.00 \mathrm{~m} 2$ (em no mínimo $65 \%$ das $\mathrm{UH}$ )

2.3.5 - Banheiro com área igual ou superior a (em no mínimo $90 \%$ das $\cup H):$

a) $4,00 \mathrm{~m} 2$ ( $100 \%$ das UH)

b) $4,00 \mathrm{~m} 2$ (em no mínimo $90 \%$ das UH)

c) $3,30 \mathrm{~m} 2$ (em no mínimo $80 \%$ das $U \mathrm{H}$ )

d) $3,00 \mathrm{~m} 2$ (em no mínimo $70 \%$ das UH)

e) $2,30 \mathrm{~m} 2$ ( em no mínimo $65 \%$ das UH)

f) $1,80 \mathrm{~m} 2$ (em no mínimo $65 \%$ das $U H$ )

2.3.6 - UH do tipo suíte com sala de estar de área igual ou superior a:

a) $11,00 \mathrm{~m} 2$

b) $10,00 \mathrm{~m} 2$

c) $9,00 \mathrm{~m} 2$

d) $8,00 \mathrm{~m} 2$

2.3.7 - UH do tipo suite elou unidades conversiveis em suites

2.3.8 - Portas duplas de comunicaçăo entre UH conjugáveis

2.3.9 - Tranca interna nas UH

2.3.10 - Rouparias aux Tares no setor habitaciona

2.3.11 - Local específico para material de limpeza

2.3.12 - Climatizaçâo adequada em $100 \%$ das UH

2.3.13 - TV a cores em $100 \%$ das UH, com TV por assinatura a cabo ou por antena parabólica

2.3.14 - TV em $100 \%$ das UH

2.3 .15 - Mini refrigerador em $100 \%$ das UH

2.3.16 - Agua potável disponivel na UH

2.3.17 - Café da manhâ no quarto

2.3.18 - Armário, "closet" ou local específico para a guarda de roupas em $100 \%$ das UH

2.3.19 - Mesa de cabeceira simples para cada leito ou dupla entre dois leitos, ou equipamento similar, em $100 \%$ das UH

2.3.20 - Lâmpada de leitura junto às cabeceiras em $100 \%$ das UH

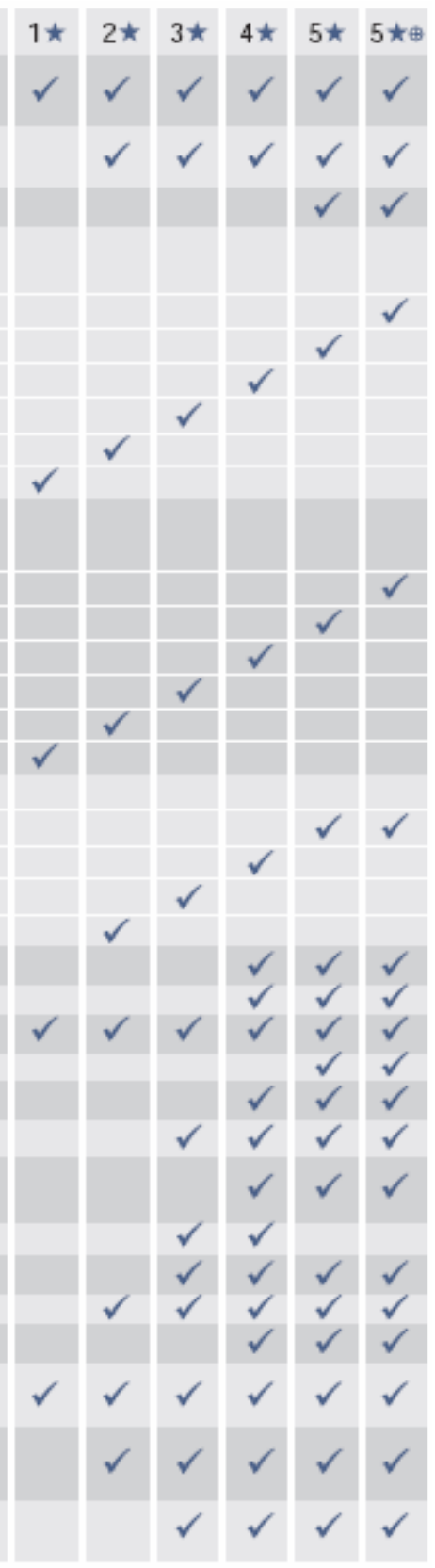

Figura 30: Matriz de classificação hoteleira (continuação).

Fonte: ABIH e EMBRATUR 

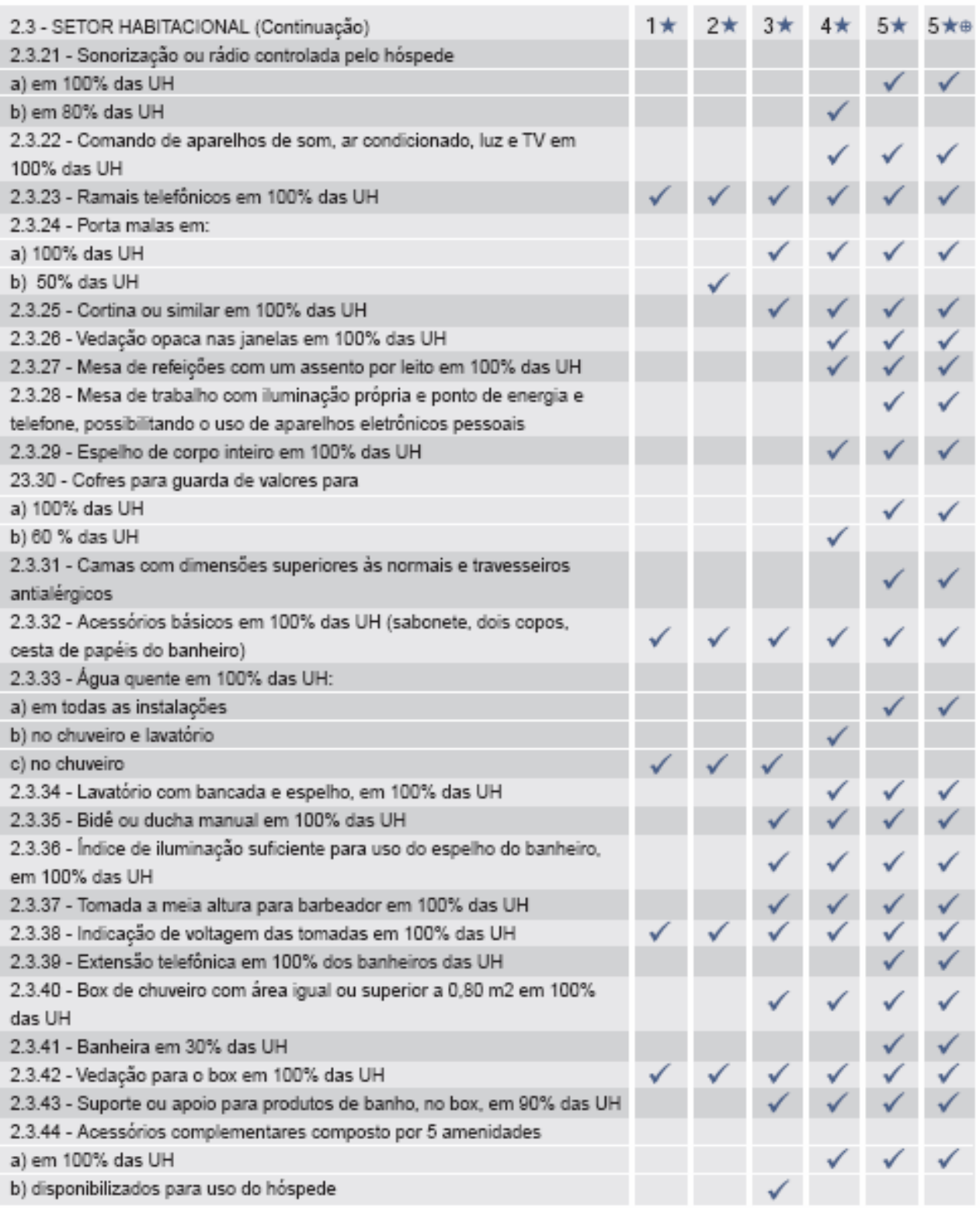

Figura 30: Matriz de classificação hoteleira (continuação).

Fonte: ABIH e EMBRATUR 
2.3 - SETOR HABITACIONAL (Continuaçăo)

2.3.45 - Outros acessórios em 100\% das UH (touca de banho, escova e pasta de dentes, shampoo, creme condicionador, creme hidratante, secador de cabelos, roupăo, espelho com lente de aumento, lixa, cotonete, espuma de banho, sais de banho, etc.)
a) mínimo de oito
b) mínimo de seis

c) mínimo de quatro

2.3.46 - Revestimentos, pisos, forraçôes, mobiliários e decoraçăo com equipamentos de $1^{2}$ linha

2.3.47 - Limpeza diária

2.3.48 - Frequência de troca de roupas de cama a cada mudança de hóspede $\mathrm{e}$ :
a) diariamente se desejado pelo hóspede
b) em dias alternados se desejado pelo hóspede
c) duas vezes por semana se desejado pelo hóspede
2.3.49 - Frequêtncia de troca de roupas de banho a cada mudança de hóspede $\mathrm{e}$ :

a) diariamente se desejado pelo hóspede

b) em dias alternados se desejado pelo hóspede

c) duas vezes por semana se desejado pelo hóspede

2.3.50 - Serviço "Näo perturbe", "Arrumar o quarto"

2.3.51 - Deta hes especiais de cordialidade

2.3.52 - Ambientação / conforto / decoraçăo compativeis com a categoria

\section{4 - AREAS SOCIAIS}

2.4.1 - Relaçâo de áreas sociais/estar por UH (năo incluida a circulaçăo) de: a) $2,50 \mathrm{~m} 2$

b) $2,00 \mathrm{~m} 2$

c) $1,50 \mathrm{~m} 2$

d) $1,00 \mathrm{~m} 2$

e) $0.50 \mathrm{~m} 2$

2.4.2 - Banheiros sociais, masculino e feminino, separados entre si, com vent lação natural ou forçada, com compartimento especial, adlaptado para pessoas com necessidades especiais, respeitando as normas e leis em vigor

2.4.3 - Estacionamento com número de vagas igual ou superior a $10 \%$ do número total de UH com local apropriado para embarque/desembarque de pessoas com necessidades especiais, devidamente sinal 'zado prevendo manobreiro

2.4.4 - Climatização adequada nas áreas sociais

2.4.5 - Revestimentos, pisos, forraçōes, mobiliários e decoraçẳo com materiais de $1^{2}$ linha

2.4.6 - Tratamento paisagístico

2.4.7 - Ambientaçăo / conforto / decoraçâo compativeis com a categoria

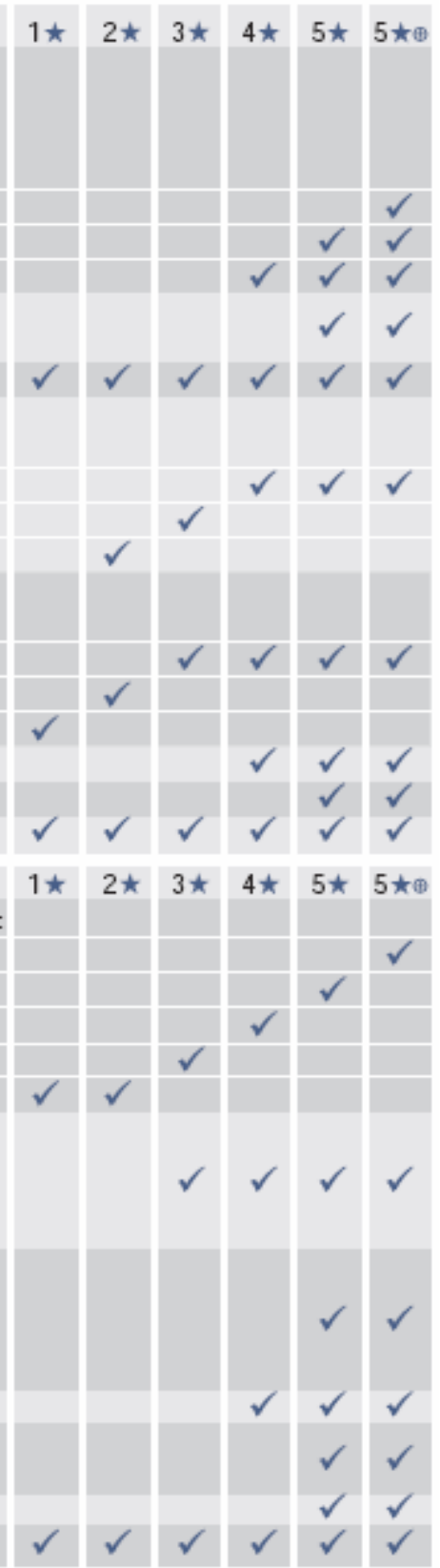

Figura 30: Matriz de classificação hoteleira (continuação).

Fonte: ABIH e EMBRATUR 


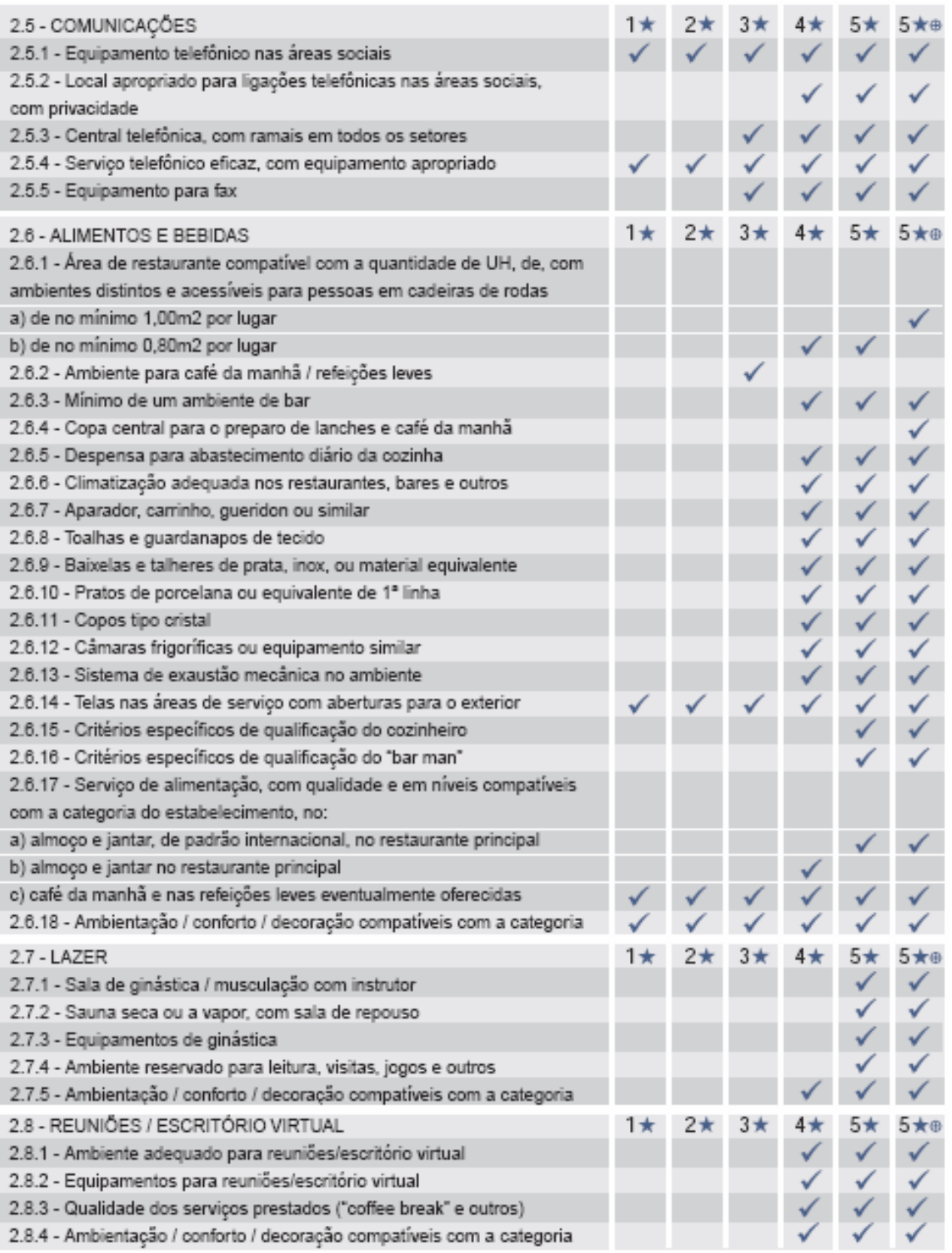

Figura 30: Matriz de classificação hoteleira (continuação).

Fonte: ABIH e EMBRATUR 


\section{9 - SERVICOS ADICIONAIS}

2.9 .1 - Ambientes, instalações elou equipamentos adequados destinados a salăo de beleza, "baby-sitter", venda de jornais e revistas, "drugstore", loja de conveniência, locaçäo de automóveis, reserva em espetáculos, agência de turismo, càmbio, transporte especial e outros:

a) mínimo de seis

b) mínimo de très

2.9.2 - Critérios específicos de qua ficação dos concessionários

2.9.3 - Divulgaçâo dos serviços dispon bi zados

2.9.4 - Ambiente, instalaçôes e equipamentos adequados para eventos e banquetes

2.9 .5 - Serviço de apoio disponivel para eventos e banquetes

2.9.8 - Sala VIP com equipamentos para atender ao hóspede executivo (microcomputador, FAX, copiadora, TV, mini sala de reuniões, área de estar e outros)

\subsection{0 - AÇŐES AMBIENTAIS}

2.10.1 - Manter um programa interno de treinamento de funcionários para a redução de consumo de energia elétrica, consumo de água e reduçăo de produçăo de residuos sólidos

2.10.2 - Manter um programa interno de separação de resíduos sólidos 2.10.3 - Manter um local adequado para armazenamento de residuos sólidos separados

2.10.4 - Manter local independente e vedado para armazenamento de resíduos sólidos contaminantes

2.10.5 - Dispor de critérios específicos para destinaçâo adequada dos resíduos sólidos

2.10.6 - Manter monitoramento específico sobre o consumo de energia elétrica

2.10.7 - Manter critérios especiais e privilegiados para aquisiçăo de produtos e equipamentos que apresentem eficiència energética e reduçăo de consumo

2.10.8 - Manter monitoramento específico sobre o consumo de água 2.10.9 - Manter critérios especiais e privilegiados para aquisiçăo e uso de equipamentos e complementos que promovam a reduçăo do consumo de água

2.10.10 - Manter registros específicos e local adequado para armazenamento de produtos nocivos e poluentes

2.10.11 - Manter critérios especiais e privilegiados para aquisiçăo e uso de produtos biodegradáveis.

2.10.12 - Manter critérios de qualificaçâo de fornecedores levando em consideraçăo as açöes ambientais por estes realizadas.

2.10.13 - Ter um certificado expedido por organismo especializado quanto a efetividade de adequaçăo ambiental da operaçăo
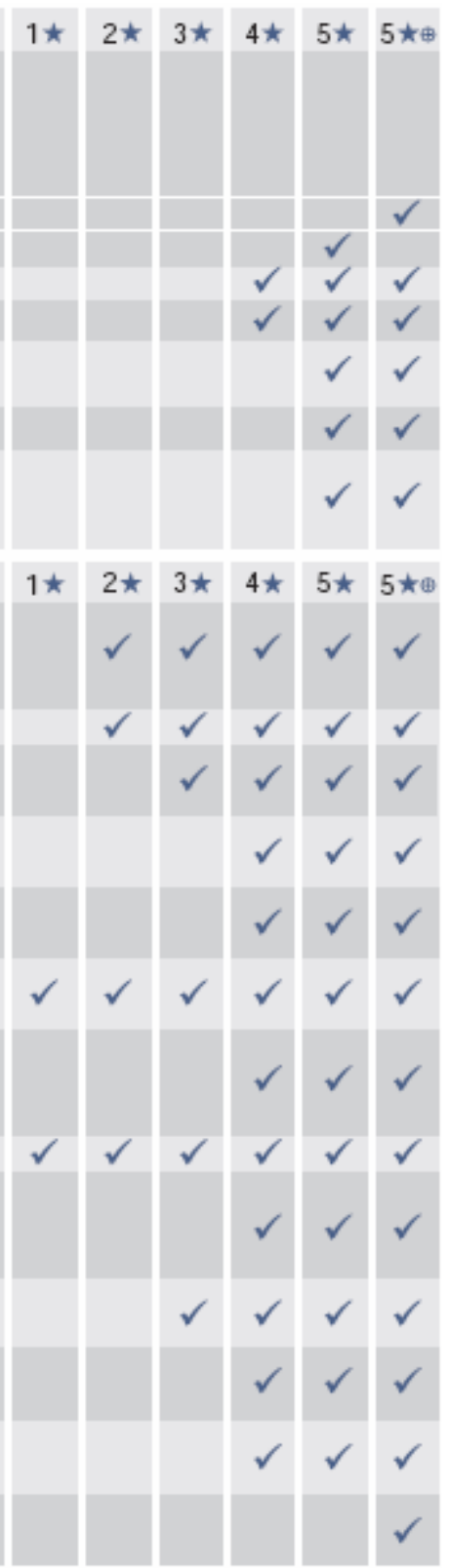

Figura 30: Matriz de classificação hoteleira (continuação).

Fonte: ABIH e EMBRATUR 